\title{
Evaluating the influence of governance on the built form: The redevelopment of Wellington, New Zealand's waterfront precinct
}

\author{
By \\ Colin Myron O’Byrne
}

\begin{abstract}
A thesis
submitted to the Victoria University of Wellington

in fulfillment of the requirements for the degree of

Doctor of Philosophy
\end{abstract}

Victoria University of Wellington

2016 

No material within this thesis may be used without permission of the copyright owner. 



\section{Abstract}

Because there are many ways of structuring and managing a land development process, this research asks the question: What influence do different decision making approaches have on the built form of the Wellington waterfront redevelopment?

The form of the built environment is shaped by existing physical and economic conditions; the values of those involved in the planning and design of it; and, the activities of those who occupy it. However, the social structure and mechanisms of decision making (i.e. the governance) within the urban planning and design stages of the development process act as a filter for identifying and prioritizing factors that will have the greatest influence on the form. Because of the filter effect, this thesis argues the governance of a development process has observable effects on the built form of the associated development project.

A review of urban design, urban morphology, and land development literature identified related research on the governance-built form relationship. Studies in urban design and development processes have generally identified single, overall governance approaches for development projects and have not effectively identified relationships with the built form. Recent work in the field of urban morphology has more effectively identified relationships between governance practices and the evolution of the built environment; however, these studies have tended to treat governance as a single process rather than a sequence of different governance approaches. Therefore, this study examined the redevelopment of the Wellington waterfront to look for and identify the different governance approaches that were used over the study period and how these influenced the resulting built form.

To address the question of what effect different governance approaches had on the built form, the history of the redevelopment was analyzed in depth. Through analysis of written records, semi-structured interviews with participants involved in a variety of redevelopment related roles, and site visits, it was possible to characterize different governance approaches within the overall project and how these have influenced the 
form of the built environment. Triangulation of the three methods was used to provide a richer description of the redevelopment and improve confidence in the findings.

Between 1974 and 2012, Wellington transitioned through seven separate governance approaches, each having some influence on the form of the redevelopment. Each governance approach was marked by different driving values and forms of stakeholder involvement that affected the redevelopment. For example, periods dominated by top-down or corporate approaches resulted in larger and more internally focused buildings and building sites than periods with more inclusive governance arrangements.

Characterizing the governance approaches and their effects on the built form provided a useful tool for evaluating and understanding the development process and the evolution of the built form of the Wellington waterfront. This level of understanding of the different governance approaches and their influence on the built form has not been previously described in the literature. While the findings cannot be assumed to be descriptive of other development projects, they do identify patterns that should be investigated in other development contexts. The approach and findings from this thesis therefore contribute to the literature on the relationship between the processes and products of urban design, and the social structures of development processes. 


\section{Acknowledgements}

The work contained and embodied by this thesis has only been possible due to the kindness, patience, graciousness, enthusiasm and many other admirable qualities of the people who have helped me along the way.

I would like to thank Prof. Brenda Vale for her invaluable supervision, encouragement, and support throughout the process. I always looked forward to our meetings and certainly appreciated the insightful comments and questions that inevitably challenged my assumptions and offered a fresh perspective when I was stuck. You have certainly set a high bar for supervision (and research) that I will aim for in my career.

To the School of Architecture and Design, the Library staff, the International Office, the Scholarships Office, and other staff at the Victoria University of Wellington, thank you for the Doctoral Assistantship Scholarship and supporting postgraduate students with various seminars, workshops, and events. Without the financial, administrative, and academic support so ably given, the whole process would have been far more difficult.

To those who agreed to be interviewed for the research and others who joined me for a cup of coffee to talk about the case study, your experiences, opinions, and perspectives taught me a great deal. Thank you for answering my questions candidly, pointing me towards other people and material I was often not aware of, and giving so much of your time to help me. Your responses to my questions did not just satisfy the aim of the research, but they made the projects come to life and probably raised more new questions than were answered.

Thank you finally to my family for your unwavering and enthusiastic support. It never failed to lift me up and keep me motivated. Specifically, thank you to my wife, Alaina, for agreeing to move halfway round the world so I could pursue this and for managing virtually everything else in our lives for the past few years. Your ongoing love and support, interest in my research, and occasional kick in the pants to get it done mean a lot to me. 
Last is both an apology and a thank you. While I have enjoyed the personal growth that came with doing a Ph.D., it was not without cost. Too many dinners were missed, family vacations interrupted, birthdays of friends and relatives forgotten, and particularly weekends and evenings playing with my sons, Cole and Arthur, did not happen. For all of that I am truly sorry. Everyone involved was very understanding and for that I am truly thankful. 


\section{Table of Contents}

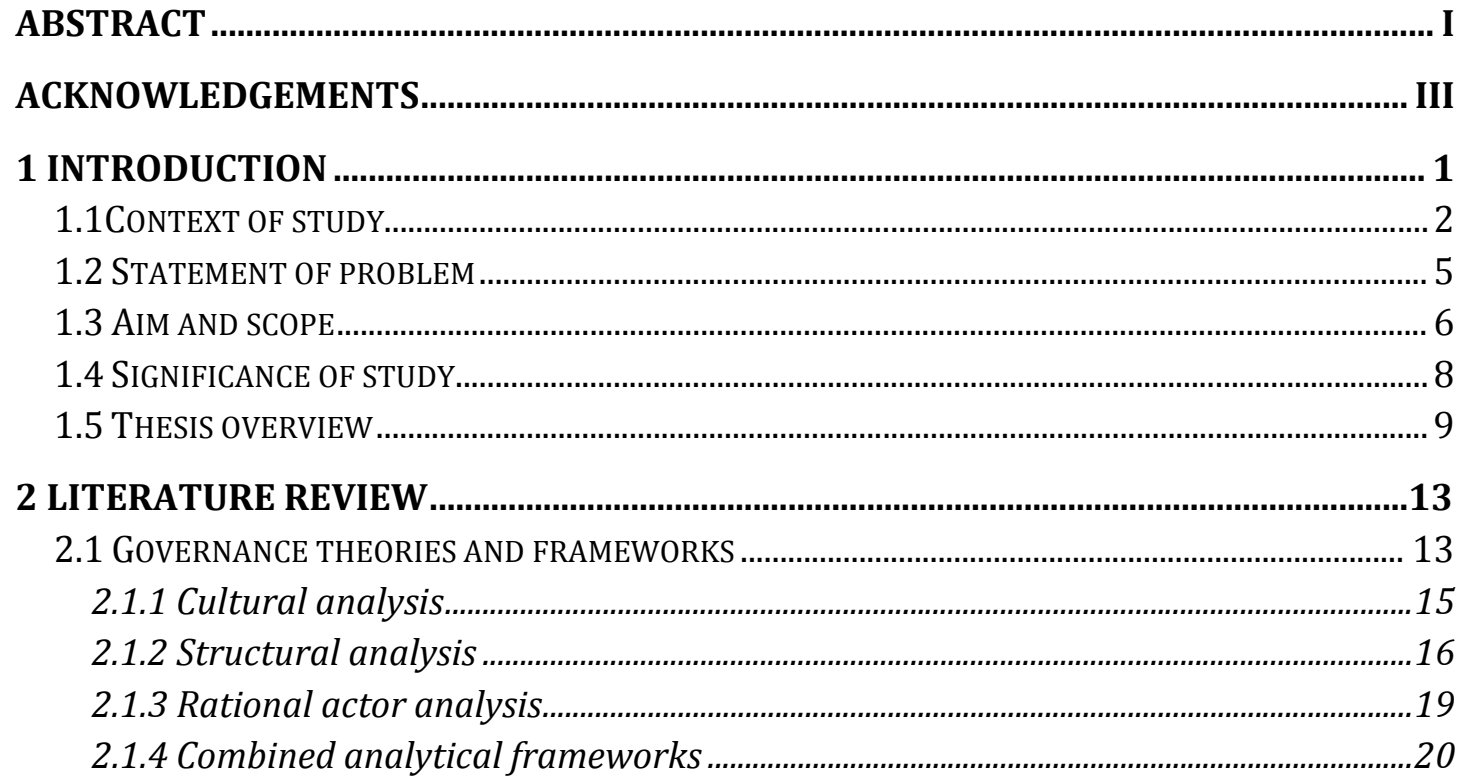

2.2 GOVERNANCE-BASED APPROACHES TO ANALYZING THE PRODUCTION OF THE BUILT FORM .... 25

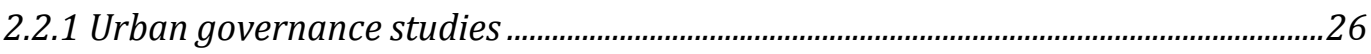

2.3 OTHER APPROACHES TO ANALYZING THE PRODUCTION OF THE BUILT ENVIRONMENT .............. 32

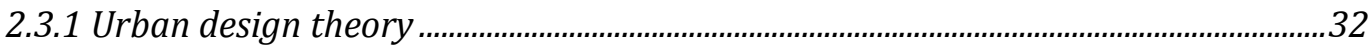

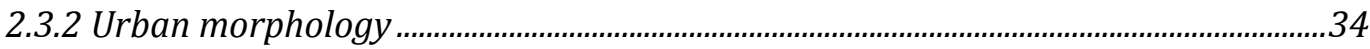

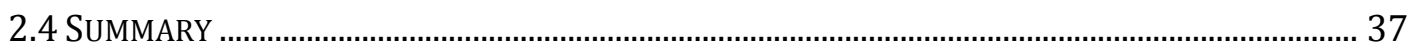

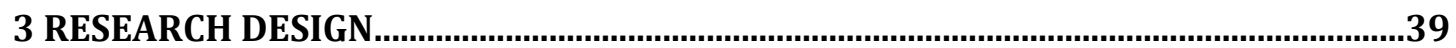

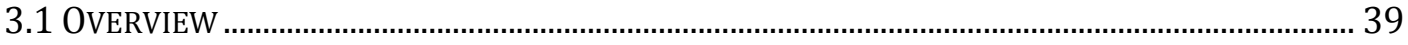

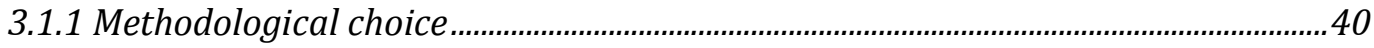

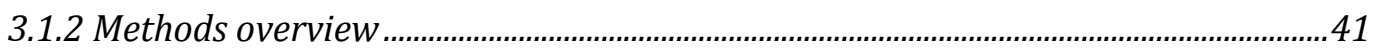

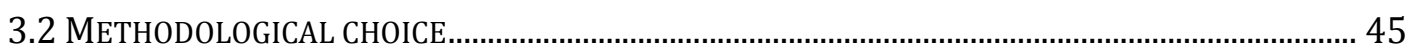

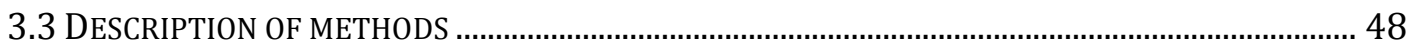

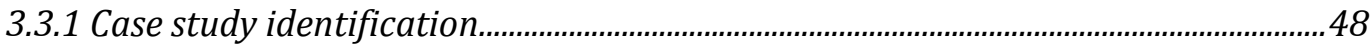

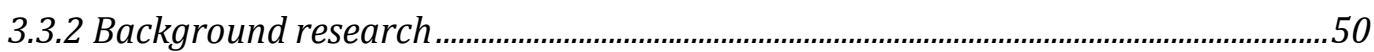

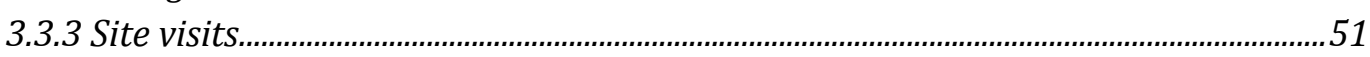

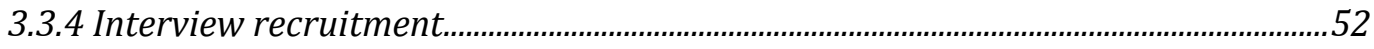

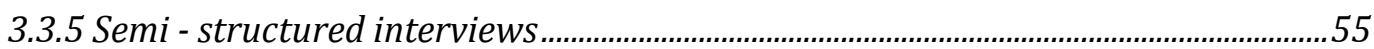

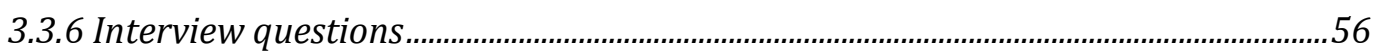

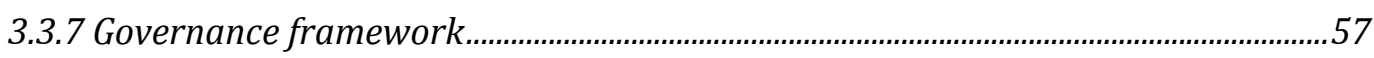

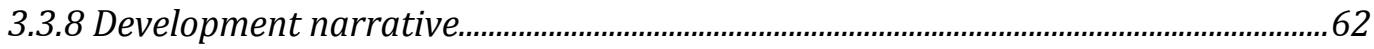

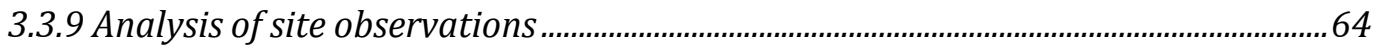

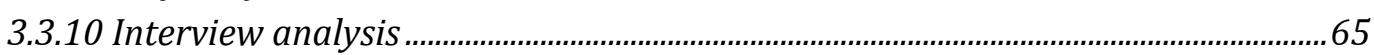

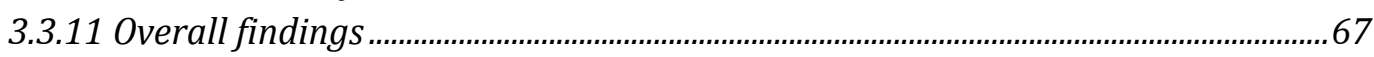

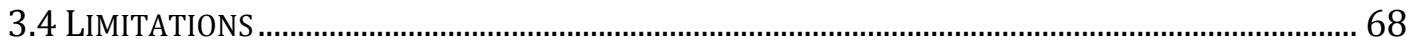

4 ANALYSIS OF ARCHIVE AND BACKGROUND INFORMATION...................................69

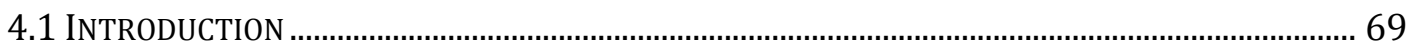

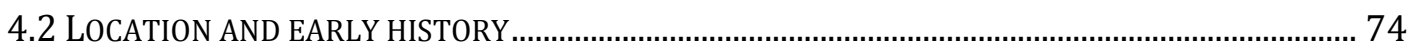


4.3 Phase 1 governance (1974 to 1985) - The Wellington Harbour BoARd Was WilLing TO ENTERTAIN IDEAS FOR NEW USES OF THE WATERFRONT .............................................................. 75

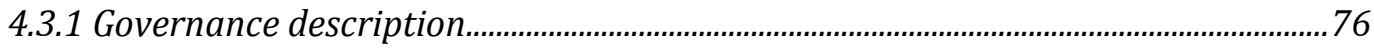

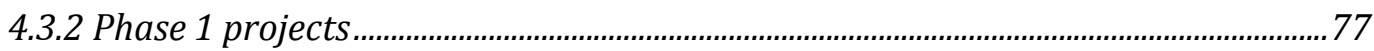

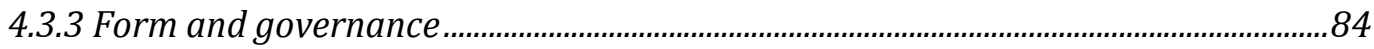

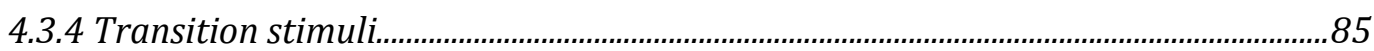

4.4 PHASE 2 GOVERNANCE (1985 To 1986) - PLANNING FOR A JOINT VENTURE ........................... 85

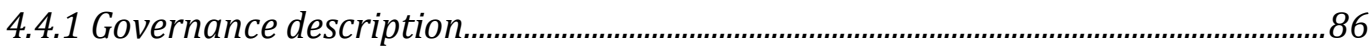

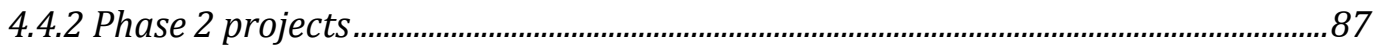

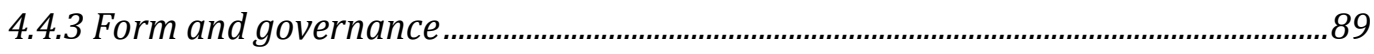

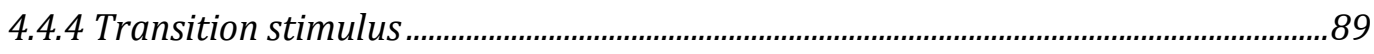

4.5 PHASE 3 GOVERNANCE (1986 TO 1996) - A LARGELY INDEPENDENT DEVELOPMENT

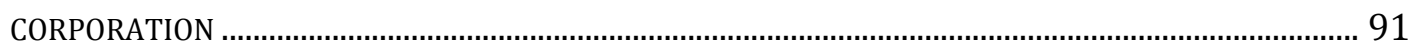

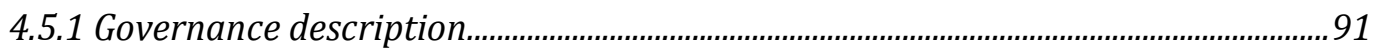

4.5.2 Phase 3 projects ....................................................................................................... 94

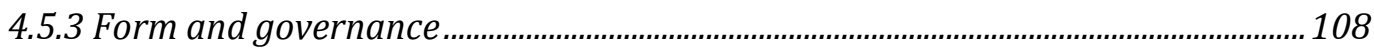

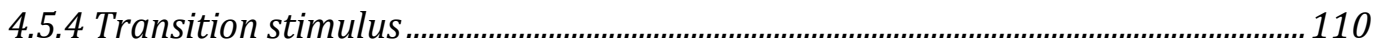

4.6 PHASE 4 (1996 TO 2000) WCC TOOK CONTROL OF THE PROCESS AND INITIATED A GOOD-

WILLED TOP-DOWN CONSULTATIVE PROCESS …………........................................................ 111

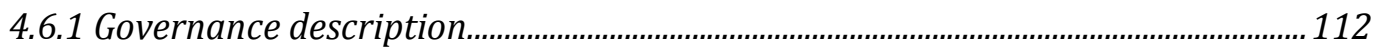

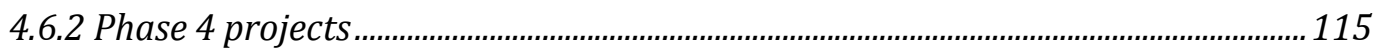

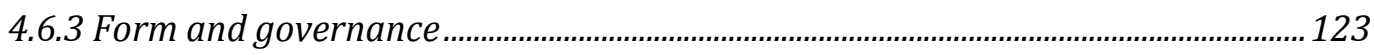

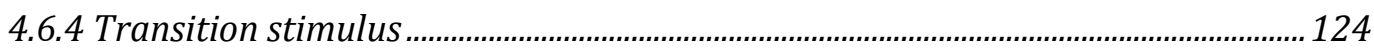

4.7 PHASE 5 GOVERNANCE (2000 TO 2001) - INTEGRATED DECISION MAKING..................................

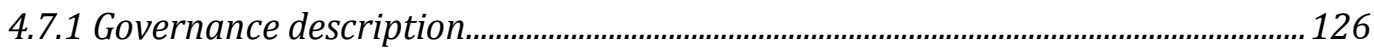

4.7.2 Phase 5 projects............................................................................................................128

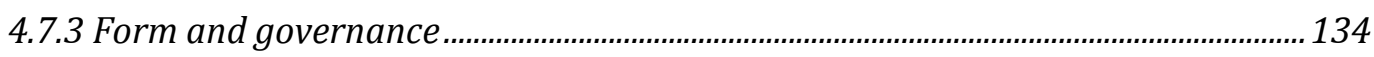

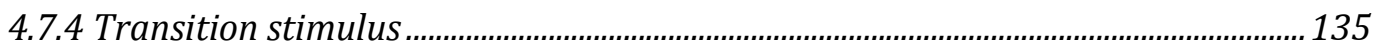

4.8 PHASE 6 GOVERNANCE (2001 TO 2006) - DESIGNER LED DECISION MAKING WITH ENHANCED

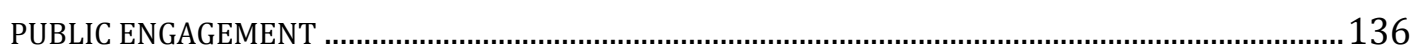

4.8.1 Governance description................................................................................................137

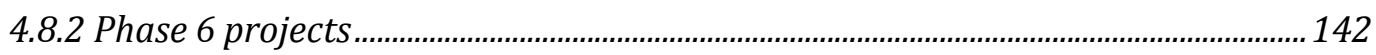

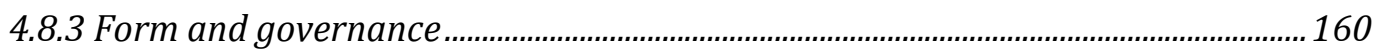

4.8.4 Transition stimulus ....................................................................................................161

4.9 PHASE 6B GOVERNANCE (2004 TO 2008) - PUBLICLY TRANSPARENT DESIGN COMPETITIONS

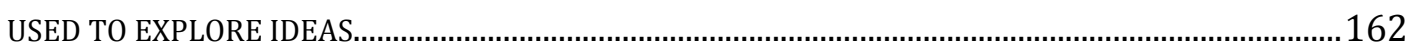

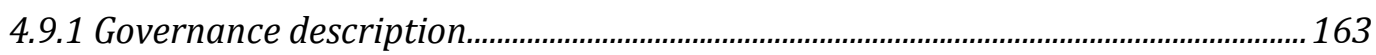

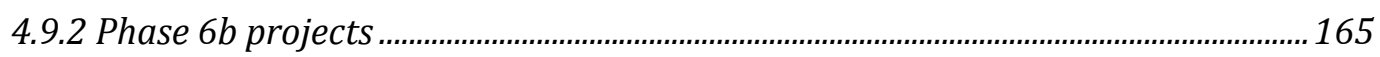

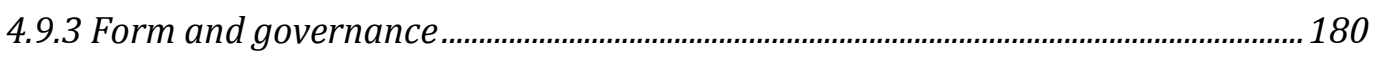

4.9.4 Transition stimuli........................................................................................................181

4.10 PHASE 7 GOVERNANCE (2008 TO 2010) - A LESS INCLUSIVE, MORE STREAMLINED PROCESS

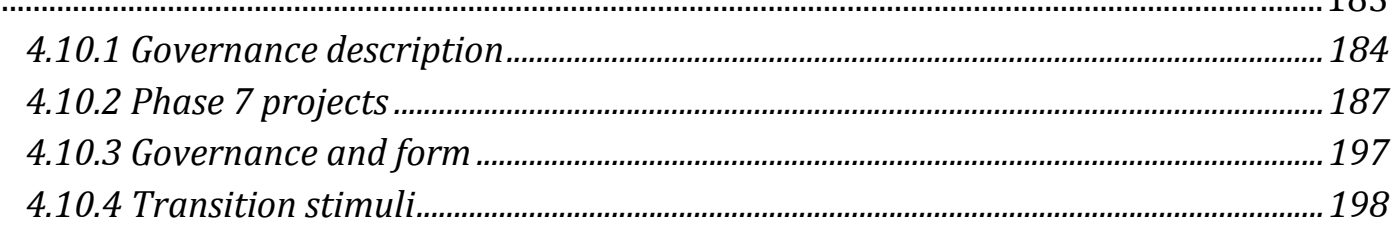


4.11 PHASE 8 GOVERNANCE (2010 TO 2012) - INTEGRATION OF DEVELOPMENT ROLE WITH WCC OPERATIONS

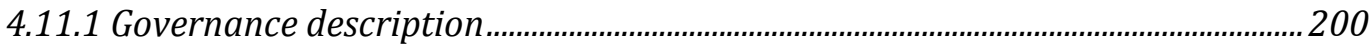

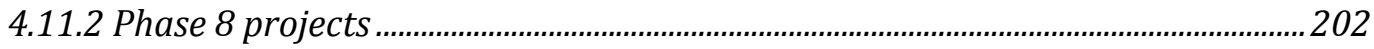

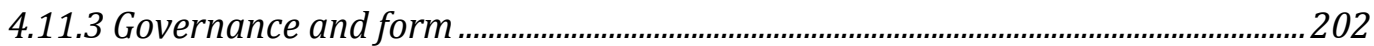

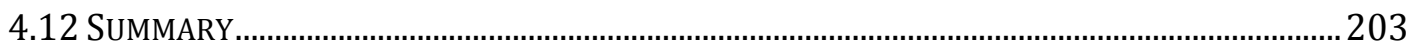

4.12.1 Patterns in the different governance approaches and their influence on the built form

\section{INTERVIEW FINDINGS: GOVERNANCE AND BUILT FORM RELATIONSHIP}

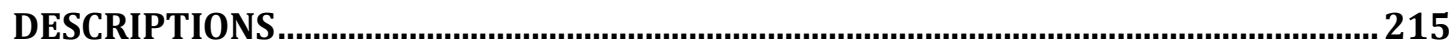

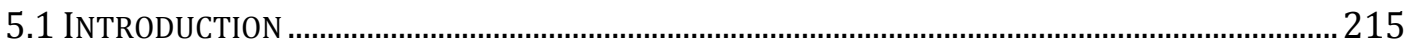

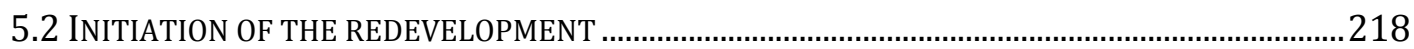

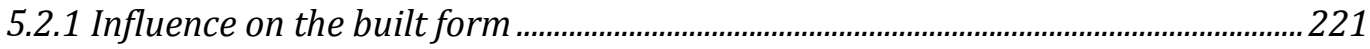

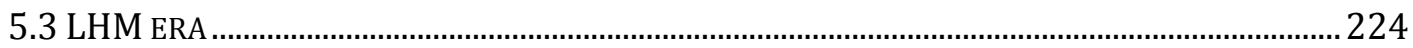

5.3.1 Influence on the built form ……………………..........................................................227

5.4 WCC RESPONSE TO PUBLIC OUTCRY REGARDING R\&E CENTRE .............................................231

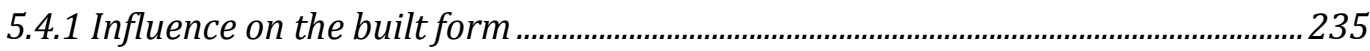

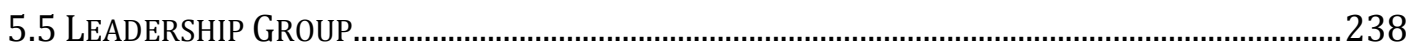

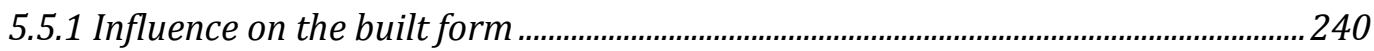

5.6 WATERFRONT DEVELOPMENT SUBCOMMITTEE ERA .............................................................242

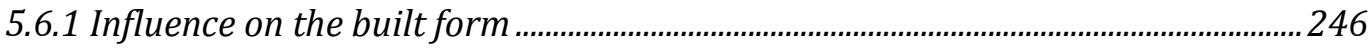

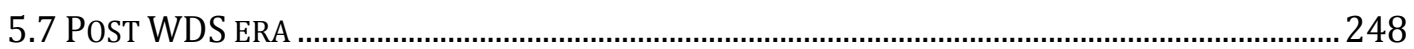

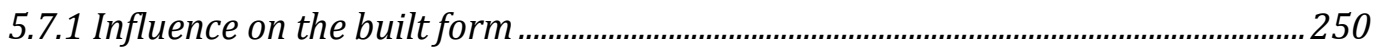

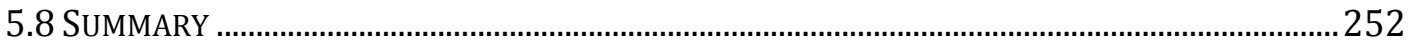

5.8.1 Patterns in the identified governance approaches and their influence on the built

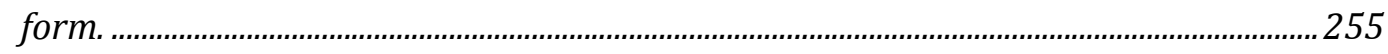

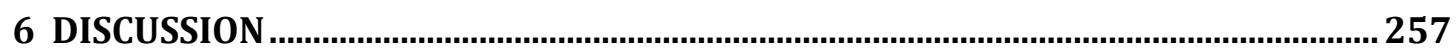

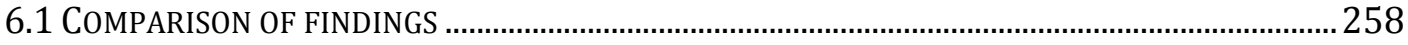

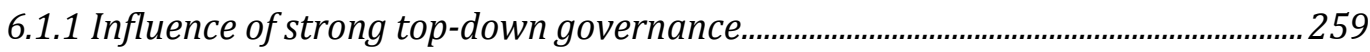

6.1.2 Influence of strong citizen activism and incorporating public feedback.............260

6.1.3 Influence of strong input by design professionals.....................................................261

6.1.4 Intentional and unintentional qualities of the relationship patterns ...................262

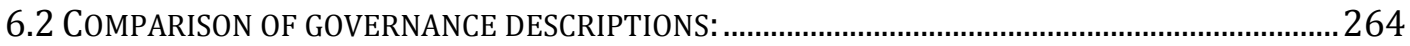

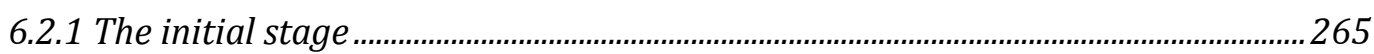

6.2.2 Lambton Harbour Management Ltd..........................................................................266

6.2.3 The Community Consultative Committee …...........................................................267

6.2.4 The Leadership Group .....................................................................................................2 268

6.2.5 The Waterfront Development Sub-committee ........................................................269

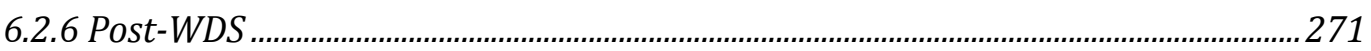

6.2.7 Historic buildings and public art projects.............................................................22

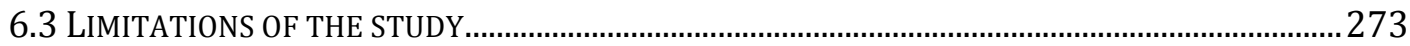

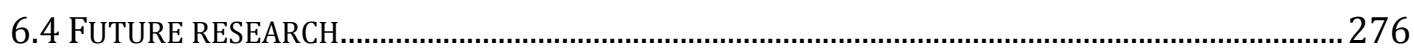

7 CONCLUSION

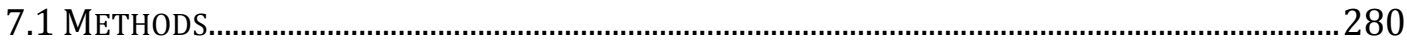

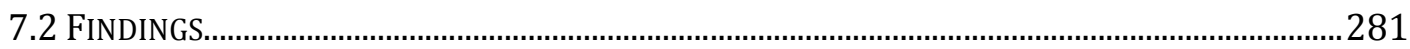


REFERENCES

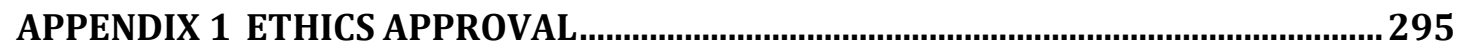

APPENDIX 2 INTERVIEW RECRUITMENT MATERIAL AND INTERVIEW

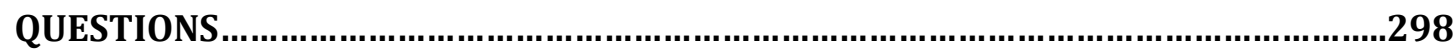

APPENDIX 3 ARCHIVE ANALYSIS BIBLIOGRAPHY …............................................ 306

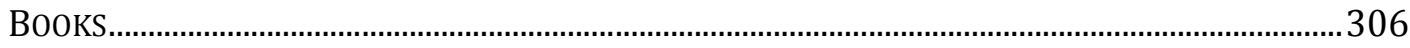

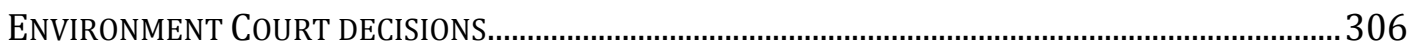

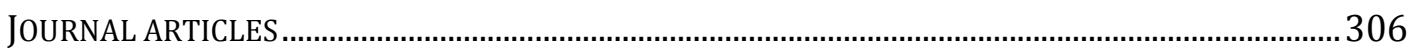

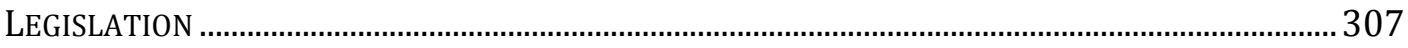

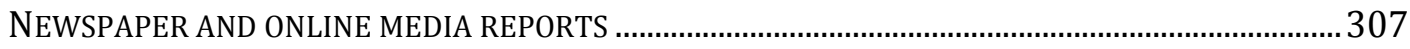

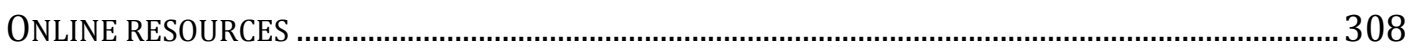

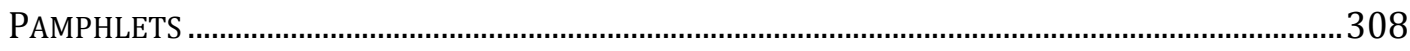

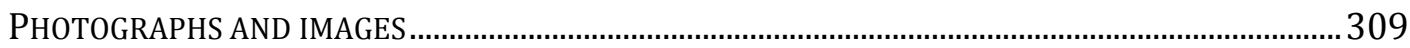

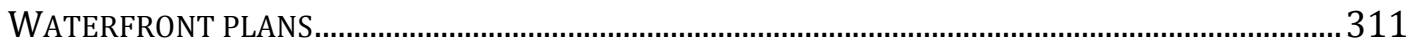

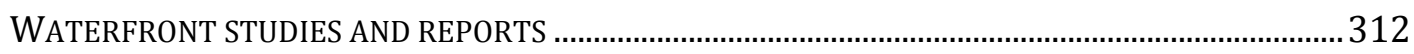

WELLINGTON CITY COUNCIL MEETING MINUTES AND REPORTS....................................................313 


\section{Figures}

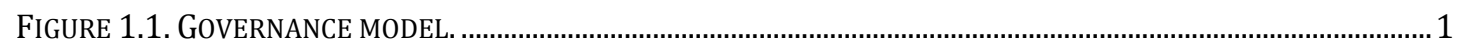

FIGURE 3.1. DIAGRAM OF THE RESEARCH METHODS........................................................................................ 41

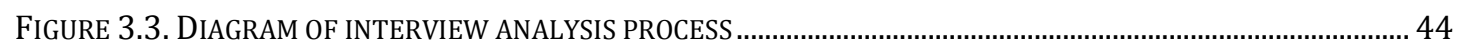

FIGURE 4.1. VIEW OF THE WELLINGTON WATERFRONT REDEVELOPMENT.......................................................... 71

FIGURE 4.2. LOCATION MAP OF THE WELLINGTON WATERFRONT REDEVELOPMENT.............................................. 71

FIGURE 4.3. LOCATION OF THE WELLINGTON WATERFRONT REDEVELOPMENT PROJECTS AND FEATURES ............ 72

FIGURE 4.4. HISTORY OF WATERFRONT RECLAMATION WORK ………................................................................. 74

FIGURE 4.5. DIAGRAM OF THE PHASE 1 GOVERNANCE ARRANGEMENTS. ................................................................ 75

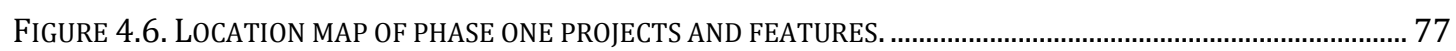

FIGURE 4.7. RECLAMATION WORK COMPLETED IN 1970. .......................................................................... 78

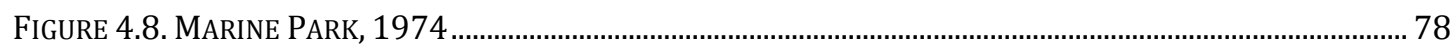

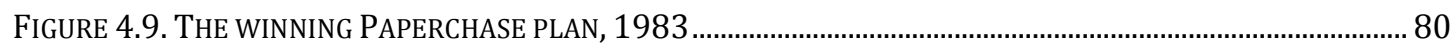

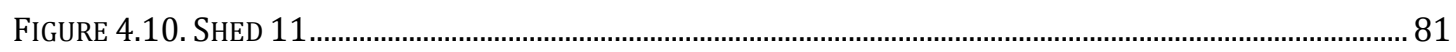

FIGURE 4.11. THE NORTHEAST CORNER OF TE PAPA, 2011 ……..................................................................... 83

FIGURE 4.12. DIAGRAM OF THE PHASE 2 GOVERNANCE ARRANGEMENTS. ........................................................... 85

FigURE 4.13.1986 LAMBTON HARBOUR URBAN DESIGN CONCEPT PEDESTRIAN NETWORK................................. 87

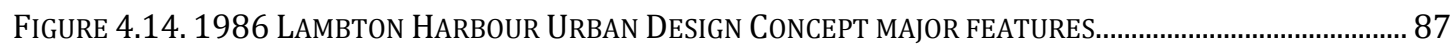

FIGURE 4.15.1986 LAMBTON HARBOUR URBAN DESIGN CONCEPT: QUEENS WHARF SQUARE. ............................ 88

FiguRE 4.16.1986 JoINT VENTURE AGREEMENT PLAN ………........................................................................ 90

FIGURE 4.17. DIAGRAM OF THE PHASE 3 GOVERNANCE ARRANGEMENTS. ......................................................... 91

FIGURE 4.18. LOCATION MAP OF PHASE THREE PROJECTS AND FEATURES. ........................................................ 94

FIGURE 4.19. ALBATROSS BY TANYA ASHKEN................................................................................................. 95

FIGURE 4.20. THE MAJOR COMMERCIAL DEVELOPMENT PROJECTS IN THE 1989 LAMBTON HARBOUR COMBINED SCHEME.

FigURE 4.21. REDEVELOPMENT OF FRANK KITTS PARK 1989...................................................................... 97

FiguRE 4.22. Moving THE STAR BoATing CLUB AND WELLINGTON Rowing CLUB BUILDings 1989................ 97

FigURE 4.23. SEATING AND WALL ON THE HARBOUR SIDE OF FRANK KITTS PARK .................................................. 97

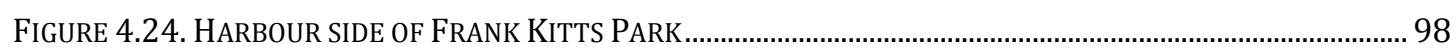

FIGURE 4.25. RETAIL SPACES ALONG FRANK KITTS PARK ……………........................................................... 98

FIGURE 4.26. INDUSTRIAL MARITIME MATERIALS USED IN THE CONSTRUCTION OF THE CITY-TO-SEA BRIDGE.... 99

FIGURE 4.27. SHED THREE AND SHED FIVE …………………...............................................................100

FIGURE 4.28. CHAFFERS MARINA ……………………………...............................................................100

FIGURE 4.29. WESTPORT CHAMBERS BUILDING FAÇADE PRIOR TO CONSTRUCTION OF THE REST OF THE CIRCA

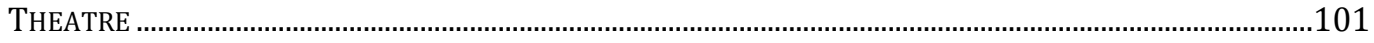

FIGURE 4.30. WELLINGTON HARBOUR BOARD OFFICES.....................................................................................102

FIGURE 4.31. MODEL OF THE FOURTH HOTEL PROPOSAL FOR THE OUTER-T OF QUEENS WHARF ........................104

FIGURE 4.32. MODEL OF THE QUEENS WHARF PORTION OF THE 1989 CoMBINED SCHEME. ................................105

FIGURE 4.33. QUEENS WHARF RETAIL AND EVENTS CENTRE CIRCA 1996 ........................................................106

FIGURE 4.34. DIAGRAM OF THE PHASE 4 GOVERNANCE ARRANGEMENTS. .............................................................111

FIGURE 4.35. LOCATION MAP OF PHASE FOUR PROJECTS AND FEATURES. .............................................................115

FigURE 4.36. QUEENS WHARF VIGNETTE FROM THE 1997 LAMBTON HARBOUR OPEN SPACE MASTER PLAN 116

FiguRE 4.37. QUEENS WHARF VIGNETTE FROM THE 1997 LAMBTON HARBOUR OPEN SPACE MASTER PLAN.116

FiguRE 4.38. 1997 LAMBton HaRBoUR OPEN SPACE MASTER PLAN. ................................................................117

FIGURE 4.39. WATERFRONT WATCH'S CRITIQUE OF THE DESIGN GUIDANCE OFFERED BY VARIATION 17 ..........119

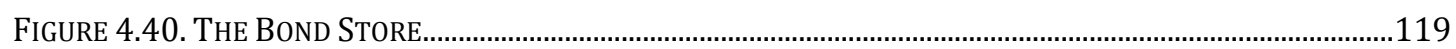

FIGURE 4.41. THE EASTBOURNE FERRY TERMINAL WITH SHEDS 11 AND 13 IN THE BACKGROUND....................120

FiguRE 4.42. PoRTION OF 1998 OPEN SPACE MASTER Plan SHOWING TARANAKI STREET WHARF .................121

Figure 4.43. VignetTE From 1998 OPEn SpaCe MASTER Plan SHOWing THE STAR BOATING CLUB BUILDing

AND TARANAKI STREET WHARF ...................................................................................................................122 


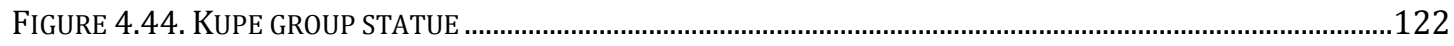

FIGURE 4.45. DIAGRAM OF PHASE 5 GOVERNANCE ARRANGEMENTS..................................................................125

FIGURE 4.46. LOCATION MAP OF PHASE FIVE PROJECTS AND FEATURES.................................................................128

FIGURE 4.47. GOVERNANCE STRUCTURE RECOMMENDED BY THE LEADERSHIP GROUP .....................................130

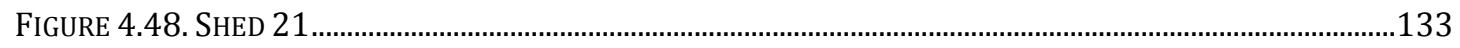

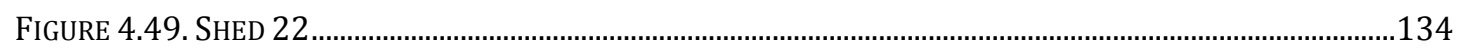

FIGURE 4.50. DIAGRAM OF THE PHASE 6 GOVERNANCE ARRANGEMENTS ...........................................................136

FIGURE 4.51. LOCATION MAP OF PHASE SIX PROJECTS AND FEATURES. ...............................................................142

FIGURE 4.52. WAITANGI PARK SITE CIRCA 2002 SHOWING THE EXISTING CHAFFERS PARK LAYOUT..................143

FIGURE 4.53. THE WINNING PARK DESIGN FOR THE WAITANGI PARK DESIGN COMPETITION ...............................145

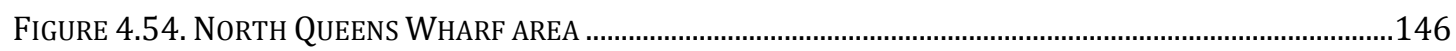

FIGURE 4.55. THE STEAMSHIP WHARF BUILDING .................................................................................148

FIGURE 4.56. THE MERIDIAN BUILDING AND HARBOUR-SIDE PUBLIC OPEN SPACE ..............................................149

FIGURE 4.57. ELEVATION DRAWINGS FOR THE KUMUTOTO PUBLIC TOILETS ......................................................150

FIGURES 4.58 AND 4.59. WRITERS WALK INSTALLATIONS.................................................................................151

FIGURE 4.60. 2004 PLAN FOR TARANAKI STREET WHARF ..................................................................................153

FIgURE 4.61. THE HERD STREET PoST AND TELEGRAPH BUILDING ….................................................................156

FIGURE 4.62. ODLINS BUILDING AND WELLINGTON FREE AMBULANCE BUILDING ..............................................157

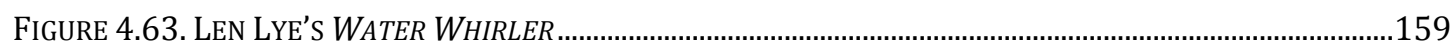

FIGURE 4.64. DIAGRAM OF PHASE 6B GOVERNANCE ARRANGEMENTS. ..............................................................162

FIGURE 4.66. AN ARTIST'S RENDERING OF THE WINNING ENTRY FOR THE OPT DESIGN COMPETITION. ...............166

FIGURE 4.67. JOHN WARDLE ARCHITECTS WINNING ENTRY FOR THE BUILDING SITES CLOSEST TO THE OPT ....173

FIGURE 4.68. ENTRANCE TO TE PAPA.........................................................................................................14

FIGURE 4.69. UN STUDIO'S WINNING ENTRY FOR THE BUILDING SITE CLOSEST TO TE PAPA ...............................174

FIGURE 4.70. THE WINNING PROPOSAL FOR BUILDING SITES EIGHT, NINE, AND TEN IN THE KUMUTOTO PRECINCT

176

FIGURE 4.71. THE WINNING ENTRY FOR THE REDESIGN OF FRANK KITTS PARK ................................................179

FIGURE 4.72. DIAGRAM OF THE PHASE 7 GOVERNANCE ARRANGEMENTS. ...........................................................183

FIGURE 4.74. SOLACE OF THE WIND BY MAX PATTE. ........................................................................................191

FIGURE 4.75. CAMPERVAN PARK AMENITIES. ................................................................................................ 192

FIGURE 4.76. 2011 QUEENS WHARF MASTER PLAN...........................................................................................196

FIGURE 4.77. DIAGRAM OF THE PHASE 8 GOVERNANCE ARRANGEMENTS. ..........................................................200

FIGURE 5.1. DIAGRAM OF THE INITIAL GOVERNANCE ARRANGEMENTS ..............................................................218

FIGURE 5.2. DIAGRAM OF THE PHASE 2 GOVERNANCE ARRANGEMENTS ..............................................................224

FIGURE 5.3. DIAGRAM OF THE PHASE 3 GOVERNANCE ARRANGEMENTS .............................................................2 231

FIGURE 5.4. DIAGRAM OF THE PHASE 4 GOVERNANCE ARRANGEMENTS .................................................................238

FIGURE 5.5. DIAGRAM OF THE PHASE 5 GOVERNANCE ARRANGEMENTS ............................................................2 242

FIGURE 5.6. DIAGRAM OF THE PHASE 6 GOVERNANCE ARRANGEMENTS ...............................................................248

FIGURE 6.1. HOW THE GOVERNANCE APPROACHES IDENTIFIED IN THE ARCHIVE ANALYSIS CORRESPONDED TO THOSE IDENTIFIED IN THE INTERVIEW ANALYSIS. 


\section{Introduction}

This thesis was prompted by a general interest in the urban design and planning processes of built environments and specifically, how different governance approaches to planning and design within a development process influence the built form. Urban design, planning, and land development are all, willingly or not, sociopolitical acts that interpret and prioritize social and cultural values; therefore, those who make decisions in the development process filter the values that direct the creation of the built form.

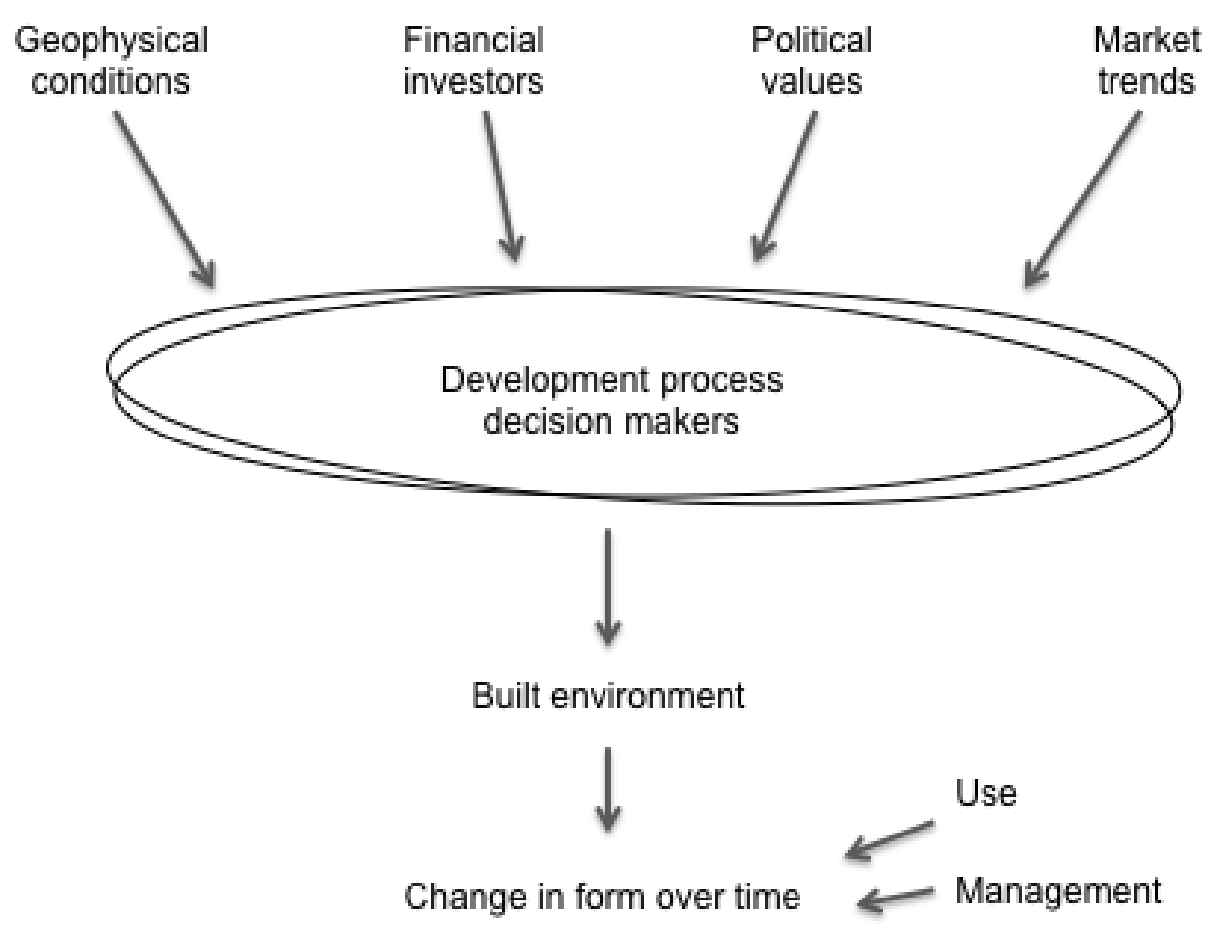

Figure 1.1. Diagram showing how those responsible for making decisions in the development process filter the various pressures to shape the form of the built environment.

Figure 1.1 illustrates this process of governance as a filter of the political, policy, geophysical and economic contexts. These contexts include evolving value sets and pressures that inform the decisions of those involved in the governance; however, these contextual pressures do not directly influence what values will be prioritized because those involved in the decision making retain agency to prioritize those values they identify as the most important. Additionally, the values brought to the process by those involved, the governance actors, are also prioritized and filtered through the 
decision making process. As a result, who is involved in the development process, and how they are involved, has a strong influence on the built form. It is these patterns of how different governance structures and methods of involvement affect the built form that will be investigated in this thesis.

The definition of governance used in this thesis is: a set of formal and informal organizations, processes, and institutions used by society to manage events and interaction within social systems. These systems include the land planning and development processes of cities and municipalities. Similar definitions of governance have been used in other fields, including studies of urban health (Burris, Hancock, Lin, \& Herzog, 2007), comparative governance (Pierre, 1999, 2014; Rhodes, 2007), and international development (UNCHS, 2000). This definition intentionally includes government, private, and public participants, in order to capture all types of participation that might affect decision making in a development project. Informal social processes that affect the decision making surrounding a development project are also included because they can have an equal or greater effect on the built form than formal processes. These informal processes include casual or unofficial meetings, lobbying, protests, and debates in the media. In comparison, formal processes include the planning, design control, and consent processes and relevant policies.

Consideration of the contextual policies, political, and regulatory changes that have affected redevelopment are important in understanding the structural forces that influence a governance process. Within this thesis, therefore, discussion of these contexts will articulate their influence on the governance; however, these observations will sit within a wider discussion of the whole definition of governance and will not be isolated for discussion. The point of this research is not to detail the influence of the individual contextual inputs (e.g. design policy or cultural values), but to identify and describe the governance approaches that filter these contextual influences.

\subsection{Context of study}

This field of inquiry was first entered via the literature on urban design based in architecture and landscape architecture. In this area, there has been some work focused on investigating the development process and place creation (e.g. Gillem, 
2007; Dovey, 2005; Calderon \& Chelleri, 2013; Carmona, 2014). This line of inquiry has been led by a general agreement that understanding the process of space creation is key to understanding the form of the space. Madanipour stated, "to understand urban space... we will need to look at the processes which produce the space” (1997, p. 374; see also Lefebvre, 1991; Barnett, 1982, p. 12; Carmona, 2014, p. 2; Punter \& Carmona, 1997; Washburn, 2013; Mumford, 1961).

While there are different views on what urban design is and includes (e.g. Gunder, 2011; Madanipour, 1997; Cuthbert, 2007) this thesis uses Carmona's (2014, p. 16) definition of the urban design process as including the design, development, use, and incremental evolution through ongoing management. While this definition includes both the creation and incremental re-creation of places, the interest in this thesis is on the portion of the urban design process involved with the initial creation of form: the planning and design processes.

There have been several lines of investigation within the portion of urban design research interested in the initial creation of the built environment. These threads include research into design practice (Carmona, Tiesdell, Heath \& Oc, 2010; Lang, 2005), inclusive design practices (Condon, 2008; Kelbaugh, 1997; Chapman, 2011), post-occupancy reviews (Gehl \& Svarre, 2013; Carmona 2014), development roles and power relationships (McGlynn \& Murrain, 1994; Lang 1994, p. 457; Dovey, 2005), and descriptions of different governance approaches related to development projects (Calderon \& Chelleri, 2013; Carmona, 2014; Gillem, 2007). Given the stated interest in how different governance structures and methods of involvement influence the creation of the built form, this thesis sits within this last field of investigation.

A second avenue of inquiry followed the Conzenian school of urban morphology. Broadly speaking, research within the Conzenian school of urban morphology is based on case studies articulating how past and present-day urban forms came to be (Whitehand, 1993; Moudon, 1997). Moudon's study of neighbourhood architecture in San Fransisco (1989) and Oliveira and Pinho’s comparison of Lisbon and Oporto (2006) are two such examples. These studies of historical development patterns have included descriptions of specific social influences and events that affected the built form, but have not include full descriptions of the governance approaches used in the 
case studies or how the governance process as a whole influenced the built form (Whitehand \& Larkham, 2013, p. 12). However, Conzenian urban morphology research has recently expanded to include analysis of the "evolving human agency in the shaping of city morphologies” (Larkham \& Conzen, 2014, p. 15). The studies undertaken in this area have described how the governance and the built form have changed and evolved over time. With their emphasis on change and evolution they have not, however, identified patterns of repeating or persistent governance approaches over the course of a development process and how these have influenced the built form.

A third avenue of inquiry into this aspect of urban development was found in the fields of urban governance and land development studies. These branches of social geography and economics have been primarily focused on understanding how different roles and actors in land development, power relations, economic pressures, and formal planning processes combine to influence development pressures (e.g. Calderon \& Chelleri, 2013; Healey, 1991, 1992, 2007; MacLaran, 2014; Pierre, 2005, 2014; Rhodes, 1997; Stone, 2015). The studies of governance in relation to the social production of the built form in these area have typically assessed the efficacy of governance processes in achieving a development-related agenda, described the governance approach for a particular project or policy direction, or identified how governance changed in response to external pressures or policy changes. While these do offer insight into different governance approaches, the studies have generally limited their descriptions to a single, overall governance approach for each case study instead of identifying multiple, different governance approaches that have been employed over the course of the case study under investigation. Even those studies that have analyzed changes in governance processes have generally treated them as a part of the same governance approach. Additionally, these types of studies have not adequately identified how the governance approaches have influenced the built form.

In each of aligned research areas described above, identifying the different governance approaches involved in a redevelopment project, articulating them in detail, and identifying their influence on the built form will provide a strong step for advancing these areas. To date, no one has looked at the governance of a development process in this detailed way; therefore, these allied areas of research can be advanced 
by the research reported on here. For example, research into the influence of different contextual pressures (e.g. design policy, development market economics, and policy changes) will benefit from a clear understanding of how the case study of interest filtered the particular values represented by the context under investigation. Studies of inclusive design practices, development roles, or power relationships will benefit from understanding the influence of context pressures and the actions of other stakeholders involved in the governance process under study. Also, studies of the changing morphology of different development projects will benefit from clarity regarding the different governance approaches and the physical fingerprints left by each of them.

In the fields of urban design and urban morphology research, therefore, there are many extensions of the work described in this thesis, all of which would benefit from a more detailed articulation of governance approaches and how these influenced the built form.

\subsection{Statement of problem}

Arguments for looking at the development process as a part of the urban design process and investigating how it influences the products of urban design are not new. Theorists, including Barnett (1982), Cuthbert (2007), and Carmona et al. (2010; Carmona, 2014), have suggested urban design professionals from all professional fields should take greater interest and be more involved in the design of the development process itself. For example, Carmona, Tiesdell, Heath, and Oc, in their textbook on urban design, Public places, urban spaces: the dimensions of urban design, extensively addressed the importance of understanding the development process and criticized the lack of understanding of how the process contributes to developments taking certain forms (2010, chapter 10). There is reasonable consensus, however, that the practice and research of urban design has been generally more focused on form, design policy, and other outcomes than on the larger social processes involved in the creation of the built form (Carmona, 2014; Carmona \& Wunderlich, 2012, p. 5; Cuthbert, 2007, p. 179).

More recently, Carmona (2014) argued for research into the relationship between the processes and products of urban design as a core area of research in the field of urban 
design. His work and other similar studies (e.g. Gillem, 2007) have reported on general governance-built form patterns found across multiple, spatially separate development projects, but Carmona acknowledged that each individual development project had its own characteristic urban design process. By extension, each of these individual urban design processes would have had unique influences on the built form. In comparison, the interest driving this thesis was a more in depth analysis of the urban design processes, that is: how the governance process of a single, large urban project shaped its form. Despite the contributions by Carmona (2014) and Gillem (2007), there is limited research into this area, especially indepth case studies of the governance of specific development projects. Identification of how different governance approaches contributed to specific patterns in the built form could provide a deeper insight into the relationship between urban design practice and its products.

As described in section 1.1, recent urban morphology studies have made inroads into the relationship between governance processes and the physical evolution of the built environment. This research approach has expanded upon previous urban morphology studies that looked at the evolution of the built form in relation to specific decisions and events. However, these expanded studies have treated the governance process as a continuously evolving process and have not sought to identify different governance approaches or patterns of how specific governance approaches have influenced the built form.

\subsection{Aim and scope}

To examine how the governance of a development process influences the resulting built form required a study of multiple governance approaches, where each approach was responsible for decisions affecting the built form. An ideal scenario was identified as a case study of a development project that included several building and open space projects that were developed under different governance approaches. This implied a project that was undertaken in phases or incrementally, allowing the governance to change and the different governance approaches to affect the planning and design of the built form. A project that was geographically cohesive, rather than spread over a metropolitan or regional area was also desired to minimize the influence of different contextual geophysical, soci-political, or economic pressures on the built 
form of the projects. With these criteria in mind the aim was refined to: identify the influence different governance approaches had on the form of a neighbourhood-scale development project.

Additional practical considerations refined the scope of the study further and guided the choice of a suitable case study. These practical considerations included the availability of background material, having available participants for interviews that represented a range of roles over the duration of the development process, and repeated access to the site. Accessible and varied background materials (including meeting minutes, consultant reports, plans, historic photos, and records of feedback from the stakeholder groups involved) were important for generating accurate and thorough descriptions of different governance approaches that guided the development of buildings and open spaces. Similarly, access to interviewees to provide first-hand knowledge of the development process from initiation through the different governance approaches would provide additional insight to address the aim of the research. Finally, having repeated access to the site would allow deeper analysis of the built form through repeat visits. Site visits over the period of analysis would enable better questioning of how the findings were reflected in the built form.

The Wellington waterfront development project met these criteria as it was a local government project, initiated in the early 1980s, and was subject to several different governance approaches as a result of the tension between competing viewpoints of various stakeholder groups involved in the process. Because it was a local government project, photographs of the site over the course of the development and the records of meetings, decisions, and stakeholder consultations were publicly available in the city's archives. Newspaper archives, trade journals, and past academic studies of the project were sourced to provide additional information and insights into the development process. Importantly, because the project was initiated in the 1980s many of those involved in the early stages of the development project would be able to participate in interviews.

The aim and scope considerations led to the following research question that guided the research for this thesis: how did the governance of the planning and design 
decision making processes influence the built form of the Wellington, New Zealand waterfront redevelopment?

To answer this question, the findings in chapters four and five will describe the different governance approaches that were used to guide the development of the Wellington waterfront over the study period and how each of these influenced the built form of the redevelopment. Additionally, comparison of these governance approaches in chapter six will identify broader patterns of how top-down management, greater control by professional designers, and incorporating public feedback influenced the built form.

To clarify the position taken in this thesis, this research question does not seek to describe a particular culture or society; therefore, it is not ethnographic in its approach. Instead, case study methodology will be used to identify and describe the social structures and operation of the development process and how these shaped the built form of the redevelopment of the Wellington waterfront. This assumes these mechanisms can be discussed and described independently of culture, an approach that is consistent with other literature that characterizes the development process (e.g. Healey, 2010; Pierre, 2014; MacLaran, 2014; Carmona, 2014) or examines archetypal roles of development process participants (e.g. McGlynn \& Murrain, 1994; Adams \& Tiesdell, 2012).

\subsection{Significance of study}

The study of the Wellington waterfront development is intended to contribute, at a theoretical level, to insight into how different governance patterns have influenced the built form. These findings will contribute most to the threads of urban design and urban morphology research described above that link practice and products, by examining the relationship between different urban governance approaches and the built form. As will be discussed in chapter two, much of the work in this area has compared multiple development projects to identify broader patterns across developments of a similar type, or worked with the assumption of there being a single overall governance approach, or has focused on how governance changed. The Wellington waterfront project examined here, is a look at one case study in depth to compare different governance approaches applied to the same development project. 
On a practical level, detailed studies such as the one reported on here provide insight into different governance approaches and development patterns. These types of findings are useful for communities and other actors in the development process to identify how to manage, or design, the governance process to get the types of development they desire. Implementation charrettes, which draw together decision makers into an intensive workshop to address issues facing a new development area, are one model of a deliberate governance approach to creating a 'local area plan' or an area specific equivalent (Condon, 2012, p. 28). However, research into different governance approaches can offer more options and flexibility in the creation and adaptation of governance processes to identify and create a vision or plan for an area.

Lastly, this study is intended to be a part of a larger research program on urban governance and urban design practices. Collecting and comparing studies of development processes will be used to develop a typology of associated governance approaches. The collected findings will also be used to push the theory on how the process of urban design (using the definition above) influences the built form at different scales. Practical applications will include developing tools to assist communities with identifying and designing appropriate governance approaches for land development.

\subsection{Thesis overview}

The following chapters begin with a critical review of the relevant literature to clarify the gap in knowledge addressed by the research question and the methods used by similar studies. A discussion of the research methodology underpinning this study and the methods used to carry it out are outlined in the third chapter. The two chapters following the description of the methods report on the analysis and findings of the background material and interviews for the case study. In each the emergent built forms are described at the appropriate points. A discussion chapter then evaluates the findings from the two analysis chapters and describes how they contribute to a deeper understanding of the case study and the aim of the thesis. Finally, the conclusion revisits the research gap and the aim of the thesis to describe what was achieved.

The literature review in chapter two states the case for investigating the influence of different governance approaches on the built form. To illustrate the context for this argument, the review will survey research in the fields of comparative urban 
governance, urban design, and urban morphology. Relevant theories and studies in this area will be identified and evaluated to articulate how the associated theory and methods respond to the aim of this thesis.

Chapter three articulates the methodological perspective that shaped the research design and describes the specific methods used to collect and analyze the data on the Wellington waterfront development project. A triangulation of methods was chosen to construct a deeper understanding of the development process and governance-built form relationship. Because governance processes are socially constructed and the built form can only be assessed through the filter of an individual's past experiences, a wide range of sources were brought together to address the aim of the thesis.

Briefly, the methods used in this thesis included thematic content analysis of archive and background literature to construct an understanding of the governance approaches used for the project and how they shaped the built environment. Interviews with people representing a range of development process participant roles were used to understand how the development process was experienced and understood to influence the built form by those involved. The findings from a thematic content analysis of the interviews were viewed as providing a complementary insight into the development process and the different governance approaches that were used. Site visits were used as a third method to collect data and supplement the analysis of the archive material and interviews. Familiarity with and analysis of the site provided additional assistance with identifying physical patterns and built form features associated with different governance approaches in the analytical stages.

Chapters four and five report on the analysis and findings from the archive data and interviews. The analysis of the archive data in chapter four, is organized based on the identified governance approaches and provides a detailed description of the waterfront redevelopment process, the individual building and open space projects, and how these two relate. Chapter five describes the governance approaches used on the waterfront and their influence on the built form as identified from analysis of the interviews. Both chapters conclude with summaries of the governance approaches identified in the respective chapters and a discussion of governance-built form relationship patterns common across the identified approaches. 
The discussion in chapter six compares the findings from chapters four and five to understand how the findings from the two different approaches contribute to a deeper understanding of the Wellington waterfront redevelopment process and how the governance of this influenced the built form. Comparison between the two approaches found significant agreement and complementary levels of details. The compiled findings of the governance descriptions identified seven unique governance approaches, with variations on two of them. The built form was found to be influenced by the different governance approaches at a range of scales. Overall, topdown governance approaches were associated with larger, and more numerous building sites, taller buildings, and more internally-oriented developments. The governance approaches that more effectively incorporated public and stakeholder feedback tended towards a greater diversity of public amenities, fewer building sites and more open space, and lower building heights. Finally, governance approaches that included professional designers in decision making roles were associated with more integration between building and open space designs, a greater emphasis on creativity over contextual considerations, and changing aesthetics.

The concluding chapter draws on the preceding literature review, methods, and findings to show how they align and how the thesis addresses the identified knowledge gap and research question. 


\section{Literature review}

The aim of this thesis is to identify the influence different governance approaches associated with the development of a neighbourhood scale project have had on the resultant built form (section 1.3). To identify the current boundaries of theory in this area, the following discussion will assess how governance approaches can be identified and how others have applied a governance perspective to studies of the built environment. It will begin with a discussion of governance theory and comparative governance frameworks. This review will establish the context for subsequent discussions of studies of urban governance in both development studies and urban morphology.

This discussion will show that current literature in this area provides the tools to identify different governance approaches and also provides precedents for examining how governance relates to the built form. It will also show that there has been little research on how different governance approaches within the same development project have influenced the built form.

\subsection{Governance theories and frameworks}

To identify and differentiate the governance approaches used in a development process, this section will look at different theories and analytical frameworks from the literature on governance and comparative governance. First, however, governance will be defined to provide a background to the field and establish the base for discussing and evaluating the different theoretical approaches.

The term 'governance' is a relatively contested term that has been defined and used in several ways. Some authors have applied it to the role of government, others have contrasted it to government, or have taken a position between those two extremes (Crespo \& Cabral, 2010; Pierre, 2014, p. 866; Stoker, 2011; Treib, Bahr \& Falkner, 2007). The varied uses and definitions are not inherently good or bad; however, there is general agreement in the literature that use of the term has shifted from referring to the operation of government to a more inclusive definition that includes all "socialpolitical-administrative interventions and interaction” (Rhodes, 1996, p. 657; also Stoker, 1998; Stone, 2015, p. 106). 
Conversely, Pierre (1999, p. 376) suggested there is a danger in being too inclusive as this leads to every form of public-private interaction becoming governance; however, it is argued here (and in the references above) that this is the point. Far from oversimplifying, the use of such an inclusive definition is deliberate in identifying all forms of interaction as governance. Unnecessarily limiting the definition or its application potentially ignores interactions that have direct and indirect effects on decision making and governance outcomes. Which social interactions are relevant is defined by the object of study. In this case, the intent of the research is to explore the unknown relationship between governance and urban form; therefore, an inclusive definition is necessary to allow for any and all possibilities.

As stated in the Introduction (page 1), the definition of governance used in this thesis is: a set of formal and informal organizations, processes, and institutions used by society to manage events and interaction within social systems. The process of land development is one such social system. In this case, the informal processes would include casual or unofficial meetings, lobbying, protests, and debates in the media. In comparison, formal processes include the planning, design control, and consent processes and relevant policies. Institutions, in turn, are the values, norms, and practices that shape behaviour and interactions between actors or organizations. Similar definitions have been used in other fields, including studies of urban health (Burris, Hancock, Lin \& Herzog, 2007), planning (Coaffee \& Healey, 2003), tourism (Hall, 2011), comparative governance (Pierre, 1999, 2014; Rhodes, 2007; Stoker, 1998), and international development (UNCHS, 2000; Rhodes, 1996, p. 656).

The spectrum of governance definitions from referring to 'only government' through to 'anything but government' has been accompanied by a range of conceptual frameworks for analyzing and describing different governance approaches. These frameworks engage with governance from different perspectives, each emphasizing different aspects. DiGaetano and Strom (2003) categorized the dominant theories and frameworks used to analyze and compare urban governance as forms of cultural analysis, structural analysis, or rational actor analysis. While there is some overlap between the different analytical frameworks, the three categories proposed by DiGaetano and Strom highlight the differences in the frameworks and provide a useful approach to understanding what analytical insights are offered by each one. 
Other classification efforts have been proposed based on how frameworks differentiate how governance processes operate and the actors within the processes interact (e.g. Jessop, 2002; Hall, 2011; Treib et al., 2007), or based on the definitions of governance used by different governance frameworks (e.g. Kersbergen \& Waarden, 2004). The classification system proposed by DiGaetano and Strom, however, incorporates both of these considerations.

\subsubsection{Cultural analysis}

The first category described by DiGaetano and Strom, cultural analysis, emphasizes description of cultural values, symbols, norms, and beliefs that drive political systems and how these are influenced by global and local forces (2003, p. 359). According to the authors, these types of analysis offer insight into the history of different governance arrangements in relation to their cultural context, including how these have changed in response to pressures of globalization. Cultural analysis studies employ anthropological methods to understand how different cultures gave rise to different governance patterns (e.g. Barnekov, Boyle \& Rich, 1989; Clark, 2000; Gillem, 2007).

Gillem's (2007) study of the planning and design processes used for overseas American military bases is a suitable example of this approach. For his study, Gillem employed institutional ethnographic methods to describe how military culture influenced base planning, design, and interacted with adjacent civilian cultures and their built environments. His analysis was based on unstructured interviews, online surveys, site visits, planning and archival documents, and media sources collected on five bases and from the adjacent civilian communities. Through articulating the drivers and institutions guiding planning, policies, and base management he was able to identify the physical effects expressed in the built form of the bases and adjacent communities, and identify the associated socio-cultural effects of the bases on the host nation. The key values, beliefs, and institutions identified by Gillem as guiding US military decision making included the consumerist behaviour of soldiers and their families, fear of attack, predictability and control, privatization of services, and a desire by military staff and their families for familiar spaces that supported cultural 
behaviours and activities. Gillem's analysis observed these drivers were expressed singly and in various combinations at various scales in the built form.

The institutional ethnographical approach applied by Gillem was useful for identifying how the built form of the bases and adjacent civilian communities reflected the cultures and institutions involved. Of interest was the identification of dominant cultural values that guided decision and policy making regarding the development of the built environment. However, Gillem's observations implied it was not just these driving values that shaped the built form, but also how these were identified, prioritized, and implemented in relation to the types of resources that were available. Despite this apparent relationship between the military's institutions and the hierarchical structure of decision making how these influenced the built form was not specifically explored.

DiGaetano and Strom (2003, p. 360) suggested the merits of using a cultural analysis framework resided in the ability of the latter to articulate how values enable governance approaches to persist. Equally they also argued this was also a weakness because it favours persistent values over understanding how governance and values change. To overcome this, a more structural explanation is required to articulate how change occurs. Gillem's work addressed this through identifying events that triggered changes in the governance patterns; however, his descriptions of the American military culture and institutions still emphasized those aspects that did not change.

\subsubsection{Structural analysis}

DiGaetano and Strom describe structural analysis of urban governance processes as primarily centered on a political economy perspective which emphasizes articulating the flows of power and capital between private investment and government (2003, p. 357; Gelman, 2011; Pierre 2005). This form of analysis articulates how socio-political networks and institutions contribute to changing market trends and forces (Kersbergen \& Waarden, 2004, p. 146; Pierre \& Peters, 2000, p. 18; Stone, 2015, p. 103).

Three analytical frameworks from the literature on governance were included in this category by DiGaetano and Strom (2003): regime analysis, intergovernmental system 
analysis (similar to network analysis), and regulation theory. Due to the urban political economic basis, all three include an emphasis on identifying public-private network structures and their influence on socio-economic market patterns.

The most prominent of the three analytical approaches has been regime analysis. Regime analysis is used to identify the occurrence of formal and informal publicprivate coalitions created to combine resources for a defined agenda, and how these relate to local and global economic pressures (DiGaetano \& Strom, 2003; Pierre, 2005, 2014, p. 870; Stone, 1993, 2015, p. 109). Stoker and Mossberger (1994, p. 196) similarly described regime theory as a conceptual framework that concentrates on understanding the collective organization, coordination, and actions of governmental and nongovernmental actors as they seek to influence urban economic change. These authors regarded analysis of coalition building as key to understanding governance because it identifies the influence of dominant groups or interests and their influence on market patterns (Stoker \& Mossberger, 1994; also Stone, 1993, 2015, p. 103).

Critics, however, argue regime analysis has run up against its limits in terms of its use as an analytical tool because the detailed descriptions of regimes limit generalization and its use as an analytical framework is considered to be primarily relevant to the U.S. political context (Hankins, 2015, p. 152; Pierre, 2005, p. 450). Some studies have, however, applied regime analysis in a European context, including Sellers’ (2002) analysis of how the agendas of urban governing coalitions in the U.S. and Germany were influenced by their political contexts, and Baeten’s (2012) analysis of neo-liberal planning in Malmo, Sweden. Although these studies demonstrate this approach remains useful for identifying and evaluating the effects of public-private coalitions, Pierre argues European urbanists are less concerned about public-private coalitions and more interested in:

“...institutional embeddedness in multilevel contexts of policy making and the subsequent rescaling of statehood, globalization, social exclusion, and the role of nongovernmental institutions (NGOs) and civil society in the delivery of public service; in other words, the role of the city's public institutions and actors in urban governance" (2014, p. 865). 
He suggests regimes only address a certain type of governance, that of public-private partnerships, and that urban governance in European and other contexts has greater diversity than can be addressed by regime analysis.

Additionally, Stoker (1995, pp. 59-60) echoes Pierre's criticism that regime analysis is focused on the influence of investors and power brokers, and does not acknowledge the influence of citizens. In response to these criticisms, Stone (2015) proposed an "urban political order" to build on regime analysis and thus become a more inclusive concept to further understand and describe governance arrangements and change. This concept includes descriptions of regimes, plus identifying how policy and institutional practices have changed as a response to citizen feedback on programs and projects. While this expanded approach does address Pierre and Stoker's criticism, the utility of applying the approach to non-coalition governance types remains a point of weakness.

In comparison, to Stone's expanded conceptualization of regime analysis Gelman used a narrower approach and argues the most important aspect of regime analysis is identifying the "constellation of actors participating in ruling coalitions” (2011, p. 46). In his analysis of Russian urban regimes, Gelman describes how these "constellations of actors" are formed and maintained by the flows of economic and political resources. This is a more focused look at the creation and maintenance of socio-political networks than other definitions of regime analysis, and has more in common with the next framework: intergovernmental system analysis.

Intergovernmental system analysis is focused on understanding the effectiveness of intergovernmental coordination (DiGaetano \& Strom, 2003, p. 358). This approach is similar to Gelman's interpretation of regime analysis as its focus is on describing and evaluating the hierarchical and operational organization of political networks.

Altes (2002) study of Dutch urban regeneration policies is one example of intergovernmental system analysis. In his study, Altes evaluated the effectiveness of multi-level government coordination for organizing and financing urban regeneration schemes. Gurran, Blakely \& Squires’ (2007) study of coastal urban growth policies and management across different levels of government in Australia is a similar study of the effectiveness of multilevel government coordination. While this framework 
uses a limited definition of who is involved in governance processes, this being government actors and agencies, findings from these and other similar studies provide useful insights into the formal aspects of governance. Because of its utility, the embedded concept of describing actor networks is used in several other analytical frameworks (e.g. Hall, 2011; Hankins, 2015; Pierre, 2014; Rhodes, 2007; Treib et al., 2007).

The third structural approach, regulation theory, investigates the influence of social, cultural and political regulation on flexibility and innovation in a social system (DiGaetano \& Strom, 2003; Hankins, 2015, p. 152). Treib et al. describe this approach as seeking to articulate the processes of creation and maintenance of policy, issues of power, and the effects of policy (2007, p. 6). Punter's (1992, 2002, 2007) analysis of design policies, their evolution, and their influence on the built form can be considered examples of this approach. This analytical focus does provide detailed insight into the regulatory processes and tools of a governance process; however, like regime analysis it has the relatively narrow scope of who is involved in governance processes and does not include many of the informal aspects of a wider governance definition.

\subsubsection{Rational actor analysis}

Rational actor analysis is the third category of urban governance analysis frameworks identified by DiGaetano and Strom (2003). According to the authors, rational actor type frameworks seek to identify how personal goals affect collective action based on an individual's interpretation of the existing and foreseeable decision making context. This type of analysis, therefore, requires identifying the social, political, and economic contexts in order to assess how the different actors' values and goals will interact with these and affect their decisions. As these contexts vary considerably, generalizations from such studies and comparison between case studies are difficult (DiGaetano \& Strom, 2003, p. 361).

DiGaetano and Strom (2003) classified regime analysis within this category of analytical types. Regimes, according to these authors, are formal and informal partnerships of public and private organizations that bring together resources to fill gaps in the ability of government to govern alone. They argue the formations of 
public-private regimes by "governing elites” meet the criteria of a rational actor approach because they are a collective action used by the elite actors to meet personal goals. Stone (2015, p. 124), however, argues regime analysis does not fit within this paradigm because rational actor theory discounts human nature and its positivist stance is incompatible with regimes as a constructed interpretation.

Rational actor analysis, however, includes research examining the roles of those involved in development processes. Literature articulating the relative influence different actor roles have on the decision making process surrounding development of the built environment, the goals commonly held by those in each of the roles, and the respective social and institutional influences that affect the choices of individuals and groups within the process, provide a useful grounding for understanding the actions of individuals in the governance process.

For example, McGlynn and Murrain (1994) proposed their 'Powergram' to illustrate the relative degrees of influence, responsibility, and interest different development related roles had on various aspects of the urban form. McGlynn's and Samuels (2000) expanded this to include the political relationships between the various roles and how these affected the practice and implementation of urban design. In each case, the work described generalized patterns of roles, goals, relationships between actors, and broad impacts on the general urban form; however, it did not account for variations in governance that may occur or relationships to urban forms at different scales.

\subsubsection{Combined analytical frameworks}

To address the biases of the different analytical frameworks described above, many authors have intentionally and unintentionally combined them to create analytical frameworks that provide a more comprehensive understanding of urban governance (e.g. Ataov \& Eraydin, 2011; DiGaetano \& Strom, 2003; Hall, 2011; Pierre, 2005, 2014; Stoker, 2011; Stone, 2015). For example, Ataov and Eraydin (2011) combined cultural, structural, and rational actor approaches in a framework that combined analysis of institutions, flows of material resources, governance capacity, and creation of governance coalitions. Their goal was to assess how regulation affects the 
expression of global influences in local governance in studies of two Turkish cities and how this is moderated by the local cultural context.

Ataov and Eraydin's findings described the governance systems of each city, how different systems for each case study interacted across scales, and the role of different influences in the evolution of the systems. While the analysis and discussion are thorough in application of their combined framework, the outcomes were limited in their ability to inform governance practice and reform. These limitations were due to a bias towards a structural analysis that remained in their governance framework.

DiGaetano and Strom (2003, p. 362) proposed a layered approach to combining cultural, structural, and rational actor approaches. They argued structural analysis provides an understanding of the contextual forces, the social and political networks, and regulatory mechanisms that shape a governance system. To distinguish between similar structural arrangements, cultural analysis provides insight into the unique local values, beliefs, and norms that affect the expression of governance. Finally, the preceding analyses provide a contextual understanding for a rational actor analysis that helps identify what individuals and coalitions prioritize in their decision making. They describe this layered approach as emphasizing an institutional understanding of different governance patterns.

To apply their framework, DiGaetano and Strom began with a description of the governance structure, including the organization of participant networks, political and market pressures, and policy direction. They then identified the "modes of governance," which addressed how the governance structure operates. This included identification of driving values, roles played by individuals and organizations, and patterns of interaction between those involved. By incorporating cultural and rational actor analysis, DiGaetano and Strom provided a more integrated look at the decision making of individuals and coalitions than Stone's criticism of rational actor theory suggested was possible.

Similar in principle to DiGaetano and Strom's integrated framework, others have looked at governance through the lens of institutional theory. Institutional theory includes analysis of the rules, regulations, and socio-political structures (i.e. formal 
institutions), and how they are influenced by informal institutions: the traditions, values, and cultural beliefs that guide social interactions (also Coaffee \& Healey, 2003; Gailing \& Leibenath, 2013; Healey, 1992; Pierre, 1999, p. 389). This theory links together ideas from urban political economy, regulation theory, phenomenology, social exchange theory, and Giddens' theory of structuration (Healey, 1999, p. 113). When proposing an institutional perspective of development processes, Healey (1991, 1992) argued political economy approaches failed to take into account the various strategies and motivations of actors. As a result, institutional theory attempts to reconcile analyses of social agency and of economic structures (Healey, 1999, p. 113; Ball, 1998, p. 1511; Guy \& Henneberry, 2000, p. 2412). Healey described this tension as an "interpretive and relational view of social life, which focuses on people actively and interactively constructing their worlds, both materially and in the meanings they make, while surrounded by powerful constraints of various kinds” (1999, p. 113).

One of the core concepts informing institutional theory, Giddens' (1984) theory of structuration addresses "how interrelations between structuring forces and actors shape actions and decisions within society” (Calderon \& Chelleri, 2013, p.410). According to Giddens, structuring forces include allocative structures, authoritative structures, and systems of meaning (1984). Allocative structures loosely relate to a political economy understanding, because they address how the compositions of social networks affect resource availability. Authoritative structures are the formal and informal social norms that shape the decision making process. Compared to DiGaetano and Strom's discussion of regulation theory in structural analysis, Giddens' concept of authoritative structures has a narrower focus on the rules and norms that guide decision making. Finally, systems of meaning are consistent with a cultural analytical approach because this aspect centers on understanding the cultural context and driving values that guide decision making. Because of these three components, there is equal emphasis on identifying who is involved, whose values are prioritized, how values are prioritized (formally and informally), and how decisions are made.

Healey proposed four analytical steps for institutional analysis of development processes: describe the development process; identify who was involved in the development process and how they interacted with other actors; outline the structural 
context of the development; and, identify how goals and values influenced the formal decision making process (1991, 1992, 1999, 2007). In this framework, the structural context includes the physical aspects of the development site, availability of financial and professional capital, and the rules and norms that govern these (Healey, 1992, p. 35).

Coaffee and Healey (2003) applied an institutional framework to analyze how the governance system reacted to institutional change with the introduction of 'area committees' by the Newcastle City Council in Great Britain. According to the authors, the introduction of these area committees was part of a modernization effort to be more responsive to local area needs within the city and create a system that was more approachable for residents. The institutional framework used by Coaffee and Healey examined the structural forces and pressures on the 'area committees', the cultural context of the planning environment, and articulated the decision making processes of stakeholders and stakeholder groups. Coaffee and Healey concluded the new committee structure did have some effect on the governance process, but the long term behaviour of the council would remain unchanged because of the persistent values held by those in power and the formal institutions that supported these. In other words, although there were more people involved in the governance, including stakeholders, the formal and informal institutions did not change significantly.

In a review of Healey’s institutional theory, Guy and Henneberry argued Healey’s model needed a more sensitive economic analysis to be useful for understanding property development cycles (2000, p. 2405); however, the criticisms and detailed approach they proposed in response is more relevant for understanding development markets and cycles than understanding the social construction of place. Hooper (1992) questioned the strength of drawing ideas from a range of different theories, but Guy and Henneberry (2000) suggested this approach was one of its strengths as it created opportunities for new insights. Further, they argued this approach opened new ways of understanding development processes and the social production of the built form.

Ultimately, the objective of institutional theory was to makes sense of urban political economy and the social relationships that had an influence on development projects 
(Healey, 1991). Previous research on urban development processes had primarily employed political economy and mainstream economic analysis; therefore, institutional theory was developed to incorporate sociological theory into this area of research (see Healey, 1991). While institutional theory may not provide a deep economic analysis, as argued by Guy and Henneberry (2000), it does incorporate a social understanding of governance with explanations of economic and regulatory contexts.

Pierre's urban governance theory (2005, 2014) also uses a broad perspective of governance that includes governmental and non-governmental actors, similar to DiGaetano and Strom's combined analytical framework and Healey's institutional analysis. Pierre's urban governance theory defines governance as the collective involvement of and action by actors from the community to achieve collective goals that are generally coordinated by local government (2014, p. 873). Therefore, it differentiates governance approaches by identifying who is involved in urban governance processes and the role they play in identifying political and institutional direction. Pierre suggested local governments typically retain the responsibility of providing direction, but setting the goals and processes of local governance is shared with commercial and societal interests (2014, p. 874; also Ansell \& Gash, 2007).

While Pierre does not explicitly address political economy or cultural perspectives like DiGaetano and Strom's framework or Healey’s institutional theory, this approach uses a similar conceptual model to that shown in figure 1.1. This model positions urban governance as filter through which market pressures, regulations, policy, cultural values, and other influences are interpreted by those involved in the decision making. The structural component is addressed by articulating the regulatory and socio-political networks of investors, politicians, and community stakeholders.

Description of the values and goals of the stakeholders involved in the governance process and how these are being incorporated into the decision making processes identifies the cultural component. Lastly, a rational actor understanding is generated by descriptions of the driving values of the actors and organizations involved in the governance process and how these different groups involve themselves in the process. Description of governance approaches using an urban governance theory approach, therefore, includes identification of who was involved, what values guided decision 
making, how these were prioritized, and the norms or traditions through which decisions are made.

Because he uses an inclusive definition of governance, Pierre argues urban governance theory can be used to describe a wide range of governance approaches, which facilitates case study comparisons (2005, p. 452, 2014, p. 885). He discusses comparing governance studies of different cities within the same country, as this is a common scale of analysis for governance studies. However, governance is a concept that is scalable to development projects within a city or even a single case study where multiple governance approaches have been employed.

What can be drawn from these and other efforts to integrate different analytical approaches into more articulate governance frameworks (e.g. Hall, 2011; Stone 2015; Trieb et al., 2007) is an improved understanding of what urban governance is and how different approaches can be identified. There are four components that can be seen in the combined governance frameworks above: a network of governmental and nongovernmental actors, values and priorities that drive decision making, the formal and informal behaviours and interactions that affect how inclusive the decision making process is, and resources or capacities that influence how these factors change. In this thesis, these four characteristics will be referred to respectively as: network structure, driving values, functional involvement, and modifying variables. These will be further discussed in section 3.3.7 of the research design chapter.

\subsection{Governance-based approaches to analyzing the production of the built form}

Moving a step closer to the aim of the thesis is the literature employing analytical governance frameworks to study the social production of the built environment. This part of the review will primarily focus on those studies that intentionally and unintentionally used institutionalist and urban governance theory perspectives. This is because these share a similar perspective to the definition of governance employed in this thesis. This section draws on studies from the fields of comparative governance, property development processes, spatial planning, urban design, and urban morphology. Rather than organizing the literature based on fields of practice or research, however, this review will cut across these fields to address the literature investigating connections between urban governance and the built form. The relevant 
literature will be described and evaluated in relation to the analytical approach, the methods used, and the findings in relation to the aim of this thesis.

\subsubsection{Urban governance studies}

This section will survey the research on urban governance that is connected to land development practices and processes. While some studies have used purely cultural or structural frameworks, as described in section 2.1, this section will focus on those studies that have applied a more holistic analysis of governance. Within this area the two general frameworks found in the literature are institutional analysis and urban governance theory.

Institutional approaches

Gailing and Leibenath argued, "institutional theory assumes that all spatialities can be regarded as institutional structures that inscribe themselves in and can be altered by human agency” (2013, p. 129). Within an institutional theory approach, therefore, the built form is regarded as a record of the governance processes used to create it (see also Gailing \& Kilper, 2009, p. 115; Healey, 2007; Massey, 2005). Despite this perspective, however, relatively few authors studying the governance of urban development processes have explored how the governance has influenced the built form. Instead, the findings from studies in this area have typically described the social, policy, and market outcomes (e.g. development types and regulations) or have evaluated the effectiveness of governance approaches at delivering a set agenda. Also, in all of the reviewed studies, the researchers described a single overall governance approach for each case study, rather than discussion of how the governance approach changed over the course of the projects.

For example, Gailing and Leibenath (2013) conducted an institutionalist analysis of the development and management of landscape policy in Germany that addresses socially constructed cultural landscapes. Their analysis included descriptions of the contextual role of formal regulatory policies, structures, and procedures, while informal institutions were described in relation to customary land uses, iconic landscape features and symbols, and traditional events. 
According to the authors, the informal local institutions had a stronger influence on the production and management of landscapes than formal institutions established by higher levels of government (Gailing \& Leibenath, 2013, p. 131). While these findings offer insight into how these landscapes continued to be socially constructed, they did not look at or report on the relationship with the form of the built environments.

Other studies that have employed an institutional-type framework include the following:

- Birkman Garschagen, Kraas, and Quang (2010) studied strategies for urban adaptation to climate change issues as they related to the governance of planning in two Vietnamese cities. Their findings described whether formal planning practices and policy used to address climate change goals had aligned with informal activities used by households to address climatic changes. The authors did not identify this as applying an institutional theory analytical framework; however, the analysis described the structural context, formal and informal institutions, and evaluated how these influenced one another. Their findings reported on the relative ineffectiveness of the governance approach in supporting residents' efforts to adapt to changing conditions. While they did discuss some built form features, these were assessed in the context of climate change responses, rather than how they were influenced by the governance approach.

- Breda-Vazquez, Conceicao, and Fernandes (2009) intentionally applied an institutionalist approach to examine Portuguese urban regeneration policies. They compared the formal regeneration planning policies with the types of regeneration projects carried out by public-private partnerships. The aim was to identify what policies supported successful partnership-led regeneration projects. The findings suggested the variability of informal institutions and their influence on governance processes made it difficult to compare what policies led to successful regeneration projects. While the analysis included physical descriptions of the renewal projects, the findings associated the governance approaches with social and market outcomes. 
- Calderon and Chelleri (2013) conducted a study of a public space urban renewal project in Barcelona. When setting out the aim of the research, the authors emphasized the need for urban designs to go beyond concern about form and look at the governance processes involved in their creation. To look at the governance process they intentionally used an institutional framework that examined how social, economic and political processes related to the production of public spaces.

Based on the field visits, archive analysis and interviews used to collect data, they described: the resources used for the development; the evolution of regulations and procedures that guided the development; who was involved, who led decision making, and who contributed which resources; and, the values, goals, and market pressures used to identify what type of development was appropriate (2013, p. 412). Using this information, the authors analyzed the formal and informal institutions framing the project's governance.

Their findings identified how the design was established by articulating the governance process (2013, pp. 421-425). Despite making connections between stakeholder values and built form features, however, Calderon and Chelleri's reported findings focused on the effectiveness of the governance process and final form of the project in stimulating cultural change, rather than how the governance shaped the built form. The authors described the governance controlling the design process as shaped by a tension between a top-down desire to renew the form and culture of the area and a bottom-up desire to improve the built form to meet the needs of existing residents.

- Carmona (2014) undertook a similar study of the development processes used for public space projects in London with the intent of identifying a generic, London model of an urban design process. Instead of directly employing an established governance framework, Carmona proposed a model of urban design that includes a description of the associated governance approach. This model included consideration of the historical cultural context of the site; the formal policy and larger economic context affecting the type of development; and, the forms of interaction between actors (p. 6). These three contexts were 
described as the forces that influenced the design, development, use, and management of the built form. While he does not reference literature on comparative governance that cover similar ideas, this perspective generally corresponds with the institutional theory approach described earlier.

From his site visits, interviews, and research into the history of the case studies, he identified an overall 'London-way' associated with different types of development and design quality. Carmona found the cultural history heavily influenced the overall governance approach and was reflected in the use of traditional urban forms, including market spaces, garden squares, and civic monuments. However, this contrasted with his suggestion that designers involved in the projects were found to emphasize innovative designs that created social and economic value. The author also identified how sociopolitical networks and resource availability influenced what types of development were promoted by public-private coalitions.

Despite his description of an overall 'London-way' of governance for public space developments, Carmona noted the development process varied from case to case (p. 19), which supports the idea that different governance approaches can exist in a single formal institutional context. This thesis argues these different governance approaches will influence the built form in different ways.

Despite aspirations to advance understanding of the relationship between the process and products of urban design, the city scale analysis of governance used by Carmona offers less insight into the relationship between the governance process and the built form than the more detailed, single case studies (e.g. Calderon and Chelleri, 2013). Instead, his findings provide a broad comparison of different governance approaches used for the development of public spaces, but how these influenced the built form beyond broad development types is not adequately resolved. These outcomes are both consistent and complementary to other studies of development processes; however, Carmona's work usefully employed an urban design lens in regards to the overall governance process. 
Other, similar, studies of the social production of the built environment employing institutional theory frameworks include Smith et al. (2009, cited in Calderon \& Chelleri, 2013, p. 411), Madanipour (1996, 2003), and Golubchikov \& Phelps, 2011. As with the examples above, these studies have described singular governance approaches in relation to development projects and do not effectively connect these descriptions to the form of the built environment.

Urban governance theory

Pierre's urban governance theory emphasizes governance as consisting of the actors involved, while institutional theory includes the regulatory and economic contexts as a part of governance. Descriptions of a governance approach include identifying who the actors are, how they interacted, their values, and the role of agency in shaping the governance process. As a relatively new theory of governance, few researchers have intentionally applied it to the study of development processes. The following examples of research on the governance of development processes have not explicitly used an urban governance theory framework; however, their studies are reasonable examples of how Pierre's theory can be applied. As per an urban governance framework, these studies distinguished the structural contexts of the developments as inputs into the governance process used to create and manage the built environment.

- The first example is Fraser, Bazuin, and Hornberger's (2016) study of homeowner associations (HOAs) in Nashville, Tennessee and their impact on landscape practices. Their research reviewed the regulatory, political economy, cultural, and historical contexts of HOAs, with a specific focus on governance around yard maintenance standards under different governance approaches. In their case studies, they described the governance process of how yard maintenance standards are set and maintained, based on information collected through site visits, interviews, and archive analysis. Their findings provided insight into participation and community formation within local government (HOA) systems and the influence different HOA governance arrangements had on landscape design and maintenance. While they found clear relationships between governance practices and yard maintenance standards, the connection to form was used as a vehicle towards understanding 
the effects different governance approaches had on community bonds, rather than due to an interest in different aspects of urban form.

- Second, Fluid City by Dovey, Sandercock, Stevens, Woodcock, and Wood (2005) described and examined the redevelopment of Melbourne's waterfront lands from several perspectives, including a narrative of the redevelopment, critiques of the design and experience of the built form, and a case study of tensions between power and meaning. The narratives of the redevelopment described the history of the redevelopment and the social, political, and economic contexts. Through the historical account and the discussions of flows of capital and power, the authors described how the actors involved in the governance processes negotiated the competing tensions of globalization and local values. While the discussion linked features of the built form with values that were prioritized through the governance process, the authors did not expand their analysis to identify how other aspects of governance influenced the built form.

- As a last example, Sepe (2013) studied the changing governance of HafenCity neighbourhood in Hamburg, Germany. The author described the structural context of regulatory, policy, and market pressures, plus the cultural history and traditions that provided an intended agenda of urban renewal for the area. Her description of the governance process and how it changed, however, illustrated the central role of actors as mediators of structural pressures in the governance process. Sepe also talked about the building and public space types necessary to meet the intended programming and agenda for the redevelopment, but did not link these observations to the governance approach used for the project.

In comparison, institutional analysis and urban governance theory use similar analytical steps for differentiating the variety of governance approaches used on development projects. Both frameworks included descriptions of the developmental history; identification of the regulatory, cultural, and market contexts; descriptions of the actors involved and their values; and, how the different actors contributed to the development process. Generally, these studies of governance and the social 
production of the built form also used similar methods: archive analysis to articulate the history and structural context of the case study, site visits to review the built form, and interviews with a range of stakeholders to identify the values of the actors involved and how different actor groups interacted with one another.

What differed was how they accounted for changes in governance. Most of the research employing an institutional theory framework only identified an overall governance approach and did not effectively differentiate new and old governance approaches. The studies that employed an urban governance theory framework illustrated how governance approaches change with the involvement of different actors over the course of the development.

However, despite the well-developed analyses of governance in relation to the production of the built environment, little research has been done on the influence different governance approaches had on the built form. The studies described above analyzed the governance of development projects and the associated built forms, but did not seek to connect the governance process and the products beyond associating the values of stakeholder with features of the built form (e.g. building types or general character).

\subsection{Other approaches to analyzing the production of the built environment}

This last section will review other research that has addressed relationships between society and the production of the built environment. These studies primarily come from research into urban design and urban morphology.

\subsubsection{Urban design theory}

A significant volume of literature on the study of urban form is concerned with how people and society understand and react to it, rather than how it is created. This is understandable in the context of informing the practice of urban design and allied professions (including architecture, landscape architecture, and planning); however, all areas of study and research within this field are impacted by and related to governance in some way. In most cases, the relationship with governance is not well articulated in this section of the literature. 
Jan Gehl (1996), Allan Jacobs (1995), and William Whyte (1980), among others, have examined the social and behavioural effects of urban form at the scale of the street. Through study of how people use and interact with the public realm, they advocate for the application of ideas or elements that have been shown to stimulate and facilitate pedestrian activity. However, while their research is useful for understanding and creating form at the scale of the individual, it does not address the underlying cultural and political processes that helped shape those spaces.

Jane Jacobs went a step further in her book The Death and Life of Great American Cities (1961). Through her observations of how urban spaces are used, and their effect on urban vitality, she linked urban design and social behaviour at a range of scales. Her conclusions begin to illuminate the interaction between governance, policy, and urban form; however, her analysis of urban development hinged mainly on form and use, rather than comparing the various formal and informal societal institutions that were employed in creating urban spaces. Work by Kevin Lynch $(1960,1984)$, on how urban form is perceived, complements Jacobs’ work by articulating how cities affect socio-cultural systems, and also identified design approaches that may be more desirable for enabling legible urban environments that improve the human experience. However, he too focused mainly on form as it related to social activity, rather than the social tools and processes involved in its creation. Both authors therefore address the way social institutions react to urban form rather than how they inform the creation of it.

Research into best practices and public engagement (e.g. Barnett, 1982; Carmona et al., 2010; Castells, 1983), inclusive design and decision making (e.g. Condon, 2008; Kelbaugh, 1997; McGlynn \& Murrain, 1994), and the use of form-based codes (e.g. Duany, Plater-Zyberk \& Speck, 2000) and other tools to manage outcomes (e.g. Carmona et al., 2010) do give more attention to social efforts that directly influence the built form. However, despite discussion of common design and implementation issues, the relative quality of the built form, and the range of tools and techniques designers and development managers might use to resolve urban issues, the research represented by these authors does not provide an adequate framework for articulating why the built environment takes the form it does. For example, while Carmona et al. (2010) recognize certain best practices may limit what is possible in terms of design, 
they neither explore nor explain how these practices shape the built form. Also, where some examples used by Barnett, Carmona et al., and others do illustrate how certain decisions or best practices affected the built form, these observations focus on highlighting specific decisions or practices rather than providing a complete articulation of the governance and decision making relating to the example projects.

Finally, the literature on design implementation includes identifying who influences the process (e.g. Barnett, 1982; Carmona, 2014; Gillem, 2007; Knox \& Ozolins, 2000; McGlynn \& Murrain, 1994; McGlynn \& Samuels, 2000), and urban morphology studies (e.g. Moore, 2008; Moudon, 1989, 1997; Whitehand, 1972, 1993, 2001). This body of literature significantly overlaps with the governance studies of the social production of form discussed earlier. Nearly all the work in this area could be described in the context of one of the governance frameworks. In particular, Carmona (2014), Gillem (2007), and McGlynn and Murrain (1994) were used as examples above to illustrate some of the different governance frameworks.

\subsubsection{Urban morphology}

Research into urban morphology, as described by Moudon (1997), evaluates how and why cities are built and evolve in response to social, technological, and economic change. According to Moudon, much of the research focuses on urban form types and how these came into being. The three schools of thought described as core to urban morphology theory by Moudon and others (e.g. Claessens, 2005; Liu, 2011) consist of the British Conzenian tradition, the Italian Muratorian tradition, and the French School of Versailles tradition. Of these, the Conzenian school is the only one that includes study of the processes involved in the production of the built form.

M.R.G. Conzen, in fact a German, was an urban geographer and planner whose teaching and research looked at the evolution of cities and the processes involved. The approach advanced by Conzen, Whitehand, and others is focused on description and explanation of the built form (Liu, 2011; Moudon, 1997). There are four branches of research that have evolved within the Conzenian school: studies of historical development patterns, the study of actors involved in changes to the built environment, applications of urban morphology in planning practice, and the study of morphological changes within an individual plot (Pinho \& Oliveira, 2009, p. 106). The branch most 
relevant to this thesis is research on the study of actors involved in changes to the built environment.

In the book Shapers of urban form: Explorations in morphological agency the editors, Larkham and Conzen (2014), argued studies of urban morphology have only recently undertaken detailed research into how actors in a development process influenced changes in the built form (also Whitehand \& Larkham, 2013). This resurgence carries on from earlier work by Carter (1970, cited in Larkham \& Conzen, 2014, p. 2) and Gordon (1984, cited in Larkham \& Conzen, 2014, p. 2) on the influence of actors' values on decision making behaviour in a development process. According to Larkham and Conzen, this line of inquiry addresses the "evolving human agency in the shaping of city morphologies... [and with] focus on the human actors whose perceptions, preferences, and felt pressures have led to decisions and actions producing the myriad forms that comprise the built environment” (2014, p. 15).

The collection of studies within Larkham and Conzen's book, as with other similar studies, provides insight into the evolution of different governance processes and how the built form responded to these changes. This approach builds on studies of historical physical development patterns that followed earlier Conzenian methodologies (e.g. Moudon, 1989; Whitehand \& Larkham, 1992: Oliveira \& Pinho, 2006). These earlier studies discussed the underlying historical causes of how cities have developed and have identified some of the cultural roots that continue to help shape cities today. However, while they noted the origins of different urban patterns, their work largely focused on understanding how these were a result of individual decisions and specific influences (Whitehand \& Larkham, 2013, p. 12).

For example, Kostof (1999) describes how various European cities were shaped by different influences throughout history. The star shaped walled cities such as Palmanova in Italy reportedly arose in response to the technological advancements in the design of cannons for attacking cities, whereas other cities, like Rome were shaped by the periodic growth and decline associated with the rise and fall of trade (Kostof, 1999). In a following book, The City Assembled (2005), Kostof and Castillo take a similar approach to the shaping of specific urban features and forms such as plazas. They talk about the historical events that shaped city elements and contributed 
to their current form. This is very similar to Mumford's approach in his book The city in history (1961) in which he looks at different factors that shaped urban form from pre-history through to the post-World War II period. While the analyses of these authors are useful for understanding how specific cities or urban forms in certain contexts came to be, they do not push further to an investigation of the systemic influences of society and the governance structures formed by it that contributed to the generation of these forms.

In comparison, Moore's (2008) review of the Dublin waterfront regeneration is an example of an urban morphology study into the role of governance in shaping the built form. In her thorough analysis of the history of the regeneration project she identified the individuals, institutions, organizations, events, politics, decisions, and trends that contributed to shaping the waterfront. Her findings identified local and national policy and political changes that influenced the development process and realized built form. However, the patterns Moore drew out focused on economic and urban form trends with less consideration of the role of informal institutions.

Additionally, while Moore provided a detailed account of the waterfront's transformation, and arguably this was the sole purpose of her work, Moore did not differentiate the governance approaches that were used on the waterfront. Had she compared the effects of different governance approaches that occurred over the study period, a deeper understanding of how social, political, and economic changes influenced the built form would have been provided.

Like the other studies addressing morphological agency within urban transformation projects, Moore’s analytical framework functions as a hybrid variation of the institutional and urban governance frameworks described earlier in the chapter. Significantly, this type of analysis offers detailed insight into the evolution of urban forms and their social, economic, and political contexts. The major drawback, however, is the emphasis on understanding change and evolution, rather than identifying different governance periods and comparing how these influenced the built form. Such an approach could provide a means to identify and understand governance and morphological periods. 


\subsection{Summary}

A review of the literature on governance theories and frameworks provided insight into tools that can be used to understand the governance of different case studies of development projects or periods of change in the built form. The subsequent review of urban governance studies that applied these frameworks in order to analyze development processes found they typically described singular, overall descriptions of governance approaches. The alternative would have to identify a set of different governance approaches for different aspects of the same case study or for different phases. Additionally, the descriptions of governance for case studies in this area have not been well associated with their effects on the built form.

Early urban morphology studies assessed the evolution of built environments with some consideration of the influence of policy, political change, economics, market conditions, and cultural changes. Recent work, however, has built on this line of research to incorporate analysis of different actors, including their values, goals, and participation in the decision making process. While this expanded scope overlaps with urban governance research, the urban morphology studies have typically not adopted established governance frameworks to guide their analysis.

Of interest to this thesis, however, are the identified relationships between the governance processes and the built form found in the expanded urban morphology studies. A shortcoming of this approach, however, is the emphasis on describing how changing governance processes have influenced the built forms. Through this emphasis, these case studies have remained focused on describing the evolution of the built form, but with expanded explanations of how the social context (i.e. the governance processes) has effected change in the built form. A missing piece in this line of study is exploration of governance patterns within the developmental history of an area and how different governance approaches have affected the built form.

In this context, the single type governance description found in urban governance studies and the descriptions of continuous governance change found in urban morphology studies form two ends of a spectrum. In the middle is a line of research that draws analytical tools from urban governance research to identify and describe different governance approaches (or phases) used over the course of a development 
project or study period. Additionally, from the field of urban morphology, comes the precedent for establishing links between governance practices and the built form.

What is consistent between the different approaches, however, is the types of data used for analysis. For studies of governance and urban morphology, archived material and literature relevant to the case studies provide material for analyzing the social, political, economic, and regulatory contexts. Studies of recent development projects often included interviews with different actors involved in decision making processes. Site visits and past plans have also been frequently used to understand the built form and complement the analysis of archive material and interviews. Collectively these different sources are considered to have generated deep understandings of the case studies and robust findings. 


\section{Research design}

This chapter outlines the design of the study and the reasoning behind it. The overview introduces the general methodological approach and the specific methods applied to addressing the aims of the research. Part two explains how the methodological approach adopted for the thesis reflects my ontological and epistemological perspectives. Part three describes the chosen methods used to collect and analyze the data for the case study, and how the parts of the analysis contribute to achieving the aim of the thesis.

\subsection{Overview}

The existing research on how the governance of the land development process influences the form of the built environment was described in the literature review (chapter 2). The lack of case studies articulating how development projects can include a set of different governance approaches, each having different effects on the built form, means there remains a lack of understanding of the nature and patterns of this relationship. To investigate this governance-built form relationship and how its patterns vary, the redevelopment of the Wellington waterfront was chosen for a detailed case study.

While case studies are often used in qualitative and quantitative research, the qualitative 'case study method' has been described as “a method...that seeks understanding of a social situation or process by focusing on how it is played out in one or more cases” (Richards \& Morse, 2013, p. 76; see also Flyvbjerg, 2001). Detailed investigations of individual studies, employing multiple methods and perspectives, enhance our understanding of the particular expression of a relationship; while, comparison of the different approaches used within or between studies improves our understanding of the different patterns of these relationships (Thomas, 2011). Because the research objective targets the changing social situation of the development process and how this influenced the built form of the waterfront redevelopment, describing these social processes in the form of a suitable case study was identified as the most appropriate approach. 
This approach follows the assumption that a deep understanding of such a complex relationship is best studied in a naturally occurring context. The Wellington waterfront was chosen for the research because preliminary analysis of the waterfront's history revealed it went through several iterations of the development process. Investigating this relationship through comparison of different governance approaches acting on the same redevelopment project eliminated as many external variables as possible. These variables could have included cultural differences, different policy and planning environments, different locational and geographical influences, different building codes and construction methods, and different funding environments.

\subsubsection{Methodological choice}

A qualitative approach was chosen to analyze the governance-built form relationship of the Wellington waterfront because the research question did not lend itself to using quantitative methods. This thesis needed to articulate the patterns of this relationship before a quantitative approach could be used to examine the strength and extent of the patterns. Within the set of possible qualitative approach, thematic analysis was chosen to probe the collected data, using both inductive and deductive thematic frameworks.

The use of multiple qualitative methods was a pragmatic choice that responded to the need to establish an understanding of comparative governance approaches and the governance of the Wellington waterfront redevelopment. Ritchie et al. talk about pragmatic research design as using “...the best approach or a hybrid of approaches that best fit the research question” (2014, p. 20).

The research aim calls for identifying, describing, and comparing the different governance approaches that occurred over the study period. To assist with this, a framework consisting of three characteristics and an additional four variables that modified these were identified from the literature on comparative governance (see section 2.1.4 for the background and section 3.3.7 for detailed descriptions of the characteristics and variables). Applying these as a deductive thematic framework within which to develop interview questions and analyze the interviews helped with understanding different aspects of the redevelopment project's governance. 
The governance characteristics and variables were useful for a thorough induction into the field of comparative governance, for providing a basis for the semi-structured interviews, and for providing detailed insight into the governance of the waterfront. To meet the aim of the thesis, however, another approach was required. The analytical framework was too focused on the individual characteristics of the governance, so an inductive approach was also applied to identify the different governance approaches and how they influenced the built form.

\subsubsection{Methods overview}

Thomas (2011, p. 9) notes case studies often use a variety of methods to provide insight into the particular case. The test of quality, therefore, is not whether particular methods were used, but rather whether the results provide a well-rounded description of the particular phenomena, of which the case study is an example. To understand and provide a well-rounded description of the governance and built form relationship, this study drew on several sources and methods of analysis: archive and background literature, interviews with a range of participants who had been involved in the redevelopment, and site visits.

\section{Data}

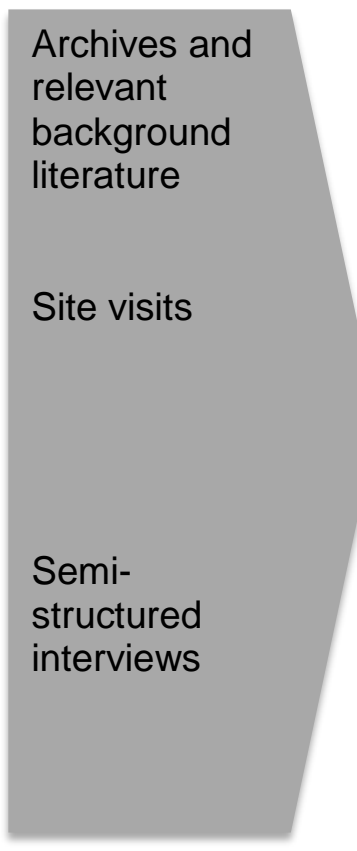

\section{Analysis}

$$
\begin{aligned}
& \text { Chronology of built } \\
& \text { projects and their } \\
& \text { governance contexts. }
\end{aligned}
$$

Notes on character and form at different scales. Used as additional input into analysis of archive and background material.

Deductive thematic analysis using a framework of governance characteristics and inductive thematic analysis.

\section{Findings}

Comparison of governance contexts to identify governance approaches and their influences on the built form.

Comparison of perspectives to identify and describe governance approaches and their influences on the built form.

Figure 3.1. Diagram of the research methods. 
As per figure 3.1, the data collection for the study included collecting background information, semi-structured interviews, and site visits. The development history, interview summaries, and site visit notes that were produced from this data formed the basis for analysis to look at the relationship between governance and the built form of the Wellington waterfront.

The archive research of background material was used to create a descriptive time line of the redevelopment project that emphasized both governance and built form changes. To provide a well-rounded description of the governance-built form relationship, multiple background data sources were used when drafting the development narrative. Such descriptions are common in case study research (Richards \& Morse, 2013; Thomas, 2011, p. 6; Byrne, 2009), including urban morphology (see Moore, 2008; Moudon, 1989, 1997), and urban design (see Barnett, 1982; Carmona, 2014; Dovey, 2005; Gillem, 2007; Mumford, 1961).

From this narrative, different governance approaches were identified using an inductive thematic approach. Compiled descriptions of plans and development projects corresponding to each of these approaches were examined for similar governance approaches and, subsequently, built form patterns that were characteristic of the different approaches. More general relationship patterns emerged when comparing the governance descriptions and built form relationships. These two steps are shown in figure 3.2 . 
Review of archive and background literature.
Descriptions of the governance processes and forms for individual waterfront plans and projects.

\section{Identification of governance approaches Grouping descriptions of individual plans and projects based on similarities between governance descriptions.}

\section{Comparison of governance} descriptions.

\section{Identification of built form relationships Identifying built form features associated with the different governance approaches.}

Figure 3.2. Diagram of archive analysis process.

The archive research was also used to identify people who had detailed knowledge of the projects and experience of the development processes to contact for interviews. As shown in figure 3.3, the recorded interviews were first analyzed deductively using the governance characteristics as a set of analytical themes. This approach dissected the essential character of the governance practices and what caused them to change. Second, the collected interviews were re-examined using an inductive approach. By comparing the interviewees' descriptions of the development process, governance phases were identified along with their perceived effects on the built form. As with the archive analysis, broader governance-built form relationship patterns emerged when comparing the governance descriptions generated using this approach. 


\begin{tabular}{|c|c|c|}
\hline $\begin{array}{l}\text { Semi-structured } \\
\text { interviews with } \\
\text { informants who } \\
\text { represented a range } \\
\text { of roles in the } \\
\text { development process. }\end{array}$ & $\begin{array}{l}\text { Deductive thematic } \\
\text { analysis of the } \\
\text { interviews using the } \\
\text { governance } \\
\text { characteristics. Using } \\
\text { thematic tables to } \\
\text { organize the data and } \\
\text { compare within and } \\
\text { between interviews. }\end{array}$ & $\begin{array}{l}\text { Identification of the } \\
\text { essential character } \\
\text { of the waterfront } \\
\text { governance, but this } \\
\text { did not help identify } \\
\text { governance } \\
\text { approaches or built } \\
\text { form relationships. }\end{array}$ \\
\hline $\begin{array}{l}\text { Inductive thematic } \\
\text { analysis of the } \\
\text { interviews. The } \\
\text { themes used to } \\
\text { analyze the interview } \\
\text { arose from a } \\
\text { reviewing how the } \\
\text { interviewees } \\
\text { described the } \\
\text { development } \\
\text { process. }\end{array}$ & $\begin{array}{l}\text { Identification of } \\
\text { different governance } \\
\text { approaches and how } \\
\text { these influenced the } \\
\text { built form. }\end{array}$ & $\begin{array}{l}\text { From the compiled } \\
\text { descriptions of the } \\
\text { governance } \\
\text { approaches, more } \\
\text { general governance } \\
\text { patterns were found. }\end{array}$ \\
\hline
\end{tabular}

Figure 3.3. Diagram of interview analysis process

Lastly, the site visit observations were recorded as notes, sketches, and photographs.

These collectively provided insight into the character of the built form at scales ranging from an overall impression to specific details that provided a detailed reading of the built form. As shown in figure 3.1, this was used to evaluate and supplement the findings from the archive analysis.

The final analytical steps compared the governance-built form patterns derived from the interviews with patterns identified in the narratives. The site visit observations were used to evaluate if these patterns were evident in the built form. Each of these final steps was used to address the aim of the research from a different perspective. As suggested above, the purpose of a case study is to provide a rich description and the use of multiple qualitative methods supports this approach.

A risk with the different approaches included confirmation bias due to employing an a priori analytical framework for creating questions and analyzing the interviews. Also confirmation bias of a single researcher using multiple methods was a concern. In both cases the risk was the researcher would only see evidence that supported their 
expected findings (Gerring, 2012, p. 82; Thomas, 2011, p. 112). The use of multiple methods was used to mitigate this risk. Additionally, conscious self-reflection during the analysis of the collected interviews and other transparency measures, including clearly connecting the analysis back to the original interviews and archive material, were also used to address this problem.

\subsection{Methodological choice}

As stated in the introduction (section 1.2), the aim of the thesis was to describe how the organization and methods of decision making (i.e. the governance) of the development process shaped the resulting built form of the Wellington waterfront. The relationship between these two objects of study, the governance of the development process and the form of the built environment, cannot be directly observed, but can be articulated through description and analysis.

This choice, and subsequent research design, reflects assumptions of how the two objects of study can be understood and studied. The first object of study, the planning and design processes (i.e. the governance process), was seen here as being a collectively constructed reality that is experienced in different ways by the participants in the process. By collecting a variety of perspectives and experiences through archive research and interviewing a range of people involved with the redevelopment project, this constructed reality can be characterized. This perspective falls within the ontological perspective of contextual idealism (see Hughes \& Sharrock, 1997; Madill, Jordan \& Shirley, 2000; Shaw, 1999 cited in Ritchie et al. 2014, p. 5).

The other object of study is the realized built form which exists independently of social processes and values, yet our understanding of it is always filtered through our individual perceptions. It is held here that there is both a concrete reality to this that exists outside of us and an overlying reality that is created by the viewer. The created individual perspective is filtered by the viewer's past experiences, senses, and mental state at the time of experiencing the space. This perspective is known as depth realism (Blaikie, 2007) or critical or transcendental realism (Bhaskar, 1978; Robson, 2002, p. 29). 
Exploring the governance-built form relationship within the Wellington case study by using a variety of sources and perspectives (including my own) respects these two ontological perspectives and recognizes the results will be one of many constructed interpretations of how this relationship exists. Using a range of sources for evaluating and understanding the creation of the built form, including the archive material, interviews, and site visits, was intended to provide a more complete description of the constructed reality and its relationship to the values held by those responsible for its creation. This approach was informed by literature addressing the direct influence of values on the built form (including Madanipour, 1997; Sennett, 1992, p. xi).

Identifying and describing the values that drove decision making regarding the built form and the collectively constructed governance process required gathering a range of perspectives from those involved in the development process. This and the complexity of the social institutions and processes under review led to the decision to employ qualitative methods to investigate the phenomenon. In support of this decision, qualitative research has been described as useful for identifying "features that are formative in complex or difficult to understand behaviours; or...processes that are based on a complex interplay of perceptions, expectations, circumstances, resources, incentives, barriers, and so on" (Spencer, Ritchie, O’Connor, Morrell \& Ormston, 2014, p. 331). The intent was to examine the decision making process holistically, identify potential patterns and types of relationships in the built form, and identify what aspects might benefit from future study. To do so required the use of two thematic analytical approaches to identify relationship patterns in the collected data.

Case studies are used in a range of methodological traditions; therefore, there is debate on the flexibility and variation in the methods that can be applied (Richards \& Morse, 2013, p. 78). A general consensus, however, is individual case studies should be bounded studies of a particular subject in its natural setting (see Richards \& Morse, 2013; Spencer et al., 2014; Thomas, 2011; Flyvbjerg, 2001). Thomas describes the outcome of a single case study as a "rich picture - with boundaries" (2011, p. 21), this is generally a thorough description of the case that is focused on the aims of the research. To achieve this, multiple data sources and multiple qualitative methods were 
used to examine the governance-built form relationship of the Wellington waterfront. These are then brought together in the findings to provide a "rich picture."

Thematic analysis, or thematic content analysis, is described by Rivas (2012, p. 367) and by Spencer et al. (2014, p. 271) as useful in a wide array of analytic traditions for interpreting patterns of ideas and relationships in the data. The purpose is to provide systematic review of patterns and relationships within the data to develop higherorder concepts that explain them and address the research question. This approach is described further under the discussion of methods (section 3.3). In alignment with Spencer et al.'s discussion of inductive and deductive thematic frameworks, this thesis employed both types to provide a deeper understanding.

The thematic framework used in the deductive analysis of the interviews (described in more detail in section 3.3.7) was comprised of a set of characteristics and variables that were derived from the literature on comparative governance examined for this thesis. Using an a priori model carries inherent risk as Gerring warns a researcher may only finding patterns that support the theory or analytical framework they were expecting to find (2012, p. 82; also in Spencer et al., 2014, p. 300). The risk of this, however, was minimal because this framework for characterizing the governance was only used as a base to structure the interviews and to provide a detailed understanding of how the interviewees perceived the governance of the redevelopment project. As described in section 3.3.10, the findings from the application of the governance framework did not directly inform the overall findings of the thesis because they divided up the governance approaches into discrete character descriptions that were too specific for addressing the research aim. Instead, an inductive approach was used to identify the key findings. The results of the governance framework analysis were, however, useful for understanding the different aspects of the identified governance approaches in isolation. This understanding provided a valuable perspective for identifying and describing the separate governance approaches. 


\subsection{Description of methods}

\subsubsection{Case study identification}

Choice of case study was relatively simple as the Wellington waterfront had several convenient attributes: it was easily accessed, it had clear physical and administrative boundaries, there were sufficient resources available (including people involved and background materials) to provide a well-rounded description, and the scale and age of the redevelopment were enough to reflect a series of governance changes.

When judging its suitability, the foremost considerations were whether it had clearly employed multiple governance approaches and whether it was relatively well defined spatially as these factors directly responded to the aim of the research. Gillem's (2007) cultural analysis of overseas United States Air Force bases was close to the ideal of a suitable case study. In these projects, the political agreements that enable these types of development mean the policies guiding their development are almost exclusively developed by U.S. military personnel and the hierarchical structure of the military restricts who can influence decisions regarding the planning and design of the built form. Even outside of the military, development projects with clear administrative boundaries provide a convenient scope for investigation and can produce clear edges in the built form. Choosing a reasonably well defined urban area also set a convenient boundary for simplifying site visits, discussion during interviews, and collection of background information (see figure 4.12).

Other types of case study areas that had been considered included: central business districts, neighbourhoods designed and constructed under a single developer, well defined neighbourhoods bounded by natural features, brownfield redevelopments, and waterfront redevelopment areas. There was the potential to choose a suburban greenfield development or a suburban neighbourhood; however, it was thought the Wellington waterfront provided greater variety in the built form and would have a richer governance structure as it was a public project.

It was useful to identify a case study with a range of building and open space projects in the built environment to find points of comparison and a potential range of governance-urban form relationship patterns. Related considerations included: 
whether the project was government driven with multiple developers (civic) or driven by a single developer (developer driven), the approximate start date, and whether the project was developed in a series of phases or incrementally over time. In choosing between civic or developer driven projects it was thought study of the developer driven sites would be more reliant on access to the sole or main developer involved, thus the civic sites were more flexible in terms of having a wider pool of potential study interviewees and greater availability of background material.

Other considerations included the scale of the project area and the former land uses. It was important to find a relatively large case study that allowed for variety in the built form regarding public space, types and scales of developments, types of amenities, and relationships to surrounding urban areas. Also, development occurring over multiple decades ensured the project would be witness to change in governance practices which would be reflected in the built form.

Choosing a case study that had been developed over 30+ years ensured most of the project would be built out, rather than still being in the conceptual planning phase. Yet, it was important that the initial stages were still within living memory as this affected the availability of suitable resources. The desired resources included a range of background material, a range of people involved in the development process, and ability to visit the site. Background materials included media reports, local government records, administrative body records, and popular and academic publications.

Targeted interviews required identifying people representing different roles in the development process, time periods of involvement, and who was accessible. It was thought it would be more difficult to contact those involved in the redevelopment projects at a senior level in larger centres. Similarly, in the smaller centres it was thought some of the work might have been done by developers and designers from elsewhere and communication would again be an issue.

The Wellington waterfront redevelopment, described further in section 4.1, met all of these criteria: it had a reasonably clear formal governance arrangement and administrative boundaries, a range of size and types of internal development projects 
built incrementally over 30 years, the development had occurred within living memory, the key participants in the development project from its origins to the present were generally locally situated and accessible, and this project was local and familiar.

\subsubsection{Background research}

Once the case study was selected, the background literature on the development history was collected through available physical and online resources including: municipal archives, reports available from the development corporation, academic and popular literature, government policies and legislation, local government meeting minutes relating to the projects, newspaper archives for relevant articles and letters to the editor, and, later, material collected by interviewees (see appendix 3 for the list of resources). The material was used to learn about the development, including individual projects and plans, changes that had happened to the governance of the waterfront, and to identify who to interview in order to learn more about the development processes in greater depth. Once analysis began, each individual project and development plan for the waterfront was the subject of more directed data collection.

The value of using the archive and background material was in providing an assortment of official, academic, and public views and records of the waterfront redevelopment. This form of data triangulation, with attention to including varying sources and perspectives, provides valuable insight into the project. However, unlike interviews where additional questions can be asked, analysis of documents is limited to the information supplied. If a range of sources and perspectives cannot be found the analysis may result in an incomplete account of the case study (Gidley, 2012, p. 268). Other concerns with archival data are the credibility, and representativeness of information and views of the sources that are used (see Bhatt, 2012, p. 164). To address both of these issues attempts were made to ensure multiple sources, representing different perspectives, were used to develop the descriptions of the waterfront process and projects.

When researching the history of the redevelopment project, it was necessary to choose a start date for the time line as this would affect the discussion about the initial 
governance arrangement and the effect of subsequent changes. The decision was made to begin the time line in the year the initial redevelopment projects were carried out. This predated the establishment of the development corporation as the Wellington waterfront redevelopment area was still controlled by the Wellington Harbour Board (the port authority who owned and managed the land). Subsequent governance changes included a joint agreement with the Wellington City Council (WCC) that established the boundaries of the redevelopment area (see figure 4.12) and establishment of a development corporation initially called Lambton Harbour Management Limited.

As the redevelopment was primarily a WCC project, the plans, reports and meeting minutes from 2005 to the present were available via the council website (www.wellington.govt.nz). Older council materials (including the 2001 Wellington Waterfront Framework, older plans, newspaper articles, information pamphlets and brochures from various organizations, design competition briefs and entries) were accessed from the municipal archives, the Wellington City Library, and the personal files of those involved in the process.

\subsubsection{Site visits}

The Wellington waterfront was visited many times between January 2010 and December 2014 as it was local and easily accessed. Observation of different features of the built form and overall character were conducted over the course of these multiple visits undertaken at different times during the analysis to provide different perspectives and increase familiarity. A combination of field notes and photography were used to record observations about the built projects and un-built sites along the waterfront.

The recorded notes included observations on aesthetic and structural aspects of the built form as they presented themselves. These included spatial definition, architectural style, consistency of materials and fixtures, location and types of amenities, definition of public and private space, and presence of movement corridors. As argued above (section 3.2), the built form has a physical reality that is filtered by our personal experiences of it; therefore, this data was used in conjunction 
with findings from the archive analysis and the interviews to provide another source of insight into the character of the built form (see section 3.3.11).

Particular criteria from different visual-aesthetic analytical approaches were considered for the note taking and analysis; however, it was not clear which criteria would prove most relevant. These approaches include Lynch’s principles of imageability (1960), Cullen's principles of townscape analysis (1971), and principles of order and coherence (Carmona et al., 2010, p. 171). Instead, an iterative and inductive approach was adopted to generate a visual character description and understanding of the built form.

During the analysis of the archive data and interviews, the maps, photos, and notes of the site visits were frequently reviewed to explore what aspects of form were most relevant and what was missing from the findings. The functional, structural, and aesthetic associations and relationships of spaces and forms from the various visualaesthetic traditions were considered in these analytical steps.

\subsubsection{Interview recruitment}

Purposive or targeted sampling is a strategy that is often used when looking for people who have specific experiences or knowledge of a phenomenon (Seale, 2012b; Warren, 2001, p. 90). For this study, the background research was used to identify people who had been involved with the development in a variety of roles and were familiar with how the governance process evolved over the period they had been a participant in the processes. Those who had held multiple roles were of primary interest because it was believed they would have had a deeper understanding of the project and would be able to identify tensions and points of compromise. In addition to providing a range of perspectives, people were identified and recruited who had been involved with the project during different periods of the project's history. To identify potential interviewees, the names of people involved in the process were recorded when searching the archive material, including recording how often they showed up in the material and their position or role in the process.

From the archive search a long list of people who had been involved with the project was created. A shorter list of preferred individuals was drafted based on roles held 
and time of involvement with the projects. This was one way to establish who would be most familiar with the governance process, build an initial list of contacts to approach for interviews, and ensure these people would also cover a range of perspectives and roles. The list of targeted individuals included those who were responsible for decision making or managing the development process, were vocal in raising issues and questions about the aims and objectives of the development, were instrumental in the development process continuing, or were recognized as leaders within governmental or non-governmental organizations that were impacted by the development process or outcomes.

Each short listed contact was emailed an introductory letter outlining the study, the conditions of participation, and the list of questions that would be discussed (see appendix 2 for recruitment materials). A condition of ethics approval and, therefore, the invitation to participate included the clause that the interviewees would be kept anonymous. To retain the interviewees' anonymity, neither a preliminary list of potential participants nor a list of interviewees has been included in this thesis. Anonymity was included as a condition to encourage frank and honest reflection on the process, regardless of their past or current role and involvement.

As Wellington was a local case study, it was relatively easy to contact people involved with the project and allow flexibility in arranging interviews. While a greater number of interviews could have been arranged, it was decided to limit the number and interview a relatively even cross-section of perspectives. Because the study was not employing statistical analysis and time did not permit similar in depth interviews for a large number of participants, cross-sectional representation was seen as the only relevant priority.

As the criteria for identifying contacts became more selective a short list of 25 initial preferred contacts was drafted. Many of the people on the list had held multiple roles or had been involved in multiple projects along the waterfront. For example, one person started as a city planner, became a board member for the WWL, and later served as a development consultant on individual projects. From this long list, 10 preferred contacts were identified and invited to participate to give roughly equal representation of four different participant groups. Fortunately, all 10 of the preferred 
contacts agreed to participate and one interviewee was accompanied by another individual who had experienced very similar roles over the same time period of redevelopment. This resulted in 10 interviews with 11 interviewees. As one of the goals for this study was ensuring equal representation of perspectives, trying to attract as many participants as possible may have reduced representativeness (see Gerring, 2012, p. 89).

The four groups for this study were: staff and board members of Wellington Waterfront Ltd. (WWL, the council controlled development agency charged with managing the project) and its predecessor Lambton Harbour Management (LHM), Wellington City Council (WCC) members and staff who had direct and ongoing involvement in the waterfront redevelopment at different stages, development industry professionals and developers who had worked on public and private waterfront projects, and citizen activists who had performed leadership roles in relevant community groups or actively commented on the process and its outcomes. Table 3.1 illustrates which groups the interviewees were assigned to and which others they were involved in.

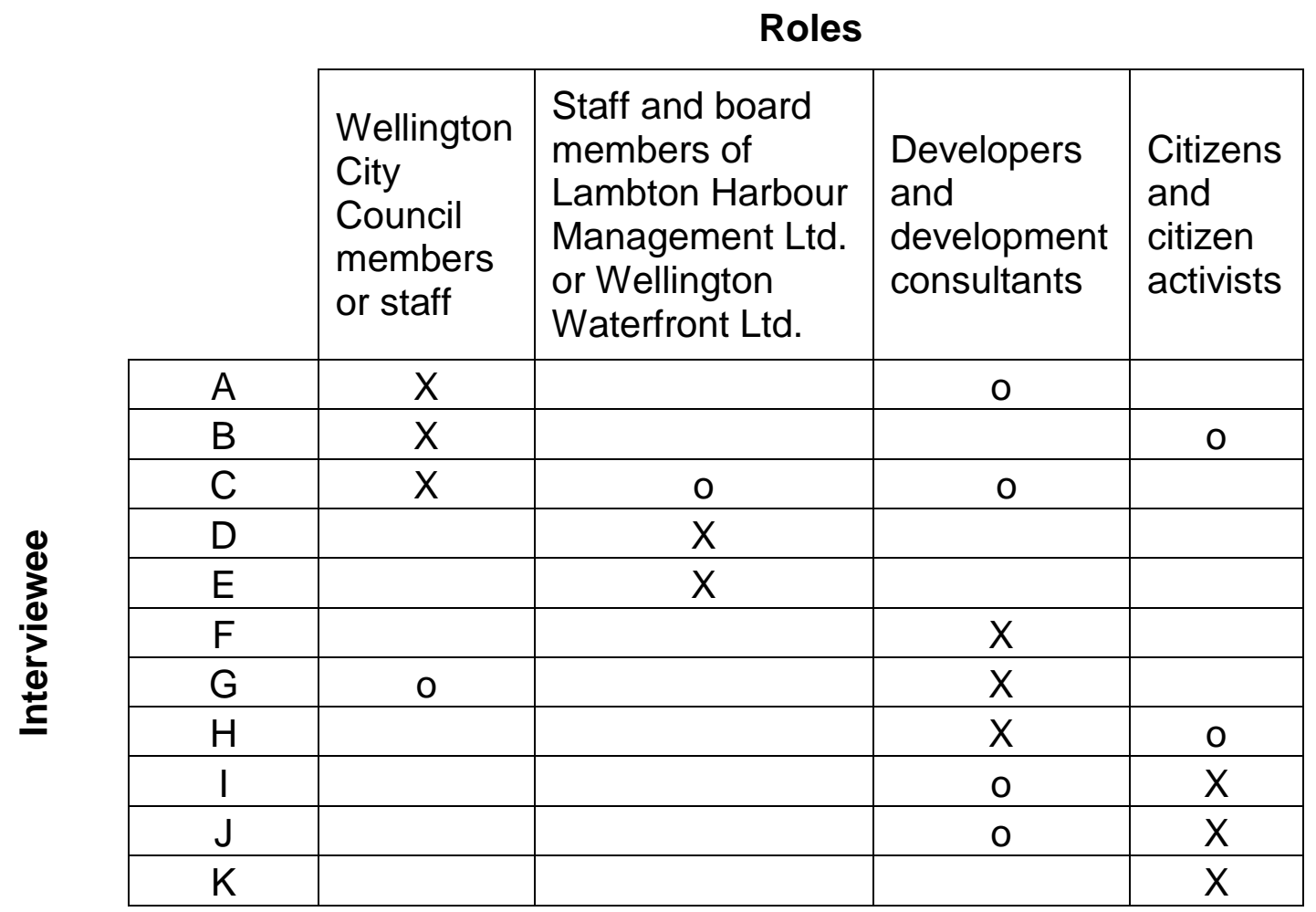

Table 3.1. Roles held by the interviewees. Xs indicate the group to which the interview was assigned for analysis, while Os indicate the additional roles held by the interviewees. 
The ethical considerations of recruitment and data collection focused on the need to balance the anonymity of the participants with providing information on their development-related roles. Interviewees were affiliated with the Wellington City Council, the development corporation, and the Environment Court; therefore, anonymity was promised to encourage frank discussion of their experiences and perceptions without concern for recrimination. The recruitment material and ethics approval can be found in appendices 2 and 3 .

\subsubsection{Semi - structured interviews}

The value of using semi-structured interviews lies in the convenience and flexibility they contribute to the research process. As noted by Richards and Morse (2013, p. 127) and Thomas (2011, p. 163), a set of open questions aids in keeping the interviews on track and ensures each interview covers the same basic material. The authors also suggest open questions allow for unexpected directions in the answers, but using the question as a guide provides some direction for responses to focus them towards the aims of the research. Ensuring the same material was covered in every interview also facilitated analysis by providing an initial framework for organizing and coding the answers.

Richards and Morse (2013, p. 127) suggest another value of semi-structured interviews is for situations where the researcher is familiar with the area being analyzed but cannot predict the answers. In this case, the governance framework provided a means of characterizing the governance of the development process; however, the specific governance of the redevelopment process was unknown.

Lastly, having a list of questions meant potential contacts could be further informed of how they were being asked to participate and encourage them to think about the topic prior to the interview. This proved advantageous as most of the interviewees came prepared with thoughts on the topics covered by the questions and, in some cases, supporting materials.

The questions (included in appendix 2) were structured to ask about the individual governance characteristics, about changes in governance, and about how these related to the built form. The questions, however, were talking points that were used to 
ensure each interviewee covered the same basic material, although all were encouraged to elaborate on their answers and add whatever they wished to the discussion.

\subsubsection{Interview questions}

The purpose of the interviews was to gain an insider's perspective of the governance process, to identify how interviewees perceived the influence of governance on shaping the built form, and to compare outcomes with findings from the archive research and site visits. To address the characterization of the governance, the relevant questions (and subsequent analysis) were based on the governance framework further described in section 3.3.7. Additional questions asking the interviewee to reflect on how they saw the governance of the process relating to the built form were more open to encourage discussion.

An initial list of 80 questions was generated to cover characterization of the governance of the development process, how it changed over the course of the project, the interviewees' experiences of the development process, and their perceptions of how the process affected the built form. The questions regarding the experience of the development process were regarded as complementary to those asking about characteristics of the governance process because the different questions addressed the relationships between governance characteristics in a different way.

Questions asking about the built form were intended to gain the interviewees' perspectives on how the physical developments were influenced by the governance process. This was asked both in a direct manner after discussing each of the governance characteristic and indirectly through questions about significant built form features. Open questions on the built form and individuals' experiences followed advice about creating opportunities for elaboration and unanticipated discussion which allowed for themes to emerge from the collected data (see Richards and Morse, 2013, p. 128; Yeo, Legard, Keegan, Ward, McNaughton Nicholls \& Lewis, 2014, p. 191).

To keep the list of questions to a manageable number, a final list of 19 questions were selected or further developed from the initial list of 80 questions. These questions 
were provisionally organized into sections reflecting the identified characteristics of governance (i.e. driving values, network structure, functional involvement, and modifying variables). The final list of questions (appendix 2) included some that tied together other questions from the initial list by asking about the same information in a broader fashion, and others that included short background descriptions of the related governance characteristics in order to clarify the question. In each section, interviewees were asked to reflect upon how the built form may have been influenced by the respective governance characteristic being discussed.

As shown in figure 3.3 above and described in section 3.3.10, the collected interviews were analyzed thematically based on the governance framework. The use of thematic tables to organize and manage the coded interviews followed the Framework approach developed by Jane Ritchie and Liz Spencer (see Spencer et al., 2014; Srivastava and Thomson, 2009). As recommended by Spencer et al. (2014) employing tables to organize coded interviews facilitated comparisons within and across the interviews while maintaining connections to the original data.

\subsubsection{Governance framework}

The aim of the thesis was to articulate how the organization and methods of decision making (the governance) of a development process shaped the resulting built form of the Wellington waterfront redevelopment. A typical case study approach to meet this aim, according to Thomas (2011, p. 141) and Rutterford (2012, p. 119), would include a full description of the development process, drawing on relevant theory to explain patterns of how governance influenced the built form. To understand the relevant theory, a review of the literature describing and comparing governance frameworks was carried out (section 2.1). The action of undertaking this review included developing the following three characteristics and five modifying variables. This resulting governance framework was developed to respond to the limitations identified in the literature of the different analytical frameworks used in governance case studies.

The framework described here was intended to enable use of the two qualitative tools most appropriate to this thesis. Among other approaches, Spencer et al. (2014) suggested qualitative analysis may employ a thematic analysis of the collected data to 
systematically and iteratively identify patterns and relationships (p. 271) or it can adopt an analytical framework from the literature if the researcher is familiar with the field (p. 272). These, and the reasoning for using them in this thesis, were described in section 3.2. Drafting the governance framework was, therefore, used to develop familiarity with the benefits and limitations of the different analytical frameworks in the literature on governance theory that could be used for thematic analysis. The other purpose for the framework described here was as an analytical tool to develop descriptions of the different governance approaches from the interviews.

In the data collection stage, this new framework was used to structure the interview questions (described in section 3.3.6) and provide the interviewees with some insight into theories of governance practices. For the analytical stages, the framework was used to facilitate analysis of the collected data by helping characterize the governance approaches used on the waterfront (described in section 3.3.10).

As discussed in section 3.2, Spencer et al. (2014, p. 300) and Gerring (2012, p. 82) warned against forcing the data to fit an a priori framework in the analysis stage. Instead, they recommended a conscious effort should also be made to allow patterns to emerge from the data to provide a richer set of findings, rather than just focus on the application of a framework. In support of this approach, the inductive thematic content analysis allowed for the unexpected in the analysis of the interviews.

For characterizing governance processes, the literature on governance and comparative governance theory presented a wide variety of analytical frameworks (see section 2.1 for a more detailed discussion). Many of the comparative governance frameworks tended to favour only specific aspects and emphasize differences rather than provide a holistic description (see DiGaetano \& Strom, 2003; Pierre, 2005). Contributing to these limitations of the different governance approaches was the wide variety of definitions of governance that were used: some only referred to the role of government, while others defined it as everything but the role of government (see Pierre, 1999, 2005; Crespo \& Cabral, 2010). To describe the influence of governance on the built form, a more complete characterization of governance was necessary to account for the range of factors that affect it and reflect the interconnectedness of society. Therefore, the definition and conceptualization of governance used in this 
thesis (see page 1) set the criteria of what a suitable analytical framework needed to address.

The governance framework used here drew characteristics from the different comparative approaches into a set of three characteristics together with modifying variables (see section 2.1.4). The characteristics used to describe a governance approach are: network structure, driving values, and functional involvement. It was noted that changes from one governance approach to another were influenced by changes to the modifying variables. The modifying variables are: leadership, economic production, social production, size of the public domain, and formality of the process.

Driving values are the values, goals, principles, and priorities that influence the choices that are made (e.g. Ashton, 2007). These drivers are the "basis of legitimacy" of governance systems - the foundational value system derived from past experience upon which the local culture operates and decisions are made (DiGaetano, 2006; Pierre, 1999). As will become evident in discussion of the findings of the thesis driving values can be held both consciously and unconsciously by those involved. Additionally, driving values may be presented explicitly in the built form as specific forms or patterns (e.g. a need to retain sufficient parking for visitors), or may be represented by a wide variety of built forms or patterns (e.g. a desire to provide an inclusive waterfront that provides amenities for all age groups).

Network structure is the relative connectedness of institutions and organizations involved in decision making. DiGaetano and Strom argue the economic, social, and political organization of a governance system offers insight into the system's complexity and the types of connections and processes at work (2003). To characterize this, four descriptors were used: fragmented, comprehensive, mixed, or centralized. These descriptors were drawn from the United Nations Human Settlements Programme (UNHABITAT) report State of the world's cities 2009 (UNFPA, 2009) addressing governance networks. Fragmented network structure is characterized by different social and political organizations having some direct influence, but where decision making and outcomes lack coordination, even when responsibilities and interests may overlap. Comprehensive network structure describes 
a situation where there is still little or no coordination; however, the outcomes are not overlapping. Mixed network structure occurs when several organizations collaborate on decision making or share responsibilities regarding the outcomes. In a centralized network structure a single body coordinates input from other groups and filters the decision making to affect the outcomes.

Functional involvement is used here to describe the relative inclusivity and engagement of a decision making process. This includes both how stakeholders are involved and how proactive the process is. Burris et al. (2007) provide a good example of functional involvement. In their discussion of 'good governance' they identify key attributes: "participation, fairness, decency (the degree to which rules are formed and implemented without humiliating or harming particular groups of people), accountability, sustainability, and transparency” (p. 155). To them, it is through inclusive, fair, and proactive behaviour that good governance is practiced. As part of this the authors also advocate those involved in governance reform embrace innovation and experimentation (Burris et al., 2007). Such an acceptance of risk and use of policy for experimentation in a process-oriented approach to governance is another behavioural example, here called the ‘investigative’ type-see the list of types below.

In addition to being experienced as hybrid mixes of these, it was important to remind interviewees that each had positive and negative aspects. Drawing from the work of DiGaetano and Strom (2003) and Pierre (1999) the types used here, listed from least inclusive to most inclusive, are:

- Clientelistic / progrowth - characterized by political favouritism towards interests or clients.

- Welfare - passive policy style combined with a static or declining local economy; economically and politically reliant on central government.

- Pluralist - government serves as a power-broker for private interests; decision making through negotiation; power lies with key actors. 
- Managerial - formal, bureaucratic, or contractual; top-down approach; focus on effectiveness and efficiency.

- Investigative - academic; process-oriented; collaborative; employs surveys and other feedback mechanisms as a means to test actions; place and system focused.

- Corporatist - a collaborative approach between governmental and civic leaders; very inclusive with delegation of authority to special interest organizations.

- Populist - grassroots mobilization influences policy; inclusive, but power rests with community engagement organizers.

Finally, changes in the modifying variables influence change in the other three characteristics and, therefore, change from one governance approach to another. The nature and quality of leadership guides the decision making process; therefore, change in leadership will result in new dominant values, possibly new network organization, and different degrees of inclusivity. The size of the public domain affects the scale of decision making, physical outcomes, and number of stakeholders. An increase or decrease in the area being managed changes the nature of the development process governance. Growth or decline of both economic and social production affects the economic and social resources available. Change in this area affects the number of stakeholders and prioritization of values influencing decision making. Lastly, the relative formality of the process affects the inclusivity of the process and the ability to adapt as formal processes tend to be more inclusive, while informal processes are more flexible.

The governance framework described here, therefore, provided a means of describing the governance of the development process and the mechanisms through which it changed. As discussed in chapter 6 this portion of the analysis provided a detailed description of the different governance characteristics from the perspective of the interviewees. While interesting, these findings were found not to be directly applicable to the research question. Instead, an inductive thematic content analysis approach was used to examine the interviews in a more holistic fashion. 


\subsubsection{Development narrative}

The first step of analysis was compiling a time line of the development based on the background and archive research. The history of projects and plans for the waterfront were treated individually and organized into the longer narrative of the whole project. These individual descriptions included discussion of the entire governance process of the individual plans and projects, photos and images, and a description of the forms. Descriptions of the waterfront plans included discussion of the proposed forms and, like the descriptions of individual projects, these were based on descriptions available in background materials, observations from the plans and available imagery, and from site visits.

Entries for plans and projects included the date the project was first mentioned, the dates of relevant approvals, the length of leases, requests for proposals (RFPs), consultation efforts, design changes that were made, construction dates, and when projects were first opened to the public. The overall narrative also included descriptions of social, economic, and political events that influenced the development of the waterfront.

As will be discussed in the findings (section 4.12), the nature of the development process became increasingly clear when constructing the narrative. The second step entailed querying the timeline by grouping plans and projects based on similarities of the described governance processes. This grouping was used to identify patterns that would form the base for identifying the different governance approaches used over the course of the redevelopment. When comparing the described governance processes in different ways, it was noticed the date projects and plans were initiated generally established the governance process used to manage the individual development efforts. Therefore, projects and plans initiated around the same time tended to have the same governance approach despite some projects continuing through many later governance phases.

Stemming from the thematic analysis approach employed in this study, the other potential relationships between the projects were examined to evaluate how the governance of the waterfront should be best described. Initially, all of the projects, plans, and events were rearranged chronologically by breaking the project 
descriptions up into a true time line of events to look for governance patterns. This approach did not reveal any recognizable patterns. However, identifying key social, political, and economic events associated with development on the waterfront was a related approach used to investigate governance patterns and changes. This attempt, rather than offering an alternative set of governance patterns, reinforced the proposal that most governance approaches used on the Wellington waterfront occurred in timebased phases. Understanding how the identified governance phases differed and the mechanisms through which they changed helped clarify the descriptions of the different phases.

In a different approach to querying the data, projects were organized by type to see if the development of plans differed from the governance of building or public space projects. In this case it was noted public art and heritage building refurbishment projects had similar governance structures, regardless of when they were initiated.

Overall, nine distinct governance phases were identified using these iterative analytical approaches and these will be discussed further in the findings (section 4.12). Once these descriptions of the phases were thoroughly tested, the projects associated with each phase and type (in the case of public art projects and refurbishment projects) were compared with one another to identify built form qualities. Of interest were those form features that were consistent across projects associated with the respective governance phase or were significant to that phase.

By itself, these findings from the analysis directly addressed the aim of the research as they identified relationships of how the governance of the process influenced the form of the built environment. To push the findings further, however, the identified governance-built form relationships were compared to see if there were any overarching patterns that could be derived. This investigation was stimulated by the findings from the interview analysis described in section 3.3.10. As reported in the findings (section 4.12.1), the governance phases that were dominated by top-down management had similar built form relationships, as did those where professional designers influenced decision making, and those where citizen input influenced decision making. 
As will be discussed in section 3.3.11 and the discussion (chapter 6), these findings were compared with similar analysis of the interviews and evaluated in relation to the site observations. This triangulation of findings provided a means of evaluating the robustness of the methods and results.

\subsubsection{Analysis of site observations}

As noted in section 3.3.3, the collected data from the site visits consisted of notes and photographs of the waterfront that described its character and form. During the earlier stages of the analysis, the focus for the site visits was to build familiarity. As the archive analysis progressed, the site observations became more focused on the form and character of individual projects and how they related to their context. At a broader scale, greater attention was also placed on the character and form of the six sub-areas of the waterfront (described in section 4.7.2), including how they functioned internally and with one another.

Analysis of the character and form, therefore, followed a combination of deductive and inductive approaches. The site visit observations were used to evaluate the patterns identified through analysis of the archive information in deductive fashion. Additional patterns in the built form were identified inductively if they were not found in the archive analysis or interview analysis. The discussion chapter (chapter 6) draws these together.

The process to identify the visual character and form of the whole, sub-areas, and individual projects was iterative and occurred over many visits and review of the collected notes, photographs, and plans. Initially, familiarization was required to understand the organizational patterns, navigation, intended uses, major features, and overall feel of the development. Subsequent visits to the sub-areas and projects focused on improving an understanding of their respective characters as the waterfront became more familiar. Once the archive and interview analysis were underway, the understanding of the waterfront developed further and raised different ways of thinking about and questioning the built form.

Similar to a grounded theory approach (see Glaser \& Strauss, 1967; Seale, 2012a, p. 395; Spencer et al., 2014, p. 271), increasing familiarization with the built form 
through repeated visits over the various analytical stages facilitated identification of patterns and relationships within the built form. The repeated evaluation of physical features and relationships, based on patterns and questions suggested by the archive and interview analyses, provided a deeper understanding of how the governance and built form related to one another.

\subsubsection{Interview analysis}

As described in section 3.1, the interviews were analyzed using two approaches. The first employed the governance framework described in section 3.3.7 while the second used an inductive thematic analysis approach.

Application of the governance framework to analyze the interviews used a modified thematic analysis method called Framework analysis that was initially developed primarily by Jane Ritchie and Liz Spencer at the National Centre for Social Research in the United Kingdom (Srivastava \& Thomson, 2009). This approach begins with the following steps:

1. Become familiar with the data by reading through it and thinking about how the different parts might relate.

2. Develop an initial classification framework for identifying themes and patterns in the data. This framework could be developed inductively from the data or deductively based on the associated literature.

3. Code the collected data using the framework.

4. Iteratively review the coding and refine the definitions of the codes and recode where needed until all of the data fits within the framework.

These four steps follow the recommended methods for thematic analysis in Spencer et al. (2014) and Rivas (2012). The Framework method extends this practice by organizing the coded data using tables for the themes to sort and organize the data for steps three and four above. Each table is organized around one theme with the interviews along one axis and codes relevant to the theme along the other axis (Spencer et al., 2014; Srivastava \& Thomson, 2009). The entries into each cell are 
either quotes from the source material or paraphrased, but with time stamps or some other means of tracking the material back to its original context. Spencer et al. argue using these thematic tables facilitates within interview and cross interview interrogation of patterns and relationships associated with the phenomena of interest (2014, p. 283).

It was found here the Framework analysis method enabled comparison of points of agreement and disagreement regarding characterization and identification of governance patterns across the interviews. These steps and use of the tables also insured transparency, by maintaining a clear connection between the source data and the findings, and maintained the varying perspectives of the interviewees. The use of semi-structured interviews facilitated this approach and comparing interviews in this way; however, the findings were not directly applicable to the research aim as discussed in section 3.2.

\section{The second analysis of the interviews}

Following the initial analysis of the interviews, the second application of thematic content analysis followed the four steps for thematic analysis identified above; however, it did not use an analytical framework derived from associated literature, nor did it use the tabular comparison format. Instead the interviews were analyzed using themes that were generated inductively from reviewing the interviews. These themes included looking for sequential, continuous, repeating, and singular governance approaches, similar to the analysis of the archive material. Because the interview questions did not ask for the history of the redevelopment and, instead, asked about different aspects of governance and form, a bias towards sequential descriptions was less of an issue than for the archive analysis.

Initially, the interviews were first evaluated based on how each participant described changes in the governance of the waterfront redevelopment. By comparing how the interviewees individually and collectively discussed what caused a change from one governance approach or style to the next, it was possible to identify different governance approaches. Among the interviewees, there was fairly consistent agreement on the events and projects that stimulated a change from one governance 
approach to the next; therefore, it was straightforward to compare and compile descriptions of the different approaches.

When compiling the different perspectives into descriptions of each governance approach, it became evident the interviewees each experienced the development process as a sequential series of unique governance phases (see chapter 5 for their descriptions). They collectively described how each governance phase operated, how they saw it influence the built form, and what stimulated a transition from one phase to the next. Additionally, however, the interview analysis found different participant groups in the development process held more influence over the decision making in different phases. Investigation of this as a theme was inspired by responses to questions about the network structure and functional involvement (from the governance framework). This led to re-examination of the governance descriptions and source interviews to identify whether larger governance-built form relationship patterns existed that were consistent across all of the governance phases. As described in section 5.9, these focused on similarities between governance phases dominated by top-down management, decision making led by designers, and decision making led by citizen input.

\subsubsection{Overall findings}

The final step of the research analysis was comparing the findings from the archive analysis, site visits, and interview analysis to look for greater insight into the governance of the redevelopment project and how it influenced the built form. This comparison of the results from using multiple methods to investigate the same research question or topic is sometimes referred to as methodological triangulation.

The use of triangulation in qualitative research has attracted some debate. Some argue it identifies a single, true reality (e.g. Blaikie, 1991), others argue it provides a wider range of insights into the same research topic that may not arrive at the same conclusions (see Seale, 1999, p. 473). Because of the constructivist stance taken in this thesis, triangulation of methods in the research design was used to build a deeper understanding of the governance-built form relationship on the Wellington waterfront using multiple, complementary approaches. This approach is consistent with the 
concept of triangulation argued by Seale (1999, p. 473) and Richards and Morse (2013, p. 103).

\subsection{Limitations}

It is important to note, however, the findings from this approach are not intended to prove causation nor account for the strength or prevalence of identified patterns. The purpose of the qualitative approach was to identify and describe governance-built form relationship patterns. As will be expanded upon in the discussion (chapter 6), the findings could be subjected to subsequent quantitative studies designed to evaluate their strength and scope.

Also, the findings will not provide a full exploration of the variety of patterns nor a typology of these relationships. Additionally, exploration of patterns within the same case study would require repeated analyses by different researchers to provide different interpretations. These relatively conventional methods ensure the studies are repeatable; however, the constructivist perspective means the findings are only one potential interpretation of the collected data. This repeated analysis of the same data, or including additional interviewees, would be another form of triangulation and enrich the findings further.

A further consideration would be to compare the findings with several similarly conducted case studies to provide additional governance-built form patterns. Comparison could help refine the analysis by providing additional insight into themes and potential patterns that could be tested using the collected data. 


\section{Analysis of archive and background information}

\subsection{Introduction}

This chapter outlines the findings from the analysis of the background literature and official reports on the redevelopment of the Wellington waterfront between 1974 and 2012. From this analysis (described in section 3.3.8) nine governance phases were identified along with their respective influences on the built form of the redevelopment. To address the question of how different governance approaches influenced the built form in this case study, the nine governance phases and their associated effects on the built form are described individually and then in comparison with one another.

While every attempt was made to uncover all of the available material on the individual projects, comparatively there was less information available on older than more recent projects. For all projects information was drawn from available city council minutes and reports, academic and professional journal articles, and stories in local print and online media venues. A full bibliography is available in appendix 3. While the following descriptions reflect the variation in available material, reporting on the individual projects was sufficient to identify similarities and differences in governance patterns using the approach described in section 3.3.8.

For each phase described in this chapter, the first sub-section describes the structure of the governance process and its context. These descriptions and associated diagrams outline how decisions were made, who the major actors were, and the relative influence of planning legislation.

The second sub-section summarises the governance and form of each of the individual projects and plans initiated during that phase. When analysing the development history of the whole waterfront and the individual histories of the different projects and plans, it was discovered the governance structure for each individual project or plan was established at its inception, including some projects that spanned several phases. Therefore, the projects are described in the phase in which they were initiated. Generally, projects with similar governance structures occurred 
during the same time period and when the governance structure changed, subsequent projects followed the new governance arrangement.

Although the governance structures for art installations and heritage building refurbishment projects were similar and relatively consistent over the duration of the study period, some of these types of projects also reflected the different driving values of the governance phase in which they occurred. As the governance phases were generally chronological, rather than varied for different types of projects, the description of each art installation and heritage refurbishment project has been included in the governance phase in which it was initiated, rather than grouping these into their own sections.

The third sub-section describes the observed influence the governance structure had on the built form for that phase. This discussion summarises the previous two subsections by describing the observed relationships between governance and the built form.

The fourth sub-section describes what stimulated the transition from one governance phase to another. Some governance phases overlap; however, it was observed that an event or decision always prompted a change in the governance structure.

The chapter concludes with a summary and comparison of the identified governance types. The comparison is intended to outline the broad governance patterns that influenced the built form of the Wellington waterfront in relatively consistent ways. In this case, the degree of influence by top-down approaches, by citizen activism and public feedback, and by professional designers on decision making had consistent impacts on the built form.

In the following chapters, the findings from the analysis of the interviews will be discussed and a comparison made between the two investigations. 


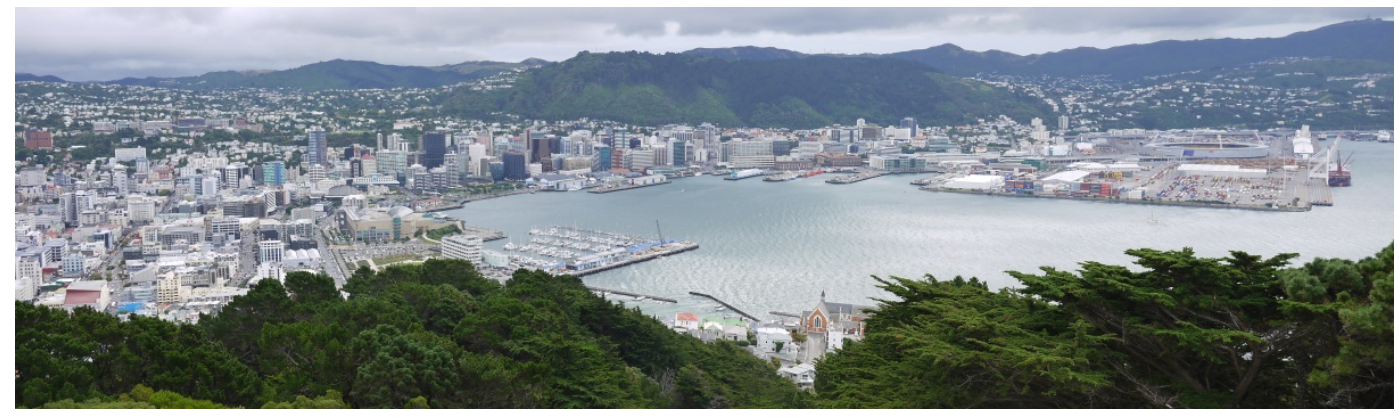

Figure 4.1. View of the Wellington waterfront redevelopment (image: author)

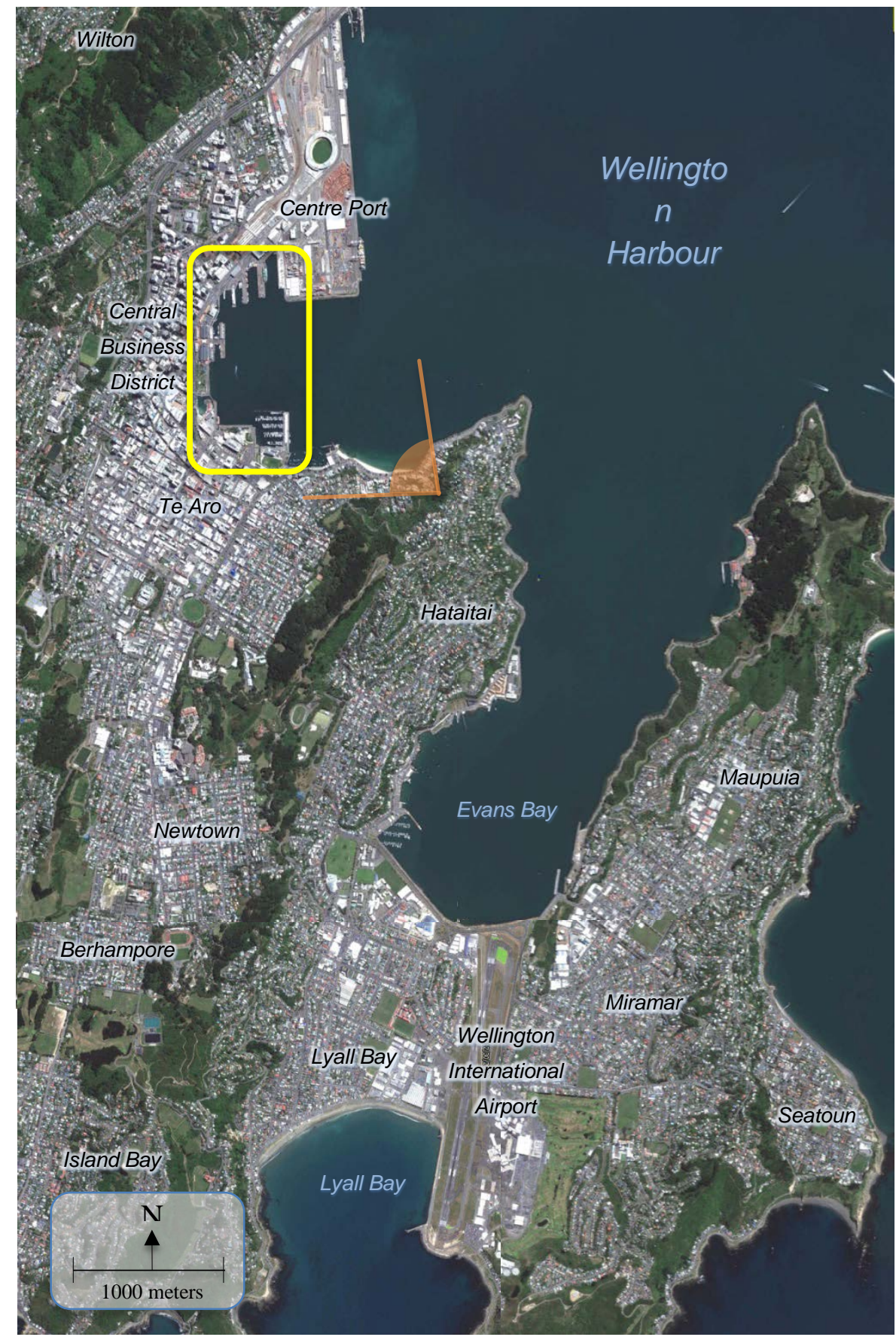

Figure 4.2. Location map of the Wellington waterfront redevelopment. Yellow identifies the study site shown in figure 4.3 and orange lines indicate the location and view of figure 4.1 (base image: Google Earth accessed November 2012) 


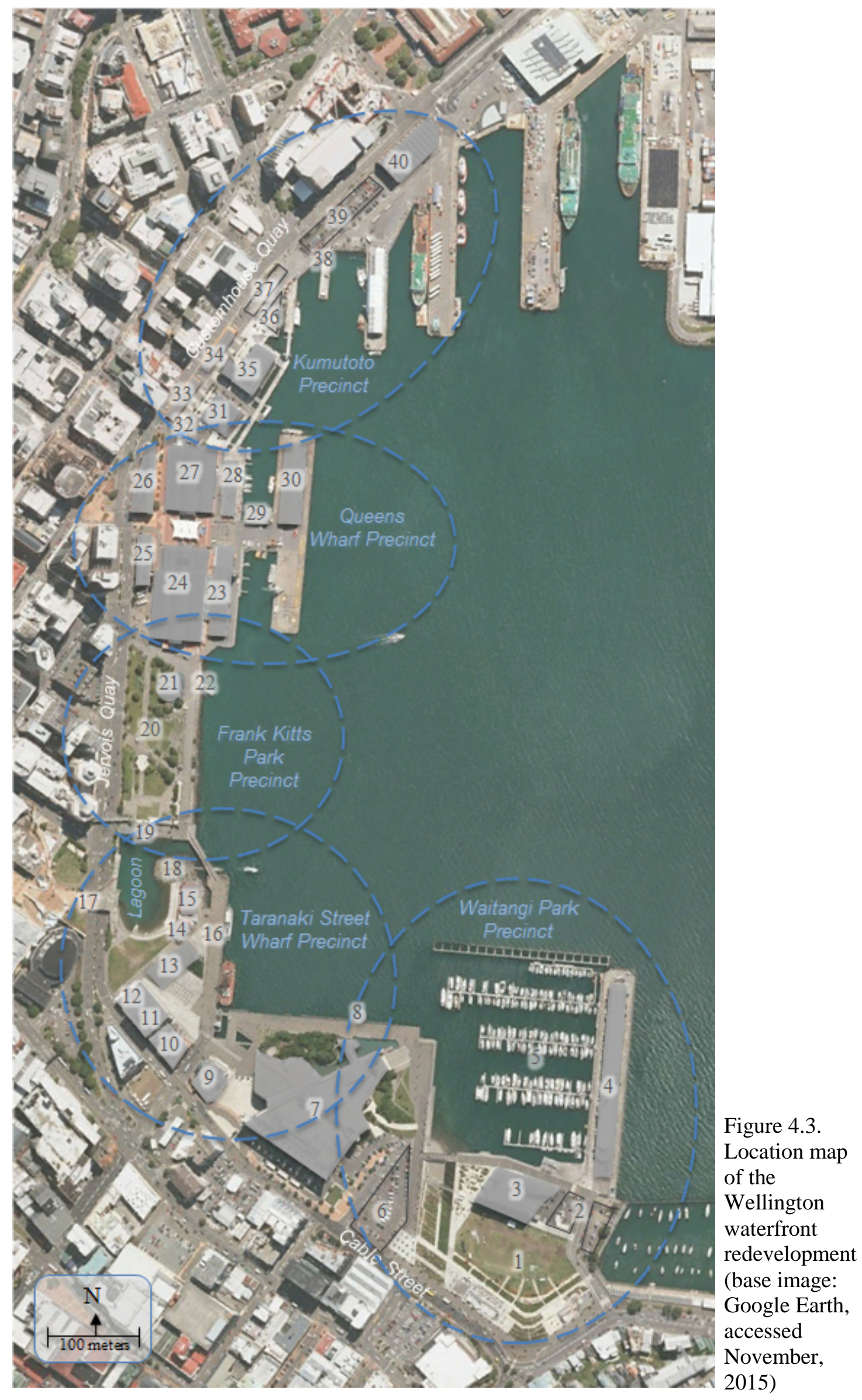




\section{Map legend}

(Date of initial action)

1. Chaffers Park (1997, renamed Waitangi Park and remodeled in 2002)

2. Proposed sites for John Wardle Architects designs (2005)

3. Herd Street Post and Telegraph Building (2003, renamed Chaffers Dock Building)

4. Overseas Passenger Terminal (2006)

5. Chaffers Marina (1991)

6. Proposed site for UN Studio design (2005)

7. Te Papa Tongarewa (1985)

8. Max Patte's Solace of the Wind (2008)

9. Circa Theatre (1993)

10. Shed 22 (2001)

11. Odlins Building (2003, renamed NZX Building)

12. Wellington Free Ambulance Building (subject of 2001 court action)

13. Wharewaka (initial proposal in 2003)

14. Wellington Rowing Club (1989)

15. Star Boating Club (1989)

16. Kupe Group (2000)

17. City to Sea Bridge (1989)

18. Treasure Island (2000)

19. Tanya Ashken’s Albatross (1986)
20. Marine Park (1974, renamed Frank Kitts Park in 1979 and remodeled in 1989)

21. Children’s playground (1989)

22. Len Lye’s Water Whirler (2004)

23. Shed 6 (2004)

24. Queens Wharf Events Centre (1995)

25. Bond Store (1999)

26. Queens Wharf Apartments (1993)

27. Queens Wharf Retail Centre (1995)

28. Shed 5 (1992)

29. Shed 3 (1991)

30. Shed 1 and outer-T hotel site (1993)

31. Steamship Wharf Building (2003)

32. Kumutoto Public Toilets (2003)

33. Shed 11 (1985)

34. Shed 13 (2006)

35. Meridian Building (2003)

36. Kumutoto development site 8 (2006)

37. Kumutoto development site 9 (2006)

38. Eastbourne Ferry Terminal (1999)

39. Kumutoto development site 10 (2006)

40. Shed 21 (2001, renamed Waterloo on Quay Apartments) 


\subsection{Location and early history}

Wellington is located on the southwestern end of New Zealand's North Island. The 20 ha waterfront redevelopment area is situated immediately east of the city's central business area and is bounded by Cable Street, Jervois Quay, Customhouse Quay, and Waterloo Quay (see figure 4.2). In addition to these streets, figure 4.3 shows the locations of key waterfront features and identifies the five sub-areas that will be referred to in this chapter.

Initially home to extensive Maori settlements and agriculture, Europeans began to settle along the harbour front in the 1840s. From 1852 through to 1970 the waterfront was subject to a series of reclamation projects that extended the waterfront from Lambton Quay to its present size (see figure 4.4). Land reclamation was undertaken

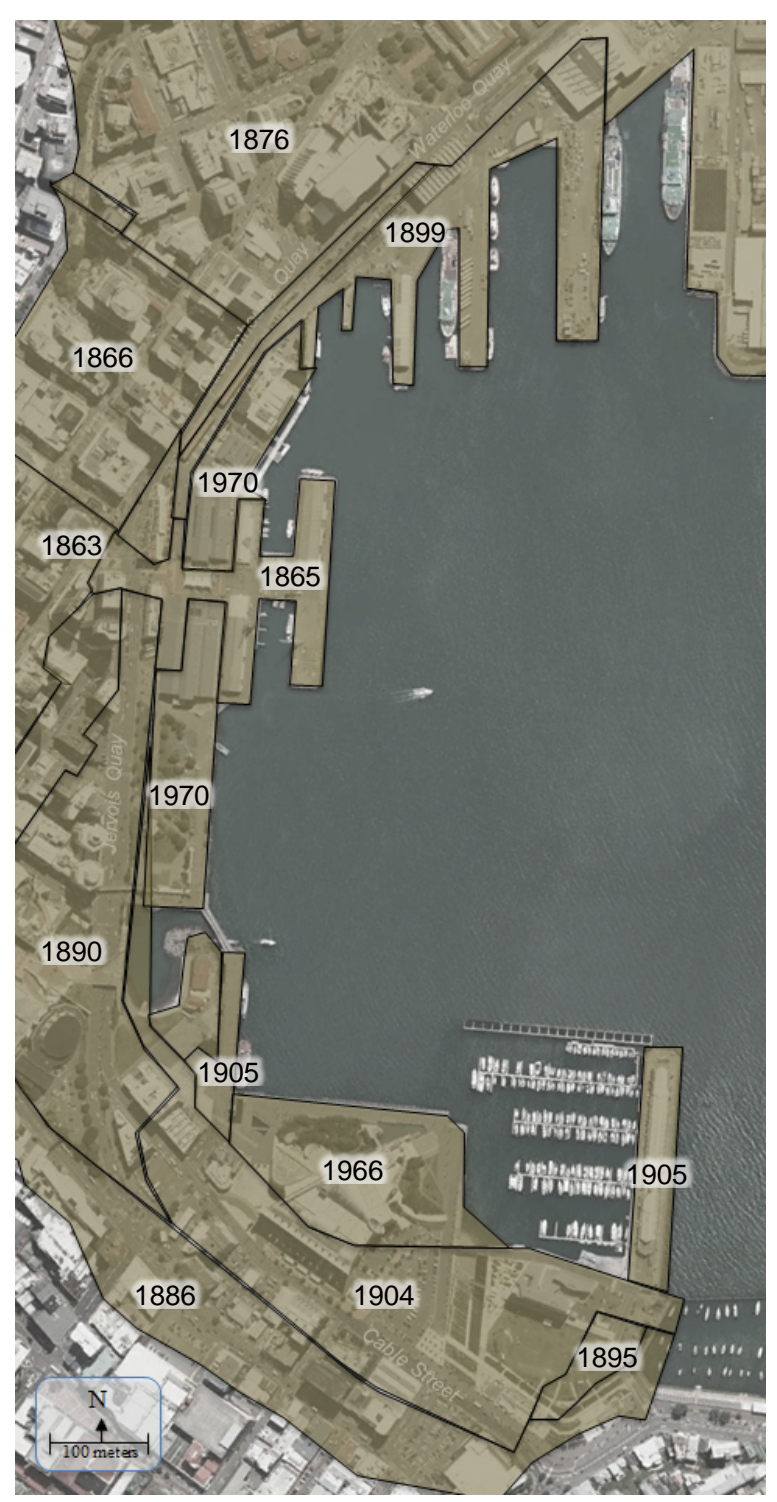
for both public and private projects to create space for development in the downtown core, industrial land, and wharves for the movement of goods.

In 1880, the New Zealand government established the Wellington Harbour Board (WHB) to own and manage the port lands independently from the city (Cochran, Murray, Kelly \& Dodd, 2012, p. 209). They continued to infill and build wharves to improve the capabilities of the port. The rise of containerisation and roll-on, roll-off cargo handling in the 1960s and 1970s led to a change in the form of the port as increased space was needed adjacent

Figure 4.4. History of waterfront reclamation work (image: based on information from the Wellington City Council website, 2011) 
to the berths for the roll-on, roll-off facilities (Hutchinson, 1973, p. 217).

Additionally, the port invested in container handling facilities along the wharves north of Queens Wharf (Cochran et al., 2012, p. 210). The Harbour Board decided to focus on container operations in 1970, resulting in a shift of most port activities to the port area north of the site (Doorne, 1998, p. 137; Hutchinson, 1973, p. 218). According to Hutchinson (1973), Wellington City Council (WCC) did talk with the Harbour Board about waterfront redevelopment and had a long standing request to allow development of surplus lands; however, little action occurred initially. This momentum built and did eventually lead to the redevelopment; however, decision making was handled in several different ways over different time periods.

\subsection{Phase 1 governance (1974 to 1985) - The Wellington Harbour Board was willing to entertain ideas for new uses of the waterfront}

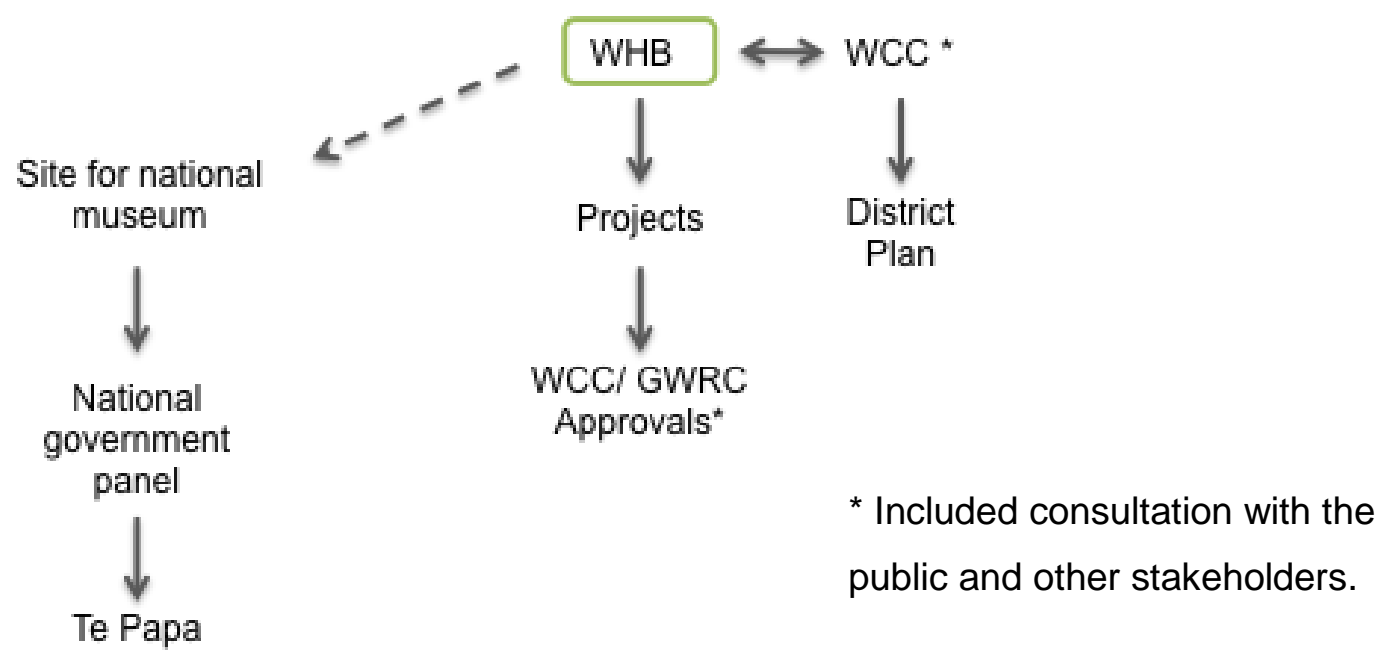

Figure 4.5. Diagram of the phase 1 governance arrangements. The green rectangle identifies the Wellington Harbour Board as the central decision maker regarding the form of the waterfront.

A summary of the effects of these decisions on the form of the waterfront included:

- Frank Kitts Park, set back from the water’s edge;

- removal of four warehouse sheds built in the early 1900s, but retention of other historic port buildings; 
- identification of a site for a new National Museum of New Zealand;

- a pedestrian walkway on the city side of the lagoon, connecting Frank Kitts Park to Taranaki Street Wharf; and

- berths for large vessel on Taranaki Street Wharf and on the Queens Wharf outer-T with associated vehicle access.

\subsubsection{Governance description}

The national government passed the Wellington Harbour Board and Corporation Land Act in 1880 to create an independent body to manage the harbour foreshore and shipping related activities for the Wellington Harbour. Later, under the Harbours Act (1950), the Harbour Board retained control of the waterfront lands, but the land use designations were legislated by the Wellington District Plan. The Harbours Act identified areas below the high-water mark as within the local regional council's control while lands above the high-water mark were included in the local government's district planning processes as outlined by the Town and Country Planning Act (1977). The waterfront, therefore, was included in the Wellington District Plan but the relevant sections were written to support the intended use of the waterfront lands as a port.

In this capacity, the WCC had an interest in the waterfront and some influence in the drafting of the District Plan through collaboration, but no direct decision-making authority. Decisions about the waterfront were, therefore, controlled by the Harbour Board in this initial phase. As summarised by figure 4.5, the WCC provided input to the Harbour Board; however, the latter had the final say on the use and development of the waterfront.

A construction boom in the late 1970s and early 1980s intensified developer and WCC interest in the port lands adjacent to the downtown areas. WCC did talk with the Harbour Board about waterfront redevelopment as described in a 1974 report by Rolland O’Regan, then Chair of the Harbour Board (O’Regan, 1974). 


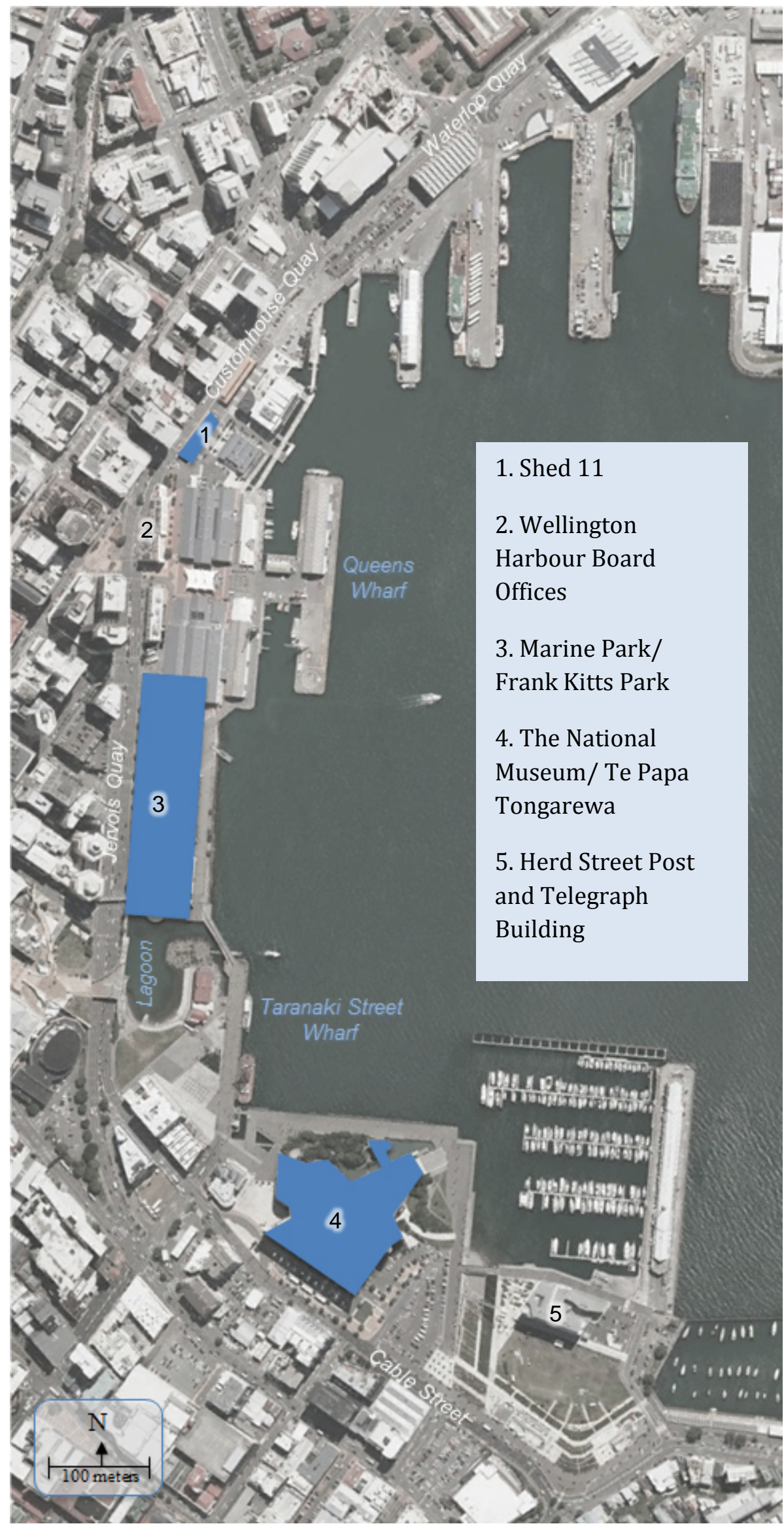

Figure 4.6. Location map of phase one projects and features. Blue polygons identify constructed projects. (base image: Google Earth, accessed November, 2015). 

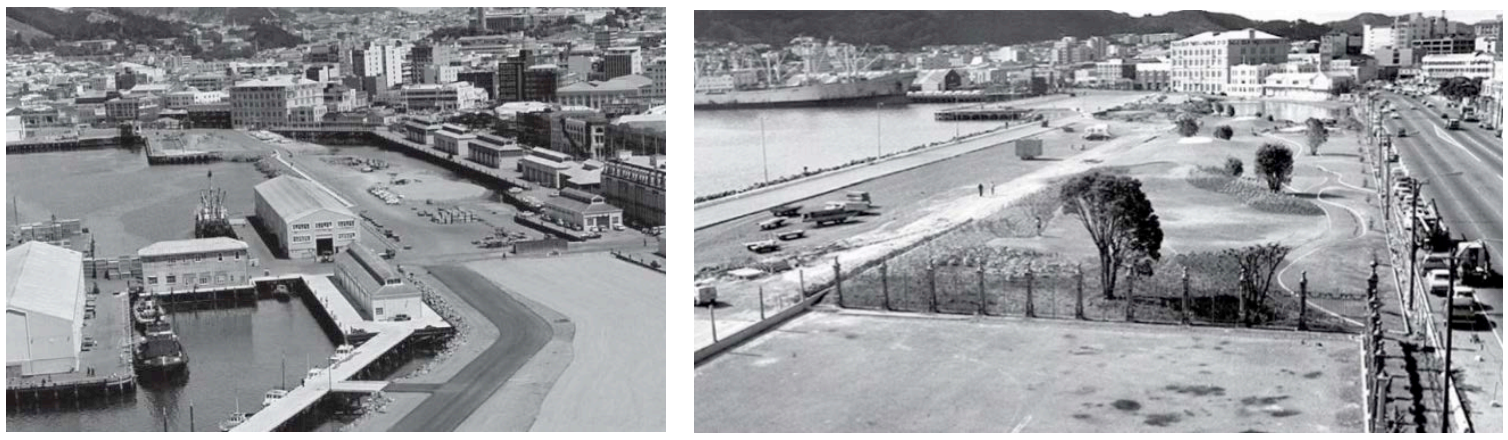

Figures 4.7 and 4.8. On the left is the reclamation work completed in 1970 to accommodate roll-on, roll-off cargo handling. On the right is Marine Park, built in 1974, on the infilled area where four port storage sheds had previously stood. (images: The Dominion Post Collection, Alexander Turnbull Library).

The introduction of containerisation and roll-on, roll-off cargo handling in the 1960s required more space adjacent to shipping berths to accommodate these activities (Hutchison, 1973). The final infill project on Wellington's inner harbour, shown in figure 4.4, extended from Queens Wharf north to the Ferry Wharf and south towards Taranaki Street wharf, creating the lagoon in the process (Cochran et al., 2012, p. 210). Soon after its completion, however, the Harbour Board shifted the focus of its operations north to a new container-only operation near Thorndon on a portion of the area infilled in 1876 (Cochran et al., 2012, p. 210). Though the waterfront development site continued to be used for occasional shipping activities, the first waterfront public space, Marine Park, was built on a portion of the infilled area between Queens Wharf and the lagoon in 1974 (Waterfront Information Centre, 2011; STQRY, 2015a).

As shown in figure 4.8, the park was isolated from the central city area by the busy quays, had limited pedestrian access, and was set back from the water's edge. It did, however, connect to the lagoon and the rowing and boating clubs situated on Taranaki Street Wharf. The form of the park reflects a continued interest in retaining port access to the water's edge and berthage space, while offering some public amenity on the waterfront. Additionally, in 1973 four early 1900s warehouse buildings were demolished in the area where Marine Park was constructed. While it is not clear whether this demolition was specifically related to construction of the park, removal of the buildings indicates they were not valued for their heritage. 
Access to the rest of the waterfront north of Marine Park was restricted to port activities by fences and gates. A few port sheds and various former industrial lands sitting largely unused were located south of the lagoon and clubhouses. Marine Park was later renamed Frank Kitts Park, in 1979, after a Wellington mayor who held the post from 1956 to 1974 (STQRY, 2015a).

1983 Harbour Cities Competition and the winning Paperchase plan

A local citizen interest group, Wellington Civic Trust, organised the Harbour Cities Competition in November 1982 with sponsorship from the Evening Post newspaper, WCC and the Harbour Board. This public ideas competition stimulated interest in redeveloping the waterfront as a public amenity, illustrated the potential of using the land for development purposes, and built public support for redevelopment (Kernohan, 2011; Doorne, 1998, p. 138). The area considered for the competition was from Oriental Parade at the south end to the railway station at the north (Paperchase, 1983). WCC and the Harbour Board as sponsors had representatives on the jury, but did not initially take action on the ideas generated by the competition (Cayford, 2014).

The winning plan, shown in figure 4.9 , by a multi-disciplinary team called Paperchase, simulated a new era for the waterfront. The plan set several enduring principles that continued to influence later planning and design on the waterfront. These principles included: balancing public space and private development; a promenade that protected public access to the water's edge and provided opportunities for interaction with the water; creating multiple routes through the development for all forms of non-vehicular traffic; protecting view shafts; retaining existing waterfront structures; retaining evidence of the industrial past; including references to historical Maori use; using buildings to define public space; ground floor uses that engaged with and complemented adjacent public spaces; and providing protection from inclement weather (Paperchase, 1983).

Many of these ideas were later expanded upon in subsequent waterfront plans. For example, the 2001 Wellington Waterfront Framework (see section 4.7.2) states "There will be a public walkway/promenade along the length of the waterfront, 


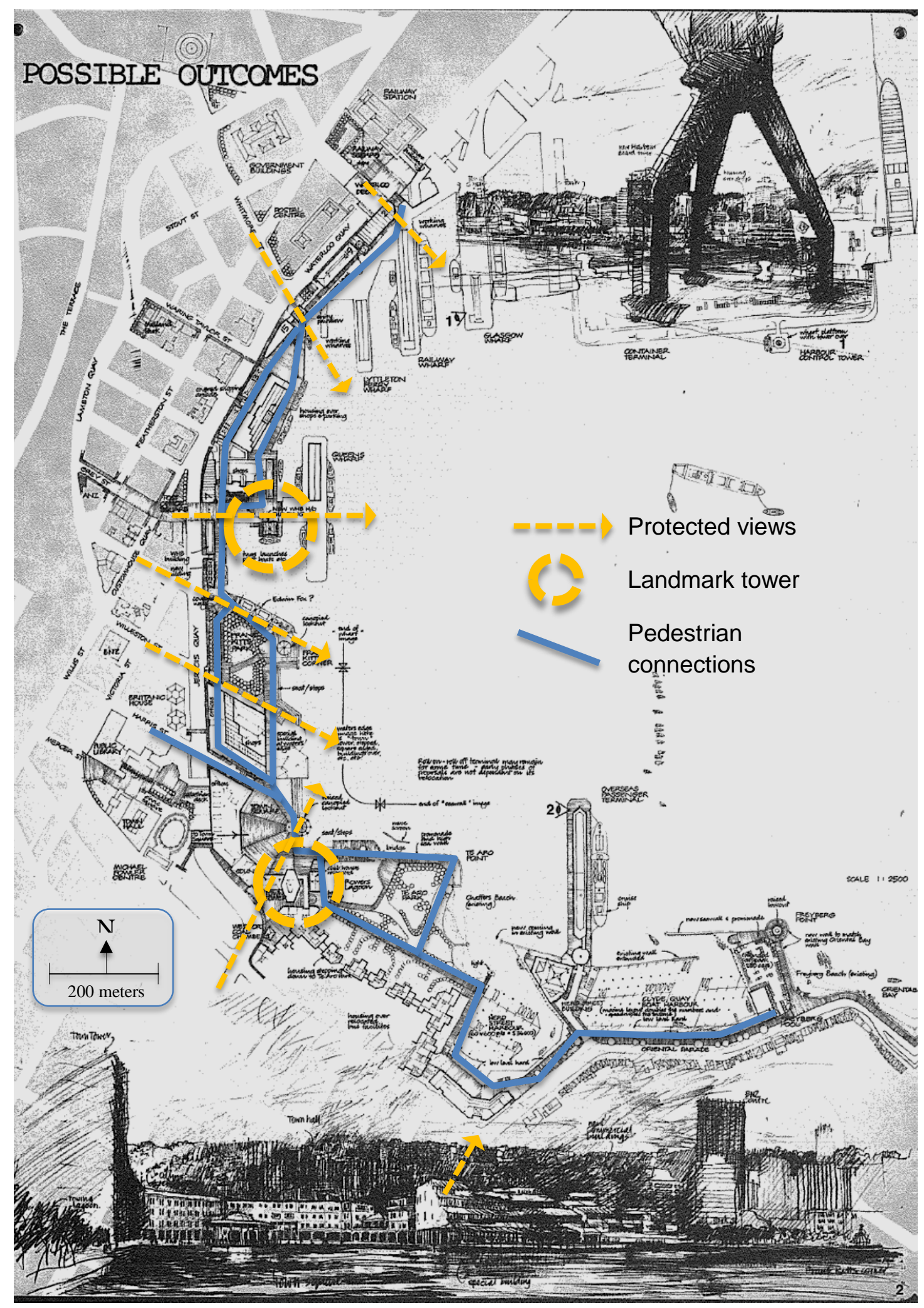

Figure 4.9. The winning Paperchase plan, 1983 (image: Paperchase) 
predominantly at the water’s edge.” (2001, p. 20). The Waterfront Framework then provides additional guidance, reminiscent of the Paperchase plan, that buildings were to open onto the promenade to offer a range of activities, and that access to the water for all users at various points along its length should be accommodated (pp. 13-14).

The Paperchase team, alone among the entries, also included recommendations on governance structures necessary to implement the redevelopment. Primarily, they suggested creating a development agency owned by the city, but structured to operate separate from city politics.

\section{Shed 11 refurbishment}

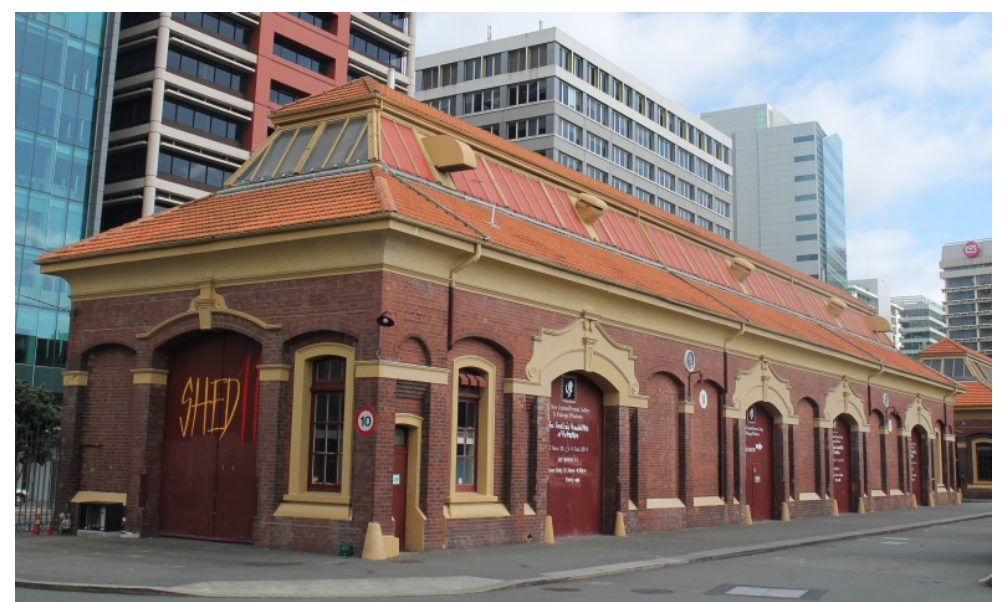

Figure 4.10. Shed 11 (image: author)

Shed 11, shown in figure 4.10, was built in 1904, adjacent to the Harbour Board offices for storing bales of wool (WCC, n.d., Old Shoreline Heritage Trail). It was built to the same design as the four sheds that were demolished to make way for the 1970 reclamation and, later, the site of Marine Park. Approval was given by the Harbour Board in 1985 to earthquake strengthen, and refurbish the building, and to fit out the interior to house the National Art Gallery and, later, the New Zealand Portrait Gallery (Waterfront Information Centre, 2011; Blackley, 2014). To do so required planning consent from WCC as the then operative Wellington District Plan was written to support industrial activities on the waterfront.

The refurbishment of shed 11's exterior, using the original colours and materials where possible, was consistent with most subsequent heritage building refurbishment projects. With some exceptions, which will be discussed in their own sub-sections, 
most heritage refurbishment projects made few changes to the exterior except to include signage and, occasionally, additional doors and windows. Because most of the heritage refurbishment projects had minimal changes to the exterior and the waterfront was to be identified as a mixed use area (allowing residential, commercial, and retail land uses), these changes did not require public consultation to receive planning consent (i.e. they were non-notified).

1985 National Museum of New Zealand (later called Te Papa Tongarewa)

According to Shadwell's (1989) description of the project, the lack of space to display and store growing collections in the existing National Art Gallery and National Museum stimulated proposals for a new National Museum of New Zealand. A 1985 study of options for a new location suggested the National Gallery and the National Museum should be incorporated with a Pacific Cultural Centre that had been proposed for the Wellington waterfront. Upon presentation of the report to Cabinet, an agreement in principle was approved by the national government and the concept was incorporated into the 1986 Lambton Harbour Development Concept (described below). After some consultation with the public and museum professionals, the project was approved by Cabinet in April 1987.

The project was originally proposed for a site that included the location of the Herd Street Post and Telegraph Building; however, the cost of demolishing the Herd Street building and addressing geotechnical issues inspired the choice of another site nearby that faced fewer hurdles (Shadwell, 1989). For the new site adjacent to Taranaki Street Wharf, a complex of three buildings that opened towards both the city and the waterfront promenade was proposed to house space for exhibitions on art, Maori and Pacific art and culture, and on human society and the natural environment (Shadwell, 1989).

Once the national government negotiated purchase of the site in 1988, planning and development of the project was coordinated by a board appointed by the Minister for Internal Affairs (Shadwell, 1989). The Project Development Board hired its own staff to draft the program for the museum, to manage design, and undertake project management. At this point, neither the Harbour Board, nor its newly formed 
waterfront development corporation (Lambton Harbour Management Limited) (described in section 4.5.1) were involved in the planning and design of the project (Shadwell, 1989).

The final design was the result of a design competition that responded to a brief drafted by the Project Development Board, in consultation with museum consultants and existing National Museum of New Zealand staff. The Project Development Board required that entries and design teams must be led by New Zealand firms, but encouraged international collaboration (Shadwell, 1989). Construction began on the museum in 1993 and was completed in 1998.

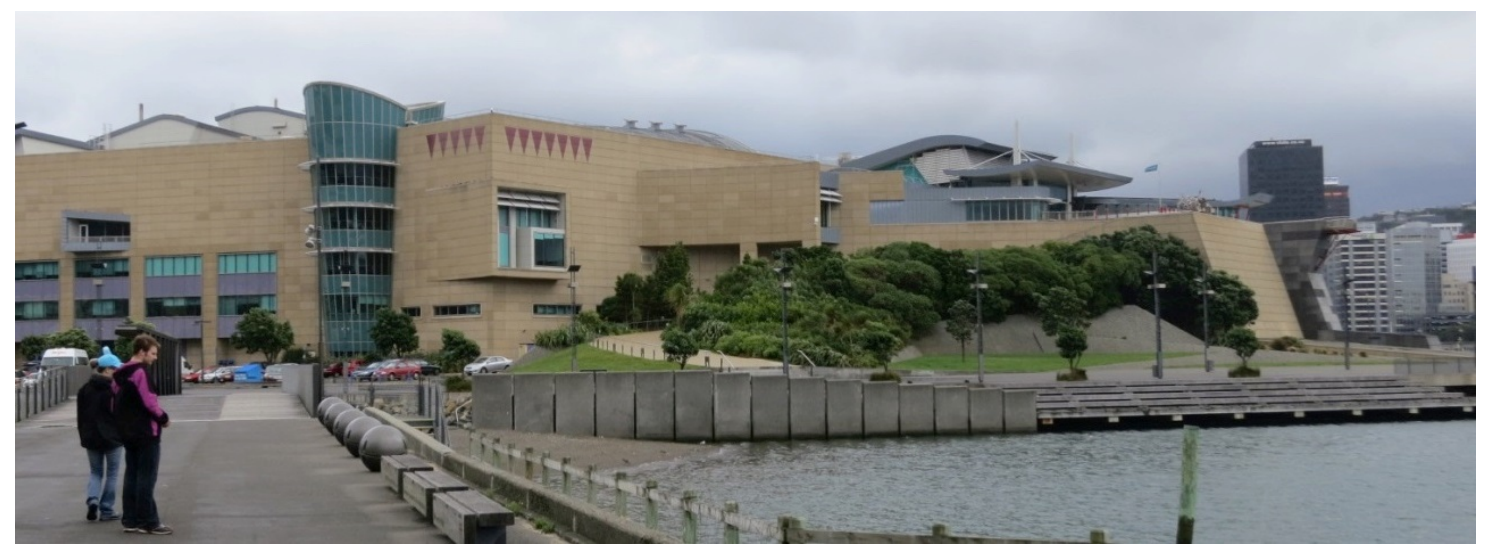

Figure 4.11. The northeast corner of Te Papa, 2011 (image: author)

The winning design for the building was said to represent having its 'feet' in the water of the harbour (Cochran et al., 2012), but the wide waterfront promenade and lack of windows or other forms of engagement with the public realm on the waterfront side of the building shown in figure 4.11 does not reflect this. Contributing to the lack of interaction with the waterfront promenade, the main entrance to the museum fronts onto Cable Street, facing the city rather than the waterfront. Other influences on the design of the museum may have included the annual Nissan 500 car street race that ran along portions of the waterfront and the requirement by the Harbour Board that the adjacent wharf area remain available for berthing and servicing large vessels. Both could have affected the orientation of the entrance and lack of interaction between the museum and the waterfront promenade. 
The design was also intended to be adjacent to a dense residential development shown on a plan for the waterfront produced in 1989 (the Lambton Harbour Combined Scheme, see figure 4.20); therefore, the east side of the building was intended to address reasonably large buildings, rather than step down to what is now a parking lot and Waitangi Park.

\subsubsection{Form and governance}

In this initial phase, the Harbour Board was the sole decision maker; however, the decisions to include Marine Park and tie it to the lagoon and, later, refurbish shed 11 were a result of collaborations with the city. The removal of four old warehouses and the form of the park, including maintaining water's edge access for port activities, reflected the initial values and priorities of the Harbour Board. This provision of amenity on the waterfront and the ideas of establishing better visual and pedestrian links to the city reflected the involvement of the city and ideas from the Harbour Cities Competition.

The Harbour Board's perspective of the waterfront did change and they acted upon the ideas from the Harbour Cities Competition with refurbishment of Shed 11 and agreement to allocate a site for the National Museum in 1985. These two actions reflected a change in the Harbour Board's values towards use of the waterfront lands. The changing values were stimulated by discussions with the WCC and the competition organised by the Civic Trust.

The form, therefore, reflects the values of those involved in this process; however, it is clear the Harbour Board retained control as its values were most strongly reflected in the built form. The initial values are represented in the form reflected in the removal of four historic sheds and the setback of Marine Park from the water's edge, while a later appreciation for the waterfront's potential is reflected in the refurbishment of shed 11 and agreement for siting the National Museum on the waterfront. 


\subsubsection{Transition stimuli}

To build on the momentum generated by the design competition, the Civic Trust organised the Harbour City Conference in July 1984. The WCC and the Harbour Board sponsored event raised the idea of a waterfront "special development zone" jointly managed by WCC and the Harbour Board (Smith, 2011; Urban Perspectives, 2014). A subsequent symposium held in November 1985 was also organised by the Civic Trust to maintain momentum. At the symposium, representatives from the Council, the Harbour Board, members of the public, and other stakeholders were invited to share their thoughts on the future of the waterfront (Johnson, 1996).

\subsection{Phase 2 governance (1985 to 1986) - Planning for a joint venture}

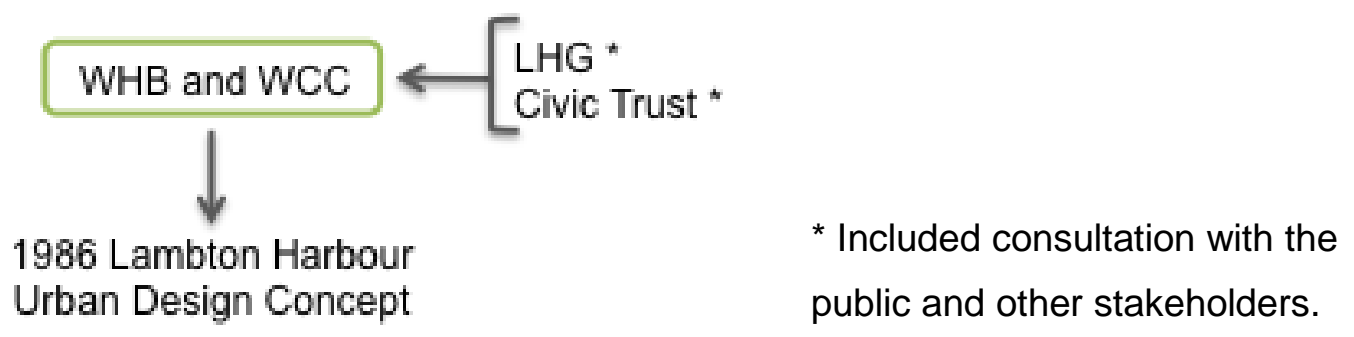

Figure 4.12. Diagram of the phase 2 governance arrangements. The green box shows decision making was more collaborative than the previous phase and the stars indicate more opportunities for stakeholder input.

A summary of the effects on the form of the waterfront included:

- a preference for building sites with either large, low-rise buildings or slim, tall towers;

- an industrial maritime aesthetic for architecture and landscape architecture projects;

- a mix of residential, commercial, civic, industrial, retail, and recreational uses (e.g. apartment buildings, Chaffers Marina, the National Museum, a shopping complex, and rowing clubs);

- a series of public open spaces defined by buildings with limited vehicle access;

- refurbished former port buildings; and 
- a pedestrian bridge connecting the waterfront to the city.

\subsubsection{Governance description}

Following the 1985 symposium, the WCC and the Harbour Board commissioned a local planning and design firm, Gabites Porter and Partners, to produce a concept plan for the waterfront based on the winning Paperchase scheme and other ideas from the 1982 Harbour Cities competition (Johnson, 1996; Wellington Waterfront Framework, 2001). This design team was augmented by the WCC and Harbour Board with other design professionals and academics from teams who had entered designs for the waterfront (McEldowney, 1986). Collectively, the expanded design team was identified as the Lambton Harbour Group (LHG) (Wellington Waterfront Framework, 2001; McEldowney, 1986).

In this phase, the waterfront area was still owned by the Harbour Board; however, the central location and proximity to the city's central business areas meant anticipated land uses would have a big impact on how the city evolved. As represented in figure 4.12, both organisations therefore had a strong interest in having a say in how the waterfront would be developed. Reportedly, the Harbour Board and City Council were not interested in public engagement at this stage, yet the design professionals commissioned for the project emphasised the need for continued public involvement (Gray, personal communication). 


\subsubsection{Phase 2 projects}

1986 Lambton Harbour Urban Design Concept

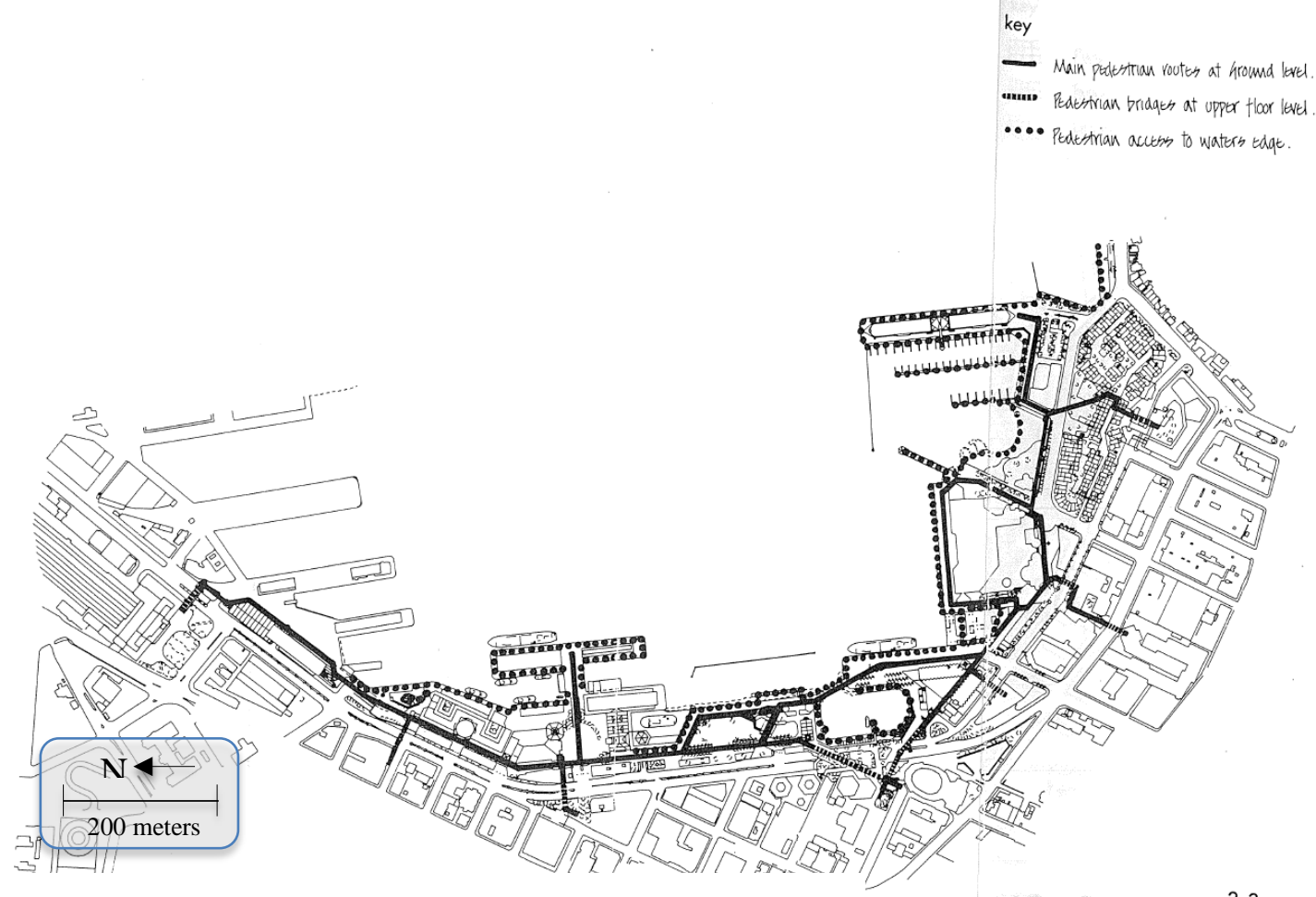

Figure 4.13. 1986 Lambton Harbour Urban Design

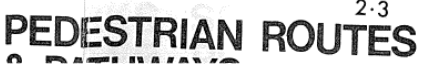
Concept pedestrian network. (image: Gabites Porter \& Partners)

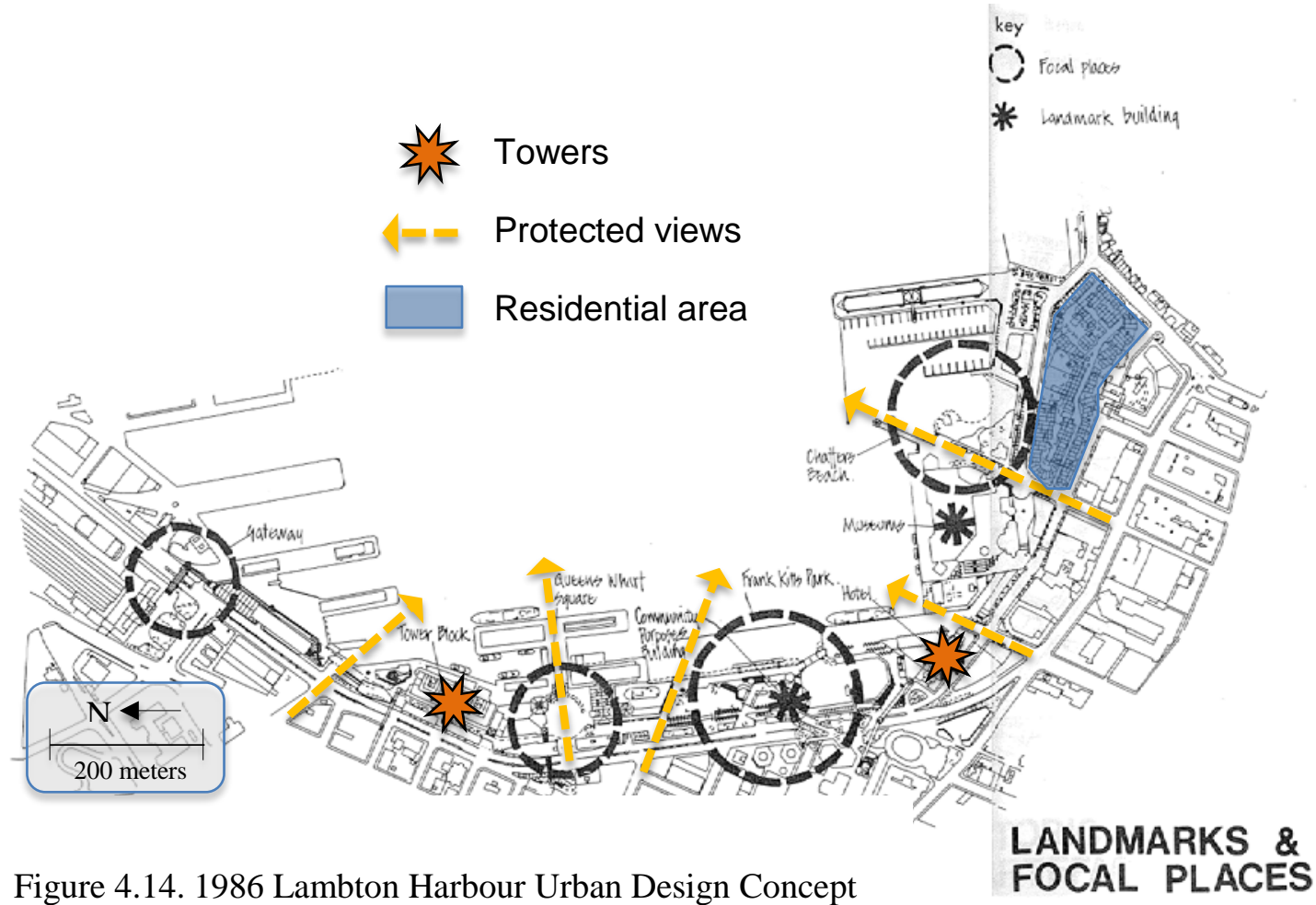
major features. (image: Gabites Porter \& Partners) 
LHG was commissioned to develop a design for the waterfront that connected the waterfront and the city, retained historic buildings, included a site for a national museum, and was self-funding (i.e. private development would pay for the development of public space) (Doorne, 1998, p. 138; McEldowney, 1986); therefore, they had to emphasise a balance of public amenity with financial feasibility.

New buildings were intended to relate with nearby waterfront and city buildings and reflect the maritime character of the area (McEldowney, 1986). To do this, buildings near the central business area at the north end of the site should be 'large-and-low'. As shown in figure 4.14, tall and slender buildings were to be used as punctuation points along the waterfront to create landmarks without blocking views. Parking was to be mostly underground and vehicles were to have limited access to the waterfront (McEldowney, 1986). The plan included a residential area and a marina in the Chaffers area, retention of berths along the waterfront, different ways of accessing the water, a series of public open spaces framed by buildings, consideration of microclimate effects and protection from adverse weather, retention of most harbour views down streets, a pedestrian bridge from the lagoon over Jervois Quay to a new civic plaza, a range of maritime artefacts, a tram along the waterfront, a market hall and office space at Queens Wharf (see figure 4.15), two hotels (one with convention

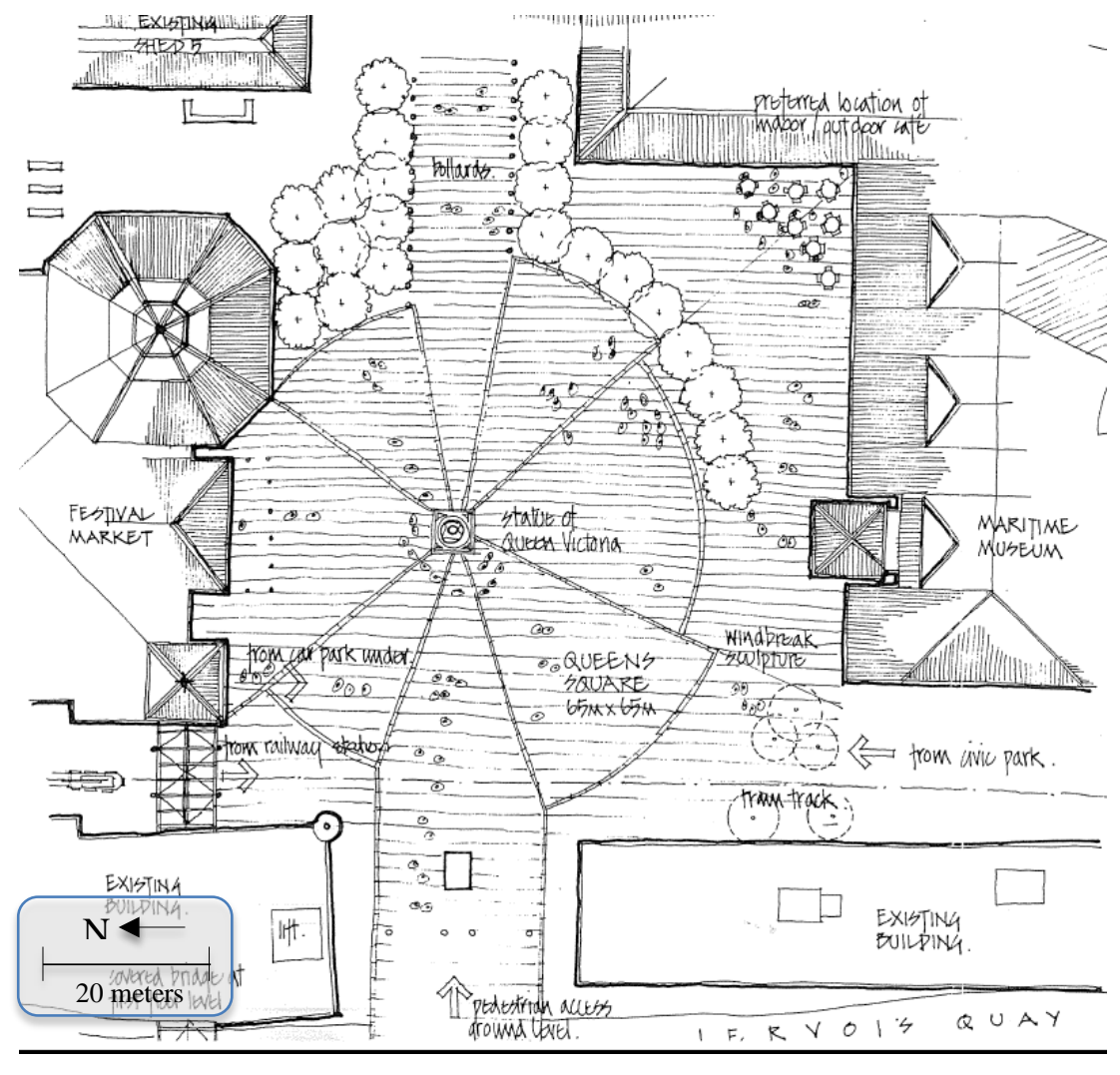
facilities), a tower north of Queens Wharf, and the potential for several mixed use areas (McEldowney, 1986).

Figure 4.15. 1986 Lambton Harbour Urban Design Concept: Queens Wharf square. (image: Gabites Porter \& Partners) 


\subsubsection{Form and governance}

At this stage, the waterfront was still under the control of the Harbour Board, though they formed an agreement to work with the City Council on redevelopment plans for the surplus lands. McEldowney (1986, p. 16) emphasised this was just strategic planning and policy changes would be needed to enable the plan to move forward.

The changing nature of the governance is reflected in the collaboration by the Harbour Board on a waterfront plan whose form largely departs from the former port use of the area. Ideas that no longer supported a working port environment included: repurposing heritage buildings, limiting vehicle access, emphasising pedestrian connections along the water's edge and to the city, encouraging interaction with the water, provision of residential and commercial buildings along the waterfront, and emphasising pedestrian scale and comfort.

The desire for a plan that was self-funding reflects a risk adverse approach, possibly because the Harbour Board and WCC were not developers and this model of development was relatively new. The self-funding mandate is reflected in the commercial aspects of the plan: a marina, 4000 car parks, two hotels (one with convention facilities), a national museum, office space oriented to the central business area, a large residential neighbourhood, a tower development, a shopping centre, and mostly small public open spaces strung along the waterfront.

\subsubsection{Transition stimulus}

1986 Joint venture agreement

Following presentation of the 1986 plan to the Harbour Board and WCC, the two organisations signed a joint venture agreement (Wellington Waterfront Framework, 2001). The agreement established a trustee corporation named Lambton Harbour Overview Ltd. (LHO) that owned the waterfront redevelopment land and assets, plus a subsidiary development corporation named Lambton Harbour Management Ltd. (LHM) to manage planning and implementation of the project (Harris, 2000). LHM was advised by a commercially oriented board of directors, jointly appointed by the 
Harbour Board and WCC, and included a representative from each organisation (Harris, 2000).

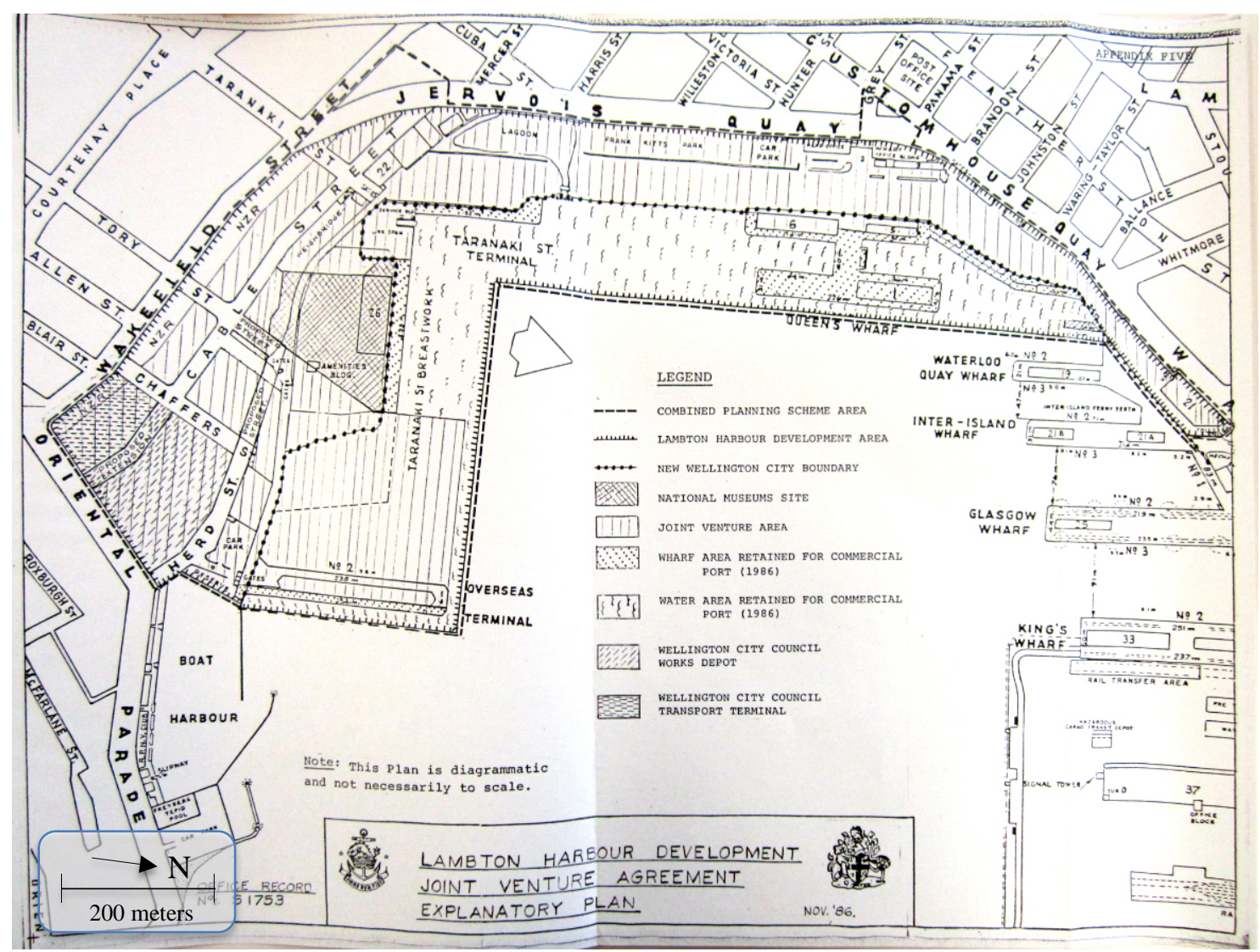

Figure 4.16. 1986 plan illustrating the waterfront area included in the joint venture agreement (image: Cayford, 2014).

The agreement also defined the 'special development zone' shown in figure 4.16 running from shed 21 on the north end around to the Overseas Passenger Terminal on Clyde Wharf, and from the water's edge to Waterloo, Customhouse and Jervois Quays, and Cable Street. According to Harris (2000), the 'special development zone' was chosen to include a "good representation of heritage buildings.” This decision, influenced by the Paperchase and subsequent plans, confirms a shift in values from the previous phase where several original sheds were demolished. Also retained in the joint venture concept were several wharf areas for berths for large vessels and associated wharf space for servicing them. 


\subsection{Phase 3 governance (1986 to 1996) - A largely independent development corporation}

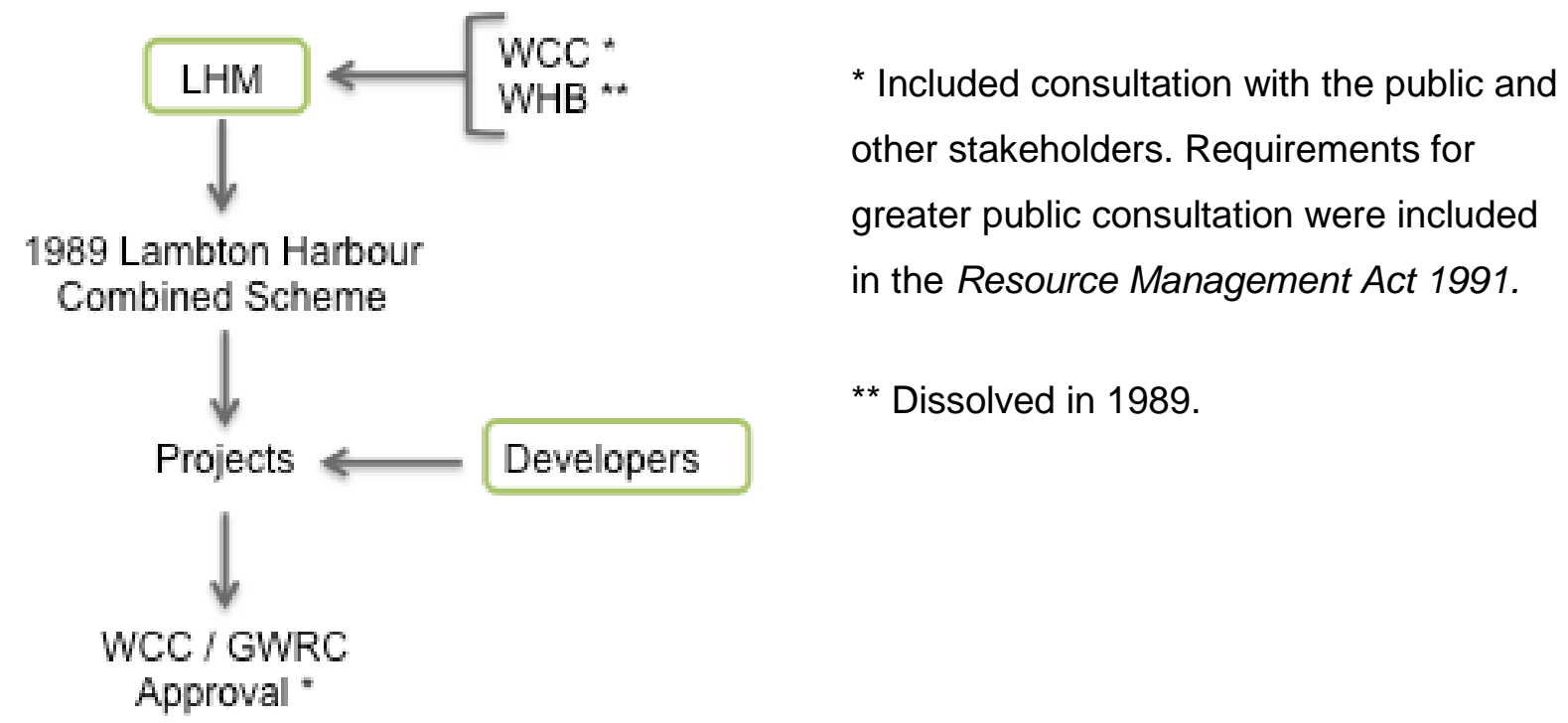

Figure 4.17. Diagram of the phase 3 governance arrangements. Compared to previous governance phases, and as indicated by the green box, decision making for the development of the waterfront was largely transferred to Lambton Harbour Management Ltd. (LHM) with limited opportunities for direct stakeholder input.

A summary of the effects on the form of the waterfront included:

- large building sites;

- mostly small public open spaces;

- $\quad$ some blocked views from the city;

- a wall along the harbour side of Frank Kitts Park and an internally oriented layout;

- installation of public art; and

- internally oriented developments that lacked engagement with adjacent public open space.

\subsubsection{Governance description}

A new governance phase for decision making about the waterfront was initiated with the joint venture agreement. The corporations established by the agreement were under 80\% Harbour Board and 20\% Wellington City Council ownership (Doorne, 1998). By creating a largely independent development corporation, the governance of 
the redevelopment closely mirrored the governance recommendations in the Paperchase entry (1983) and a resolution from the 1984 Harbour City Conference for joint management of the redevelopment effort (Urban Perspectives, 2014). LHM's role was to redevelop and manage the waterfront redevelopment in a way that was self-funding (Buchan, 2011; Wellington Waterfront Framework, 2001). As shown in figure 4.17, decision making under the joint venture agreement was therefore handed over to LHM, with advice from its board of directors.

The Wellington Harbour Board and Wellington City Council Vesting and Empowering Act (1987) modified the planning requirements outlined in phase 1 (i.e. proscribed by the Harbours Act, 1950 and the Town and Country Planning Act, 1977) by removing bureaucratic hurdles to facilitate the redevelopment. The Empowering Act was drafted to centralise control of the land and seabed under the wharves within the designated waterfront redevelopment area. The Act allowed WCC and the Harbour Board, or LHM as their designate, to act as a developer and released them from the need to draft a district plan for the site, provided a suitable development plan was in place. Allowed land uses under the Act included: commercial, maritime, residential, educational, cultural, social, recreational and other uses, activities, and characteristics without restriction from otherwise applicable planning acts. Under this arrangement, planning permissions would still be required for projects that deviated from the accepted development plan.

Two years later under a 1989 effort by the national government to reorganise local boards across New Zealand, the Wellington Harbour Board was dissolved. As a result of the 1986 joint venture agreement, LHO and its subsidiary, LHM, became fully owned by the Wellington City Council (Harris, 2000). The remainder of the former Harbour Board's assets and responsibilities passed on to the Port of Wellington Ltd., a Greater Wellington Regional Council-owned company which was established by the Port Companies Act (1988 in Harris, 2000). Despite these ownership changes, LHM remained a largely independent development corporation with a mandate to redevelop the waterfront.

National planning reform in the late 1980s resulted in the Resource Management Act (RMA, 1991). The RMA replaced 69 Acts, plus 19 additional regulations and orders 
(RMA, 1991, Schedule 6). The emphasis of the Act was sustainable management of natural and physical resources (RMA, 1991, Section 5). In setting this emphasis, planning shifted from regulating land use to an effects-based approach where one must determine what the effects of development will be on the long term viability of affected natural and physical resources. Under the planning changes introduced by the RMA, planning required public consultation when development proposals were deemed by planning staff to have more than minor effects on the quality, use or enjoyment of the environment (see Sections 93 to 103 of the RMA). Additional planning permission was also required from the regional council (i.e. Greater Wellington Regional Council) for developments that extended beyond the mean high water mark (i.e. changes to the wharves and structures upon them or additional development on the harbour) (Section 12). Given the public nature of the waterfront redevelopment area and its prominence in views to and from the city, the policy of requiring public consultation when the potential effects of a development are more than minor, eventually had broad effects on the overall planning, design, and development of the waterfront. The effects included: slower, more careful, redevelopment due to long consultation periods and blocked projects due to Environment Court challenges of planning approvals by various stakeholders.

The waterfront plan approved by the WCC, the 1989 Lambton Harbour Combined Scheme (described in section 4.5.2), became the district plan for the waterfront (District Plan Policy Group [DPPG], 1999, September 30 Report, p. 3). The subsequent 1994 Wellington District Plan did not include detailed design provisions for the waterfront as it was anticipated a specific set of design guidelines would be produced and used to amend the district plan (DPPG, 1999, September 30 Report, p. 3). Many of the projects that were built within this phase reflected the commercial, self-funding nature of the 1989 scheme. 


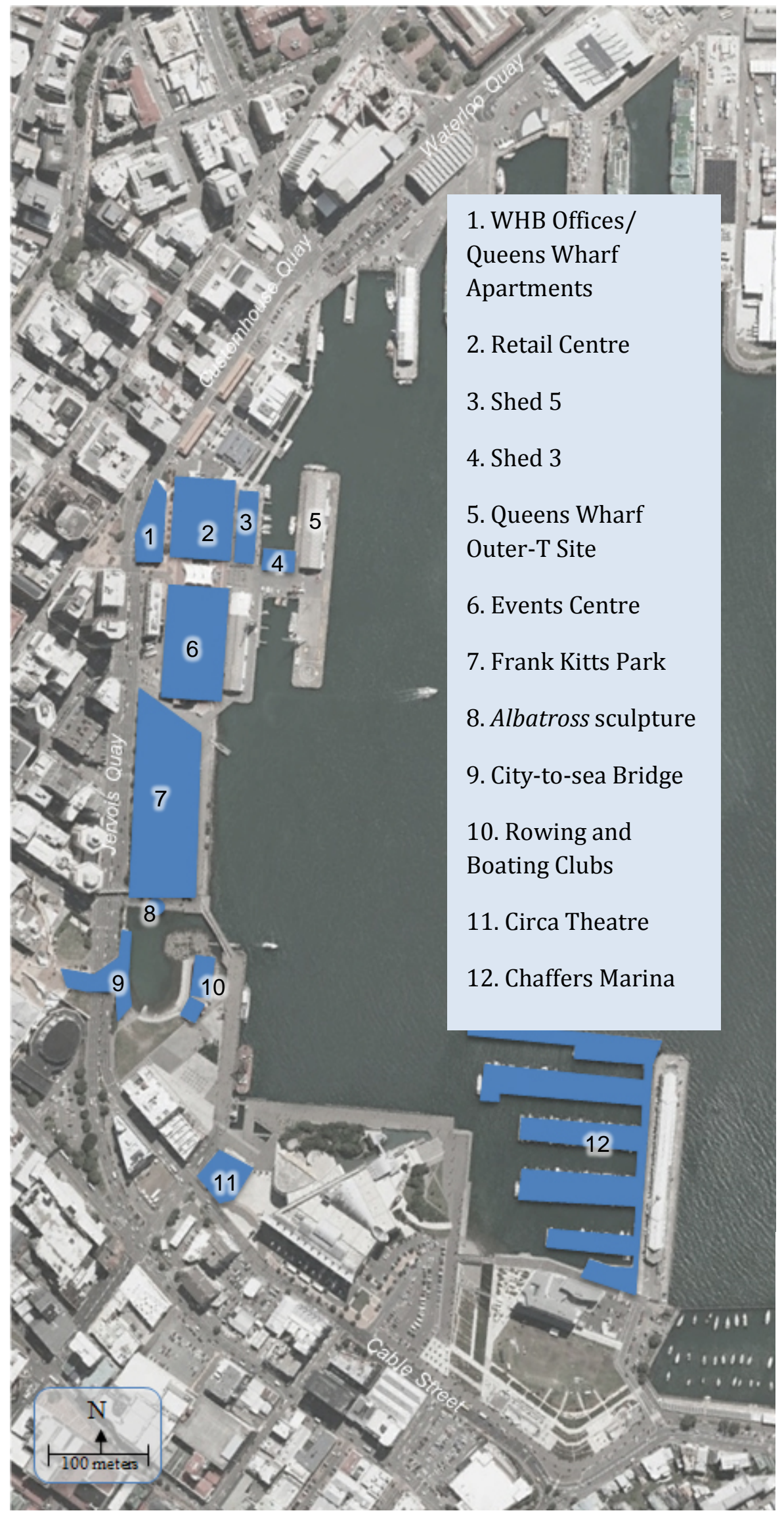

Figure 4.18. Location map of phase three projects and features. Blue polygons identify constructed projects. (base image: Google Earth, accessed November, 2015). 


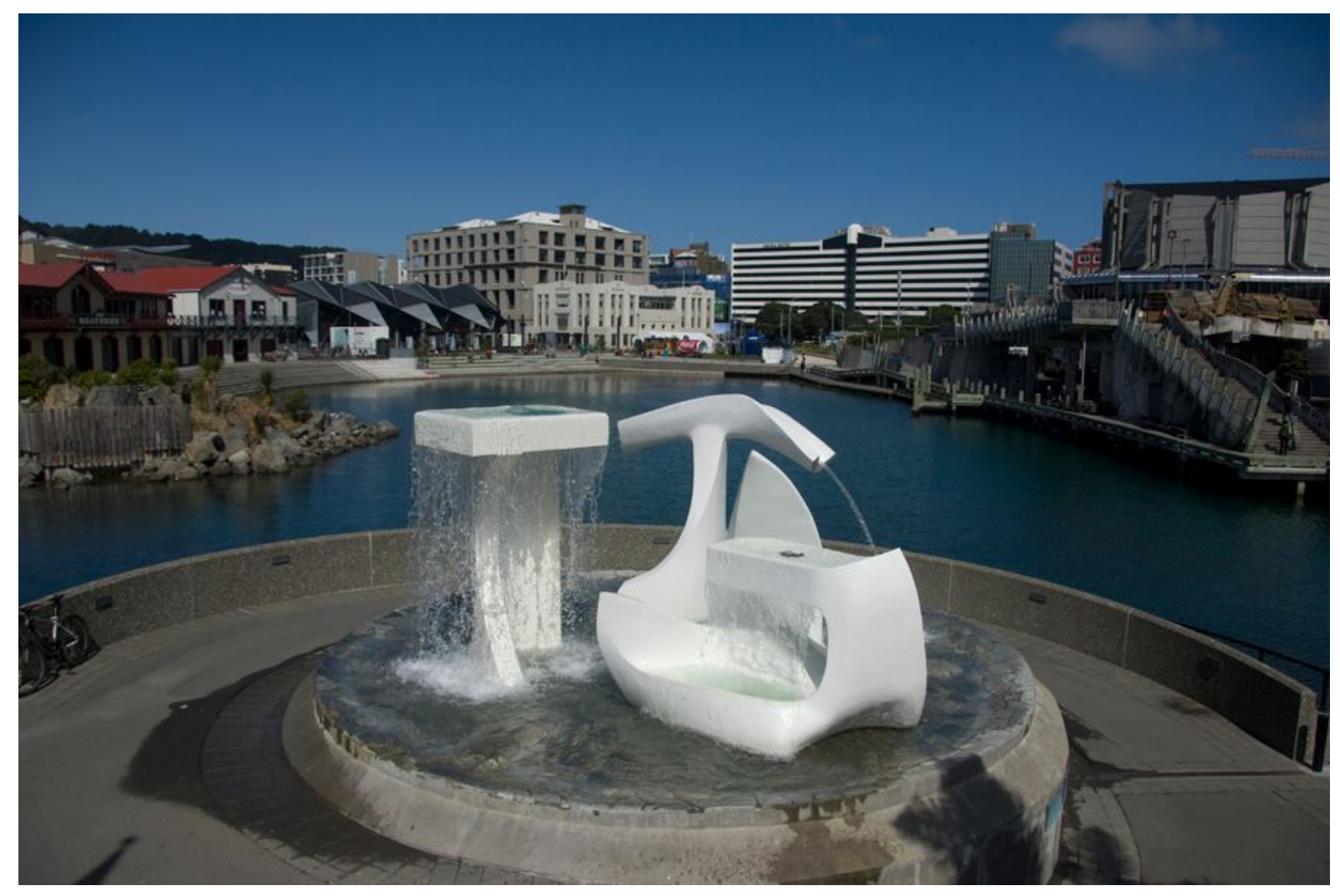

Figure 4.19. Albatross by Tanya Ashken. (image: Wellington Sculpture Trust)

Albatross, by Tanya Ashken was installed in 1986 on the lagoon, beside Frank Kitts Park. The sculpture was the first installation by the Wellington Sculpture Trust (Harper \& Lister, 2007, p. 35). The intent of the Trust was to promote the idea of including more sculpture in the city’s public spaces as cultural amenities (Harper \& Lister, 2007, p. 35).

Very little information is available on the decision making around the design and approvals of many of the sculptures that have been installed along the waterfront. Of the few that are discussed in the available minutes and reports, decisions on these types of projects were made by LHM in consultation with the funding agencies and with advice from designers involved with respective public space projects or who had been appointed to design advisory panels during later phases. 


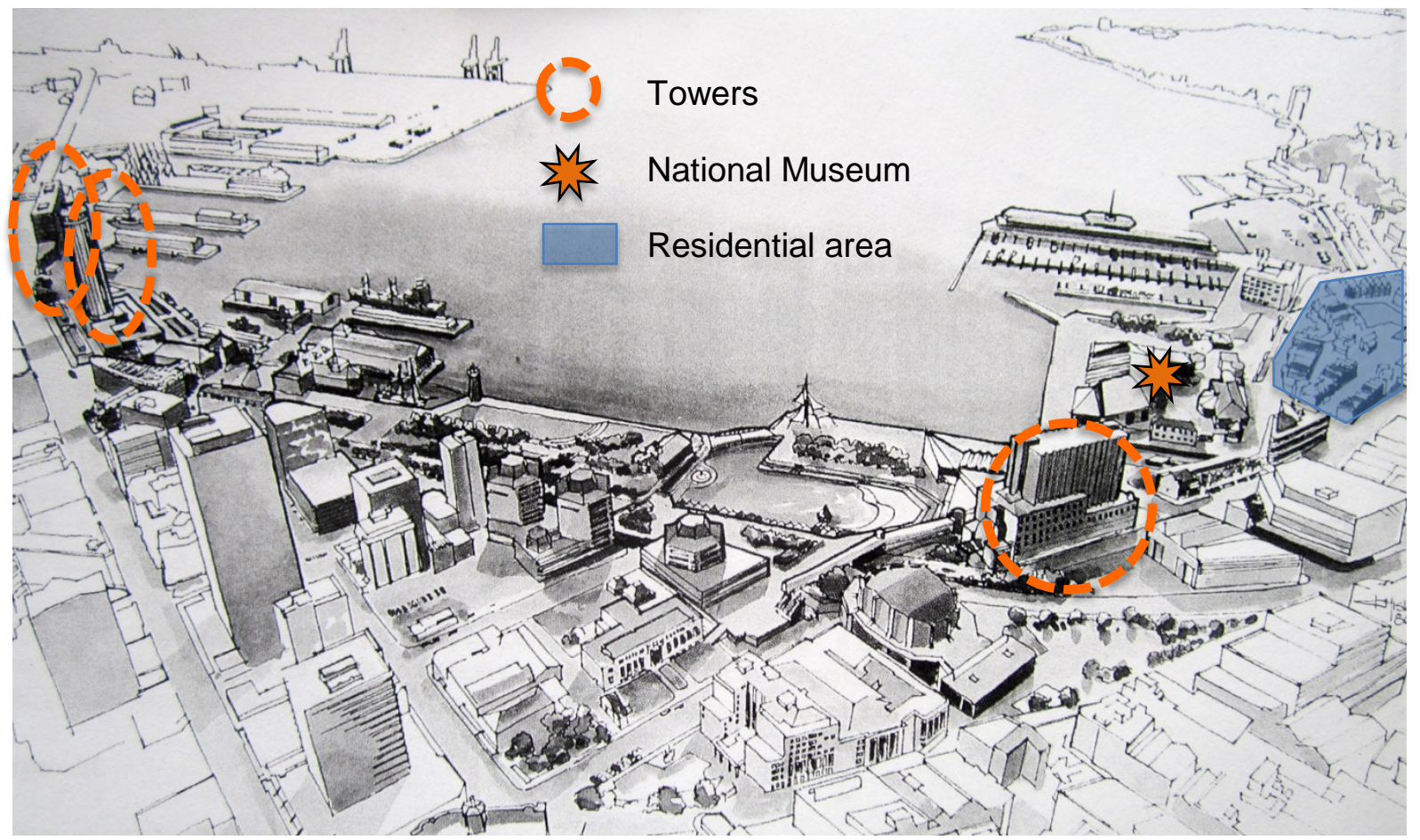

Figure 4.20. The major commercial development projects in the 1989 Lambton Harbour Combined Scheme. (base image: Gabites Porter and Partners, 1989)

The first major act of LHM was to commission a more detailed development plan for the development area it controlled, based on the 1986 plan produced by the LHG (Buchan, 2011; Wellington Waterfront Framework, 2001). The firm contracted to produce it was the same firm that was the core part of the Lambton Harbour Group. This revised plan, shown in figure 4.20, also reflected the self-funding mandate (i.e. using private development income to pay for public space investments) by including a dense residential subdivision in the current location of Waitangi Park; an eight storey hotel and convention centre; an 11 storey office block on the north end, a market building on Queens Wharf, a large 31 storey tower adjacent to Queens Wharf with two six storey podium buildings flanking it, and a national museum adjacent to a marina by Clyde Wharf (Buchan, 2011; Wellington Waterfront Framework, 2001). The plan also specified Queens Wharf as the first area for development.

The plan was initiated during a construction boom and many of the projects were approved; however, the 1987 stock market crash in October of that year had a sobering effect on implementation of the plan (Buchan, 2011; Wellington Waterfront 
Framework, 2001, p. 8). Economic capital was no longer readily available and as the redevelopment project was just getting underway there were no past profits for LHM to use for initiating development of the waterfront.

1989 Frank Kitts Park and lagoon
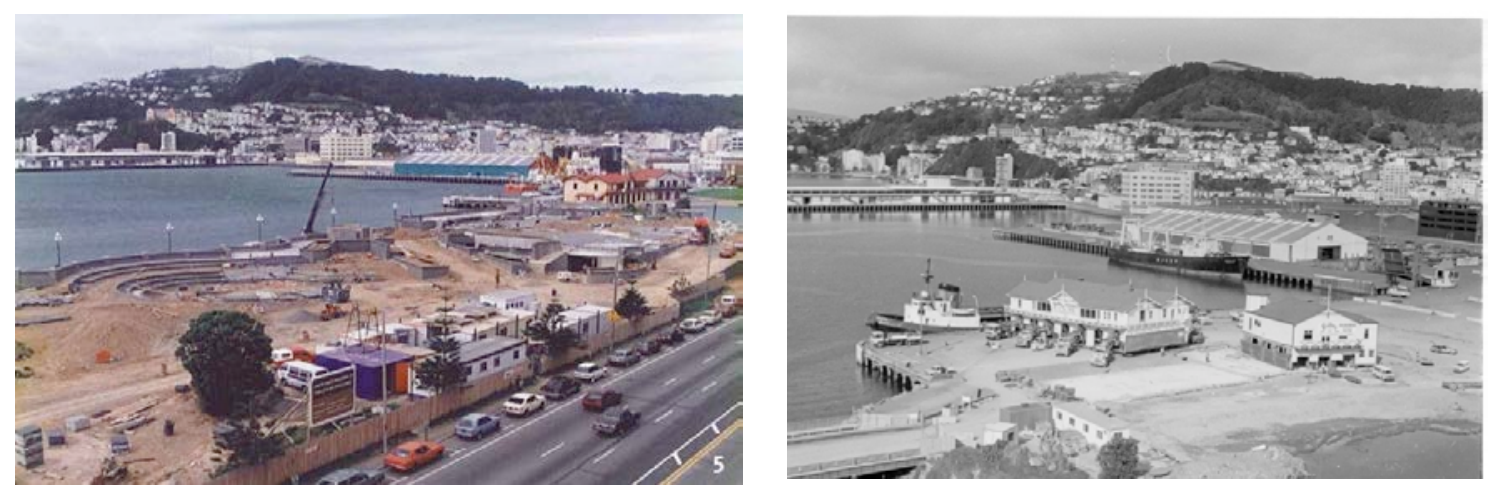

Figures 4.21 and 4.22. Left: Redevelopment of Frank Kitts Park 1989. Right: Moving the Star Boating Club and Wellington Rowing Club buildings 1989. (images: The Dominion Post Collection, Alexander Turnbull Library)

Starting in 1989, LHM began developing non-commercial projects in a bid to generate development momentum and attract private investment (Wellington

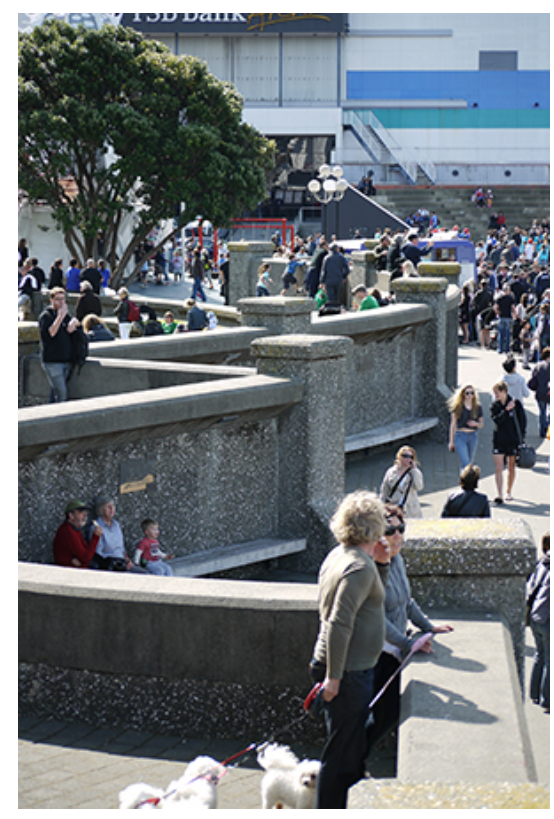

Figure 4.23. Seating and wall on the harbour side of Frank Kitts Park (image: author)
Waterfront Framework, 2001). The first public space project was a remodelling of Frank Kitts Park (figure 4.21) and the lagoon (figure 4.22) from late 1989 to August 1990 (Waterfront Information Centre, 2011).

The redesigned park included a children's playground, underground parking, and various seating and activity areas that gradually sloped up towards the top of a one storey wall on the seaward side of the park. The crenulated one storey wall between the park and the water's edge promenade (see figure 4.23) incorporated sheltered seating spaces for protection from inclement weather, plaques commemorating maritime events associated 
with the harbour, an entrance to the underground parking, and small spaces that have been used for both storage and small retail businesses. The wall also provided a safe vantage point to view the starting grid for the annual Nissan 500 street car race that ran through the city from 1985 to 1996 (Cochran et al., 2012; Wellington Waterfront Framework, 2001). Due to this separation, however, the green space of the park sloped up from Customhouse Quay to the wall providing shelter from winds off the harbour, while limiting views of the harbour from the park itself (figure 4.24).

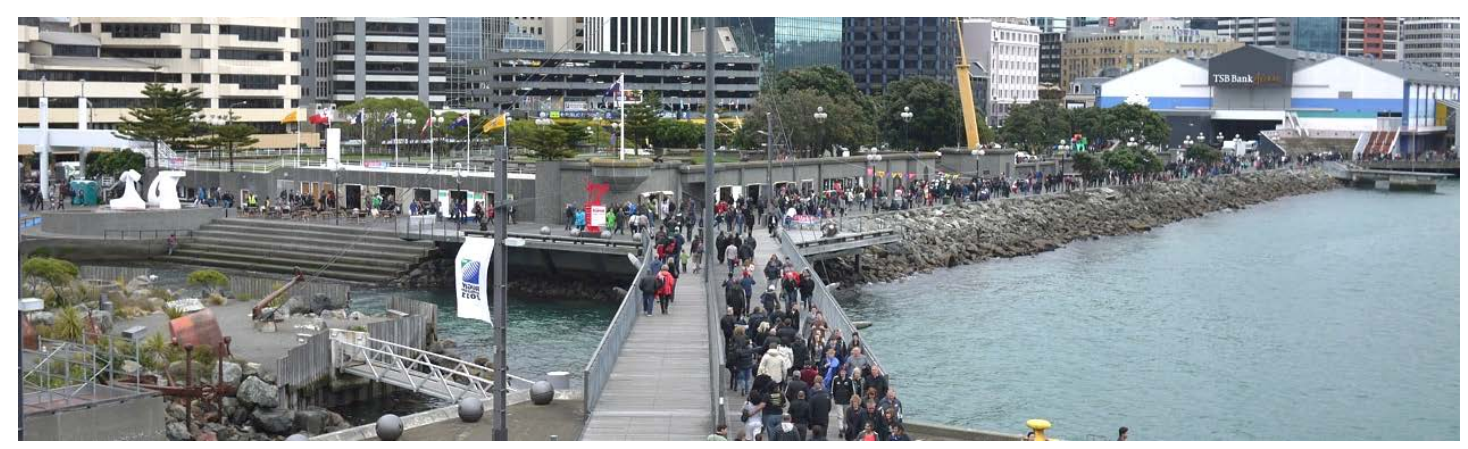

Figure 4.24. Harbour side of Frank Kitts Park showing the wall, promenade, and harbour edge relationships (image: author)

In accordance with the strategy first identified in the 1986 plan to remove surface parking from the waterfront and put it underground, the pay parking retained a desired amenity for waterfront users while providing an ongoing source of income for LHM. This particular parking garage, however, is only slightly below the grade of the waterfront promenade, though the park does extend over top of it. The wall along the seaward side of Frank Kitts Park exposes two sides of the parkade that face the harbour and the lagoon. It is these exposed sides that include the small spaces for storage and retail businesses shown in figure 4.25.

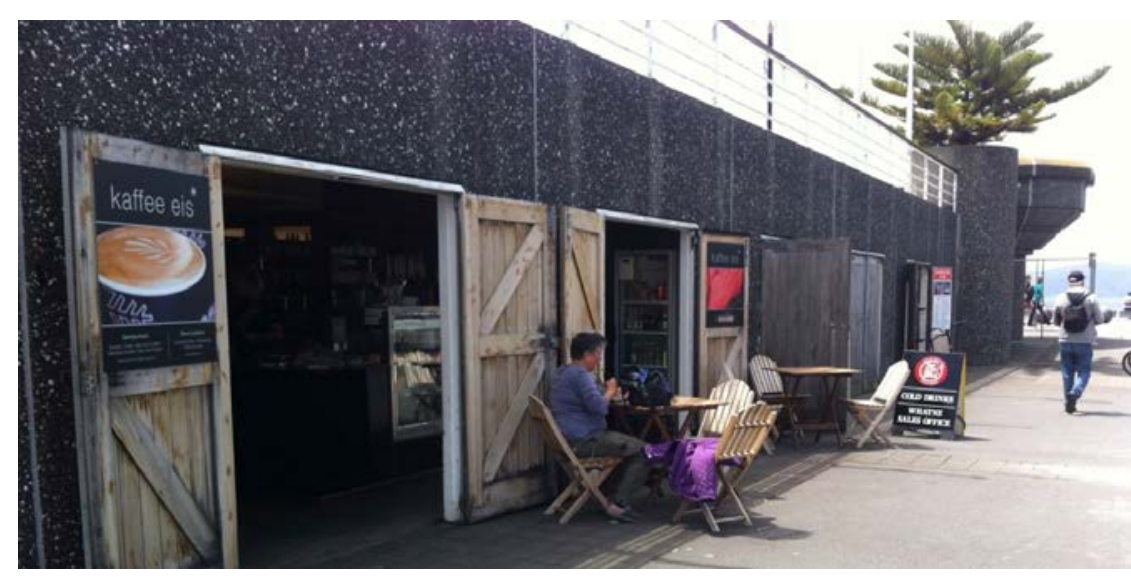

Figure 4.25. Retail spaces along the wall separating Frank Kitts Park from the waterfront promenade. (image: Wellington Absolutely Positively, 2014) 
In addition, public space was built adjacent to the lagoon and connected to the Civic Square (constructed between 1990 and 1992) by the City-to-Sea Bridge (Wellington Waterfront Framework, 2001; Buchan, 2011). The bridge was built using large roughcut timber and heavy exposed bolts that reflect the port and maritime heritage (see figure 4.26). This desire to improve pedestrian connections between the city and the harbour is reflected in later changes to the built form, including construction of a large median strip along Customhouse Quay and Jervois Quay to provide a refuge for pedestrians crossing those streets and generally protecting views of the water for streets that lead towards it.

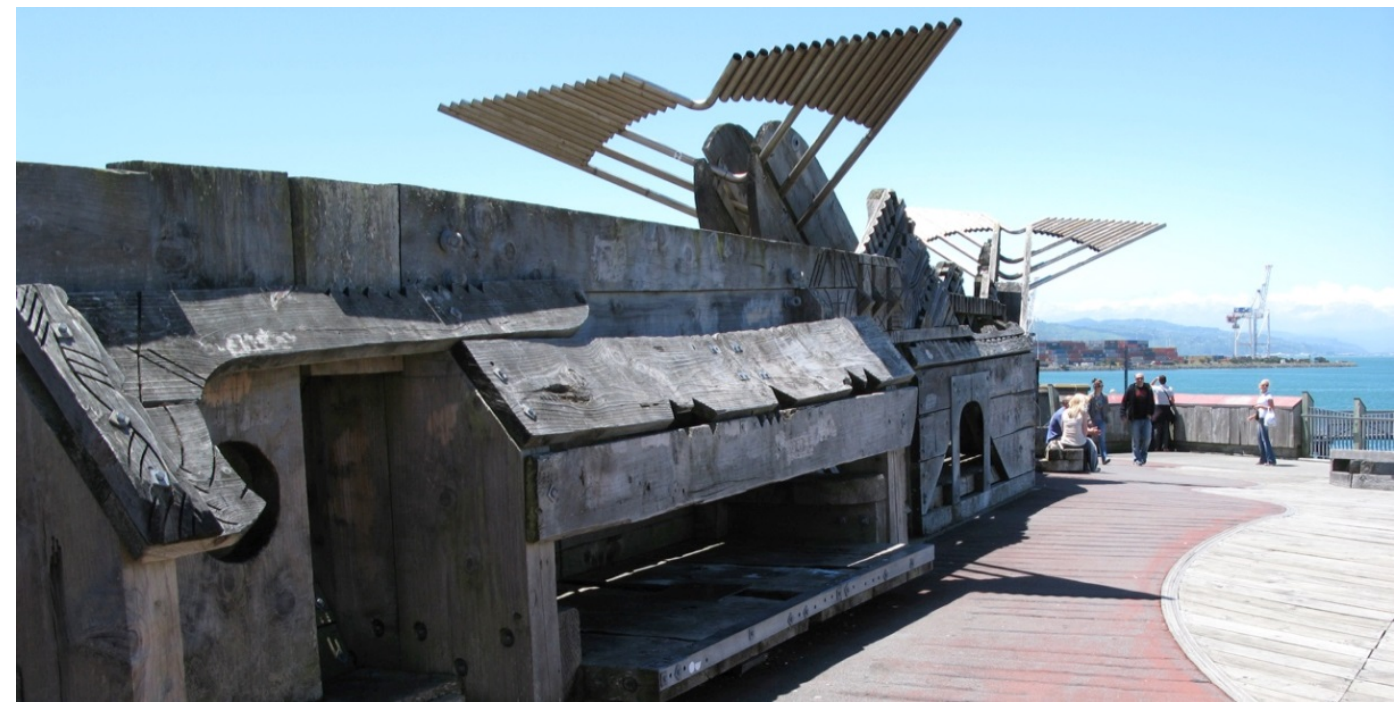

Figure 4.26. Industrial maritime materials used in the construction of the City-to-Sea Bridge (image: Author)

Included in the design for public space around the lagoon, the 1885 Star Boating Club and the 1894 Wellington Rowing Club buildings were moved from their location on Taranaki Street Wharf to their present sites, as shown in figure 4.22 (WCC, n.d., Old Shoreline Heritage Trail). These historic club houses and their still active club membership retained links to the harbour's past.

1991 to 1992 Sheds three and five

Sheds three and five, adjacent to Queens Wharf, were the first private developments on the waterfront, undergoing transformation from 1991 to 1992. Both buildings were built in 1887 and largely retained their original form in the refurbishment, with the exception of additional windows and added verandas fronting onto the water as seen 
in figure 4.27. As a part of the restoration, the underlying wharf structure was upgraded and these former warehouses were converted into restaurants and bars (Wellington Waterfront Framework, 2001; Strategy and Policy Committee [SPC], 2009, May 14 report 2).

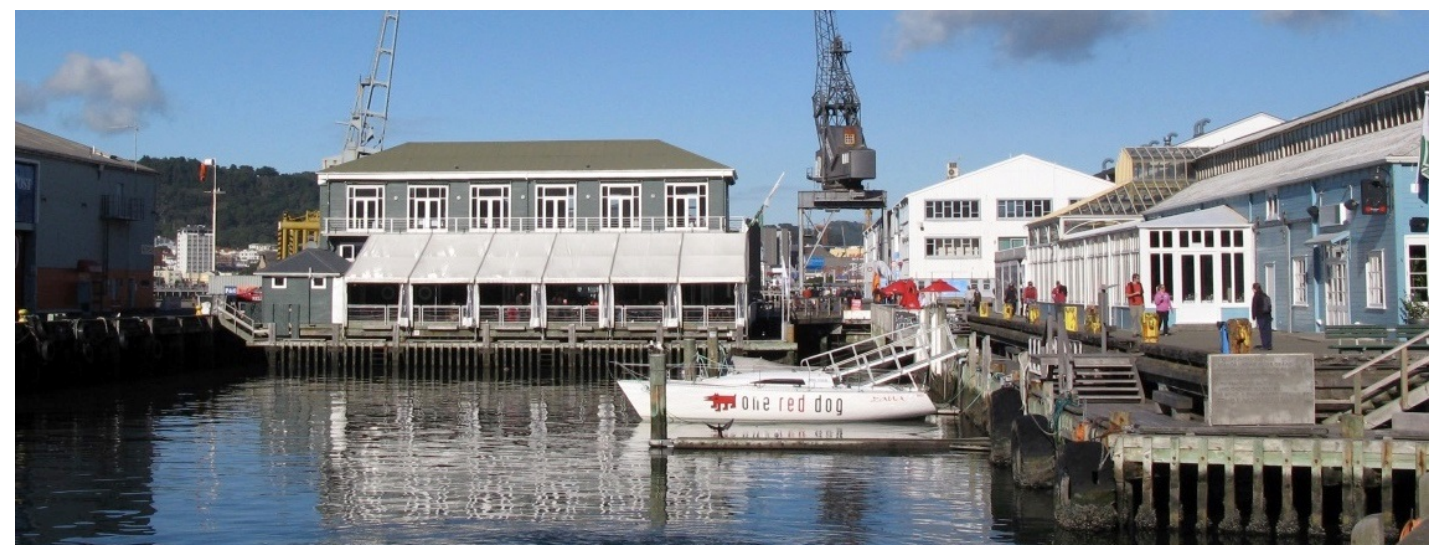

Figure 4.27. Shed three (The grey building in the centre) and shed five (the blue building on the right). (image: author)

\section{Chaffers Marina}

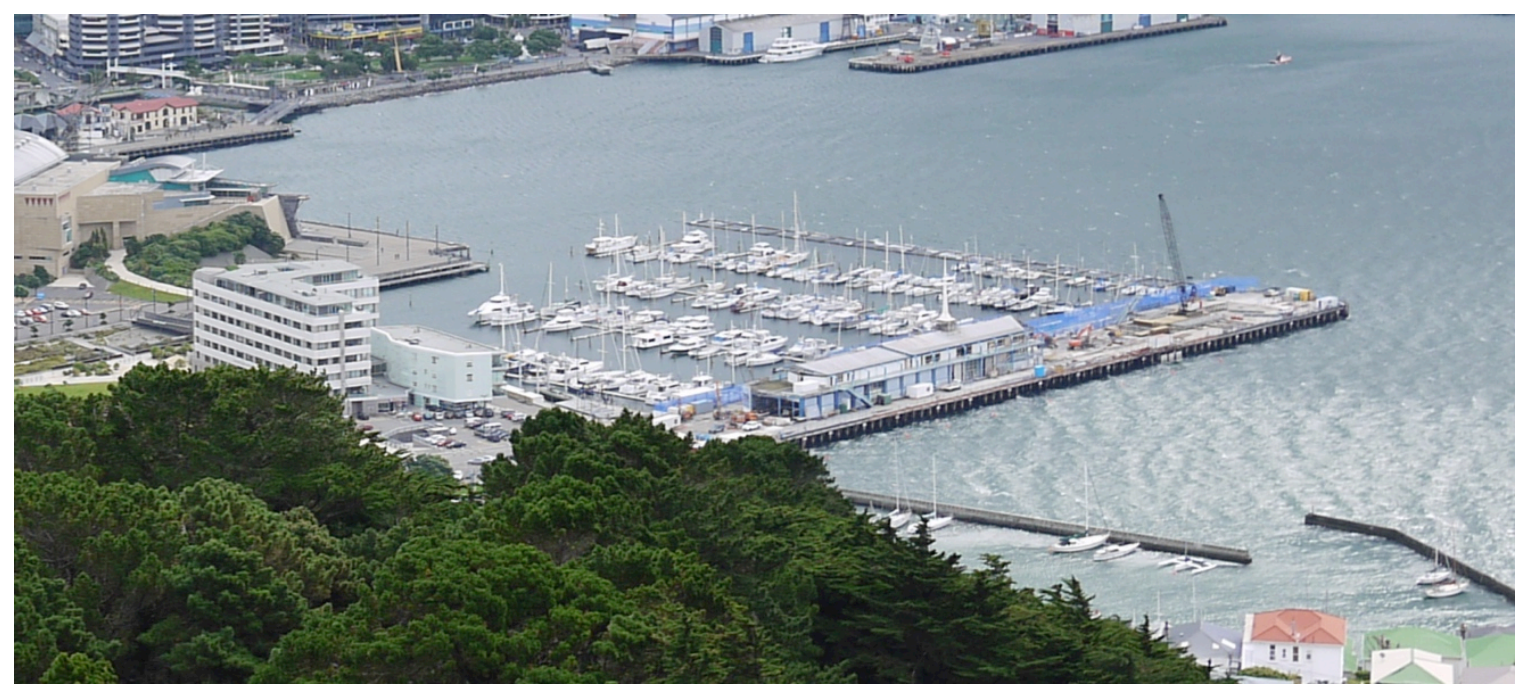

Figure 4.28. Chaffers Marina to the left of the Overseas Passenger Terminal (image: author)

The intention for development of a commercial marina for private boats had been included in all of the early waterfront plans. Including a marina and encouraging other water-based activities (e.g. the rowing clubs) would contribute to the vibrancy of the area and the built connections between the city and the harbour. Constructed in the lee 
of the Overseas Passenger Terminal with a protective breakwater (see figure 4.28), Chaffers Marina was opened in 1993 having received resource consent (i.e. planning permission) from the Greater Wellington Regional Council (GWRC) in 1991 (Pene, 2008). The marina included 165 berths to accommodate boats up to 20m and haul-out facilities for hull maintenance on boats up to 40 tonnes (Pene, 2008). From a commercial stand point the marina and surface parking lots along the waterfront were income generators for LHM.

\section{Circa Theatre}

The Circa Theatre was constructed in 1993 adjacent to the site of the new National Museum. The building was designed to incorporate the front facade from the then vacant 1916 Westport Chambers buildings shown in figure 4.29, which was located across Cable Street (WCC, n.d., Old Shoreline Heritage Trail; Wellington Waterfront Framework, 2001). The Westport Chambers building was identified in both the 1983 Paperchase plan and the 1986 plan as having sufficient architectural value to be retained and refurbished.

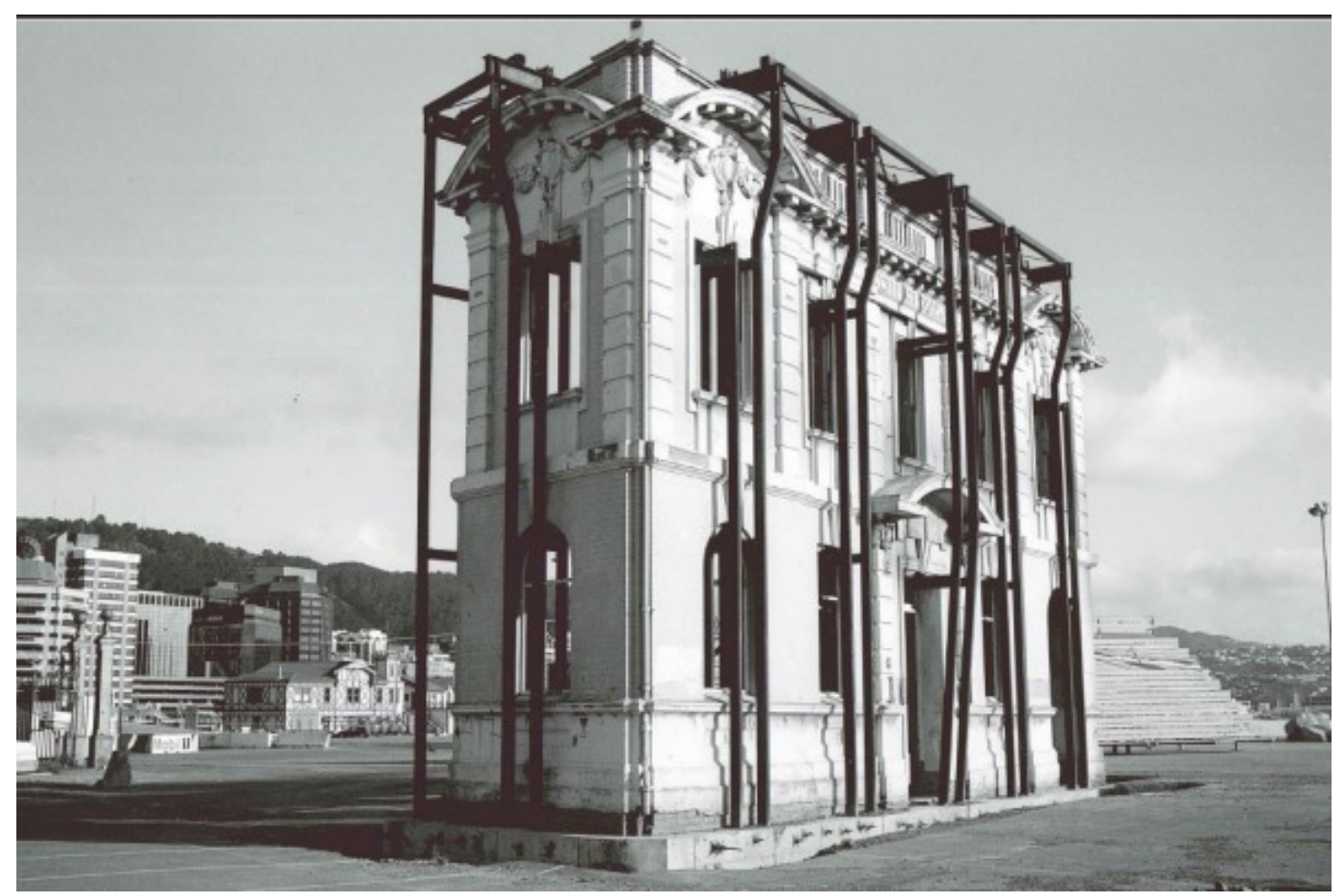

Figure 4.29. Westport Chambers Building façade in place prior to construction of the rest of the Circa Theatre. (image: The Dominion Post Collection, Alexander Turnbull Library) 
The building was commissioned by the Circa Council (the organisation that runs the Circa Theatre) with support from several corporate sponsors (Circa, 2012). While much of the building was new, some of the timber used in the reconstruction of the theatre was salvaged from the nearby Odlins building (STQRY, 2015b). These efforts to incorporate local architectural heritage reflected the desire to retain and reuse heritage buildings on the waterfront.

\section{Queens Wharf Apartments}

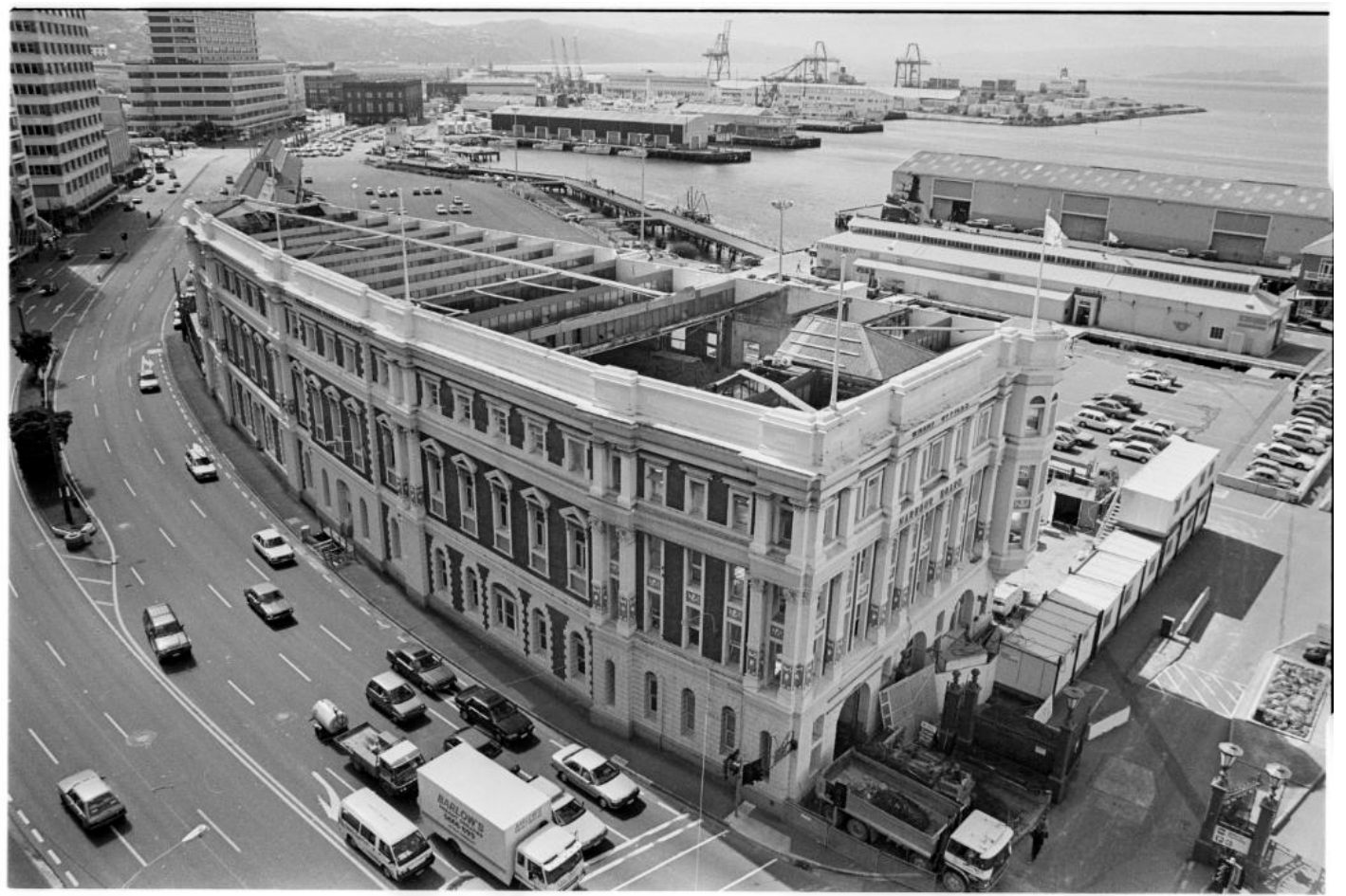

Figure 4.30. Wellington Harbour Board offices being converted into the Queens Wharf Apartments. (image: The Dominion Post Collection, Alexander Turnbull Library)

The first residential development was the refurbishment of the Harbour Board offices, as shown in figure 4.30, between 1993 and 1994 (Buchan, 2011; Wellington Waterfront Framework, 2001). According to Morrison and McMurray (1999), the refurbishment of the building by LHM was well received by the public and the units sold out quickly, but the concept of developing inner-city apartments was viewed as risky by real estate professionals. At the time, Wellington had very few people living in the downtown area and few amenities for them; however, early plans for the waterfront all included a mix of residential and other uses. Later, in 2000, the ground floor was occupied by the New Zealand Academy of Fine Arts (STQRY, 2015d), 
responding to LHM's goal for the ground floor of all buildings to include publicly accessible uses.

1993 Hotel on outer-T of Queens Wharf (later known as the Hilton Hotel proposal)

In 1993 LHM signed an "investigation licence” with a developer to identify options for constructing a hotel on the outer-T of Queens Wharf (SPC, 2009, May 14 Report 2). It was not until 2005, after ten years of negotiations and design exploration with the developer, that WCC approved the construction of a hotel in this location (Waterfront Development Subcommittee [WDS], 2006, May 8 Report 2 Appendix 1).

Initial ideas included converting the existing shed one on the site to a hotel (Buchan, 2006) and, later, the 1997 Open Space Plan included ten storey buildings on either end of the outer-T. When the 1989 Combined Scheme plan was replaced with the Wellington Waterfront Framework in 2001 (see section 4.7.2), the private developer submitted a third proposal that included a hotel based on utilising shed 1 and shed 6 (adjoining the Events Centre). This proposal was rejected by WCC prompting a fourth concept, based on replacing shed one with a taller structure, that was presented to the new council sub-committee on waterfront development (see figure 4.31) in 2001 (Buchan, 2006). While the council subcommittee recommended rejecting the fourth proposal, WCC approved it in 2002. Wellington Waterfront Ltd (formerly LHM) was then encouraged to move forward with negotiating a lease for a hotel on the site of shed one and to continue consulting on the design of the building (Buchan, 2006). Throughout this process, Wellington Waterfront Limited (WWL) continued to support the project as profits from the lease were intended to pay for refurbishing the piles under part of Queens Wharf and new public space on the waterfront (WDS, 2002, September 9 Minutes cited in Buchan, 2006: 3).

The proposed hotel was to be 7.4 metres taller than the existing $12 \mathrm{~m}$ tall shed 1 , with some service areas extending up a further 2.6m (Environment Court, 2008). The building was to cover the same footprint as the existing shed, so the volume and visual impact of the proposed building was far greater due to the added height. The ground floor was to include restaurant, service and reception areas which did not fully comply with the idea described in the 2001 Waterfront Framework of the ground floor 
being publicly accessible. Additionally, vehicle access to the hotel was to be provided by some surface access on the wharf and a 50m tunnel underneath.

As the outer-T is situated over the harbour, resource consent was required from the Greater Wellington Regional Council (GWRC) as per the Local Government Act (2002). To receive consent, the proposal needed to meet the Wellington Region Coastal Plan, which had been drafted to reflect the Wellington Waterfront Framework (described in section 4.7.2). The GWRC approved a revised version of the fourth hotel proposal, with some constraints on vehicle access, in September 2006. In response to concerns over the proposal's impact on the waterfront and nearby businesses, two public interest groups (Waterfront Watch and Wellington Civic Trust) were joined by two property investment firms and the Intercontinental Hotel Wellington in launching an appeal against the approval decision in the Environment Court (Environment Court, 2008). Ultimately, the Environment Court rescinded the resource consent in April 2008, preventing the development of the hotel as it was proposed.

In comparison to the commercially-oriented 1989 Combined Scheme, the Waterfront Framework (2001) identified the outer-T of Queens Wharf as a key site on the waterfront due to its history and location. Any development in this area was to be iconic and contribute to the waterfront experience. As a matter of process, the Waterfront Framework identified a design competition as the appropriate mechanism for exploring the site's potential, taking into account harbour views while retaining the ability to berth large vessels (Waterfront Framework, 2001).

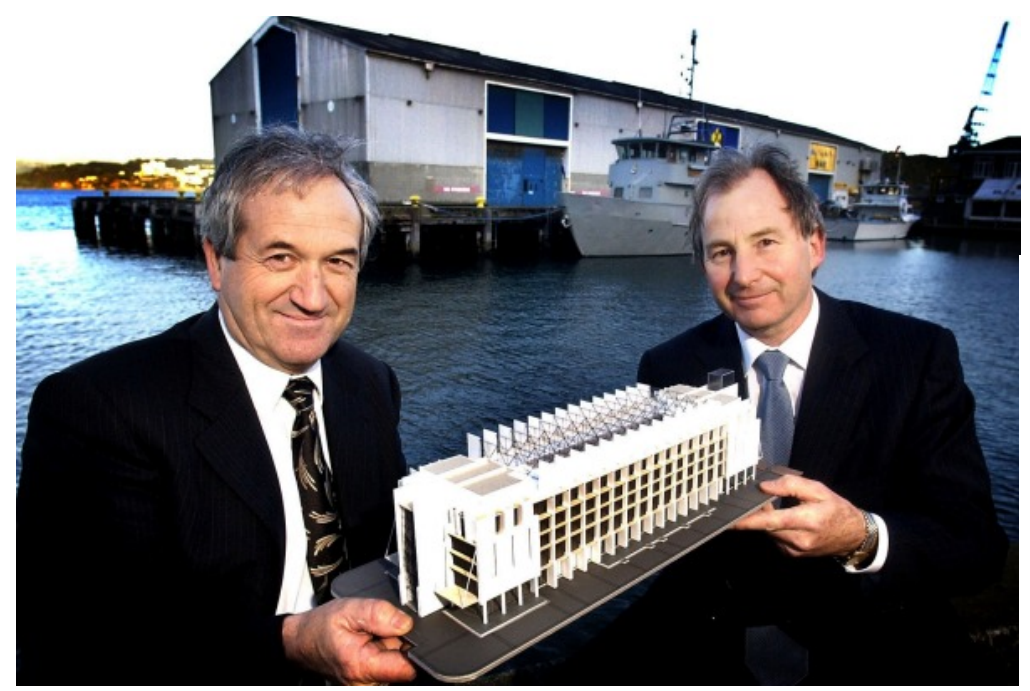

Figure 4.31. Model of the fourth hotel proposal for the outer-T of Queens Wharf to replace shed one, shown in the background. (image: Andrew Gorrie, Fairfax Media) 
The Environment Court overturned the approval in March 2008 citing the overwhelming form, the architectural style that would negatively impact the heritage character of the area, the reduced public space and reduced amenity value of nearby public space, the danger of increased vehicle access to the promenade and pedestrian areas, and the negative impact on views from the city to the harbour (Environment Court, 2008). As will be discussed in section 4.8.4, this ruling was key in the decision to move to a new governance process in 2008.

While this project ran for 15 years, spanning several governance phases that will be covered below, the initial agreement and subsequent management of the project reflects the character of a largely independent development corporation and the influence of early thinking about the form of the waterfront. The role of the WCC and its sub-committee in the approvals process was limited by the initial agreement. The final outcome was determined by a court challenge, which was the only formal avenue for the public to have an impact in this process.

1995 Queens Wharf Retail and Events Centre

In the 1989 Combined Scheme, Queens Wharf was proposed as one of the major centres along the waterfront. The plan, shown as a model in figure 4.32 below, included a market hall, a central plaza at the beginning of the wharf, and an extension of shed six that would help define the plaza space (see also figure 4.15). According to the Combined Scheme, the project required the design to fit the harbour side industrial aesthetic and to reflect the form of the existing waterfront warehouse sheds, but did not comment on scale.

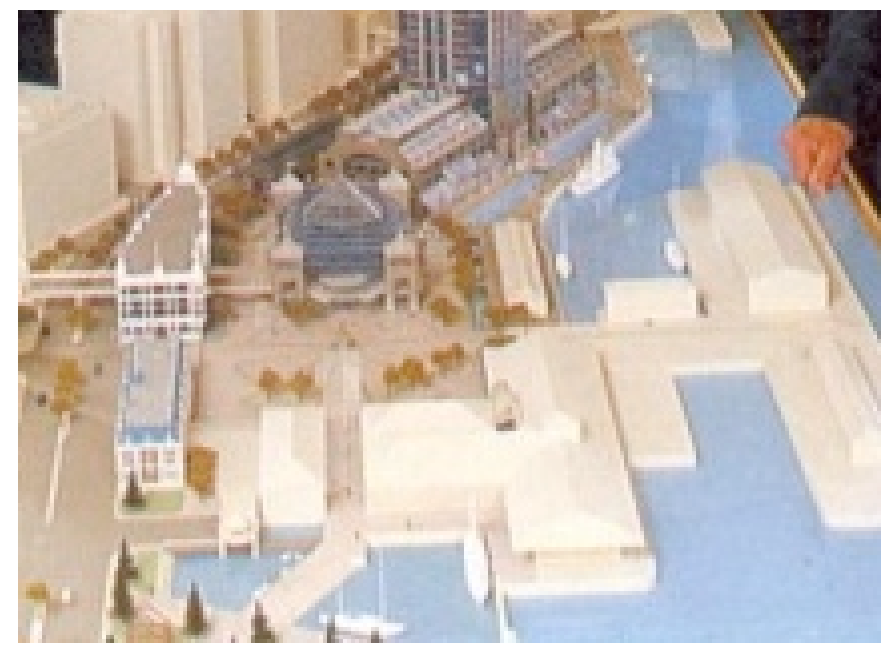

Figure 4.32. Model of the Queens Wharf portion of the 1989 Combined Scheme. This is facing the opposite direction from figure 4.33; however, the difference in the scale of the buildings and public space between the two is significant. (image: Wellington City Archives) 
As the Combined Scheme was the operative district plan for the waterfront and the proposal reflected this plan, LHM was able to pursue these projects without public consultation. The final form, shown below in figure 4.33, included two warehouse type structures that were much larger in scale than nearby existing structures, separated by a covered plaza space that was smaller than intended.

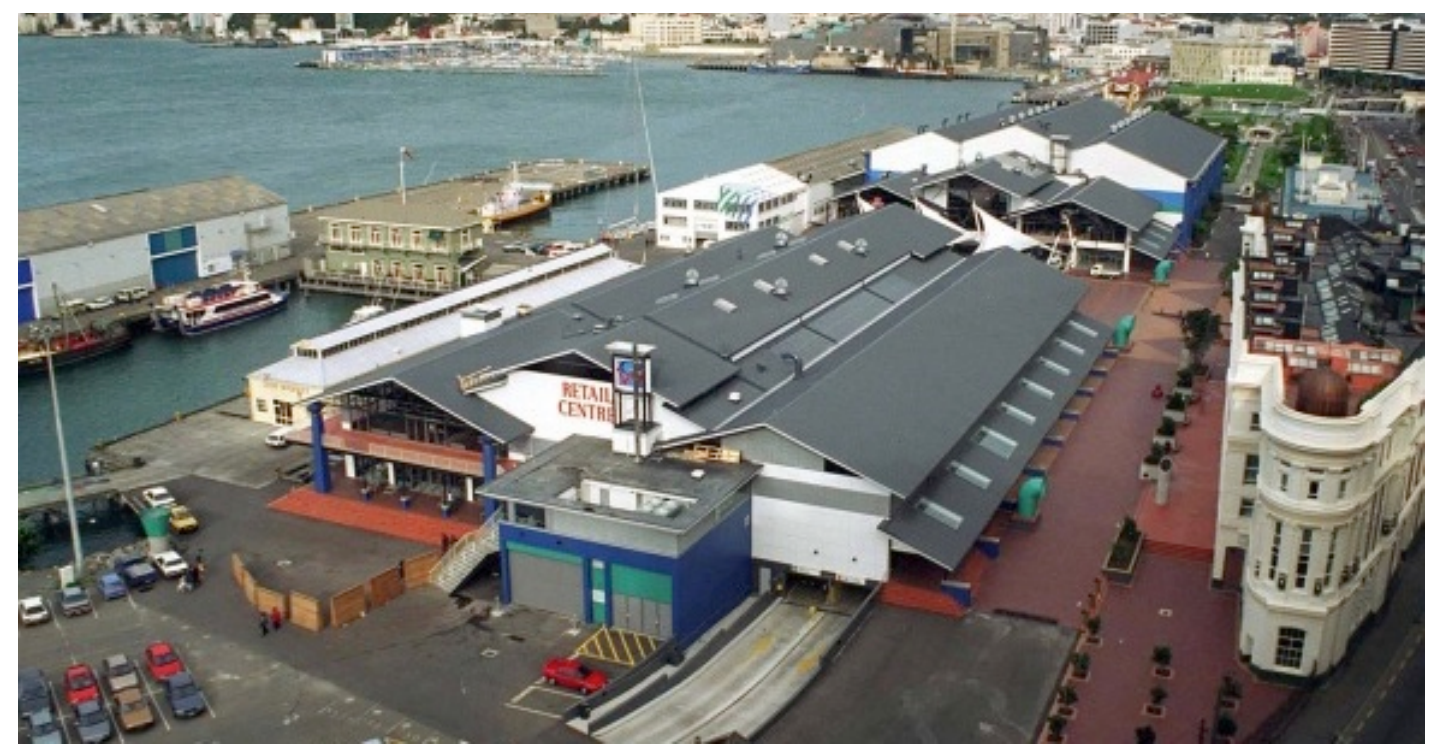

Figure 4.33. Queens Wharf Retail and Events Centre circa 1996. Shed one is on the far left, sheds three and five are immediately to the left of the Retail Centre and Queens Wharf Apartments to its right. The Events Centre is the grey roofed structure with the white façade above and to the right of the Retail Centre. (image: Fairfax Media)

The Retail Centre was designed to be an indoor shopping centre and was built on a 999 year site lease (Doorne, 1998). The design respected the intent for the ground floor of all buildings to be publicly accessible; however, only the edges facing the plaza included uses that actively engaged with the open space. Unfortunately, by 1998 the shopping centre had folded due to lack of customers and high vacancies (Cochran et al., 2012). The Retail Centre was subsequently sold and refitted to be an office space, with only the restaurants fronting the central plaza as public amenities (Willis \& Bond, 2011).

The Events Centre (renamed TSB Bank Arena in 2006) was built as an indoor venue for events and originally included seating for up to 3,635, but was refitted in 2005 to accommodate over 4,000 (Waterfront Information Centre, 2011). The lobby opened up onto Queens Wharf plaza along with restaurants, retail and, later, the New Zealand 
Olympic Committee Museum (from 1998 to 2013) occupying the plaza frontage. The rest of the building edges also failed to contribute actively to the adjacent public spaces, particularly the service entrances on the south side that face the children's playground in Frank Kitts Park.

Parking was included underneath the buildings and plaza; however, this pushed the plaza space up above the existing grades. This difference in levels interrupted the view of the harbour from the gates at the base of Queens Wharf, from Jervois Quay, and from Post Office Square.

\section{Chinese Garden}

In 1996 The Wellington Chinese Garden Society (WCGS) approached the WCC to collaborate on the construction of a Chinese garden (WDS, 2006, September 4 Report 4). As an outcome of this discussion, LHM signed a Memorandum of Understanding with WCGS, committing 3,000 sq.m. of waterfront land to the project (WDS, 2006, September 4 Report 4). The 1989 Combined Scheme did not allocate space for a project of this type; however, the concept was included in a new plan for the waterfront that was produced in 1997 and the 2001 Wellington Waterfront Framework (described in sections 4.6.2 and 4.7.2 respectively). Both plans included the Chinese garden as a part of a new park (to be called Waitangi Park) in the Chaffers area.

Later, the requirement for accommodating a Chinese garden was included in the 2002 design brief for the Waitangi Park competition and subsequent 2005 Waitangi Park Precinct design competition brief. Both of these projects accommodated public feedback; however, decisions on the location and form of the Chinese Garden did not accommodate the public input.

In the public consultation on the 2006/07 Development Plan, the WWL identified that a change of location for the Chinese Garden from the Waitangi Park Precinct had been requested by the Chinese community. Instead, the Chinese Garden was proposed to be included as a part of a planned redesign of Frank Kitts Park (WDS, 2006, June 26 Report 4). The primary concerns prompting a search for another location was the potential for delay resulting from the debate over proposed buildings in the Waitangi 
Park Precinct and technical issues with developing the garden over an underground car parking facility (WDS, 2006, September 4 Report 4). Subsequent public submissions on the Frank Kitts Park redesign and later annual waterfront development plans included opposition to moving the Chinese Garden from Waitangi Park (WDS, 2007, August 22 Report 4); however, response from WCC staff to the submissions noted the location for the Chinese Garden was not up for public debate at that point.

Planning and design of the Chinese Garden was suspended from 2008 to 2010 as construction of the garden was contingent on the Chinese Garden Society raising \$5 million at which point WWL would invest in the reconstruction of Frank Kitts Park (SPC, 2010, June 23 Report 2 Appendix 3).

Similar to the agreement for the hotel proposal for the outer-T of Queens Wharf, this project went through many planning iterations over several governance phases. Some of the phases provided opportunities for public comment on the form and location of the Chinese Garden; however, the commitment by LHM and processes used to make decisions about the project followed the top-down corporate model employed by LHM on many of its projects in this governance phase.

\subsubsection{Form and governance}

The global effects of the 1987 stock market crash in October of that year had a sobering effect on implementation of the commercially oriented 1989 Lambton Harbour Combined Scheme (Wellington Waterfront Framework, 2001). Economic capital was no longer readily available and as the redevelopment project was just getting underway there were no past profits to initiate development of the waterfront. The plans that were drafted and the projects that were built do, however, reflect the independent nature of LHM and the self-funding mandate.

The relatively large development sites identified in the 1989 Combined Scheme would have returned large developer contributions to pay for investments in public space. Additionally, the scope of the proposed development on the waterfront and comparatively few sizeable public spaces, prioritised financing over large public space amenity. The proposed large-scale projects included: the landmark tower north of Queens Wharf, the residential neighbourhood at the Chaffers site, and the proposed 
hotel and convention centre for Taranaki Street Wharf. The realised large-scale projects, however, included the Retail and Events Centre and an agreement for a hotel on the outer-T of Queens Wharf.

The protection of views was also influenced by the self-funding mandate, as the 1989 Combined Scheme included proposed developments that would have blocked views of the harbour from some streets. For example, the landmark tower, the hotel on the outer-T of Queens Wharf, and the hotel on Taranaki Street Wharf would have all impacted on views of the harbour.

The joint venture agreement and subsequent plans retained berths for large vessels and adjacent space for servicing them along the waterfront. Initially, this was a governance issue as the Harbour Board wanted to retain some port use; however, this may have transitioned into a design issue with the desire to retain active links to the area's past. The marina and maritime character of public space and the architecture of new buildings also reflected the perceived value of retaining maritime activity and contextual connections.

A desire to actively draw people down to the waterfront with events, rather than creating amenities that accommodated activities, also impacted the built form. For example, accommodating the Nissan 500 street car race was reflected in the form of Frank Kitts Park. The inclusion of the Retail and Events Centre on Queens Wharf was a significant attempt to create a destination.

Public art was introduced early on, prior to having a design for the public space. This investment in the public realm, as with LHM's response to the 1987 stock market crash, provided an upgraded public realm to serve as a public amenity and to give potential investors confidence that the waterfront would continue to attract other investment.

Lastly, the agreements for the museum, the hotel on the outer-T of Queens Wharf, and a Chinese Garden occurred prior to having a concept of how they would be integrated into the design of the waterfront. In each case, the agreements limited how LHM could integrate these ideas into future designs and, in the case of the museum, they had to surrender the design of the project and respond to it after the fact. 
Many of the individual projects proposed and built during this phase were also internally oriented or had limited engagement with the public realm. For example, the wall, gradient and layout of Frank Kitts Park does not utilise borrowed views, meaning it does not use its context to contribute to the experience of the space. The refurbishment and redevelopment of sheds three and five meant that although they are oriented to the water, they lack active edges on their other three sides. The national museum is oriented towards the city and does not engage adjacent waterfront areas with activity or provide a pedestrian scaled edge, there are few access points (except for a service entrance), and limited visual transparency. The Queens Wharf Retail and Events Centre buildings open up onto a central plaza; however, the remaining sides have limited to zero engagement with the surrounding public realm. When opened, the Retail Centre did have an entrance facing a surface car park seen in figure 4.33.

\subsubsection{Transition stimulus}

The opening of the Queens Wharf Retail and Events Centre in 1995 was a significant turning point for the waterfront. The completed project faced heavy criticism for its form and the 999 year lease that effectively privatised a portion of the waterfront. The project was also seen as a precursor for the scale and density of private developments proposed in the 1989 Combined Scheme and the lack of public engagement by LHM (Kernohan, 2011).

Public backlash to the Queens Wharf development led to further vocal concern over other parts of the 1989 Lambton Harbour Combined Scheme. Particular concern was raised about the construction of a hotel and convention centre on the site of the Odlins building, a dense residential neighbourhood in the Chaffers area, and a general concern over the ratio of private development and public space (Wellington Waterfront Framework, 2001). This groundswell of complaint led to the formation of a public interest group called Waterfront Watch organised by Lindsay Shelton and Helen Glasgow (Waterfront Watch, 2014). Waterfront Watch organised a petition in that same year protesting the intensity of private development planned for the waterfront (Waterfront Watch, 2014). The petition received 10,000 signatures, prompting LHM to hold a public forum about the future of the waterfront (Wellington Waterfront Framework, 2001; Buchan, 2011). 
The main thrust of Waterfront Watch's concern was to maximise open park space on the waterfront, protect and reuse the existing heritage structures, and stop the development of new and tall buildings (Waterfront Watch, 2014). The group claimed that multiple surveys showed public support for retaining the remaining open space for public use and strong opposition to any new buildings on the waterfront (Shelton, 2011).

At the public forum in 1996, over 800 attendees voted against the policies represented by the 1989 Lambton Harbour Combined Scheme (Wellington Waterfront Framework, 2001; Shelton, 2011). In response to the presentations and outcomes of the forum, Mayor Mark Blumsky announced a moratorium on waterfront development until a new plan and development process that was more responsive to public opinion was generated (Wellington Waterfront Framework, 2001).

\subsection{Phase 4 (1996 to 2000) WCC took control of the process and initiated a good- willed top-down consultative process}
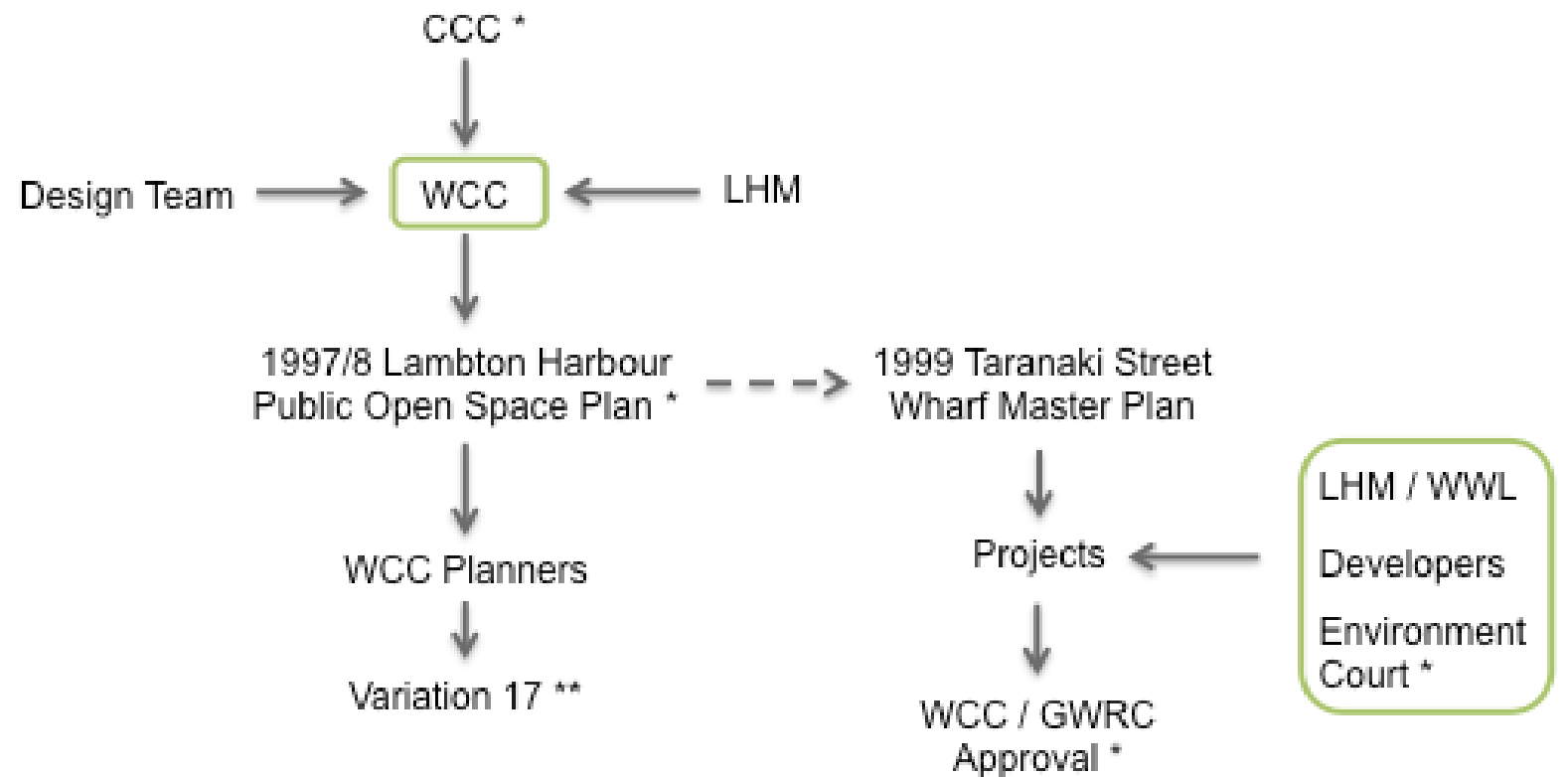

* Included consultation with the public and other stakeholders.

** Withdrawn by WCC due to public protests.

Figure 4.34. Diagram of the phase 4 governance arrangements. WCC took over the central decision making role to include more public consultation. Within the context of individual projects LHM, developers, and the Environment Court (for planning approvals that were challenged in court) became the central decision makers. 
A summary of the effects on the form of the waterfront included:

- a second large public park on the waterfront with buildings on the harbour side of it;

- fewer buildings and more public open spaces;

- no towers, but more buildings up to six storeys tall;

- Maori heritage included through installation of the Kupe group sculpture and allocation of a site for a wharewaka (shelter for the city's traditional ceremonial canoe);

- greater protection of views from the city to the harbour; and

- a greater variety of waterfront activities and ways of interacting with the water.

\subsubsection{Governance description}

Due to public dissatisfaction with the development plans for the waterfront, the WCC stepped in with a new governance process for identifying and prioritising values to guide the redevelopment. The WCC also imposed more oversight on the actions of LHM. For example, LHM could no longer authorise ground leases longer than 10 years for the development of new (i.e. non-heritage) buildings without WCC approval (SPC, 2005, November 9 Report 2).

In July 1996 the Community Consultative Committee (CCC) was established by the WCC with the mandate to review the development plans, poll public opinion, consult with stakeholders, and report back to the city council with recommendations on how the project should proceed (Shelton, 2011; Wellington Waterfront Framework, 2001). This committee was comprised of community and business representatives and was chaired by the chair of Wellington Civic Trust (Buchan, 2006; Wellington Waterfront Framework, 2001).

The CCC report, issued in November 1996, outlined 102 recommendations emphasising that the waterfront was valued as a recreation space and suggesting that the design of public space should take precedence over building design (Wellington 
Waterfront Framework, 2001; Shelton, 2011). The themes identified in the report included (Design Team, 1997):

1. The promenade was to be a key public space along the water's edge.

2. New buildings were to be innovative and respond to the scale and aesthetic of their context.

3. Old buildings were to be refurbished and creatively used.

4. More quality public space for the waterfront redevelopment, with more public green space and considerations of local ecology.

5. A network of pedestrian routes needed to be developed that incorporated different ways of engaging with the water.

6. The redevelopment was to accommodate a range of activities, uses, and be creative with development opportunities.

7. Design of buildings and public spaces was to be of a high quality.

8. All developments should maximise use of the site and their contribution to the waterfront.

9. Planning of the waterfront was to be visionary.

10. No surface parking; instead, all parking should be in underground parking facilities.

From November 1996 to July 1997, WCC, CCC, and LHM looked at different funding options as the development intensity represented in the 1989 plan was based upon a self-funding model of development. In responding to calls for less intense development and more public space, these three groups identified three possible development scenarios (Hastings \& Young, 1997):

1. A self-funding option that was associated with the more intense, commercially oriented development approach.

2. A LHM preferred option that eliminated large towers and reduced density in some areas, but retained a commercially oriented development approach.

3. A balance between commercial development and public amenity. This included more parks and public open space partially funded by the WCC, no landmark towers, and incremental development over a longer time frame. 
A survey was commissioned by the WCC in July 1997 to poll residents on their preferred funding model as it related to likely built form outcomes associated with these (Hastings \& Young, 1997). The poll identified 56\% of the 286 respondents preferred option three. Those who preferred the other options identified cost effectiveness and having a deadline for completion as important (Hastings and Young, 1997). This effectively meant the end of the mandate for the project to be selffunding; however, it does not appear that this decision was formally made but rather became a point of ongoing debate. Development plans produced by Wellington Waterfront Limited (the successor to LHM) in late 2000s clearly stated there remained a preference for a self-funding approach (e.g. WDS, 2006, May 8 Report 2 Appendix 1; SPC, 2010, April 15 Report 1 Appendix 1); however, some funding was provided by the WCC to support the management of the project and public space development.

Public interest in the balance of public amenity and private development on the waterfront resulted in the formation of a second public advocacy group, called “Chaffers Park: Make it Happen”, in July 1997 (Shelton, 2011). While Waterfront Watch had the same position on preferring open space over low rise residential development, Chaffers Park: Make it Happen was formed to lobby exclusively for open public space on what eventually became Waitangi Park. This demonstrates there was considerable interest in that particular portion of the waterfront and in providing more public open space on the waterfront.

As illustrated in figure 4.34, the WCC and its planning staff played a central role in decision making during this phase. The CCC consultation efforts identified what the public valued; however, the CCC was a WCC initiative. That report was subsequently used to direct the design of a new waterfront plan, commissioned by the WCC. This new plan, described below, was subsequently revised by WCC staff, however, demonstrating the central role the WCC played in making decisions about the form of the waterfront in this phase. Lobbying by public interest groups did indicate a preference for certain values; however, how these values influenced the design of the waterfront was filtered by the WCC, GWRC, and the Environment Court through the planning approvals process. 


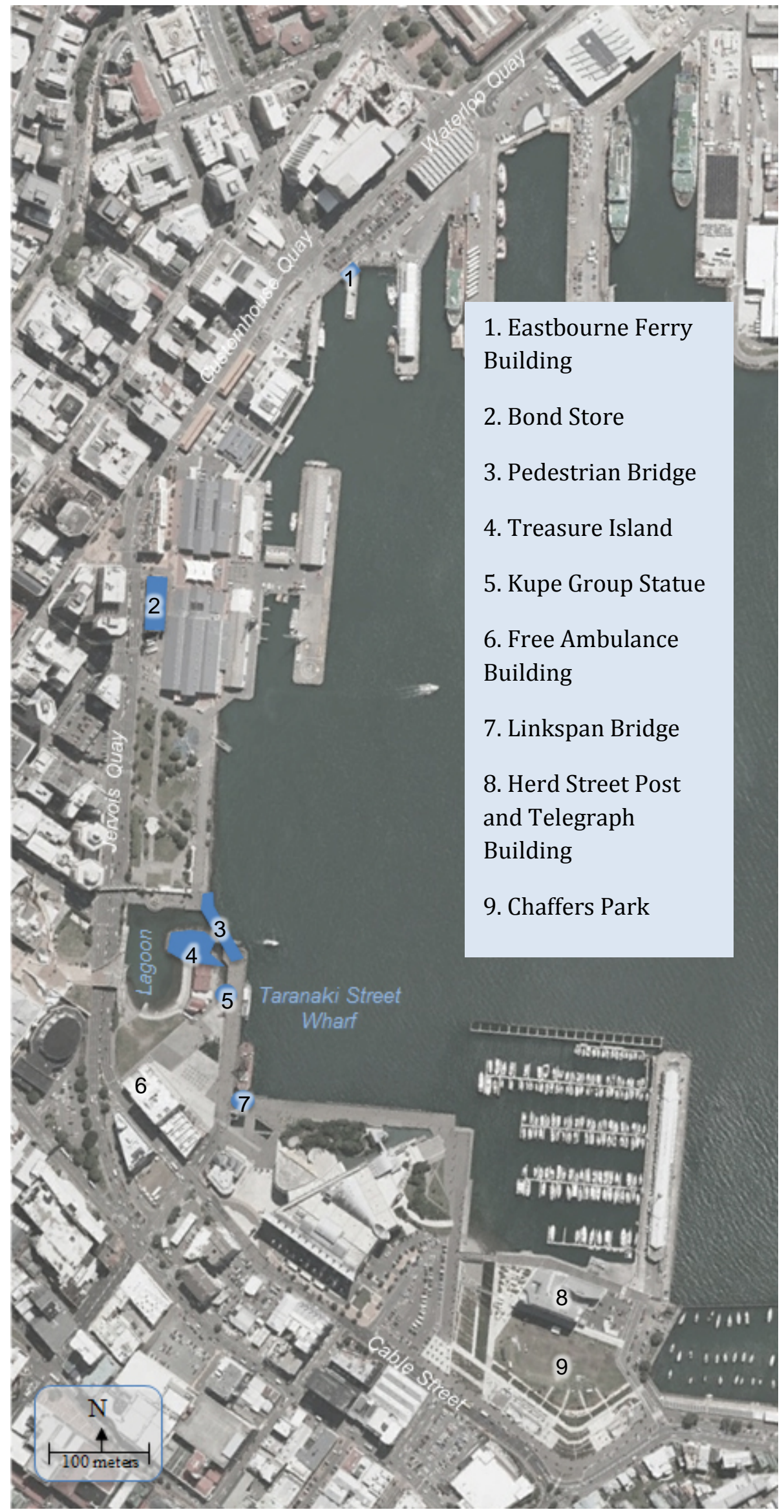

Figure 4.35. Location map of phase four projects and features. Blue polygons identify constructed projects. Features with only numbers are referenced in the text (base image: Google Earth, accessed November. 2015). 
1997 and 1998 Lambton Harbour Open Space Master Plans
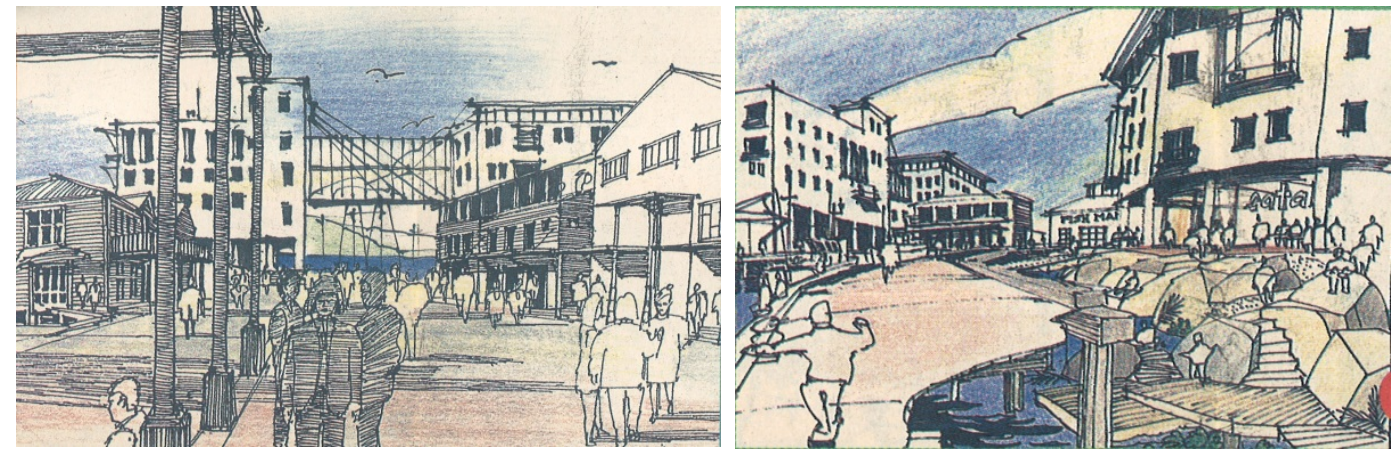

Figure 4.36 and 4.37. Queens Wharf vignettes from the 1997 Lambton Harbour Open Space Master Plan (images: Design Team, 1997).

Following the results of the survey on the funding options, in September 1997 WCC commissioned a multi-disciplinary team of designers, iwi representatives, and development consultants to draft a new waterfront plan that emphasised public space along the waterfront (Design Team, 1997; Wellington Waterfront Framework, 2001). The initial plan, entitled Lambton Harbour Open Space Master Plan, was presented to the public for feedback in October 1997. The plan included four options for the Chaffers area (see figure 4.38): green space, development on the seaward or city side of a park, or a smaller park with development on both the seaward and city sides.

The CCC surveyed residents and waterfront stakeholders on the Open Space Master Plan and reported back to WCC in December 1997 (Wellington Waterfront Framework, 2001). There was some dispute, however, whether the CCC had only consulted with members of organisations represented on the CCC or had provided adequate public consultation (Shelton, 2011). Following the report, the CCC was dissolved (Wellington Waterfront Framework, 2001).

Upon review of the plan and of public feedback, the 1997 public space plan was revised to better align with the CCC's recommendations. This revised plan, along with the Chaffers Park option that included buildings only along Cable Street was adopted by WCC in March 1998 (Wellington Waterfront Framework, 2001). A subsequent technical study advised against moving the Herd Street Post and Telegraph building, necessary to implement the chosen Chaffers Park option; therefore, the council decided to retain the Herd St. building and allow buildings to be 
built adjacent to it on the seaward side of Chaffers Park (Wellington Waterfront

Framework, 2001).

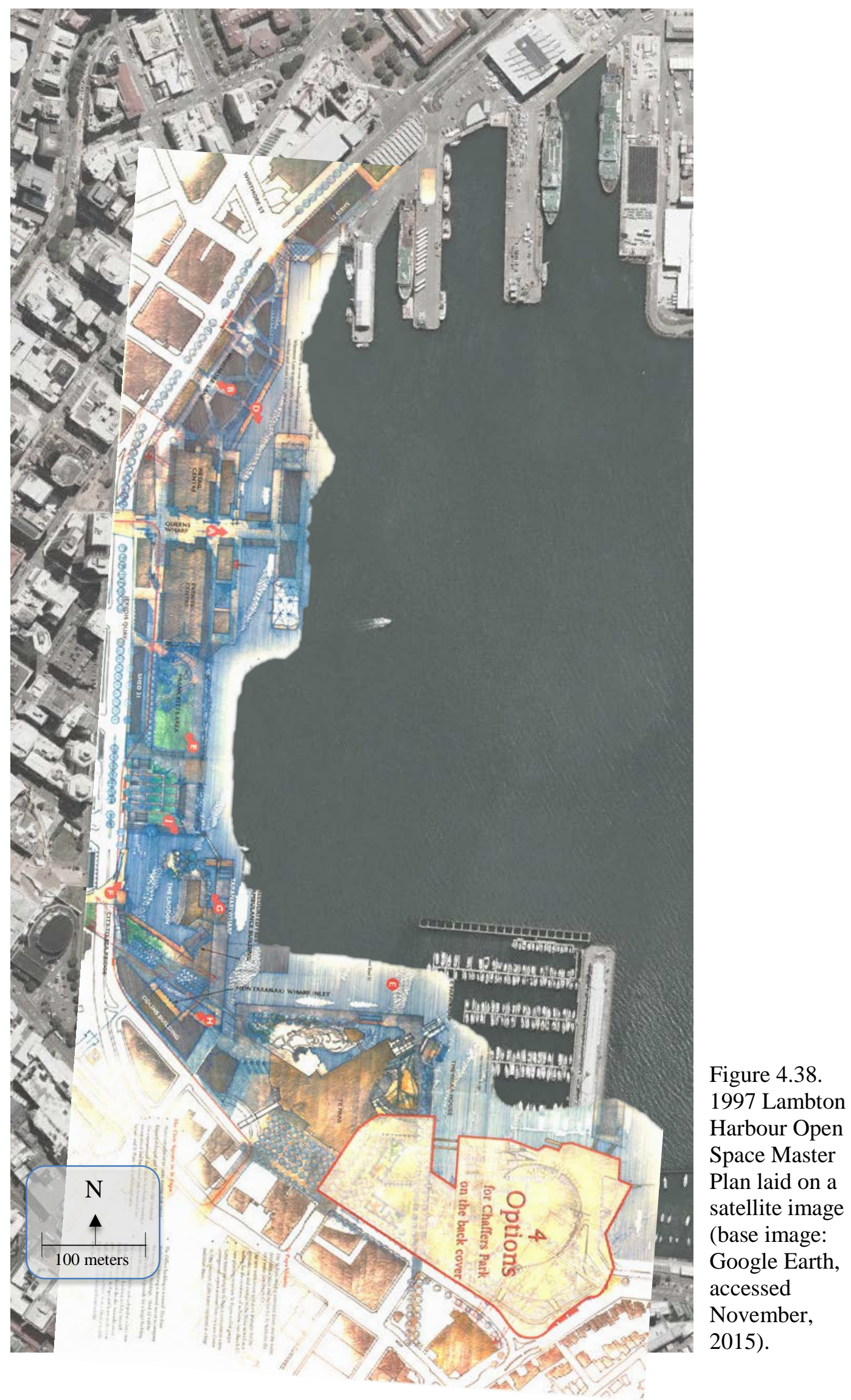


In March 1999, a Community Advisory Group was formed by the WCC to continue to consult with the public on the 1998 plan; however, it was suggested by Waterfront Watch they were told not to criticise the waterfront planning process (Shelton, 2011).

The plan was described as a "necklace of open spaces and a choice of pathways" with buildings used to define these spaces (Design Team, 1997; Shelton, 2011). It included many public spaces and amenities distributed along the waterfront, including cut-outs in several of the wharves to open up the public space to the water below, inclusion of a wharewaka to house the city's ceremonial waka (traditional canoe), and the accommodation of a wider range of activities than in previous plans (see figures 4.36 and 4.37). New buildings proposed in the plan were generally shorter than in the 1989 Combined Scheme. These were arranged to protect and frame views, used to define public spaces, and provide activities on the ground floor that engaged adjacent public spaces. However, while there were no towers, figures 4.36 and 4.37 show there were more buildings proposed for the area around Queens Wharf, each between four and six storeys in height.

\section{Variation 17}

The WCC planning department drafted the statutory rules to guide the implementation of the approved Open Space Master Plan in 1999, and released them for public review as Variation 17 (Wellington Waterfront Framework, 2001). At this point, the 1989 Combined Scheme was still the operational statutory planning and design framework for the waterfront. The proposed $17^{\text {th }}$ variation to the city's district plan replaced the 1989 plan with one that reflected the new approach to planning and design of the waterfront redevelopment. The resulting draft, however, did not fully respond to the CCC's recommendations due to "a breakdown in the design management and communication process” (Wellington Waterfront Framework, 2001, p. 9). The plan identified building and open space sites, along with maximum height limits; however, as shown in figure 4.39 the result was perceived to include a higher density of development than was recommended by the CCC (Waterfront Watch, 1999). 


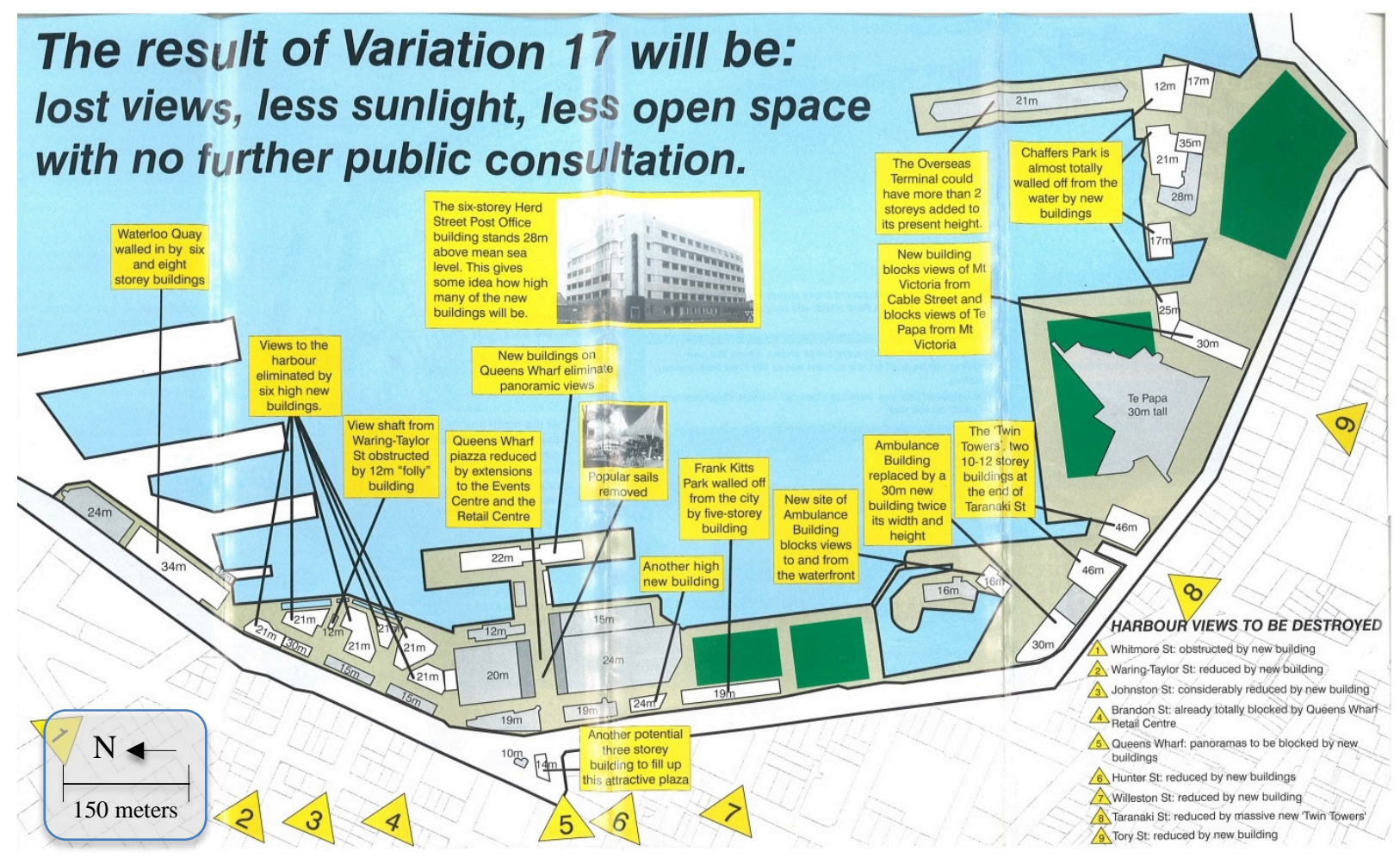

Figure 4.39. Waterfront Watch's critique of the design guidance offered by Variation 17. (image: Waterfront Watch, 1999)

As an example of the disconnect between Variation 17 and the 1998 Open Space Master Plan, a review of its application to the Kumutoto (North Queens Wharf) area in 2008 noted Variation 17 showed heights of 30m in an area adjacent to Shed 13 when the 1998 plan identified a stepping down of height to $21 \mathrm{~m}$ to relate better to the heritage structure (SPC, 2008, December 4 Report 1 Appendix 1 Attachment 1).

1999 Bond Store

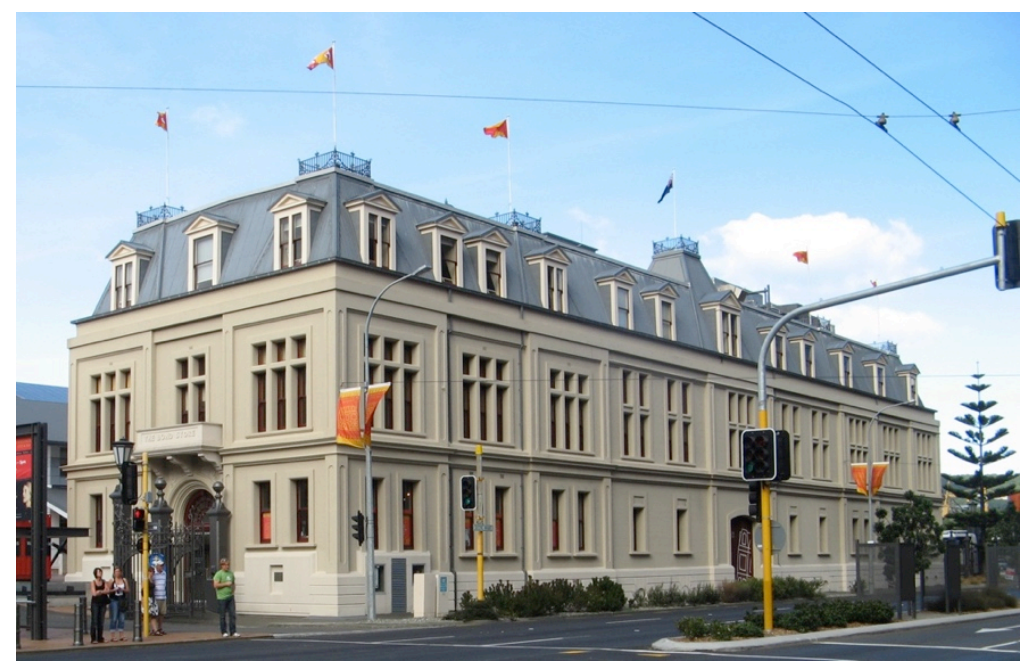

Figure 4.40. The Bond

Store. (image: Wikimedia Commons) 
In 1999 the Bond Store, located at the base of Queens Wharf, was refurbished and structurally reinforced to newer earthquake standards. Originally built in 1892 for warehouse and Wellington Harbour Board office space, a portion was used to house the Wellington Maritime Museum that opened in 1972. Following the 1999 upgrades, it became home to the Museum of Wellington City and Sea (Heritage New Zealand, 2015a).

Like many of the other refurbished sheds and older buildings on the waterfront, this project was uncontroversial as it met the ongoing desire to retain and reuse these heritage buildings identified in early plans and reinforced by the CCC's findings. Because this, and other projects like it, did not substantially change the form of the building, little to no consultation occurred and the project was handled by LHM.

1999 Eastbourne Ferry Terminal

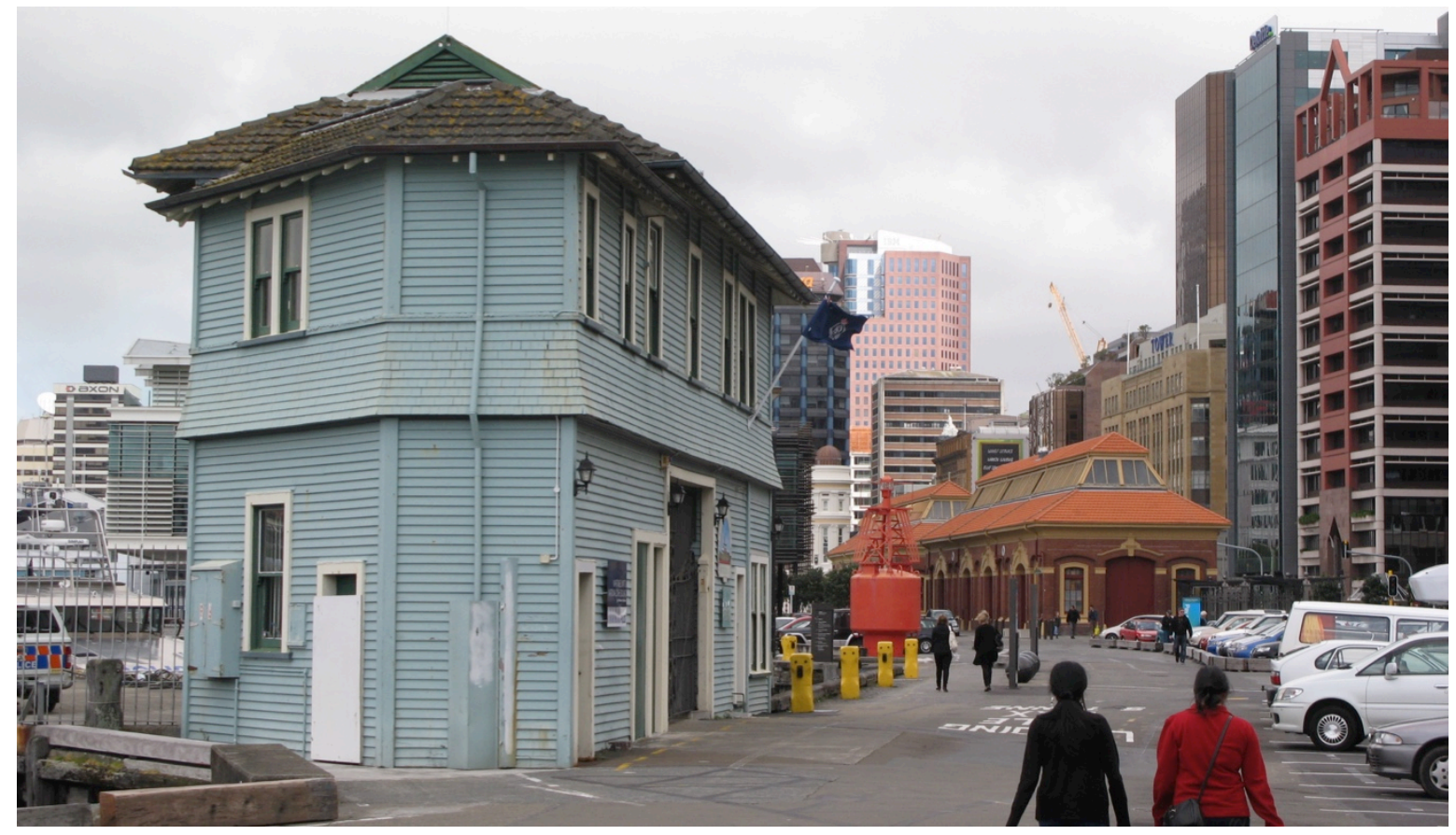

Figure 4.41. The Eastbourne Ferry Terminal with sheds 11 and 13 in the background. (image: author)

The old Eastbourne Ferry Terminal, built in 1912, was similarly refurbished by LHM. It was occupied by a variety of commercial tenants prior to it becoming the headquarters for the Police Maritime Unit and National Dive Squad in 2009 (Cochran et al., 2012). 


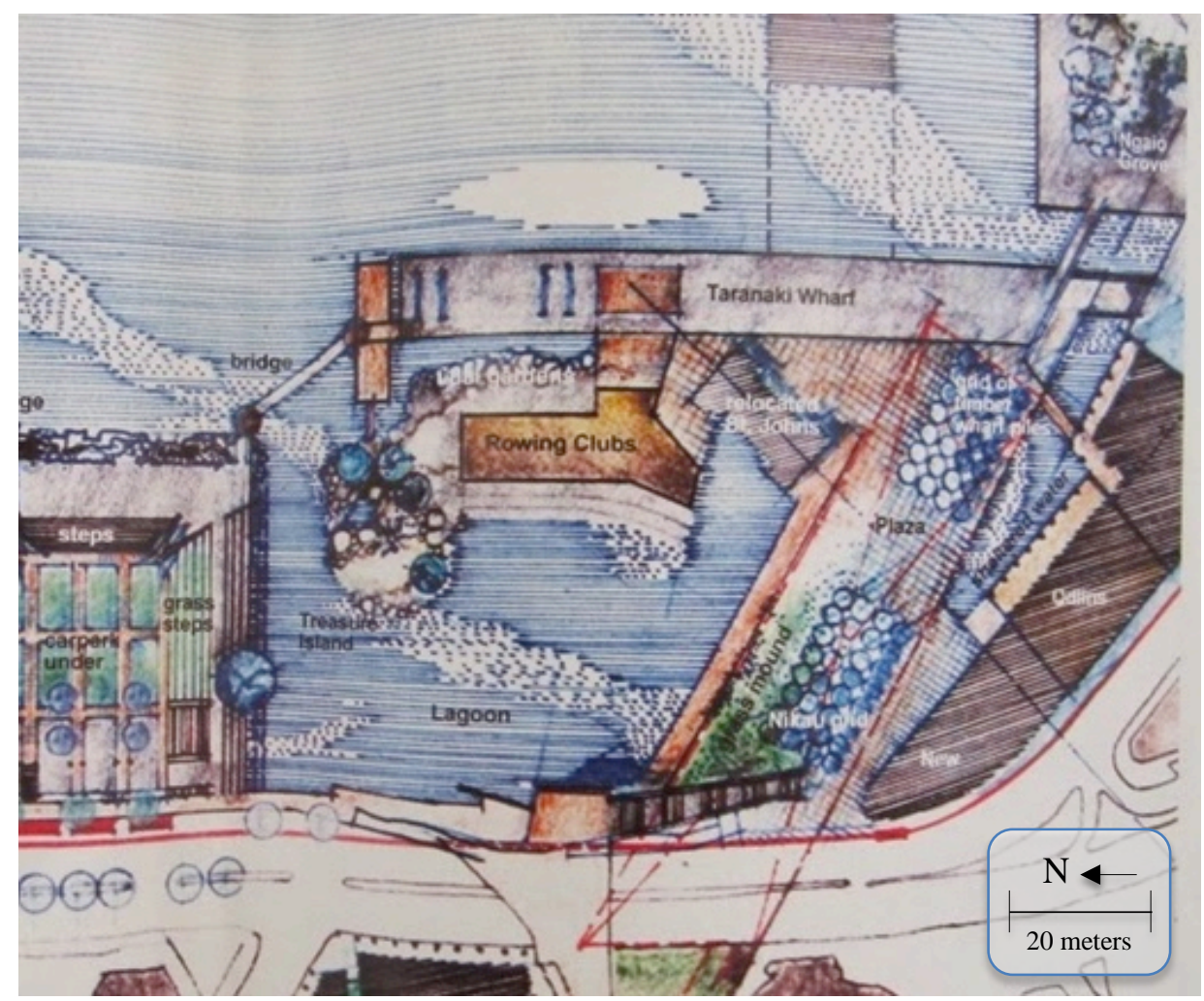

Figure 4.42. Portion of 1998 Open Space Master Plan showing Taranaki Street Wharf. (image: Design team, 1998)

In 1999 LHM received planning approval for redevelopment of public space on the Taranaki Street Wharf. The plans were based on the 1998 Open Space Master Plan (shown in figure 4.42) and incorporated underground parking, a new bridge across the mouth of the lagoon, new landscaping adjacent to the Star Boating Club building, cut outs in the wharf to expose the water underneath, and a new pedestrian bridge that was to reflect the character of the former linkspan bridge that was used for roll-on, roll-off cargo handling. According to Environment Court records, LHM wished to move the Free Ambulance Building, built in 1930, to accommodate underground parking (2001); however, this was successfully challenged by Waterfront Watch (Shelton, 2011).

The Environment Court favoured Waterfront Watch's argument, supported by the Civic Trust and the New Zealand Historic Places Trust, regarding the heritage and urban design value of retaining the heritage listed building in its existing location, fronting on to Cable Street (Environment Court, 2001). While the Free Ambulance 
Building was retained, other aspects of the public space development went ahead and were completed by 2002. For example, the lagoon bridge and landscaping of the adjacent “Treasure Island” were completed in 2000 (STQRY, 2015a).

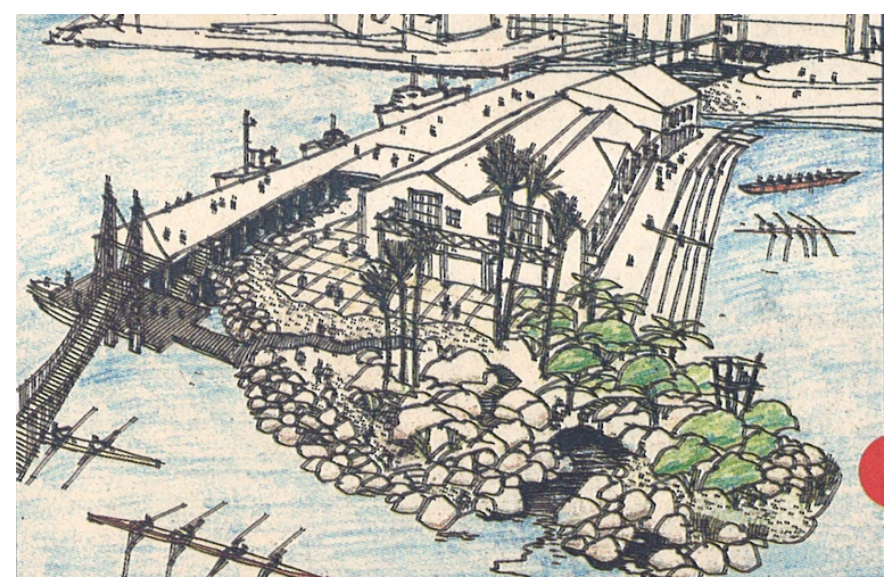

Figure 4.43. Vignette from 1998 Open Space Master Plan showing the Star Boating club building and Taranaki Street Wharf (image: Design Team, 1998).

The landscape design, shown in figures 4.42 and 4.43, included some of the large maritime artefacts that dot the length of the waterfront. The use of maritime artefacts reflects the original, and persistent, values of reflecting the maritime location and heritage of the site.

\section{Kupe Group Statue}

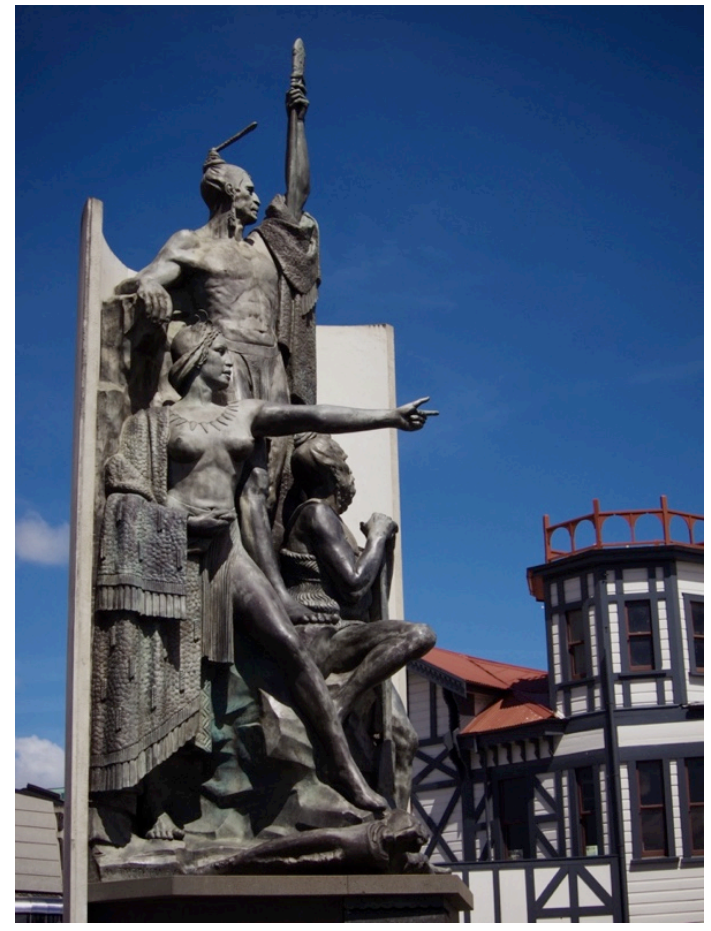

Figure 4.44. Kupe group statue. (image: Paul Lloyd, Wikimedia Commons)

On the Taranaki Street wharf, a cast version of the Kupe group statue was installed in March, 2000 (Harper \& Lister, 2007). The original plaster version was made in 1940 
for the NZ Centennial Exhibition held in the Wellington suburb of Rongotai. The version installed on the waterfront was cast in bronze and memorialises the Maori explorers Kupe Raiatea, his wife Te Aparangi, and tohunga Pekahourangi who discovered the Wellington harbour (Wellington Sculptures, 2011). While infilling has pushed the shoreline out into the harbour, the location of the statue and the concept of including a wharewaka nearby in the 1997 Public Spaces Concept Plan recognised traditional use of this part of the harbour for landing Maori waka.

\subsubsection{Form and governance}

As a response to public outcry over the intended form and development approach represented by the 1989 Combined Scheme, the WCC temporarily halted the redevelopment project and set up a consultation process. The consultation stages included compiling public values regarding the future of waterfront, feedback on the 1997 waterfront plan, feedback on funding options for implementing the waterfront, and feedback on the revised 1998 waterfront plan.

From the consultation effort and a new perspective that the development did not need to be completely self-funding, the new 1998 plan for the waterfront included: a new public park in the Chaffers area, the need for public open space to be designed before or in parallel with new building projects, public space projects that included a wider range of public amenities and potential uses, greater protection of key view sheds, and new buildings that reflected the scale and context of the waterfront. A combination of public pressure and city funding enabled development plans to be scaled down; however, the contrasting opinions about development intensity, the role of buildings in defining public space, and building heights remained due to the way public values were filtered through the top-down decision making.

The 1998 plan was translated into Variation 17 by planning staff and a design for Taranaki Street Wharf by LHM. Both initiatives were successfully challenged by Waterfront Watch. One of the major ideas from the initial public consultation was to design the public space first, but this was translated into rules around building envelopes and land use requirements in the production of Variation 17 with the 1998 plan incorporated as the design guide for the public space. It was acknowledged that the public space design would be revisited as development in the different parts of the 
waterfront evolved; however, some members of the public took exception to the fact the designated maximum building envelopes would allow buildings up to six storeys without public consultation.

The Taranaki Street Wharf open space plan adopted and implemented many of the ideas for the area outlined in the 1998 plan; however, Waterfront Watch successfully challenged the proposal to move the Free Ambulance Building to make way for an underground parking facility. Stopping this project altered the way the spaces of the lagoon and Taranaki Street Wharf were defined and the provision of parking along the waterfront. Conversely, restoration of two heritage buildings, public space upgrades reflecting the maritime history, and installation of a monument to the Maori history of the area, went ahead uncontested. The values these moves represented were widely held; therefore, the form they took was more open to interpretation.

\subsubsection{Transition stimulus}

Variation 17 was released for public review in October 1999 and met with heavy criticism. Some submitters claimed the city was ignoring public opinion and planning to sacrifice public space for private development (Wellington Waterfront Framework, 2001). To this end, Waterfront Watch distributed material as a part of an ultimately successful campaign to "Stop the Wall” (see figure 4.39).

The WCC and LHM contended that Waterfront Watch was fearmongering and Variation 17 did not actually allow the built form to be built out to the extent shown in Waterfront Watch's literature; however, the damage was done (Wellington Waterfront Framework, 2001, p. 9). Arguably, the city did not provide enough information regarding the intended form of the built environment under Variation 17, which allowed Waterfront Watch to adopt a leadership role in shaping the public discussion during the public consultation phase.

As a part of their campaign, Waterfront Watch organised a public meeting to protest against Variation 17 in February, 2000. The meeting attracted 2000 residents who opposed plans to add new buildings to the waterfront and supported provision of more public open space (Shelton, 2011). The council extended the deadline for submissions due to public pressure and by 7 February, 2000, the city received an unprecedented 
2,500 submissions, 94\% of which opposed Variation 17 in whole or in part

(Wellington Waterfront Framework, 2001). The council withdrew Variation 17 two months later and began exploring ideas for a new waterfront planning process (Wellington Waterfront Framework, 2001).

\subsection{Phase 5 governance (2000 to 2001) - Integrated decision making}

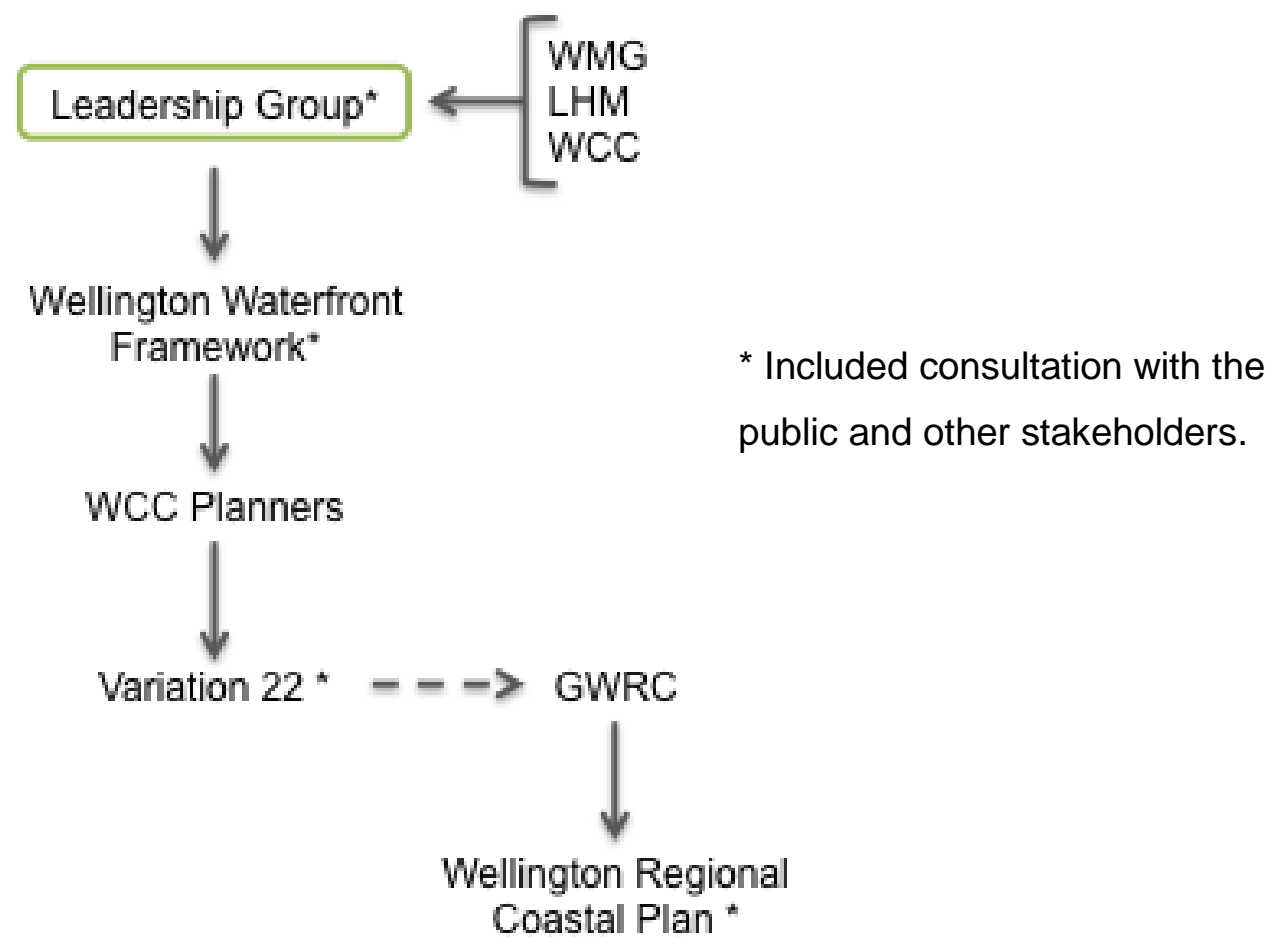

Figure 4.45. Diagram of phase 5 governance arrangements. Unlike the previous phase where the CCC was a public engagement exercise to identify the public's values, the Leadership Group was delegated the decision making role for producing a design framework. In this arrangement the WCC was involved, but did not have final decision making authority.

A summary of the effects on the form of the waterfront included:

- fewer building sites for new buildings with a minimum of $66 \%$ of the waterfront area to be public open space;

- greater emphasis on new buildings to be in scale with nearby waterfront heritage buildings;

- greater emphasis on contextual designs for the different parts of the waterfront to reflect the heritage of the waterfront; and 
- lack of direction on whether buildings should edge Waitangi Park or provide a transition in scale from Te Papa. The lack of direction prolonged debate on what was appropriate for this area.

\subsubsection{Governance description}

To find a way forward for waterfront planning following the demise of Variation 17, city staff consulted with community groups and individuals whom had been active in the planning process (Wellington Waterfront Framework, 2001). The process that evolved from this round of consultation included three phases: establishment of a guiding framework for the entire waterfront project; generation of detailed performance briefs for the five waterfront precincts based on the framework principles; and, implementation of individual projects, guided by the framework and performance briefs (Wellington Waterfront Framework, 2001; Kernohan, 2011). The implementation of the first phase is illustrated in figure 4.45 with a committee of stakeholder representatives tasked with drafting the design framework based on input from the public, the WCC, LHM, and an advisory design committee.

This was another wave of community engagement but one that was more inclusive than previous exercises as the community stakeholder group that drafted the guiding framework, the Leadership Group, had a direct voice in its production. This input was direct, informed by an extensive public engagement process, and not filtered by city staff or development consultants as in the previous governance phase.

To draft the guiding framework, a ten member working group was appointed in September 2000 (Wellington Waterfront Framework, 2001). The Leadership Group, as it was identified, consisted of three city councillors, a co-founder of Waterfront Watch, a director from LHM, the chair of Wellington Civic Trust, two representatives of local iwi interests, the head of the Victoria University of Wellington School of Design, and the president of the Newtown Residents Association. A communications and mediation consultant was the facilitator, and the chair of the Leadership Group was the Chief Operating Officer from WCC. To provide design advice and feedback on planning strategies for the Leadership Group, an independent six member Waterfront Monitoring Group (WMG) was also appointed by the WCC (Wellington 
Waterfront Framework, 2001; Urban Perspectives Ltd., 2014). The WMG membership included professional urban designers and planners.

The Leadership Group process was designed to be inclusive by allowing public attendance at all 23 meetings, and encouraging submissions and presentations by interested parties. Progress reports were published and distributed online and via direct mail upon request, through publication of eight newsletters, inclusion of a supplement in the WCC's household mail out, and regular media coverage (Wellington Waterfront Framework, 2001). The process attracted 170 submissions, 64 presentations by members of the public, and 32 reports from consultants and advisors (SPC, 2011, September 8 Report 4). 


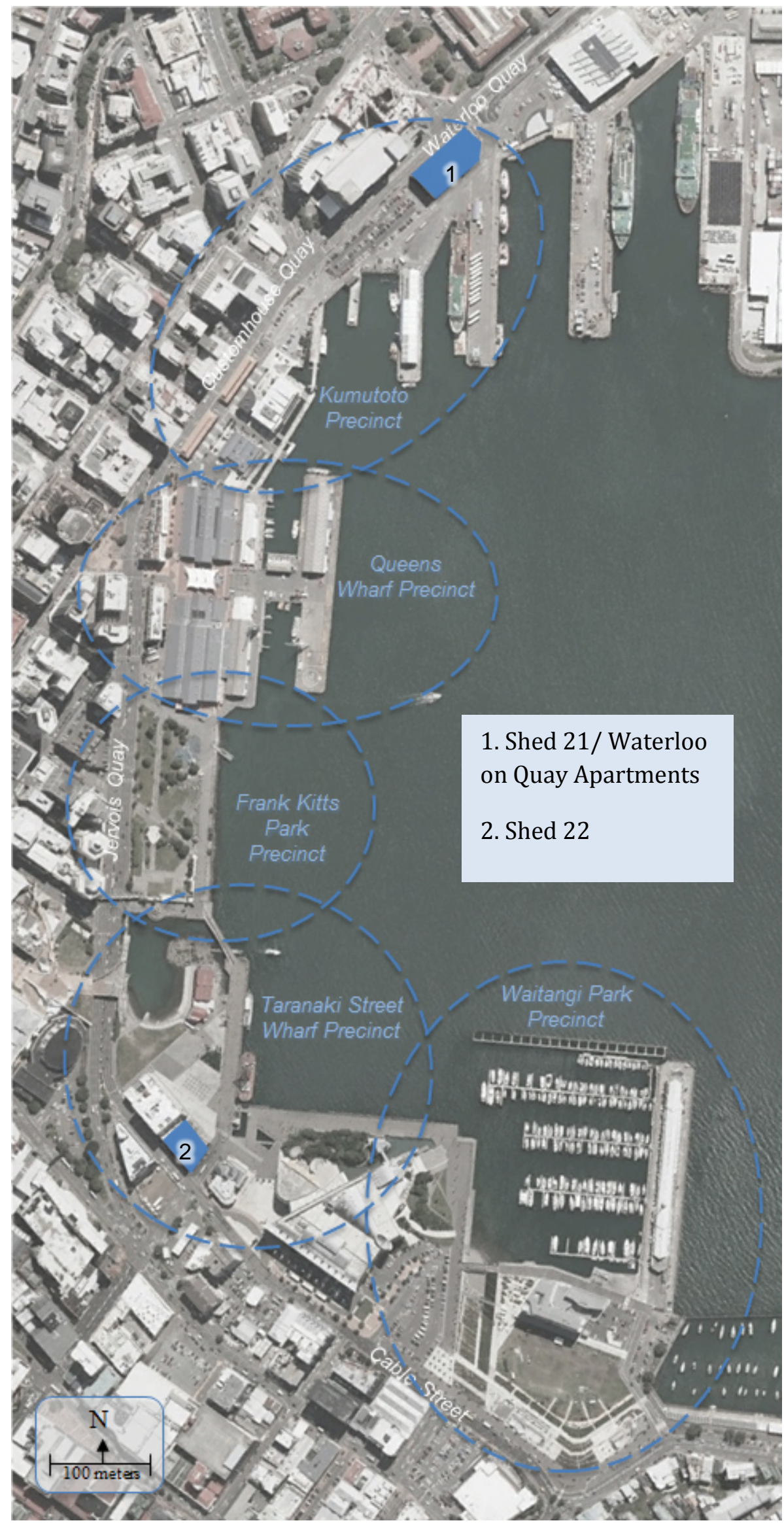

Figure 4.46. Location map of phase five projects and features. Blue polygons identify constructed projects. (base image: Google Earth, accessed November, 2015). 
The Wellington Waterfront Framework was the major product of the Leadership Group’s efforts. The document, accepted by council in April 2001, was not written as a statutory planning or design tool. Instead, it was identified as a strategy to outline a vision for the waterfront, complete with guiding themes, values, principles, and specific ideas for the future of five sub-areas that comprised the waterfront development area (Wellington Waterfront Framework, 2001).

The Waterfront Framework establishes six governance principles and a suggested governance format that reflects these. The six principles are:

1. Transparency of the process to public oversight.

2. Public engagement as an ongoing effort to inform decision making, rather than in response to controversial plans and projects. The Leadership Group identified the events surrounding the construction of the Queens Wharf Retail and Events Centre and release of Variation 17 as times when the city and LHM acted without sufficient public engagement in the planning and implementation (Wellington Waterfront Framework, 2001, p. 41).

3. Momentum. The recommended process needed to be adopted quickly to show the city's confidence in the Leadership Group’s efforts.

4. Separation of planning and implementation to ensure the planning was done in a transparent fashion and allowed for the implementation entity to focus on the commercial and financial aspects of the project. It was argued these two aspects required different management styles and separating them would improve delivery of the two roles.

5. Separation of planning and implementation from council's regular duties. “Arm’s length governance” would ensure politics could not interfere substantially with the redevelopment effort.

6. Continuing accountability of the council for the project and the actions of the planning and implementation entities, as the redevelopment was no longer intended to be fully self-funding.

The recommended governance format identified in the Waterfront Framework separated planning, strategy, and approvals from implementation and management. A ‘Waterfront Development Group’ was to be developed to undertake detailed planning and design for each area, identified as stage two of this process, with substantial 
public consultation and to monitor the implementation. The proposed Development Group was to include professionals and members from the community.

On the topic of public consultation, the Leadership Group advised new buildings and major changes to existing structures were to require notified consent to allow the public and interested stakeholders to offer comment (Wellington Waterfront Framework, 2001, p. 44). This policy meant the public would have the opportunity to comment on the drafting of the performance briefs for the sub-areas along the waterfront, on the design of the individual projects prior to them receiving planning consent, and to challenge any performance brief or planning consent awarded to any project through the Environment Court - the planning appeal body as identified under the Resource Management Act (1991).

Second, a "Waterfront Implementation Agency” would be tasked with implementation of the approved plans and designs through managing the business side of working with developers and maintaining the waterfront. Referred to as a LATE (local area trading enterprise) in figure 4.47, it would have a board of directors, similar to the existing Lambton Harbour Management Ltd., to advise on commercial matters.

Wellington City Council

- Approves waterfront policy

- Approves work plan and budget

- Monitors both entities

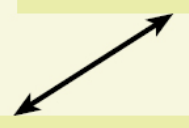

Waterfront Development

\section{Group}

(Membership includes

professional and

community representatives)

- Prepares development plan

- Runs public engagement process

- Prepares performance briefs for design work

- Monitors delivery of plans to brief (including sign-off of design plans)

- Monitors implementation of plans.

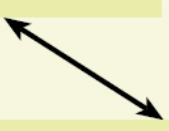

Waterfront Implementation Agency

(LATE structure. Board has commercial expertise)

- Implements performance briefs, including engaging designers to do detailed plans based on performance briefs

- Day-to-day operational management of the waterfront

- Point of contact for potential developers.
Figure 4.47. Governance structure recommended by the Leadership Group. (diagram: Wellington Waterfront Framework, 2001, p. 43) 
In accordance with principles five and six identified above, the WCC would make the final decisions on waterfront policy, based on advice from the "Waterfront Development Group”; sign-off work plans and budgets; and monitor the work of the two organisations (Wellington Waterfront Framework, 2001, p. 43).

Under this structure, Lambton Harbour Management would no longer undertake both strategic planning and manage the physical development of the projects. This was a deliberate effort to formalise a consistently inclusive planning and design process to avoid the cyclical top-down and bottom-up nature of past planning and development on the waterfront.

To ensure the intended form and uses of the five identified waterfront sub-areas described in the Waterfront Framework were followed, the document recommended writing a variation to the Wellington District Plan to include the recommendations of the Waterfront Framework. This would replace the existing transitional District Plan for the area (i.e. the Lambton Harbour Combined Planning Scheme and Concept Plan) which was now out of synchronisation with public opinion over the waterfront's future (Wellington Waterfront Framework, 2001, p. 44).

A further planning matter addressed the portions of the wharves that were seaward of the mean high water line. Under the RMA (1991, section 64) these parts of the redevelopment area fell under the jurisdiction of the Greater Wellington Regional Council (GWRC). The Leadership Group noted, in the Waterfront Framework, that the GWRC would revise the Coastal Plan to reflect the proposed WCC variation to the District Plan.

Notably, the Waterfront Framework did not include plans detailing the design of the waterfront. Instead, it identified the guiding values and principles that were to be addressed generally across the whole waterfront and gave specific guidance on issues and ideas unique to each of the five precincts. For example, the overall redevelopment project was to reflect the maritime heritage of the waterfront, including pre-European Maori settlement and use of the harbour. For North Queens Wharf, future design work was to observe the maritime character and accommodate continued use by fishing and recreational boats. In comparison, future work on Taranaki Street Wharf was to 
accommodate a wharewaka (a shelter for traditional Maori canoes) and opportunities for other Maori cultural activities due to its proximity to a historic Maori settlement, Te Aro pa, and the current site of the Te Papa marae (meeting house for local iwi).

Other guidance for the overall form of the waterfront included:

- listing of buildings to be refurbished and repurposed;

- prioritising an 'urban' landscape over a naturalised one, while still acknowledging Wellington's coastal ecologies through the choice of planting and paving materials;

- including public art, crafts, and performance spaces;

- providing a range of connections with the city;

- providing protection from inclement weather through the design of the landscape and buildings;

- $\quad$ enabling access to the water;

- providing a promenade along the length of the water's edge and other forms of public open space;

- providing natural surveillance through the planning and design of the waterfront;

- providing clear signage and lighting to aid navigation and improve safety;

- reducing surface car parking and restricting vehicle access;

- $\quad$ ensuring buildings engage adjacent public space and incorporate publicly accessible ground floor uses;

- $\quad$ ensuring buildings were in scale with nearby buildings and public spaces with details that related to the scale of the pedestrian; and

- providing a range of uses and visual interest along the waterfront while fitting in with its character.

Guidance for the individual areas provided more direction of contextual issues and how these were to be responded to in relation to the list above. 


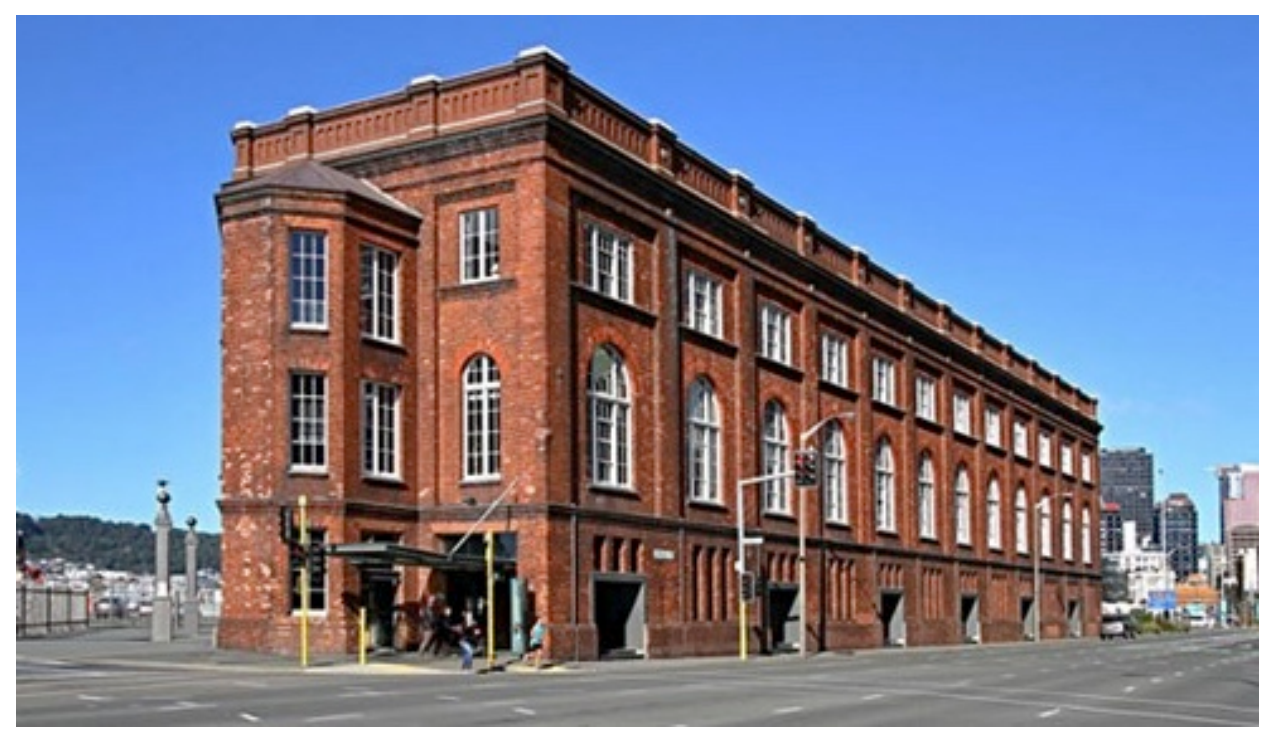

Figure 4.48. Shed 21. (image: Paul Le Roy, Heritage New Zealand, 2014)

The conversion of shed 21 into Waterloo on Quay apartments began in 2001 and was completed in 2002 (Waterfront Information Centre, 2012). Built in 1910, it is located at the northern end of the waterfront redevelopment area, close to the railway station and the central business area.

Formerly a wool storehouse, the building was earthquake strengthened and refitted with apartments on the upper two storeys and commercial office space on a portion of the bottom floor. While the main pedestrian entrance to the building faces away from the waterfront, towards the railway station, there is one commercial entrance facing the waterfront even though blocked by the adjacent Railway Wharf that was fenced, as it was not a part of the redevelopment area.

\section{Shed 22}

Located adjacent to the gates on Taranaki Street Wharf and built in 1921, shed 22 was also refurbished between 2001 and 2002 (Waterfront Information Centre, 2012). The three storey warehouse was converted into a brewery and restaurant that fronted onto Taranaki Street Wharf with a large outdoor patio space. Due to the exterior changes to the façade and addition of a patio area, the project would have required some public consultation. 


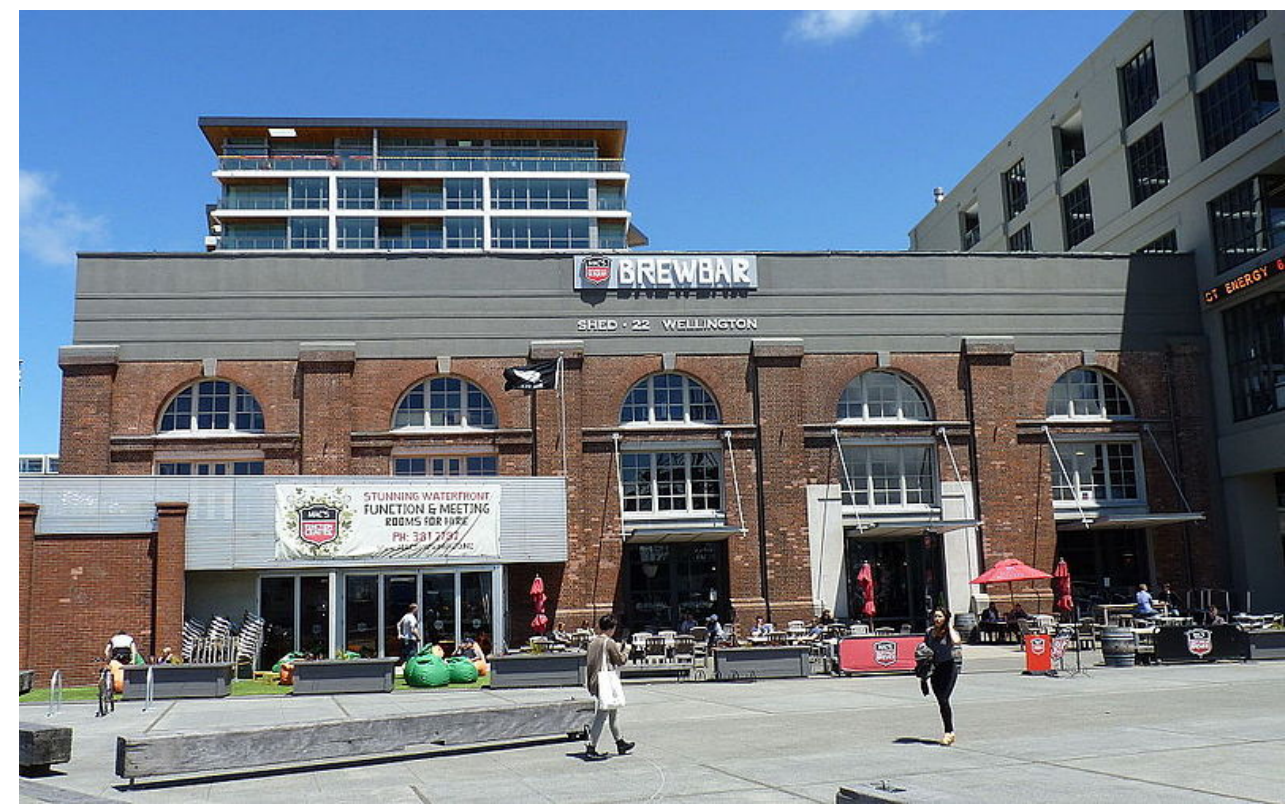

Figure 4.49. Shed 22. (image: Michal Klajban, Wikimedia Commons)

\subsubsection{Form and governance}

In this phase, conversion of the two heritage building projects generally followed the same pattern as other heritage buildings as straightforward refurbishment projects handled by LHM. The form of the two developments similarly followed the treatment of previous similar projects with restoration of the building exterior, some window upgrades, and some upgrades to the ground floor to respond better to adjacent public space.

Shed 22, centrally located on the waterfront near Te Papa and facing onto Taranaki Street Wharf, was opened up onto the pedestrian area with a large patio area and large glass windows. Shed 21 is on the edge of the waterfront redevelopment area with adjacent public space limited to pedestrian walkways. The conversion to apartments and office space with relatively limited visual interaction between the interior and adjacent open space is partly a result of the building's architecture and partly due to the limited need for such interaction on this part of the waterfront. The apartments, commercial space, and generally heavy pedestrian traffic to and from the railway station would provide passive surveillance at most times of the day.

The governance arrangement of the Leadership Group had little impact on the form of the two shed refurbishment projects; however, the design guidance for non-heritage 
building projects provided by Waterfront Framework reflected the integrated process used to draft it. Overall principles for the waterfront were established and given greater direction for each of the five precincts along the waterfront. This direction clarified development intentions for each area in a contextual fashion. The identified issues and guidance reflected key points of concern for the Leadership Group; however, there was no relationship between the degree of specificity of design guidance and whether issues were contentious. For example, the decision of whether or not the new park site at Chaffers was to be defined by buildings was left for the subsequent governance phase. This was a point of heavy debate from when the 1997 Open Space Concept Plan was opened for public consultation. Conversely there was more guidance about responding to historical Maori and maritime heritage, two issues that had never been strongly debated.

Overall, as a result of greater community involvement, development intensity was reduced with fewer sites for new buildings, a greater emphasis on respecting the scale of adjacent buildings, a minimum of $66 \%$ open space specified for the waterfront redevelopment area, and greater direction on the implementation of previously established waterfront values (including prioritising non-motorised uses, protection of heritage buildings, and providing amenities).

\subsubsection{Transition stimulus}

\section{Variation 22}

Following several opportunities for the public to provide feedback, WCC planning staff drafted Variation 22 to translate and incorporate the Framework into planning policy as per the Leadership Group’s advice. As required under the RMA (1991), variations (i.e. changes) to a district plan require public notification (see Schedule 1), which provided the public an additional formal opportunity to comment on the Leadership Group’s work and how it was to be translated into planning policy. In accordance with this requirement, Variation 22 was released for public review in August, 2001 and incorporated into the District Plan in July, 2004 without changes.

Variation 22 encompassed the values, principles and ideas expressed in the Waterfront Framework and replaced the 1989 Lambton Harbour Combined Planning 
Scheme and Concept Plan as the planning framework for the waterfront redevelopment (Wellington Waterfront Framework, 2001, p. 44). It is important to note, however, that the Waterfront Framework was not a design guide, yet Variation 22 was written to integrate it into the district plan as if it were one (Environment Court, 2008). Instead, the Leadership Group envisioned the design details of the five precincts being worked out through a public process which would then result in additional, more specific, variations to the district plan as design guides. This is reflected in their proposal that detailed waterfront planning be undertaken by the Waterfront Development Group, which was to consist of professionals and community representatives and have the mandate to run public consultation (Wellington Waterfront Framework, 2001, p. 43). As a mechanism to ensure public consultation occurred on every development project, Variation 22 outlined a zero metre height limit for new developments on the waterfront.

\subsection{Phase 6 governance (2001 to 2006) - Designer led decision making with enhanced public engagement}

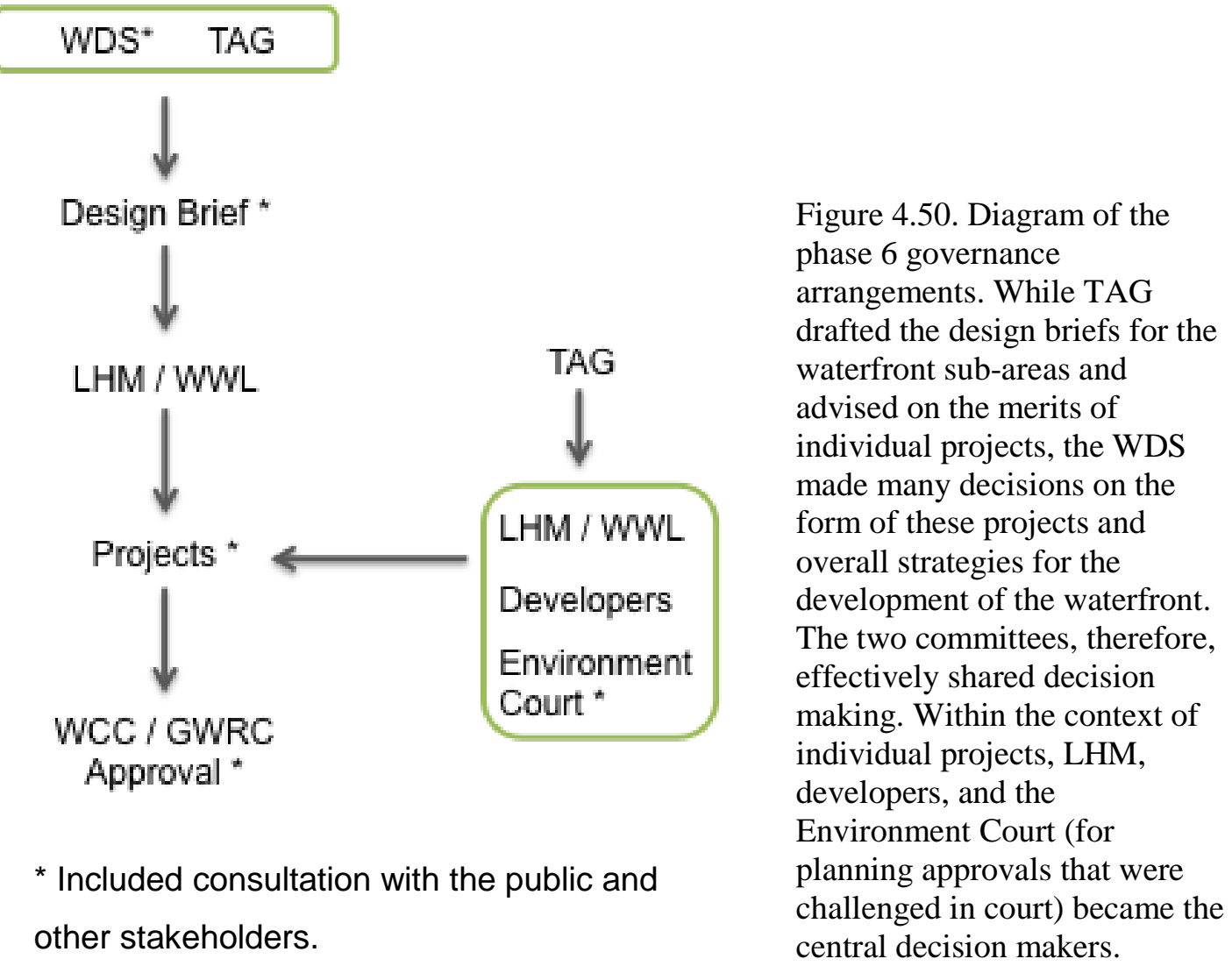


A summary of the effects on the form of the waterfront included:

- More "active” frontages for new buildings and heritage refurbishment projects than in previous projects on the waterfront and

- Public space was detailed to meet the needs of waterfront tenants. For example, landscape designs were reconsidered to improve vehicle access and parking for the rowing clubs and marina users.

\subsubsection{Governance description}

WCC established the Waterfront Development Subcommittee (WDS) in August 2001, largely following the governance structure recommended by the Leadership Group shown in figure 4.47. One key difference was the Waterfront Development Group was intended to be an independent body, yet the WDS included the mayor and four councillors. As per meeting minutes of the WDS, the remainder of the membership included an independent business consultant as the chairperson, the chair of the Technical Advisory Group, a representative from the local iwi, an architect, a representative from the real estate industry, and a professor of architecture from Victoria University of Wellington. While the balance of the WDS included both professionals and community representation, as suggested by the Leadership Group, it included a large number of development professionals.

The composition of the WDS was augmented by an independent four person Technical Advisory Group (TAG) that included architects, landscape architects, and planners appointed by WCC. TAG reviewed the waterfront planning and designs for their compliance with the Waterfront Framework, provided feedback to the WDS and WCC on design proposals, and worked with developers' design teams on refining the proposals to maximise their contributions to the form and use of the waterfront (WCC, 2004, May 27 Report 3 Appendix 1).

The mandate for the WDS was to set the strategy for the redevelopment, engage the public on redevelopment plans and projects prior to their approval and, through the formal consent review process, be the approval body for detailed designs, and monitor implementation by a modified LHM (WDS, 2005, May 16 Report 2 Appendix1). The redevelopment strategy was to be drafted as performance briefs (referred to as 'design 
briefs' by the WDS) for each of the five waterfront precincts, using the Waterfront Framework as a guide and incorporating feedback from public consultation (WDS, 2004, May 27 Report 3 Appendix 1). As illustrated in figure 4.50, however, the central role of WDS was shared with TAG. Within the planning and design decisions by these two committees, however, the form of individual projects were further shaped by input from WWL, developers, and Environment Court decisions on project approvals that were challenged by other waterfront stakeholders.

WDS meetings were open and ensured opportunities for public submissions. Agenda items and WDS reports were advertised and made available through the council's website, as press releases, monthly email updates printed for distribution, postings on the waterfront project's website, and were made available through the development corporation's waterfront office (WDS, 2004, May 27 Report 3 Appendix 1). Complementary to the Leadership Group’s ideal of fostering public engagement, feedback on projects was also actively solicited through these venues and through other means, including: advertisements in local newspapers, signs along the waterfront, and occasionally direct invitations to individuals and organisations on WWL's contact list. They also employed a range of feedback mechanisms including focus groups, on-site surveys, questionnaires, annual public opinion surveys, waterfront community satisfaction surveys, and market research consultants for larger projects (WDS, 2004, May 27 Report 3 Appendix 1). Despite offering opportunities for public engagement, however, there were often calls for more public consultation on various matters including a request for greater consultation on the design brief for the Overseas Passenger Terminal (OPT) (e.g. WDS, 2004, May 6 Minutes) and more consultation on the annual Waterfront Development Plans (e.g. WDS, 2004, May 27 Minutes; WDS, 2005, August 1 Report 2 Appendix1).

To prepare the performance briefs for the sub-areas, the WDS process included identifying relevant issues (including market conditions, physical condition of the site, and relationship between the site and the overall waterfront project) and preparation of the brief (WDS, 2004, May 27 Report 3 Appendix 1). According to the WDS (2004, May 27 Report 3 Appendix 1), the briefs were structured to communicate the qualities and standards that developers and designers would have to 
address when working on proposals for buildings or public space. The briefs included (WDS, 2005, May 16 Report 2 Appendix 1):

- background on the purpose and intent of the brief;

- visual guidance on how the Waterfront Framework principles could be applied in the sub-area addressed by the design brief;

- description of key issues to be addressed; and

- description of issues that were raised during the public consultation on the design brief.

In practice, TAG prepared the design briefs on behalf of the WDS. These were then reviewed by the WDS prior to releasing them for public consultation. Policy guidance for decisions by WDS were informed by (WDS, 2006, June 26 Report 6 Appendix 1, p. 32):

- Wellington Harbour Board and Wellington City Council Vesting and Empowering Act (1987)

- Constitution of Lambton Harbour Management Ltd.

- Overview Agreement between WCC and Lambton Harbour Management Ltd.

- Property Trust Deed

- Waterfront Development Plan

- Statement of Intent

- Wellington Waterfront Framework

- $\quad$ Foreshore and Seabed Act (2004)

The former LHM was refashioned into an implementation and management body in 2000 and renamed Wellington Waterfront Limited (WWL). With the reorganisation, a new constitution and overview agreement were both drafted to reflect the new structure (SPC, 2011, February 17 Report 2). Once design briefs and design proposals had been approved by the WDS, WWL was tasked with marketing development opportunities, negotiating development and lease agreements, managing the effects of construction, organising events, managing maintenance, commissioning plans based on design briefs, and reporting on progress to WDS (WDS, 2004, May 27 Report 3 
Appendix 1). Despite the WDS taking over the strategic planning of the waterfront, WWL retained its board of seven directors to provide commercial advice and direction on implementation strategies (one of whom was a WCC councillor). In 2006 WCC appointed an additional director to be deputy chair to allow for additional workloads (WDS, 2006, June 26 Report 6 Appendix 1); however, board numbers were later reduced to four in 2010 as the number of remaining projects decreased (SPC, 2009, November 17 Report 3 Appendix 3).

WWL produced an annual business plan for review by the WDS and the WCC committee on council-controlled organisations, clarifying the status of ongoing projects, producing a development schedule for the following year, and accounting for income and expenses (WDS, 2005, May 16 Report 1). The business plans were available for public review from the WCC website and time was available for public comment during the committee's meetings.

The structure of WWL reflected the Local Government Act (2002), which included a definition of a "council-controlled organisation" (section 6) and its management (part 5). The Act also outlined the requirement for local government "to enable democratic local decision-making and action by, and behalf of, communities" (Section 10, sub 1a). Section 39 outlined a mandate for open, transparent, effective processes and governance structures; which was again reinforced in Part 6 on planning, decision making and accountability. The Act did not change the governance arrangement of the waterfront redevelopment, however, it did illustrate how the Leadership Group's ideas reflected contemporary thinking on planning and development in New Zealand.

For most projects in this governance phase, once the design briefs for the five precincts were approved by the WDS, WWL marketed development opportunities and commissioned plans for the public space. The responding design proposals were reviewed by TAG and made available for public feedback prior to WDS rendering a decision on them. Once the WDS approved the projects, WWL could negotiate terms with the developers; however, for projects where WWL was to be a development partner, a negotiated lease was 99 years or longer, or WWL was to be the head lease holder, and approval was needed from WCC. For projects that included redevelopment on the wharves, additional approval was required from the Greater 
Wellington Regional District as per the Resource Management Act (1991, Section 12). 


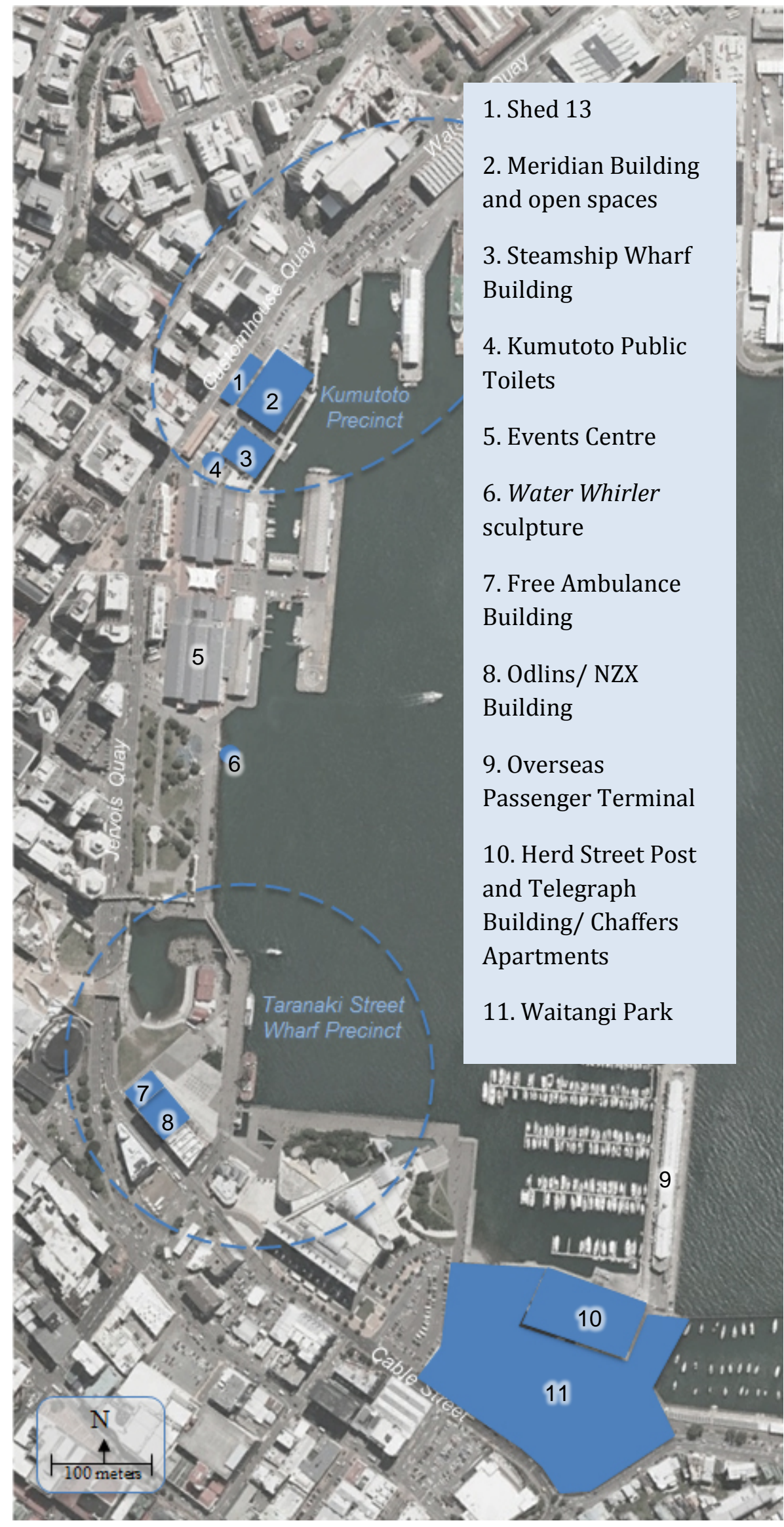

Figure 4.51. Location map of phase six projects and features. Blue polygons identify constructed projects. (base image: Google Earth, accessed November, 2015). 


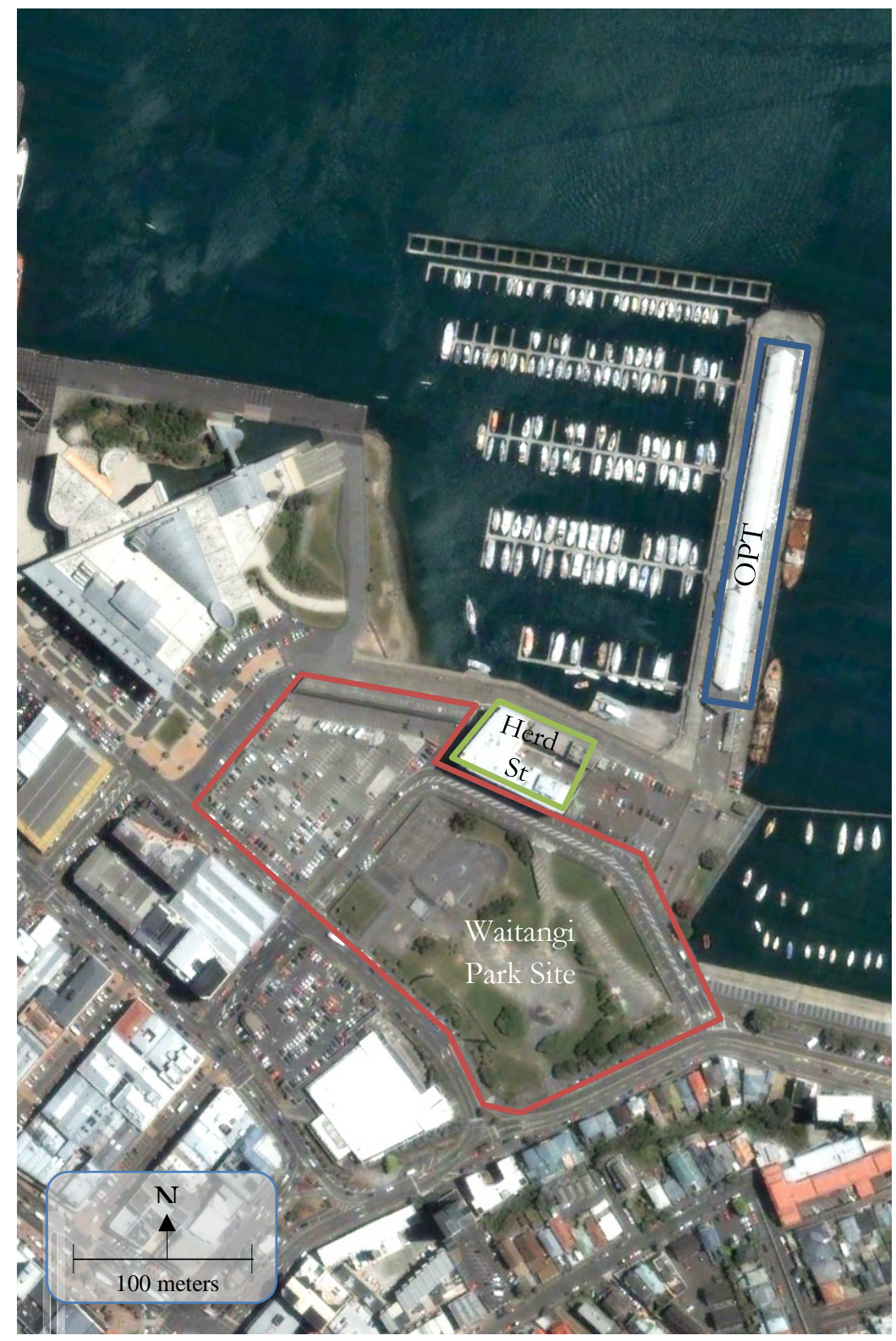

Figure 4.52.

Waitangi Park site circa 2002 showing the existing Chaffers Park layout. (image: Google Earth, accessed November 2015)

The Waterfront Framework, following on from the initial CCC recommendations and the 1997 Open Space plan, identified two large green spaces for the waterfront, the existing Frank Kitts Park and a second in the Chaffers area shown in figure 4.52 (Wellington Waterfront Framework, 2001, p. 19). The Waterfront Framework identified the following criteria for the area:

- Retention and reuse of the 1939 Herd Street Post and Telegraph building and the Overseas Passenger Terminal (OPT), both of which were to include public access to the ground floors. 
- Ground floor activities of all buildings were to complement strong, open connections between the park and the promenade.

- The new park design was to accommodate formal events and informal recreation uses suitable for all demographics and different group sizes.

- The design of the park would address the arts, culture, and heritage ideals described in the Waterfront Framework.

- The park was to be designed to become a key destination

- Past industrial contamination would be addressed as a part of the development of the site.

- Shelter from inclement weather was needed.

- Future parking provisions for the area should be discreetly located while enabling disabled access to the waterfront.

- A public space should be included on the roof of the Herd Street building.

- Designs should include a site for a Chinese Garden and a water feature connecting it to the harbour.

Notably, the Leadership Group could not reach consensus on whether a transition in heights between the north edge of the park and Te Papa should include new buildings or be achieved through landscaping (Wellington Waterfront Framework, 2001, p. 38). The debate covered whether new buildings would impose upon the park and adjacent public space or would provide complementary uses and shelter from weather.

Ultimately, the Waterfront Framework did not provide clear direction as the Leadership Group could not find consensus on the issue. Due to the lack of design direction it was recommended the WDS should consult with the public on the matter when drafting the design brief for the area (Wellington Waterfront Framework, 2001, p. 39).

In 2002, the WDS and WWL decided to move forward with the planning and design of a large park in the Chaffers site. Rather than drafting a performance brief, WDS and WWL organised a design competition for the park. The use of a design competition was a variation on the governance process under this phase.

Contrary to the Waterfront Framework, however, the competition brief consulted on and approved by WDS did not clarify whether or not new buildings could be located 
on the side adjacent to Te Papa. Instead, the decision of how the transition would be handled was left up to the designers. The entries were publicly displayed and the public had an opportunity to vote for their favourite. Contrary to the vote, however, WDS chose a different design based on criteria developed for the competition. The decision followed a four hour special meeting of the WDS which included presentations by TAG, the four finalists, and consideration of public feedback (WDS, 2004, May 27 Report 3 Appendix 1).

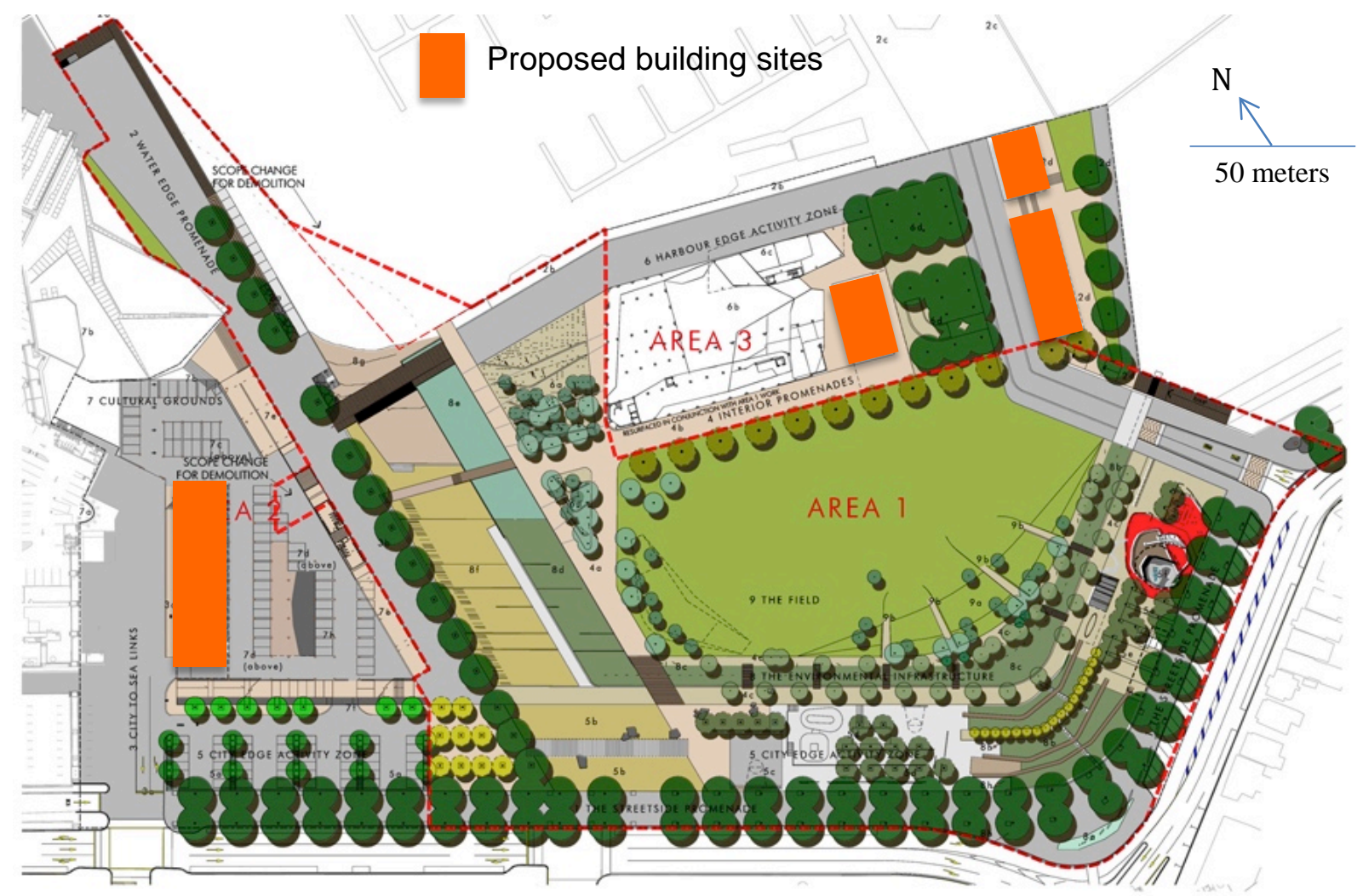

Figure 4.53. The winning park design for the Waitangi Park design competition highlighting proposed building sites (in orange). (base image: Megan Wraight, Wraight \& Associates)

In the winning entry, three building sites were identified east of the Herd Street Post Office, to transition in scale from the Overseas Passenger Terminal and Herd Street building to the open park, and one building site was identified to transition from Te Papa on the west side of the park (identified in orange in figure 4.53). To identify a direction for these, WWL organised a one day public workshop in December 2004 to investigate suitable publicly accessible ground floor and adjacent open space uses (WDS, 2005, May 16 Report 2 Appendix 1). 
The remainder of the park proposal, identified as 'Area 1' in figure 4.53, included a large open grassy area, a skate park in the south east corner, a children's playground on the east side, a wetland area running around the south side of the open grassy area that emptied out into the harbour between the Herd Street building and Te Papa, and a wide sidewalk along the street edge lined with trees.

2002 North Queens Wharf (later called Kumutoto)

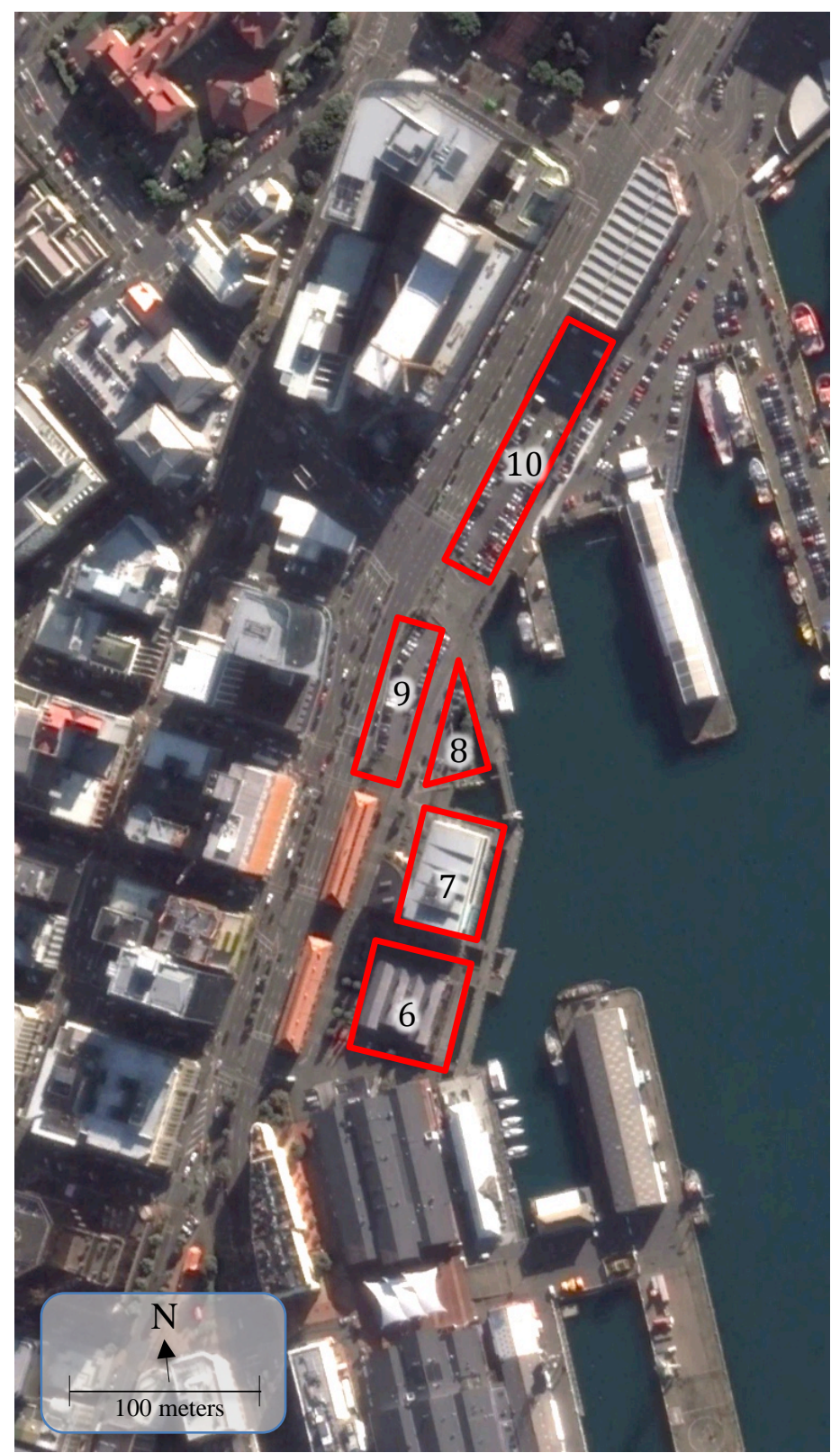

Figure 4.54. North Queens Wharf area. The five building sites identified in the North Queens Wharf Design Brief are outlined in red and labelled with their numerical building site designations. (image: Google Earth, accessed November 2015)

The first sub-area design brief drafted under the new governance arrangement was for the North Queens Wharf area in 2002. Prior to the design brief, a study was commissioned to analyse the area and identify appropriate bulk and form of buildings 
for it (SPC, 2008, December 4 Report 1 Appendix 2 Attachment 1). The Waterfront Framework identified the following guiding principles for this area (pp. 32,33):

- This area would have more buildings than other parts of the waterfront as it was closest to the city centre. This would also be reflected in the use of squares and lanes having a more urban character.

- The buildings would reflect the scale of existing heritage buildings, which are higher at the northern end than the southern end.

- A maritime character would be a part of the open space design, including accommodation of berths for fishing and recreational boats by Tug Wharf.

- Parking should be accommodated underground or within a purpose built facility adjacent to shed 21 .

- Views of the harbour should be maintained and improved down Waring Taylor, Whitmore, and Johnston Streets.

- In addition to widening the promenade by Tug Wharf, a second inland, more sheltered route, should run parallel with the waterfront. Development along the promenade should include a colonnade.

- Open spaces should contain a focal point, should be designed for an obvious use, have their own character, and be defined spatially by buildings and other activities, with views in and out.

- All ground floors to include publicly accessible uses and edges facing key open spaces should provide some complementary activity to them.

- New buildings should provide a mix of uses, possibly including a maritime museum.

The subsequent design brief, drafted by TAG, identified the five potential building sites shown in figure 4.54 and design criteria for the public space (WDS, 2004, December 13 Report 5). Following a period of public consultation, the design brief was approved by WDS in August, 2002 (WDS, 2004, September 30 Report 1). WWL commissioned a public space concept design in 2003 to move the project forward and included criteria for relating new buildings to adjacent public open space. The Steamship Wharf building (identified as site six - see figure 4.54), Meridian building (site seven), and adjacent public areas were initiated by WWL in 2003. 


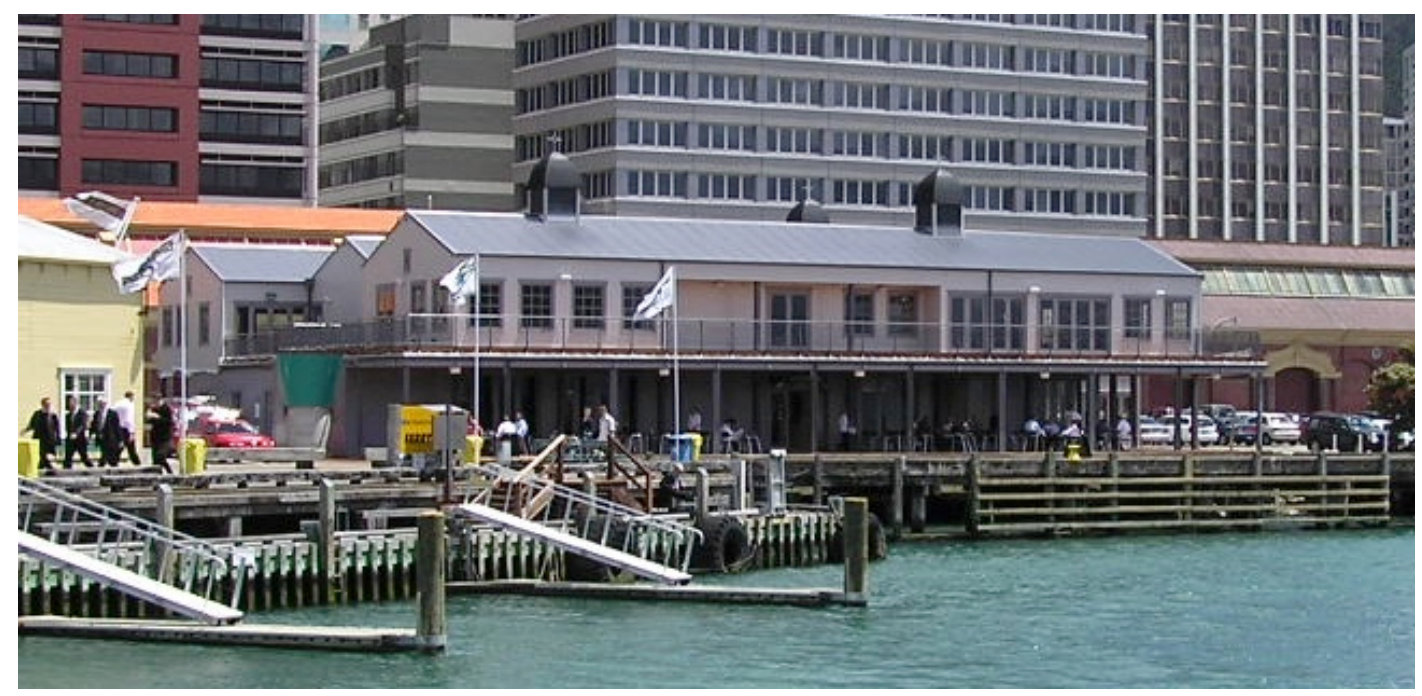

Figure 4.55. The Steamship Wharf building with Shed 13 behind it to the right. (image: author)

The Steamship Wharf building was moved from Greta Point in Evans Bay (located on Wellington Harbour to the south of the waterfront redevelopment site) to site seven, adjacent to the Retail Centre in 2003 (SPC, 2008, December 4 Report 1 Appendix 2 Attachment 1). The building was originally a linen store and laundry for the Union Steamship Company and was the last $19^{\text {th }}$ century, wooden warehouse on the Wellington Harbour (WCC, n.d., Old Shoreline Heritage Trail). It was moved by barge from Greta Point to its current location and fitted out to accommodate two restaurants and function facilities.

2003 Meridian building

WWL also commissioned a design for a new building on site seven, adjacent to the Steamship Wharf site, and a more detailed design of the surrounding public space in 2003 (WDS, 2004, May 27 Report 3 Appendix 1). As with all of the projects in this governance phase, TAG provided design review and comment based on the principles and ideas articulated in the Waterfront Framework and the new Kumutoto public space plan. The design concepts for the new building and adjacent open space were then released for public consultation in October and November 2004. 


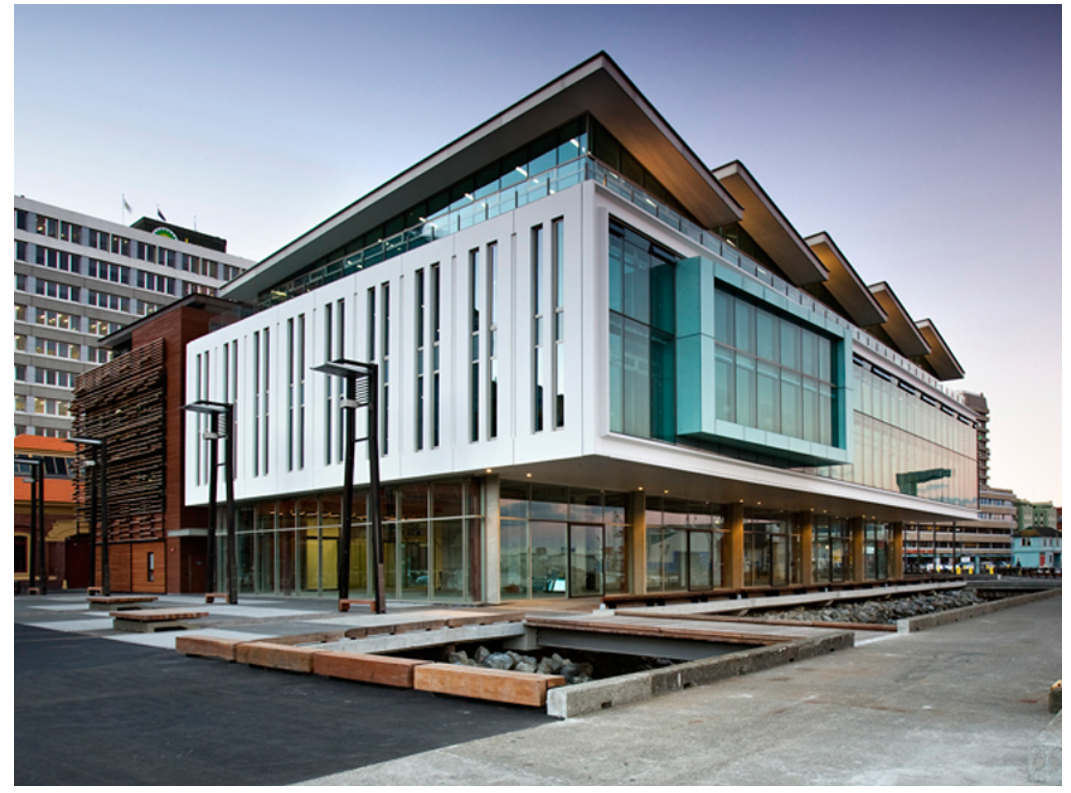

Figure 4.56. The Meridian Building and harbour-side public open space. (image: Peddle Thorp Architects)

The proposed building followed environmentally sensitive design principles based on the Greenstar Rating system, and included ground floor restaurant and retail space with offices above on three floors. One major impact of the decision to embrace environmentally sensitive design was replacing required basement level parking with internal ground floor bicycle parking (SPC, 2005, November 9 Report 2). This elimination of parking was easier for this part of the waterfront as the central business district and train station are both within a five minute walking distance.

In addition to special meetings with neighbouring leaseholders and tenants, the plans were advertised in local newspapers, on the radio, in the WCC newsletter, on WCC and WWL websites, and at local libraries (WDS, 2004, December 13 Report 5). Also, a public open day was held on 30 October, 2004 at Queens Wharf Events Centre. Following review of the submissions, the WDS approved the concept design in December 2004 without changes (WDS, 2004, December 13 Minutes). Two resource consents were awarded in July 2005, one for the building and a separate one for the public space (WDS, 2005, May 16 Report 2; WDS, 2005, August 1 Minutes).

Once the approvals were received, WWL advertised the project to developers and prospective tenants in July 2005. WWL signed a long-term tenant lease and a development agreement with a developer to construct and manage the building by October 2005 (SPC, 2005, November 9 Report 2). The conditions of the development 
agreement included WWL taking the head lease for the ground floor so it could manage the commercial use of the space, and even subsidise subleases, to maintain the principle of a publicly accessible ground floor (SPC, 2005, November 9 Report 2).

2003 Kumutoto Public Toilets

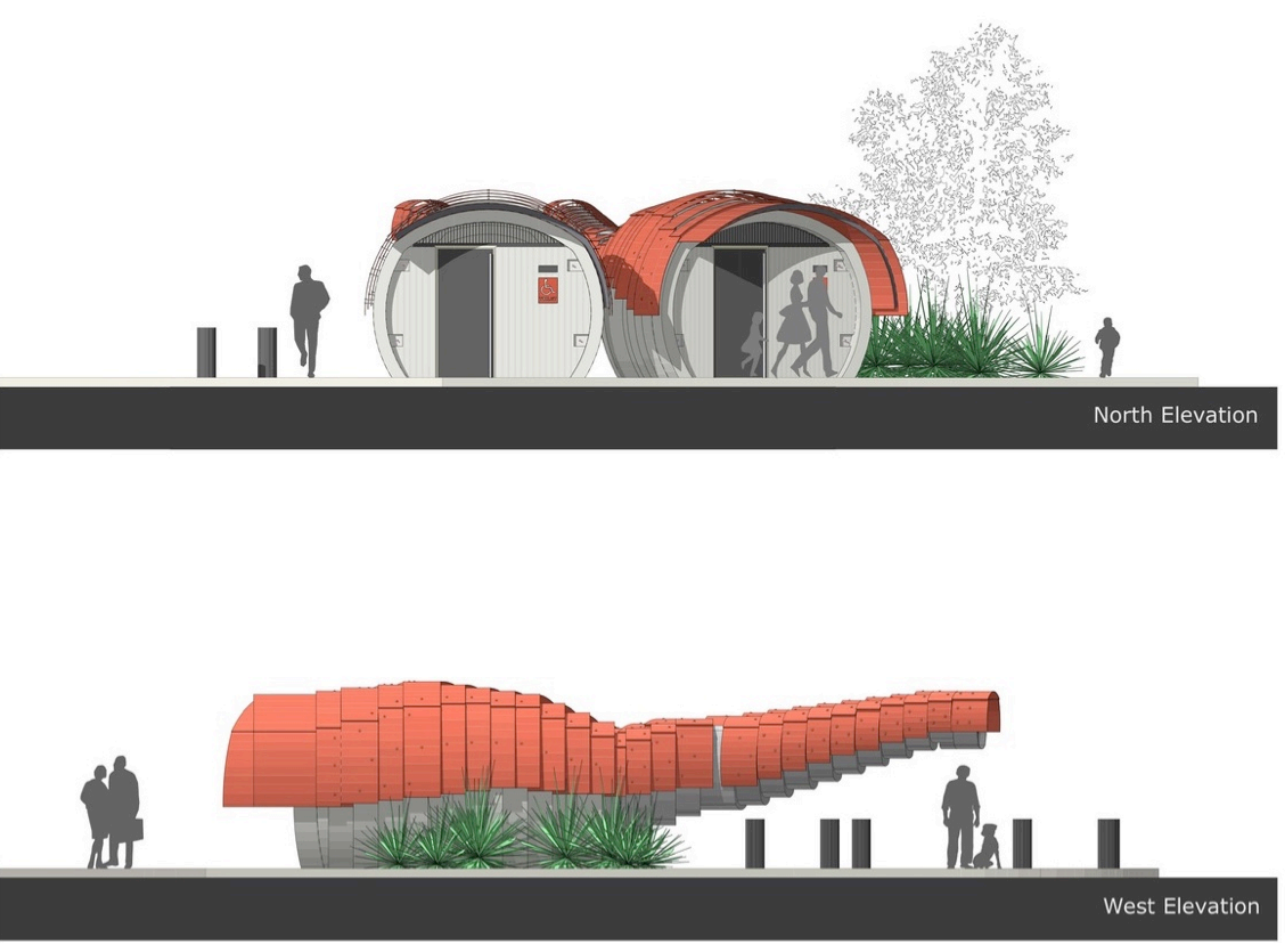

studiopacificarchitecture

Figure 4.57. Elevation drawings for the Kumutoto Public Toilets. (image: Studiopacific Architecture)

The public space plan for Kumutoto included a concept for a sculptural public toilet building (SPC, 2009, November 17 Report 3). The only other public toilets on the north end of the waterfront were the relatively basic facilities in shed six (men's toilet), on the outer-T (women's toilet), and facilities located beside the lagoon.

Public submissions on the 2009/2010 Development Plan supported the concept of public toilets, but 9 of the 45 submissions took exception to the potential costs (SPC, 2009, November 17 Report 3). Further review by WWL and TAG of the public space plan and public feedback reported it would be unlikely to spend less than $\$ 400,000$ (SPC, 2010, April 15 Minutes). In reviewing a design for the toilets commissioned by WWL, TAG supported the need for the buildings to be visually expressive and reflect 
the shipping and built form heritage of the space through materiality and colour (SPC, 2010, April 15 Report 1). Following review of the public submissions, SPC approved the construction of the toilets in April 2010 without changes to the design (SPC, 2010, April 15 Report 1).

2002 Writers Walk
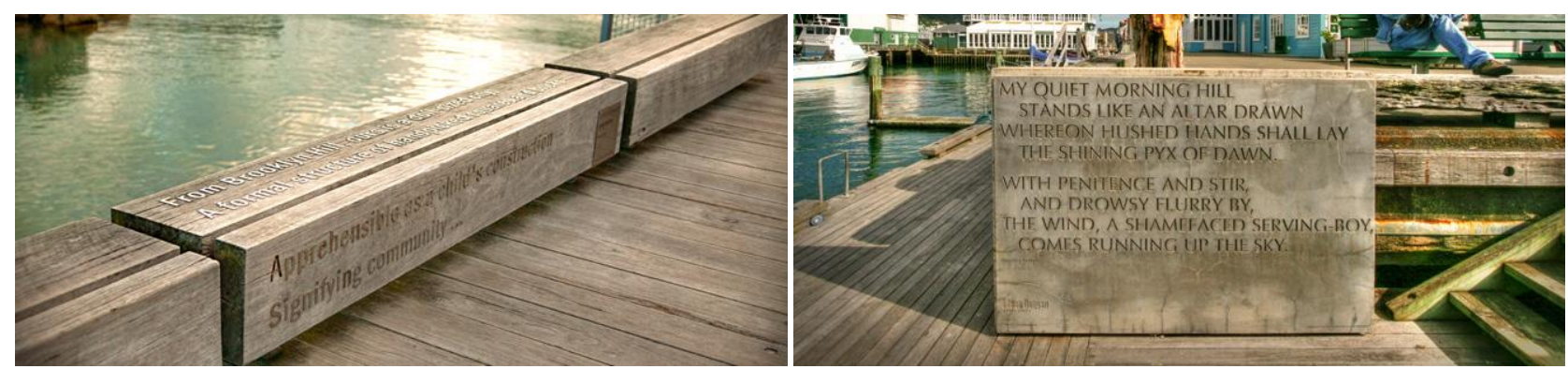

Figures 4.58 and 4.59. Writers Walk installations. (images: Wellington Writers Walk, 2015)

During the New Zealand International Arts Festival in 2002, 19 text installations were permanently installed along the waterfront (Harper \& Lister, 2007). These installations included concrete panels, benches, and boards incorporated into the waterfront promenade that included quotes from literary works by prominent New Zealand writers and poets. Additional installations were added in subsequent years along with other pieces of sculpture.

The installations were sponsored primarily by Wellington based businesses and institutions. Their installation on the waterfront, like other pieces of sculpture, was approved by WWL in consultation with TAG as a part of implementing and managing the public space plans. Like the Len Lye Water Whirler discussed below, public feedback occurred through the public consultation on the annual development plans produced by WWL, rather than as individual projects. The annual plans identified the planned work on public space and building site development projects over the course of the following year.

\section{Taranaki Street Wharf}

Following the December 2001 Environment Court decision overturning the consent approval to move the Free Ambulance Building (described in section 4.6.2 on the 
1999 Taranaki Street Wharf plan), several open house days and special meetings with nearby property owners and tenants were held by the WDS and WWL in late 2002 and 2003 about proposed changes to Taranaki Street Wharf (WDS, 2004, September 2 Report 6).

Building on previous changes to Taranaki Street Wharf, the Waterfront Framework recommendations included:

- Improve the shoreline of the lagoon to improve access to the water's edge.

- Build on the existing link created by the City-to-Sea bridge, between the wharf and Civic Square.

- A site adjacent to the rowing and boating clubs would be most suitable for a wharewaka as this part of the waterfront had strong historical links with Maori settlement.

- The area between Te Papa and the water should provide better links between the two, recognise the presence of the Te Papa marae more effectively, and provide more pedestrian amenities (including seating and shelter from the weather).

- The Circa Theatre organisation should continue to be a waterfront institution, whether in the existing Circa Theatre building or a new building.

- Any redevelopment of Shed 22, the Odlins building, and Wellington Free Ambulance building should respect the form and scale of the waterfront and provide active edges that contribute to the adjacent open space areas.

A new design for the Taranaki Street Wharf and Lagoon area was then commissioned by WWL and approved by WDS in 2003 (WDS, 2004, May 27 Report 3 Appendix 1). Building on many of the ideas represented in the 1998 Open Space Master Plan, the new design reduced the size of a popular grassed mound at the south end of the lagoon, reshaped the shoreline, and improved connections to the city to sea bridge (WDS, 2004, May 27 Report 3 Appendix 1). At the time, however, the design of a wharewaka (described below) and adjacent public space was still up in the air and work on the design continued.

In August 2003 the WDS approved locating a wharenui (traditional meeting house) adjacent to the rowing and boating clubs as a component of finalising the public space design for the Taranaki Street Wharf (WDS, 2004, September 2 Report 6). This 
approach allowed the public space design for the area to be open for consultation, even though the design of the wharenui and the immediate landscaping had not been investigated. The design released for public consultation in September 2004 (shown in figure 4.60) included a wharewaka , Te Raukura, adjacent to the City to Sea Bridge that housed Wellington's ceremonial waka. The separate wharenui was situated adjacent to the boating and rowing club buildings (WDS, 2004, September 2 Report 6 Appendix 1). After public consultation closed in October 2004, WDS approved the more detailed concept design for the buildings and open space in December 2004 (WDS, 2005, May 16 Report 2 Appendix 1). Planning consent was then granted by the GWRD in late 2005 (WDS, 2006, May 8 Report 2 Appendix 1).

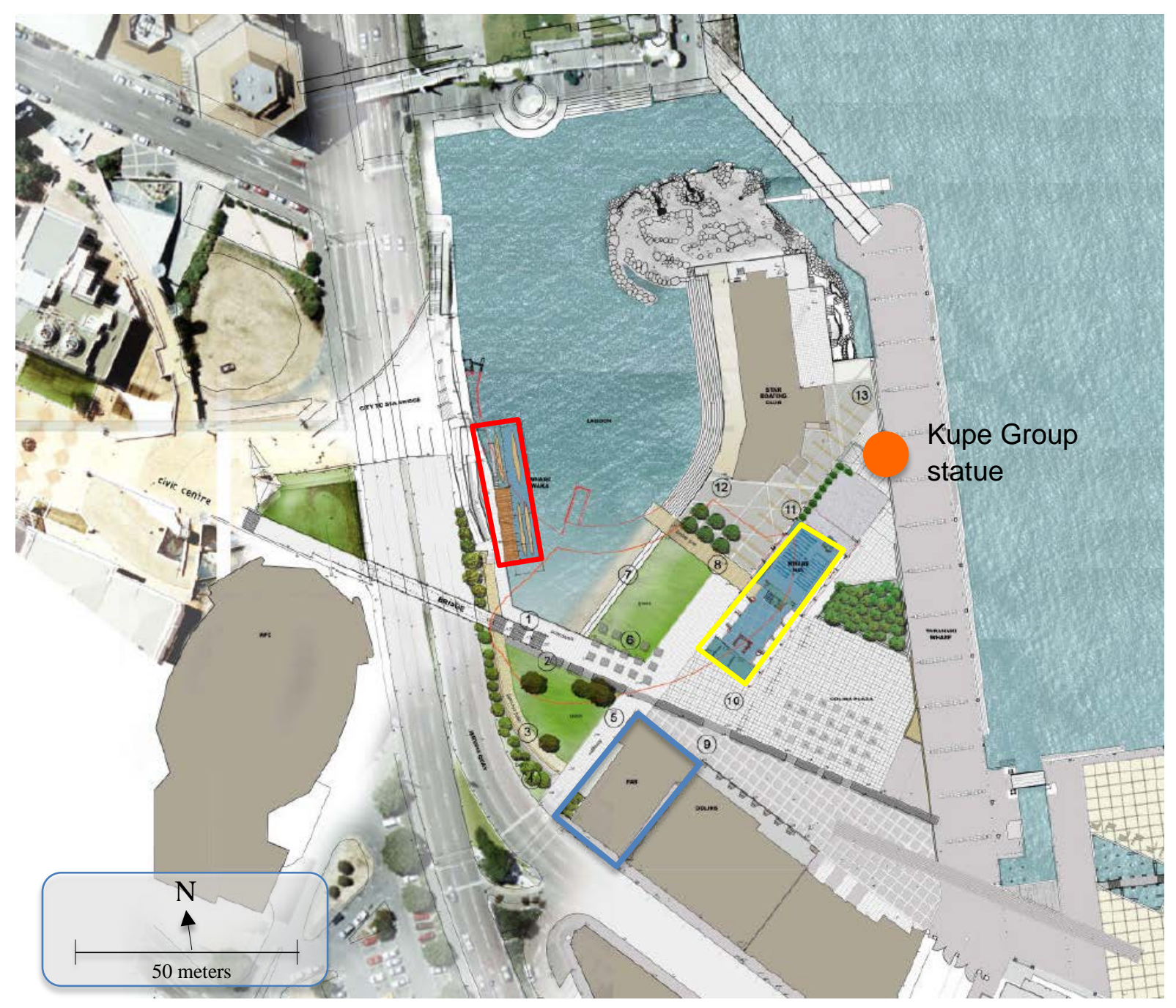

Figure 4.60. 2004 plan for Taranaki Street Wharf by Athfield Architects Limited. The red outline indicates the location of the wharewaka, the yellow outline indicates the location of the wharenui, and blue indicates the Free Ambulance building. (base image: Athfield Architects Limited) 
Subsequent design detailing of the wharewaka and wharenui (outlined in red and yellow respectively in figure 4.60) included consultation with interested parties, neighbouring property owners and tenants to help shape the general building envelope and expectations of the project (WDS, 2004, December 13 Report 4). During this design development phase the Taranki Street Wharf public space plan was altered by removing a small water channel on the landward side of the wharenui site, inclusion of additional trees, and shifting the wharenui towards the rowing and boating club to provide sufficient space between it and the Free Ambulance building (outlined in blue in figure 4.60) (WDS, 2004, December 13 Report 4).

Despite WWL's efforts to begin work, some aspects of the Taranaki Street Wharf public space plan were deferred until WWL was able to obtain additional income from commercial development projects (WDS, 2006, May 8 Report 2). Also, while consent was received for the development of the public space, WWL appealed to the Environment Court over some of the consent conditions that affected parking and vehicle access to the rowing and boating clubs (Environment Court, 2006). WWL successfully negotiated new parking and vehicle access plans with the rowing and boating clubs to the approval of the Environment Court in 2006 (WDS, 2007, August 22 Report 4 Appendix 2). This included installation of traffic controls, comprised of wooden beams delineating the vehicle access and mechanised bollards with a pin pad to limit access at the Taranaki Street entrance (SPC, 2010, April 15 Report 1).

Other issues affected the implementation of the consented plan however, including the following:

- The iwi groups involved in the project chose to not develop the wharewaka and wharenui as designed and continued to work on the design in consultation with TAG and WWL.

- Negotiations with the rowing and boating clubs meant additional surface parking was required that was not a part of the consented plan.

- The merit of a proposed pedestrian bridge running between the wharenui site and the Odlins building, linking Taranaki Street Wharf with an overhead route to the City to Sea Bridge, was reconsidered and the bridge was removed from the open space plan. 
- Additionally, a WCC 'Greening the Quays' project, the deteriorating condition of portions of the existing City to Sea Bridge, and a desire to provide better connections between Civic Square and Te Papa meant several parts of the open space plan required further design work (WDS, 2006, September 4 Report 3).

In response to the negotiations with the boating and rowing clubs about vehicle access and the above ongoing issues, TAG produced a new design brief for this area (WDS, 2006, September 4 Report 3). WDS approved the design brief in September 2006 and required any revised open space plans or projects stemming from this be presented to WDS to determine whether public consultation would be required (WDS, 2006, September 4 Minutes). While the norm, under the WDS process, was to consult with the public on design briefs and resulting plans, public consultation was not seen as fundamental to this redesign as the revisions were identified as likely to be minor changes to the consented plan (WDS, 2006, September 4 Report 3). Instead, designers were encouraged to consult with affected stakeholder groups in the first instance, along with the following advisory groups: TAG, WCC planning staff, Tenths Trust (an organisation established to represent local iwi interests), and the WCC Disability Reference Group (WDS, 2006, September 4 Report 3 Appendix 1).

As some of the consented open space plan had been built, the design brief recommended that the 2004 plan be used as a starting point and new projects should comply with conditions of scale, character, and development intensity identified in the resource consent unless there was good reason to seek a variation of the consent conditions (WDS, 2006, September 4 Report 3). Other considerations identified in the design brief reiterated the key principles outlined in the Waterfront Framework: to reflect historical and contemporary culture; to reflect Maori heritage and presence; to contribute to the developing sense of place; to accommodate a diversity of users and activities; having buildings and open spaces that would reinforce one another; and, that access to and through the space should be enhanced (see WDS, 2006, September 4 Report 3 Appendix 1).

Based on the design brief and requirements for variations to the consented plan, a new design for a combined wharewaka and wharenui, located on the site previously approved for the wharenui, was submitted to WDS in mid-2009 (SPC, 2009, November 17 Report 3). The intent of the redesign was to bring these two uses 
together in a way that respected the conditions of the previous resource consent (SPC, 2009, November 17 Report 3). The final design was for a two story building with a glassed-in display area for two ceremonial waka, a public exhibition area and a café on the ground floor that provided active edges on all sides. The second floor included office and meeting spaces.

During the public consultation on the new design, the height and location of the proposed building was identified as potentially limiting sightlines between the Cityto-Sea bridge and Te Papa. Other site constraints that affected the form and siting of the building included a desire to orient it towards the Kupe Group sculpture and provide ramp access to the lagoon. The form of the building was intended to reflect a traditional Maori cloak covering the building with a traditional marae-style entrance (Donoghue, 2009). WCC approved a 99 year lease for the proposal and adjacent landscape design in December 2009 (SPC, 2010, June 23 Report 2 Appendix 3). Construction began in 2010 and was completed in early 2011 (SPC, 2011, March 8 Report 1 Appendix 1).

2003 Herd Street Post and Telegraph Building (later known as the Chaffers Dock Building)

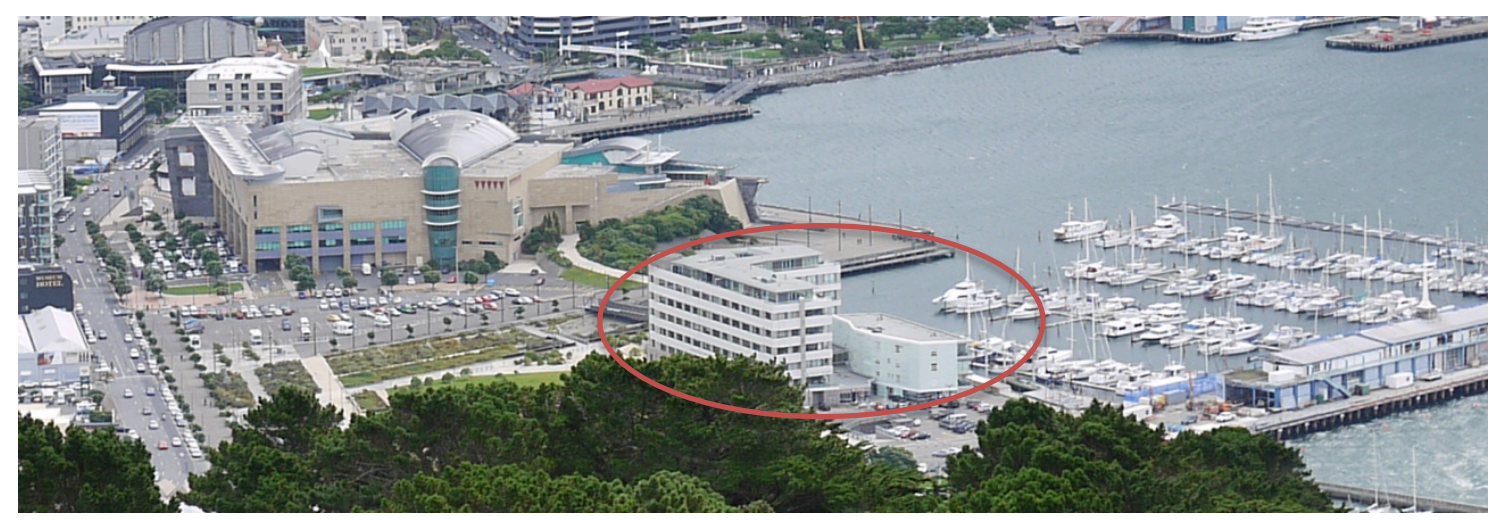

Figure 4.61. The Herd Street Post and Telegraph Building is located in the centre of the photo, between Waitangi Park and Chaffers Marina. (image: author)

With a plan chosen for a new Waitangi Park, resource consent was approved for refurbishing the 1939, six story, Herd Street Post and Telegraph building in December 2003 (WDS, 2004, May 27 Report 3 Appendix 1). There had been some debate over whether to demolish the building due to its size and position between Waitangi Park 
and the waterfront; however, there was enough support for its architectural merit to save it (WDS, 2005, June 20 Report 1 Appendix 1). As a consequence of saving the building, three building sites were identified adjacent to it and the OPT (shown in figure 4.53) with the intent these would step down in height from the two existing buildings to the pedestrian scale (WDS, 2005, June 20 Report 1 Appendix 1).

The approved proposal (identifying the redevelopment as Chaffers Dock) allocated the bottom two floors to include public uses, an atrium to allow access through the building, 56 apartments above, and a public roof top garden and viewing platform (WDS, 2005, May 16 Report 2 Appendix 1). The roof top public space became a condition of consent; however, lingering safety and security concerns prevented it from being opened to the public. Construction started in late 2004 and finished in August 2006 (WDS, 2005, May 16 Report 2 Appendix 1).

2003 Odlins Building (later called the NZX building)

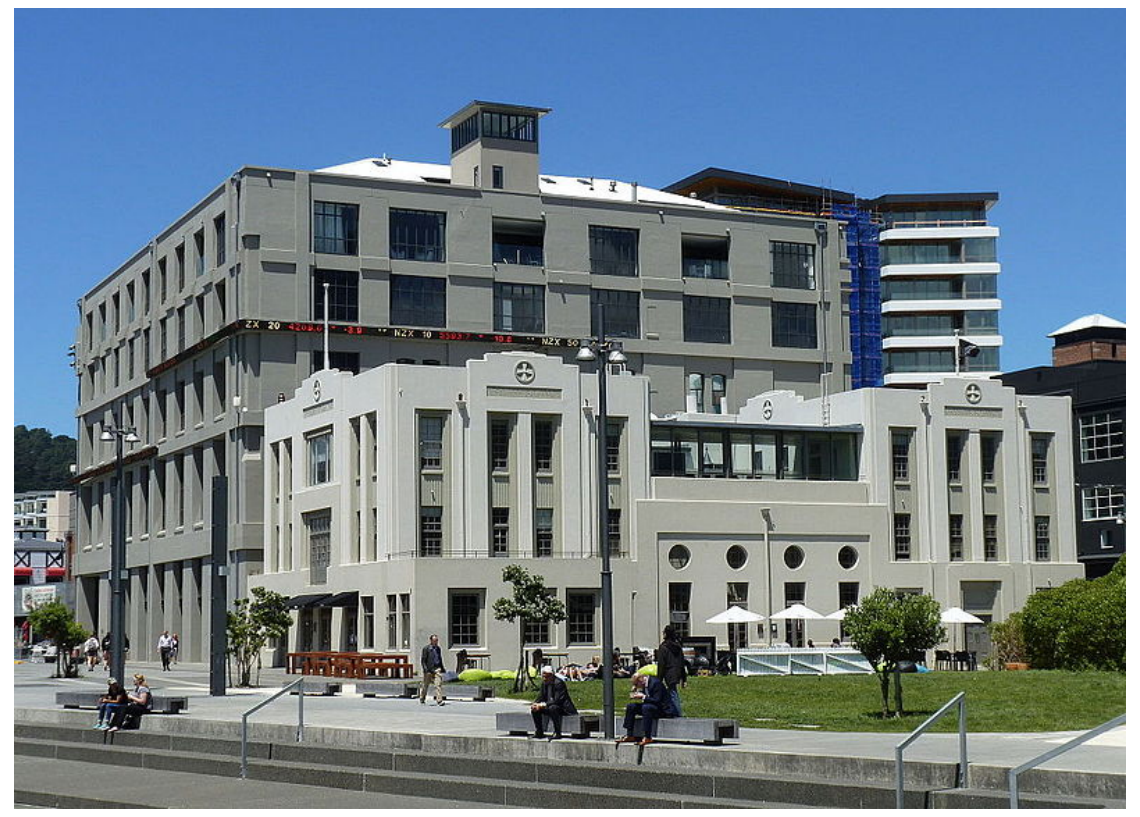

Figure 4.62. Odlins building (dark gray) behind the Wellington Free Ambulance Building (light gray). (image: Michal Klajban, Wikimedia Commons)

The 1906 Odlins building was left empty when in the 1970s the Odlins company moved its manufacturing to Petone, at the north end of Wellington Harbour (STQRY, 2015b). A development agreement was negotiated in 2003 to strengthen and refurbish the five story building into a mixed use development that included ground floor retail 
and restaurant space, four floors of office space, two floors of residential, and underground parking (WDS, 2004, May 27 Report 3 Appendix 1; Willis Bond, 2015). The New Zealand Stock Exchange moved in as the anchor commercial tenant in 2006 (WDS, 2006, May 8 Report 2 Appendix 1). Refurbishment of the building exterior included installation of a horizontal digital stock ticker and the building was renamed NZX.

2004 Upgrade of Events Centre and Shed 6

Wellington Convention Centre Ltd. was contracted by WCC to manage the Events Centre in November 2003. As a part of their review of the facility, they proposed a $\$ 6.9 \mathrm{~m}$ refurbishment to update and improve the viability of the building as an entertainment venue. The proposal was supported by WWL and was approved by WCC in February 2004 (SPC, 2007, June 7 Report 4). WWL initiated the work in 2005 to upgrade the main stage in the Events Centre through improved and additional seating and additional toilet facilities. As the changes were internal to the building, there was not a requirement for public consultation except via the annual development plan and WWL's annual business plan.

Additional upgrades were proposed in 2005 to extend the building on the south end to allow up to 7000 seats, redevelop the adjoining shed six, and improve access to the promenade along this southern edge of the Events Centre (WDS, 2005, May 16 Report 2 Appendix 1). Following a more detailed costing, however, the extension to the building and additional upgrades were found not to be cost effective (SPC, 2007, June 7 Report 4).

\section{Water Whirler}

During the design and consultation of the Taranaki Street Wharf, WWL and TAG continued to discuss where to position a kinetic sculpture crafted from a design by prominent New Zealand artist Len Lye (WDS, 2004, December 13 Report 4 Appendix 1). When drafting the public space design for Taranaki Street Wharf, a location adjacent to the Free Ambulance Building was proposed. As the plan was refined during the design of the wharewaka and wharenui, however, feedback from the public and from TAG suggested more vegetation in that area was preferred over 
installation of the art piece. The sculpture was then positioned at the south end of shed six adjacent to the promenade (WDS, 2004, September 2 Report 6). The sculpture, built on a new jetty near the Events Centre, received resource consent from GWRC in December 2004 and funding from the Lottery Board Millennium Grant (WDS, 2004, December 13 Minutes). Construction finished in 2005 (WDS, 2006, June 26 Report 6 Appendix 1).

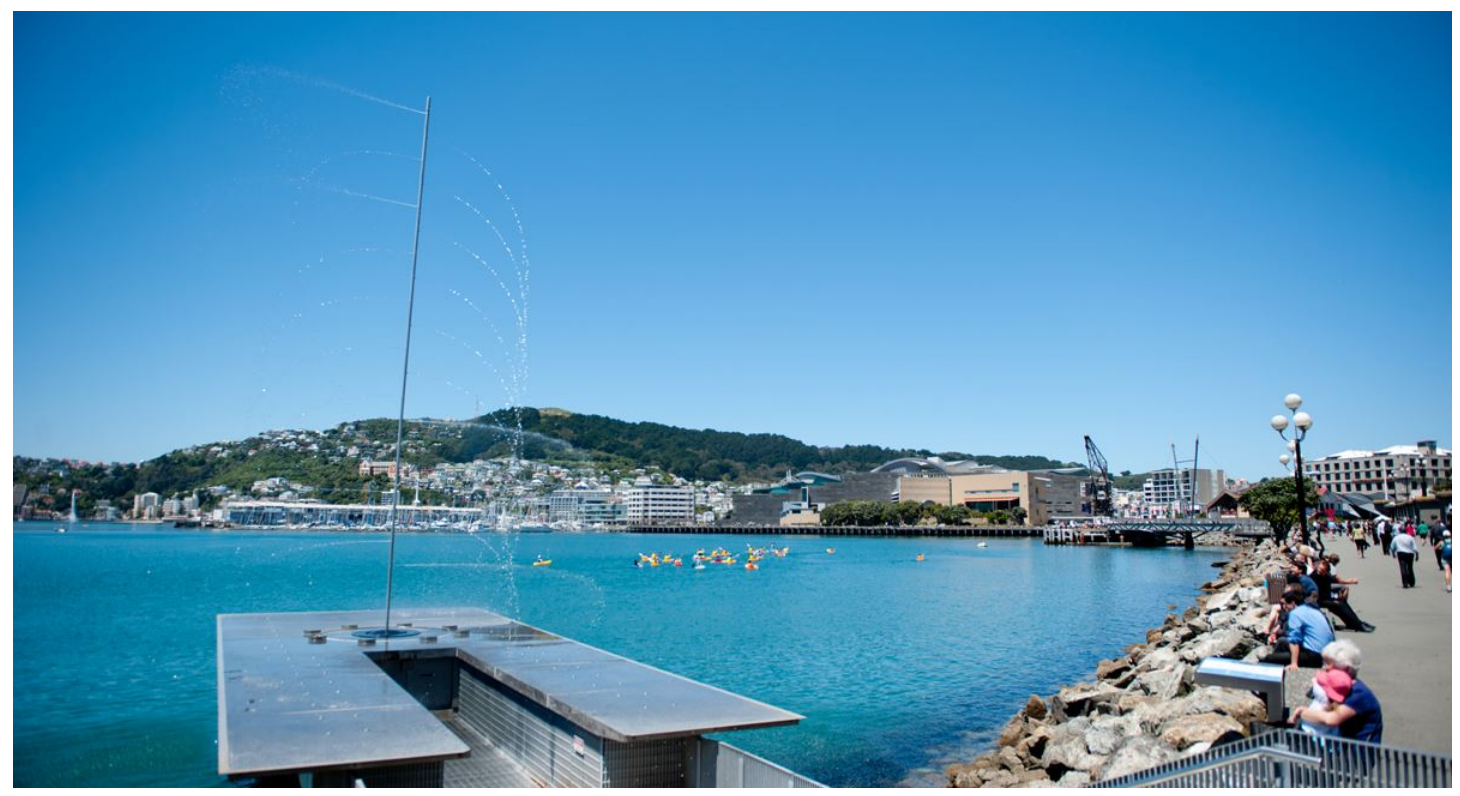

Figure 4.63. Len Lye’s Water Whirler. (image: Wellington Sculpture Trust, 2015)

2005 Wellington Free Ambulance Building

The 1932 Wellington Free Ambulance Building (shown in figure 4.62) was refurbished in 2005 and the first part of 2006 (WDS, 2004, December 13 Minutes). The building, used as a music venue and for other commercial purposes between 1994 and 2003, was fitted out with a ground floor bar and restaurant with two floors of office space above.

\section{Shed 13}

Work to strengthen and refurbish the heritage listed 1905 shed 13 was carried out by WWL in 2006 and 2007. The refurbished building was intended to become additional gallery and event space, to complement the adjacent shed 11 that was refurbished in 1985 (WDS, 2006, May 8 Report 2 Appendix 1). Although it was strengthened and refurbished, it was never used as gallery and event space. Instead, a local coffee 
roaster received consent in 2009 to transform the building into its head offices, roastery, and warehouse facility (Heritage New Zealand, 2015).

\subsubsection{Form and governance}

Design and development professionals were well represented in the decision making process of this governance phase as representatives on WDS and TAG, resulting in their having a strong influence on the waterfront. Similar to the drafting of the 1997 plan, focused design attention given to each precinct and a greater emphasis on open space design led to different visual characters and details for different parts of the waterfront and more small public spaces overall. As an example of this influence, many different means of accessing the water were created: the redesigned lagoon incorporated steps and ramps leading down to the water, the wharf area between the rowing and boating clubs and Te Papa included ladders as a means of accessing the water, and Waitangi Park included a rocky beach as yet another water edge treatment where the wetland area met the harbour. This creative integration of Waterfront Framework principles were linked to TAG's role in drafting the design briefs that emphasised the unique qualities of the five precincts and their work with developers on integrating the principles into their designs.

Even though the public and stakeholders had many opportunities to provide feedback on plans and projects, public input was treated differently from feedback from waterfront stakeholders. This difference also influenced the built form, particularly as summaries of public submissions generally discounted their status as representative of the views of Wellingtonians (e.g. WDS, 2004, December 13 Report 4). Feedback from businesses, tenants, and leaseholders on the waterfront; however, was more often acted upon. For example, WWL responded to submissions from the rowing and boating clubs on the location of the wharewaka and design of the open space regarding access, parking, and loading for their activities. Similarly, WWL responded to concerns of the developers of the Wellington Free Ambulance building when working out the siting of the wharewaka, to ensure the open space between the two was sufficiently wide. Public feedback on the siting of the wharewaka and design; however, included concerns over the loss of the popular grassy mound and impact on views between the City-to-Sea bridge and Te Papa that were not addressed. The 
impact of prioritising submissions by tenants, leaseholders, and businesses resulted in small form changes to public open space and building projects.

Other common features among the projects and plans represented in this governance phase were a response to the Waterfront Framework. These included:

- New buildings were shorter than proposed by previous plans and public spaces were larger.

- There was greater consideration of microclimate effects and attention to limiting vehicle access.

- New developments (e.g. Steamship Wharf Building, Meridian Building, wharewaka) included more active edges on all sides creating a more amenityfilled public space than previous projects.

- Several of the heritage refurbishment projects included modifications to the exterior to improve engagement with the adjacent public areas.

\subsubsection{Transition stimulus}

2004 Overseas Passenger Terminal

The Overseas Passenger Terminal (OPT) was opened in 1964 on an enlarged Clyde Quay Wharf. The OPT was initially constructed to serve as an arrival facility and customs point for passengers arriving in New Zealand by ship. Within a few years, however, air travel became the dominant mode for international travel and the OPT was largely redundant (STQRY, 2015c). The building interior had large open spaces that were used for various events, including the design studio of the Lambton Harbour Group when drafting the 1986 plan, and various industrial and commercial tenants.

The building was not officially designated a heritage building; however, it was identified in the Waterfront Framework and Regional Coastal Plan as having heritage value. The heritage qualities were primarily due to its prominence in views of and from the waterfront and some iconic features including the spire and interior details (see Pene, 2008, Appendix 7).

As a building with perceived heritage value, WWL and WDS could have followed the process used in redeveloping other historic and heritage buildings on the waterfront; 
however, the decision was made in late 2003 to run a design competition for the project. The shift to a design competition, using the following process, marked a transition in how future projects on the waterfront were designed and developed. Formerly, refurbishment projects were marketed as a development opportunity, WWL collected bids on the project, negotiated a development agreement with a developer based on a rough design concept and financial proposal, and then TAG worked with the developer to refine their design. Under this alternative approach, development proposals were selected based on a more advanced design concept in a public competition format.

\subsection{Phase 6b governance (2004 to 2008) - Publicly transparent design competitions used to explore ideas}

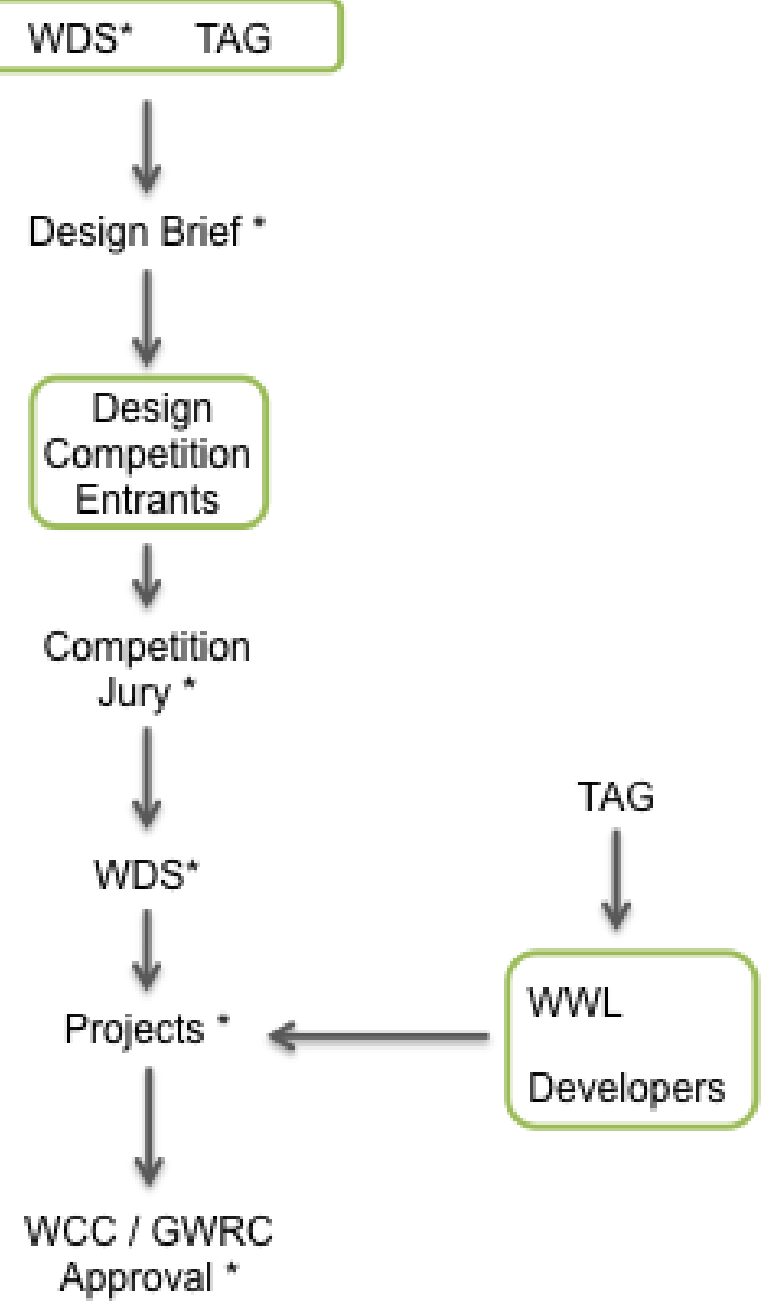

* Included consultation with the public and other stakeholders.

Figure 4.64. Diagram of phase $6 \mathrm{~b}$ governance arrangements. Generally this is a modified phase 6 governance arrangement for design competitions, but with two differences. One relatively large influence on the form of the waterfront was competition entrants pushing the boundaries set by the design briefs. The second was the additional opportunities for the public and other waterfront stakeholders to provide input into decisions about the form. 
A summary of the effects on the form of the waterfront included:

- Designs reflected less of the waterfront's heritage, character, and existing context, and

- Proposals included larger buildings for the development sites than were outlined in the design briefs.

\subsubsection{Governance description}

As illustrated in figure 4.64, the overall governance structure still existed from Phase 6:

1. The WDS retained the responsibilities of planning strategy, conducting public consultation, and overseeing implementation of the waterfront redevelopment;

2. WWL retained its mandate (and advisory board) to coordinate the business of implementing the development plans set out by WDS and organising management and maintenance of the waterfront; and,

3. TAG retained its role in writing the design briefs on behalf of WDS and advising the sub-committee, developers, and WWL on the design and planning of the waterfront.

What did change, however, was using the design competition format for gathering ideas and choosing a developer for individual projects.

Under this alternate governance process, design competitions were used for specific development projects. Once a decision to use a competition format was approved by WDS, the first step would entail TAG drafting a competition design brief based on the Waterfront Framework and applicable precinct design brief (if there was one already). Before the competition brief was approved by WDS, it was released for public consultation. The second step was to solicit expressions of interest from development and design teams. From the submitted applications, a short list of five or six design teams were chosen by TAG and WWL and invited to submit design proposals for the competition. 
With the exception of the Overseas Passenger Terminal competition, all entries were publicly displayed and feedback was gathered. This was a major change from the Waitangi Park competition, where the public was given a chance to vote on their favourite, even though the vote was not used to choose a winner. Third, the appointed jury members took into consideration the public feedback and a review of entries by TAG before recommending a winning entry to WDS for approval. The winning team would then work with TAG to refine the design to align with the Waterfront Framework, test the feasibility of the project, and respond to the contextual conditions of the waterfront. Finally, once the final design was approved by WDS, WWL would negotiate a site lease and a planning consent application would be formally submitted for a final public review and final statutory approval. 


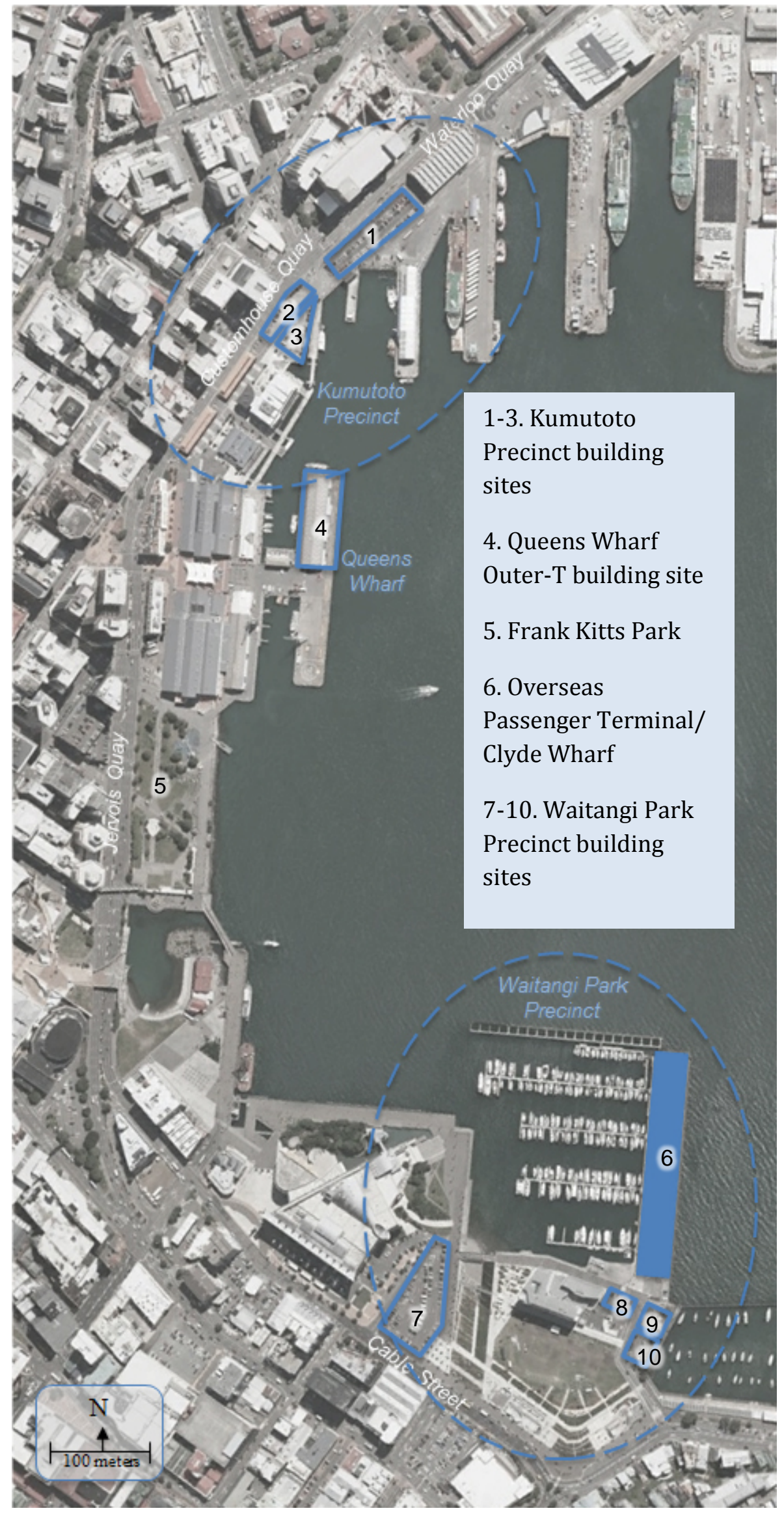

Figure 4.65. Location map of phase $6 \mathrm{~b}$ projects and features. Blue polygons identify constructed projects. Blue squares identify proposed building sites. (base image: Google Earth, accessed November, 2015). 


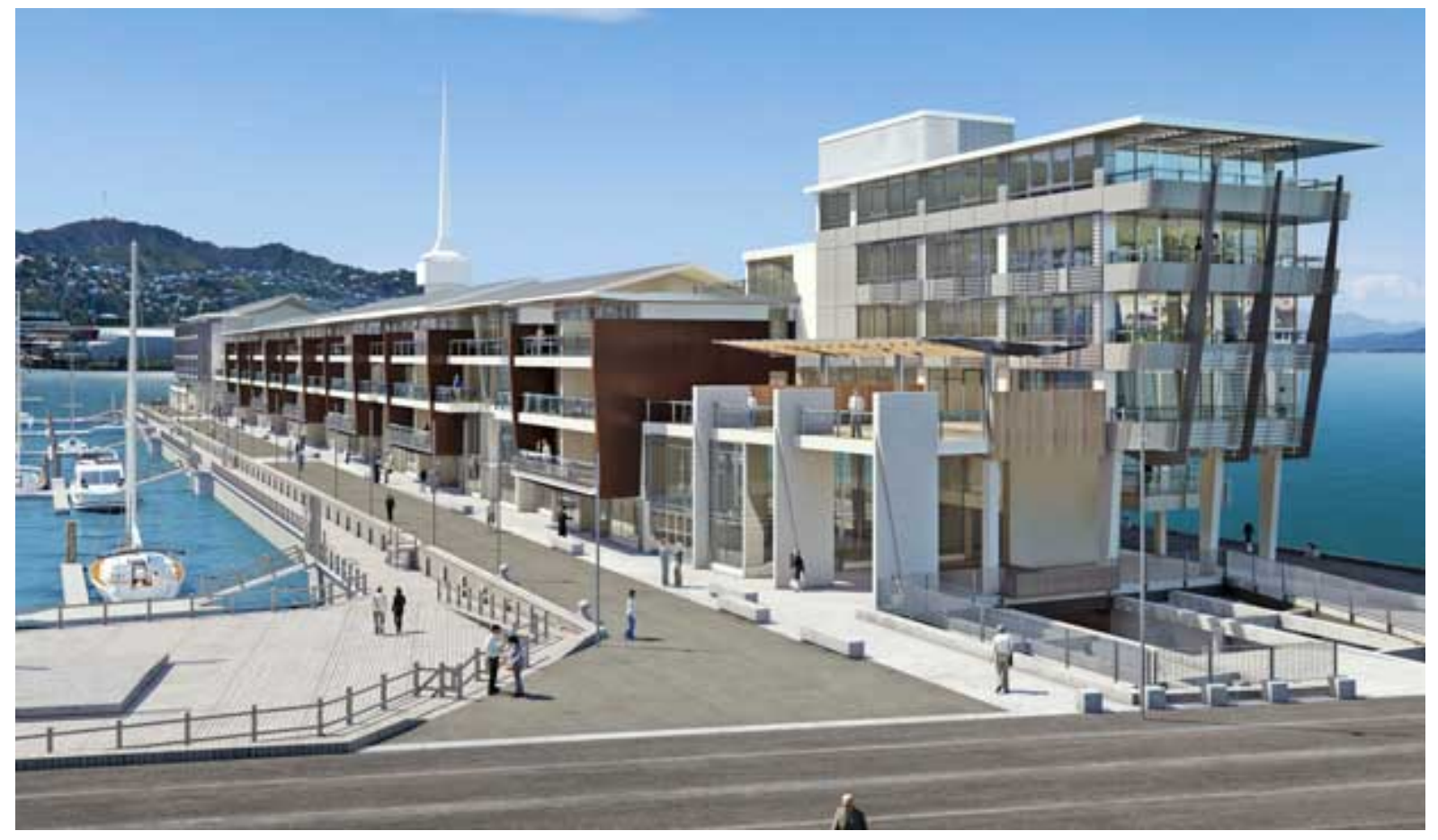

Figure 4.66. An artist's rendering of the winning entry for the OPT design competition. (image: Athfield Architects Limited)

The competition design brief for the Overseas Passenger Terminal (OPT), prepared by TAG, was approved by the WDS in April 2004 after a six week public consultation period (WDS 2004, May 6 Minutes; Pene, 2008, Appendix 1, p. 12). The brief anticipated adaptive reuse of the building and retention of characteristic details such as roof profile, structural bays, and evidence of past maritime and industrial uses. Maritime heritage included mooring bollards, pilings, and the crane rails set into the north-east portion of the wharf (Pene, 2008, Appendix 5, p. 8; WDS, 2004, May 6 Report 3 Appendix 1).

Other criteria outlined in the brief include reference to WWL design strategies on lighting and furniture; having a clear relationship to Waitangi Park and the Herd Street Post and Telegraph building; considering the impact on long and short views; providing shelter from the weather for pedestrians; programming active edges and access to the ground floor; improving access to the water; and, including vertical divisions on the façade to break up the great length of the building. The proviso for any architectural moves was the requirement they "must maintain the formal 
townscape and architectural qualities of the OPT as identified by the heritage assessment” (WDS, 2004, May 6 Report 3 Appendix 1, p. 2). While not formally designated a heritage building, the OPT was listed in the Waterfront Framework and Regional Coastal Policy as having heritage value. The direction provided in the Waterfront Framework, however, is limited to a requirement that the OPT be “retained and developed” (Waterfront Framework, 2001, p. 37).

Clyde Wharf, upon which the OPT sits was required to retain berths for a range of vessels and support uses that complement the adjacent Chaffers Marina, while parking was be provided below grade or integrated into the building with limited vehicle access to pedestrian areas. The brief did, however, allow departures from the requirements if the design was perceived to be of a very high standard and the solutions for addressing the issues and constraints of the site were particularly elegant.

The project was advertised in 2004 in New Zealand, Australia, and Singapore. In response, 29 New Zealand and international developers expressed interest in the project. From this list, six were invited to submit proposals that were evaluated by WWL, TAG, and WCC officers (SPC, 2007, June 27 Report 1 Appendix 1). To develop their proposals, the six developers were sent the design brief, a report on the history and heritage value of the OPT, an engineering assessment of the wharf, draft lease documents, certificates of title and a copy of the Waterfront Framework (SPC, 2007, June 27 Report 1 Appendix 1).

To assist in identifying the winning proposal, a two day public workshop in December 2004 was organised by WWL to help identify appropriate ground floor and adjacent public open space uses for the OPT and nearby building sites (WDS, 2005, May 16 Report 2 Appendix 1). A mix of food services, marine-oriented retail, and artist studios were identified for the ground floor of the OPT. Following the workshop, three proposals were short-listed and the developers were asked to consider the preferred uses in a revised proposal (SPC, 2007, June 27 Report 1 Appendix 1). The winning proposal (shown in figure 4.66) was announced in April 2005 and subsequently was revised in collaboration with WWL and TAG before receiving final approval by WDS in May 2006 (WDS, 2006, June 26 Report 5). 
The chosen proposal was preferred by the urban design and planning staff at the WCC and TAG because it "best retained parts of the heritage fabric and referencing [sic] the existing building.” (Gerald Blunt, Manager Urban Design Policy, WCC quoted in Pene, 2008, Appendix 1, p. 14). Assessment of the design by TAG identified the proposed design of the new building as reflecting the form of the original structure while adding contemporary design cues (cited in Pene, 2008, Appendix 5, p. 2), even though it retained very little of the original structure. The TAG report also argued the added height and bulk of the new building was appropriate to the adjacent buildings and the site's position in the harbour. Therefore, even though the Waterfront Framework states, “The Overseas Passenger Terminal will be retained and developed” (2001, p. 37) and the OPT was listed in the WCC 2001 heritage building inventory, the proposed design and associated public space amenity was regarded as appropriate, and in some ways superior, to the existing structure. Also, noted by Mr. Blunt was that the wharf required significant repairs and, therefore, there was a desire for proposals that minimised WCC and WWL costs to repair the wharf (Pene, 2008, Appendix 1, p. 14).

TAG met with the development team multiple times prior to the proposal being submitted for consent (Pene, 2008, Appendix 5, p. 2). The purpose of the pre-consent meetings was to review and comment on the design to ensure the proposal met the requirements of the OPT design brief. The final pre-consent meeting was held in April 2006 (Pene, 2008, Appendix 5, p. 2). The review of the design by TAG noted the central portion of preferred proposal maintained the architectural cues of the original building, but the design improved upon the experience and function of the OPT and adjacent public space in many other ways (WDS, 2006, May 8 Report 1 Appendix 3). The TAG report also noted the proposed design improved the architectural relationship of the OPT to the winning design for sites one to three of the Waitangi Park Precinct design competition that had been held in 2005 (discussed below); however, some short and long views were impacted by the increased bulk of the proposal.

The chosen proposal was opened to formal public consultation from May to June 2006, including a public open day in May, receiving 74 submissions (WDS, 2006, June 26 Report 5). The report on submissions noted the largest issue raised by 
submitters (noted in 27 of the 74 submissions) was regarding the lack of parking for marina users and that WWL was working with marina users to resolve the issue (WDS, 2006, June 26 Report 5). The open space design continued to be refined in 2006 and 2007 in response to parking requirements of the adjacent Chaffers Marina (WDS, 2006, June 26 Minutes; WDS, 2007, June 25 Minutes). Other than around parking, the report noted the number of submissions in support were roughly equal to the number opposed. Further, it argued the low number of submissions could not indicate whether positions on the issues raised were widely held and recommended no changes to the proposed design (WDS, 2006, June 26 Report 5).

A recommendation for a 125 year lease agreement for the building site, with the surrounding open space to be retained by WWL, was passed from WDS to the WCC Strategy and Policy Committee in July 2006 with a recommendation to approve (Pene, 2008; WDS, 2006, June 26 Minutes). The lease terms were then passed to a regular meeting of the full WCC where it was approved in June 2007 (SPC, 2007, June 27 Minutes). Within the terms was the option for WWL to sign a head lease for ground floor space to ensure the desired mix of tenants is achieved (SPC, 2007, June 27 Report 1). Additionally, WWL would retain control of the surrounding public space.

The project then needed consent from the GWRC and was opened again for public input October 2007. Despite objections by GWRC planning staff regarding the proposal's approach to the heritage value of the existing building and adverse effects on coastal marine area, the GWRC's decision to approve the project in May 2008 noted the over-riding benefit of the proposal to the development and use of the waterfront area (GWRC, 2008). In their report, they cited the larger benefits to the city and the waterfront included: the townscape heritage value of the OPT was respected in the proposed design, the quality of the public open space was improved through design and supporting activities, and strengthening of the deteriorating wharf would allow continued use (GWRC, 2008).

The planning approval was challenged in the Environment Court in 2008 by Waterfront Watch based on a range of objections, including the loss of the heritage value of the existing structure and wharf, impact on views, adverse microclimatic 
effects, reduced public access to the wharf, increased vehicle traffic and loss of surface parking (Environment Court, 2009). The Environment Court, however, upheld the resource consent in June 2009 citing the overall benefits of the design to the development of the waterfront and the limited adverse effects on the use and experience of the public space (Environment Court, 2009; SPC, 2009, August 26 Appendix 1).

The proposed redevelopment included publicly accessible ground floor uses along the length of the building, 86 under-wharf private car parks, a further 26 public parking spots and 28 marina car parks available on the wharf itself, 95 residential apartments, and space for marina offices and marine related services (SPC, 2007, June 27 Report 1 Appendix 1).

The proposed building was taller and slightly longer than the existing building, but would retain the publicly accessible wharf area on all three sides fronting the water and some of the iconic features of the existing building. The existing building was $12 \mathrm{~m}$ tall, while the proposed was $17 \mathrm{~m}$ tall at the harbour end, $15 \mathrm{~m}$ in the middle, and $18 \mathrm{~m}$ at the end closest to Waitangi Park and the Herd Street building. The heritage elements that were retained included: the original spire, portions of the roof were restored and reused, the overall proportions were generally maintained, mosaic murals were retained, and the interior open space on the seaward end (SPC, 2007, June 27 Report 1 Appendix 1).

\section{Waitangi Precinct Design Competition}

A design competition for four building sites in the vicinity of Waitangi Park was proposed by WWL in February 2005 (WDS, 2005, November 28 Report 1). As described in section 4.7.2, the Waterfront Framework and subsequent design brief for the Waitangi Park design competition were inconclusive regarding whether vegetation or buildings were the most appropriate way of stepping down from the scales of the buildings surrounding Waitangi Park (Waterfront Framework, 2001, p. 39). The winning entry for the Waitangi Park design competition, however, indicated four potential buildings sites for this purpose (see figure 4.53). The WDS approved a design brief for the four building sites, prepared by TAG, that allowed the entries to 
vary size, number, and location from the building footprints outlined in the winning Waitangi Park scheme (WDS, 2005, June 20 Report 1 Appendix 1).

According to the brief, proposed buildings were to respond to the scale and architecture of Te Papa, Herd Street Apartments, and the OPT - all very large buildings - but transition down to the scale of the pedestrian and provide amenities that complemented adjacent open space (WDS, 2005, June 20 Report 1 Appendix 1). The design for the new buildings was also to complement the existing buildings, create a range of smaller public spaces and amenities to compliment Waitangi Park, and provide underground parking for 240 to 300 cars (WDS, 2005, June 20 Report 1 Appendix 1).

Programming consideration for the site adjacent to Te Papa also included creating space for, and responding to, the design and programming of a future Chinese Garden (moved to Frank Kitts Park in 2006), plus auxiliary museum display space (WDS, 2005, June 20 Report 1 Appendix 1). Suggested programs for the three building sites proposed for the east side of the Herd Street building included: a high-end delicatessen and seafood restaurant; recreational facilities and services (e.g. indoor rock climbing, kayak rentals, bicycle rentals); and, restaurant and café with a boutique hotel above (WDS, 2005, June 20 Report 1 Appendix 1).

Contextual considerations outlined in the design briefs included: protecting potential future view sheds along Kent and Cambridge Terraces that were currently blocked by a large grocery store, retaining and enhancing visual connections between Waitangi Park and the harbour, and providing pedestrian connections with the walking route along Oriental Parade (WDS, 2005, June 20 Report 1 Appendix 1). The design brief also noted the sites fell within an area that had historically been used by Maori for food collection and, later, various maritime industrial activities. Despite this, the building sites were described as having fewer heritage issues than other parts of the waterfront (WDS, 2005, June 20 Report 1 Appendix 1).

The considerations and programming identified in the design brief were based on (WDS, 2005, November 28 Report 1):

- the Waterfront Framework, 
- the 2003 Waitangi Park design,

- the annual public opinion surveys commissioned by WWL,

- three focus groups run in October 2004 (representing 9-12 years, 13-15 years, and 55+ years) organised to obtain feedback from portions of the population identified as currently underserved by the waterfront development,

- $\quad$ the 2004 Wellington public spaces and public life study by Jan Gehl and his team,

- an invited workshop, involving neighbouring lease holders and tenants and other interested groups held in December 2004, and

- a commissioned study of the commercial viability of ideas generated in the above sources.

In addition to informing the competition brief, the sources above were used by WWL to draft a Ground Floor Use Strategy in 2006. Based on these feedback mechanisms WWL believed that they had "a comprehensive understanding of what a wide range of Wellingtonians want to experience on their waterfront” (WDS, 2006, June 26 Report 6 Appendix 1, p. 49). As discussed in section 4.10.2 on Variation 11, this belief came back to haunt them as they undertook little to no consultation on later waterfront plans.

For the competition, 21 established New Zealand and international architects were invited to submit written expressions of interest (WDS, 2005, June 20 Report 1). From the list of invited firms, 11 registered by May 2005 and from these a short list of five were invited to submit concept plans for the four building sites (WDS, 2005, November 28 Report 1).

Concept designs were received in September 2005 and displayed in a four week public exhibition. Over 3000 visitors to the exhibition returned 315 feedback forms (WDS, 2005, November 28 Report 1). Unlike the Waitangi Park competition, the public were not asked to identify their favourite as the choice was not to be determined by public voting (WDS, 2005, November 28 Report 1). From the feedback, there was support for all five entries; however, 15\% of those who provided feedback wanted no new buildings at all (WDS, 2005, November 28 Report 1). During October 2005, the concept designs were also examined for technical 
feasibility by TAG and financial feasibility by an independent quantity surveyor (WDS, 2005, November 28 Report 1).

The competition was judged by a panel that included the chair of the WWL board of directors, a representative of the Te Papa board of directors, Ian Athfield - a highly regarded New Zealand architect, a representative from Auckland University School of Architecture, a representative from the local Victoria University School of Architecture (also a member of TAG), and Maggie Barry - “a respected and notable Wellingtonian” (WDS, 2005, November 28 Report 1). The judging panel met at the end of October and again in November to make a decision, which drew on feedback from TAG, the public, and the commissioned quantity surveyor (WDS, 2005, November 28 Report 1).

The jury awarded the three building sites adjacent to the OPT to John Wardle Architects (see figure 4.67) due to the high quality of the concept design and the belief these sites needed to be designed cohesively (WDS, 2005, November 28 Report 1). The site closest to Te Papa was awarded separately to UN Studio (see figure 4.68) (WDS, 2005, November 28 Report 1). Once the winners had been chosen, WWL began advertising for tenants in 2006 (WDS, 2006, June 26 Minutes).

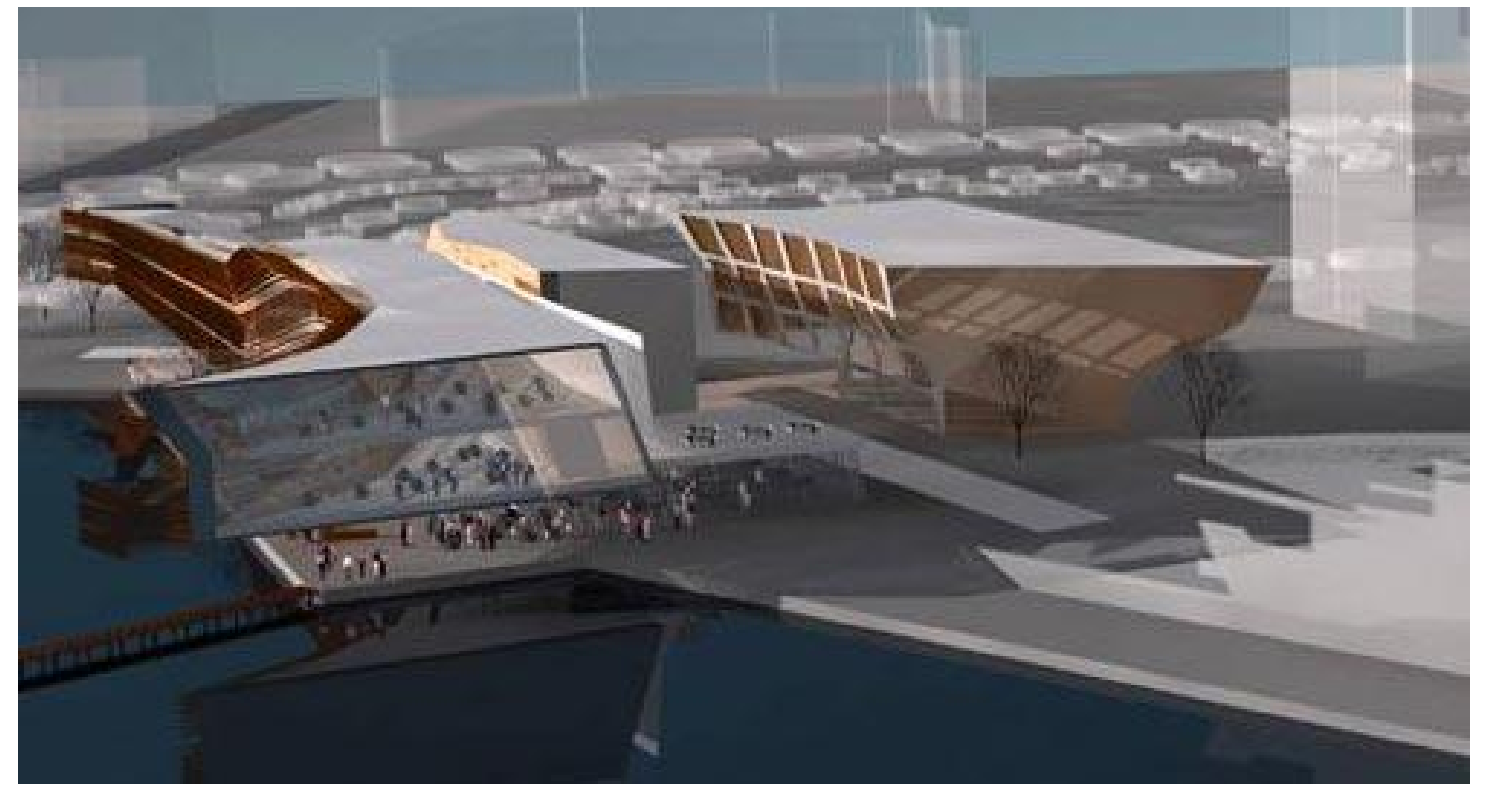

Figure 4.67. John Wardle Architects winning entry for the building sites closest to the OPT. (image: John Wardle Architects) 


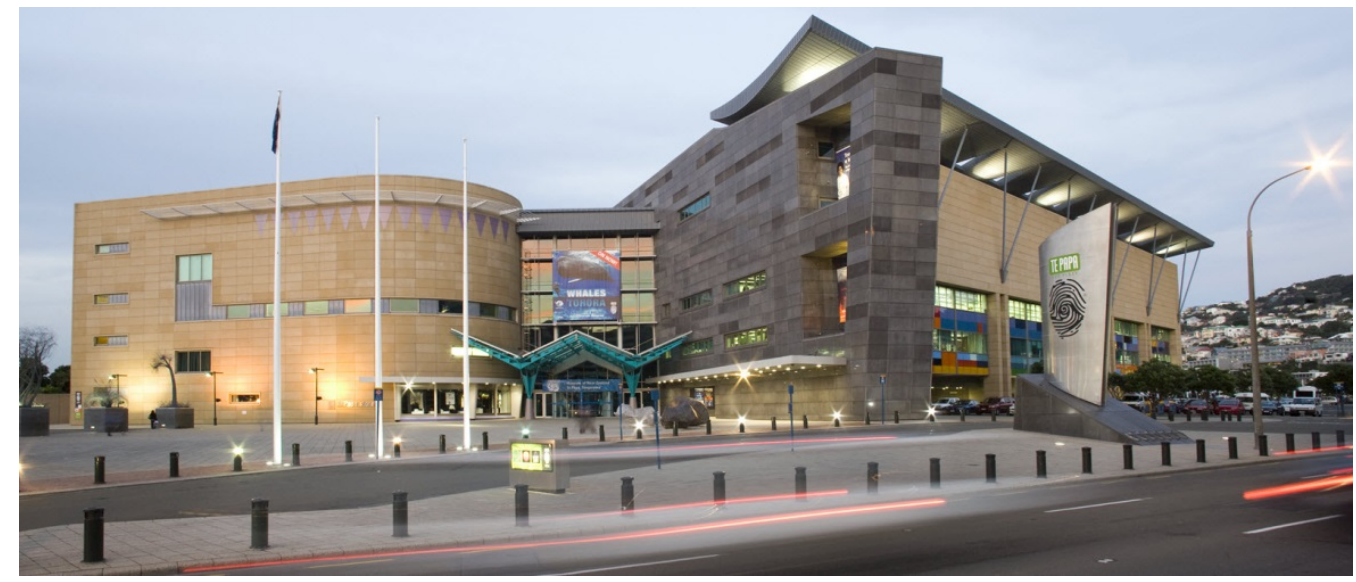

Figure 4.68. Entrance to Te Papa. (image: Wellington Regional Economic Development Agency, 2016)

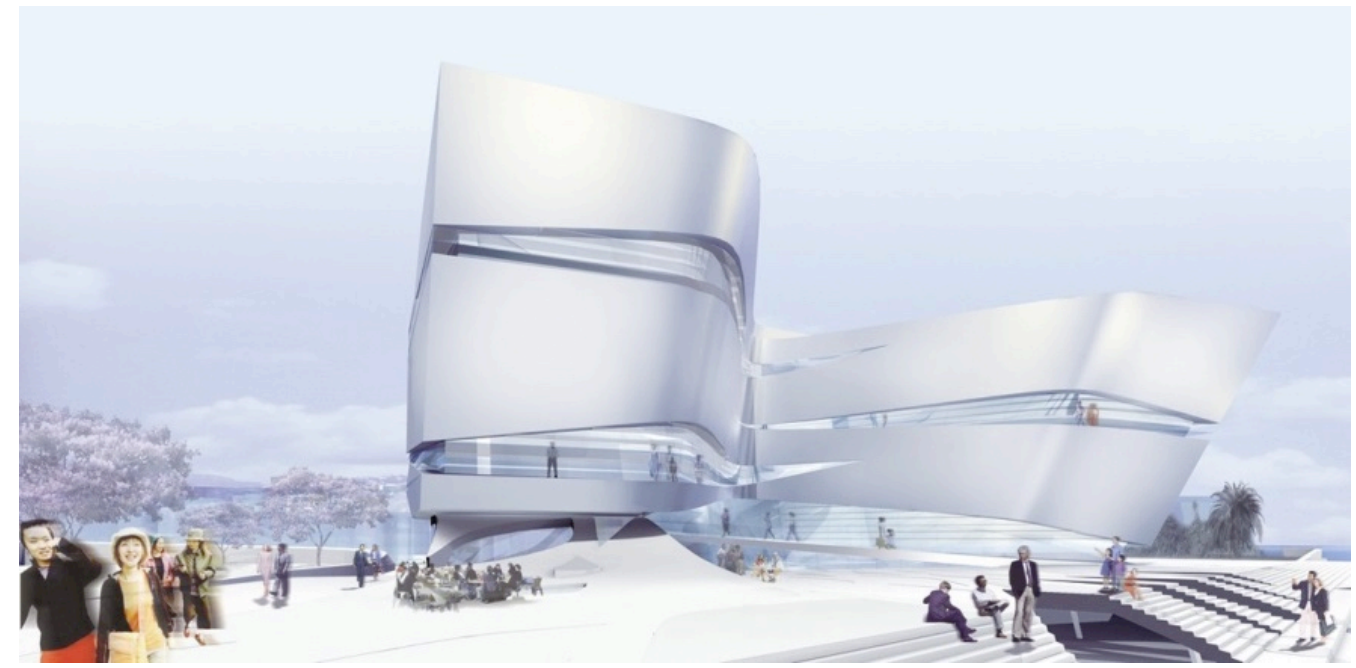

Figure 4.69. UN Studio's winning entry for the building site closest to Te Papa. (image: UN Studio)

While both winning entries had their own character, they did respond to the brief of creating pedestrian amenity and responding to the character of the adjacent buildings. As can be seen in figures 4.68 and 4.69 the UN Studio design is reminiscent of the entry to Te Papa with the recessed entry, curved walls, prow-shape and horizontal windows. At the base of the buildings there are sheltered and more exposed seating areas for pedestrians. The John Wardle Architects entry also includes protected public open space on the ground plane and prow-shaped building facades, but utilises a strong linear form that responds to the long OPT building (see figure 4.66) and horizontal banding of the adjacent Herd Street building. 
Detailed design of the adjacent open spaces continued through 2007 and 2008 (WDS, 2007, June 27 Report 1 Appendix 1). From 2008 to 2010 the projects were shelved due to the global recession affecting interest in developing the projects and WWL trying to move other waterfront projects forward (SPC, 2010, April 15 Report 1). In 2010, WWL proceeded with the feasibility studies for the proposed buildings (SPC, 2010, April 15 Report 1).

While the building projects were delayed, the site closest to Te Papa was used as a market space on weekends, as additional parking space during the week, and as a proposed site for a temporary high tensile fabric shelter to be used for events (SPC, 2010, June 23 Report 2 Appendix 3).

2006 Kumutoto Development Sites eight to ten

WWL also began working on advertising for expressions of interest for sites eight to ten in late 2006 (see figure 4.54) (WDS, 2006, September 4 Minutes). The 2007/08 Development Plan outlined a strategy to run design competitions for the remaining three sites following the model used for the Waitangi Park Precinct competition (WDS, 2007, June 25 Report 1 Appendix 1); however, neither the WDS minutes nor the WWL development plans mention public consultation on the competition design brief. Possibly WWL's statement of "having an understanding of what Wellingtonians expect” (WDS, 2006, June 26 Report 6 Appendix 1, p. 49), in the context of the Waitangi Park Precinct design competition, indicates they proceeded with a competition brief drafted using feedback from previous briefs instead. The public did, however, have the opportunity to provide feedback on the entries (WellUrban, 2007) and the final design prior to them being submitted for resource consent (WDS, 2006, June 26 Report 1 Appendix 1).

In 2008, designs were chosen for all three sites; however the appeal of Variation 11 (see section 4.10.2) and the 2008 financial crisis prevented these projects from progressing (SPC, 2010, April 15 Report 1; Forbes, 2013). Also, a review process of WWL's ten year work plan was initiated in 2008 delayed progress as there was negotiations between WWL and WCC about which parts of the waterfront were to be prioritised (SPC, 2008, August 21 Report 4). 


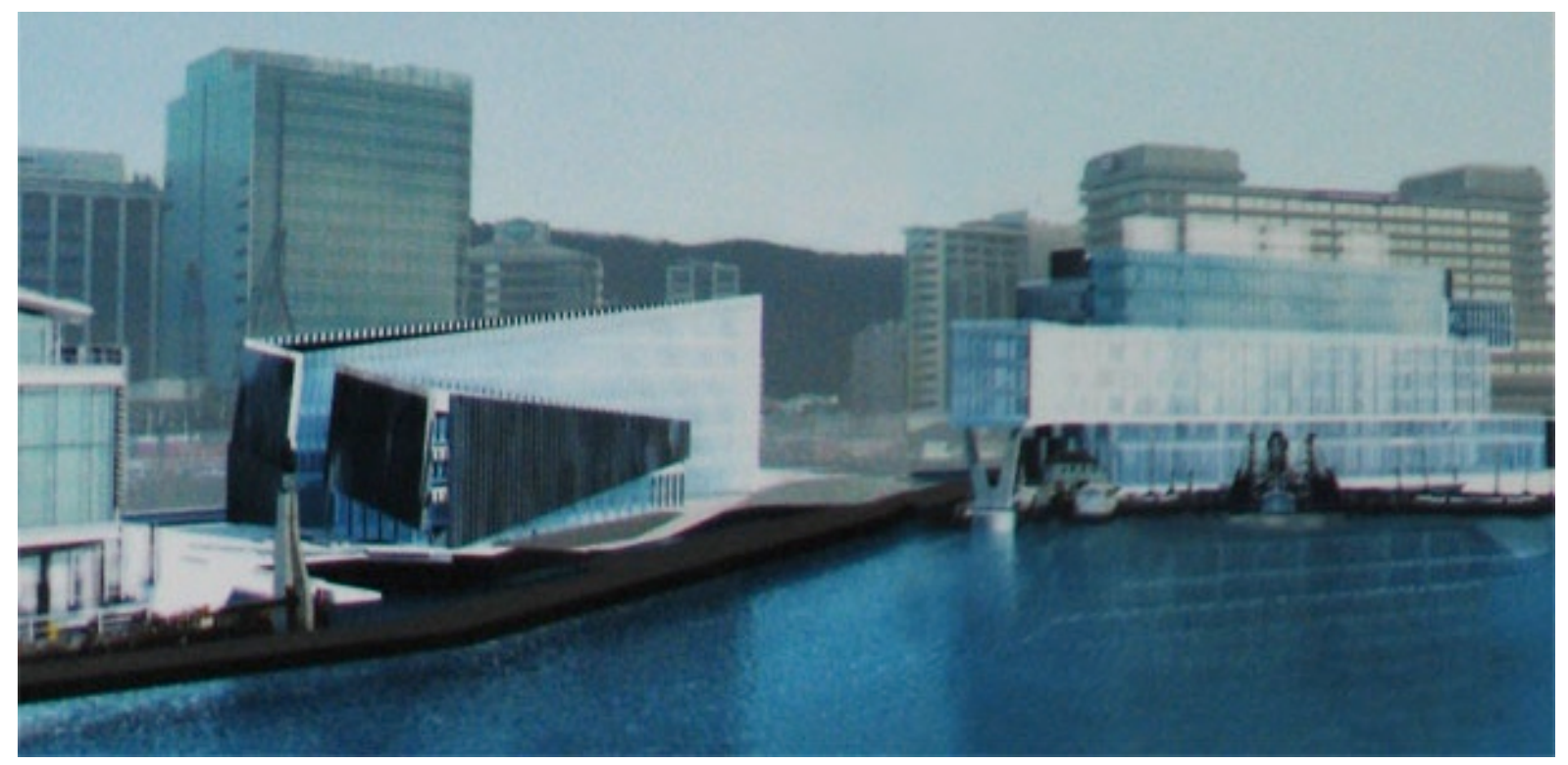

Figure 4.70. The winning proposal for building sites eight, nine, and ten in the Kumutoto precinct. (image: Athfield Architects Limited)

In the winning proposal, shown in figure 4.70, the building on the left rising from left to right responded to a requirement in the design brief for the side closest to respond to the height of the Meridian building (just visible on the left side of the image) and nearby heritage buildings. Up to six stories was permitted on site ten (where the rectilinear glass building on the right is located) to respond to the height of the adjacent shed 21 (discussed in section 4.7.2). The building proposed for site ten, however, was eight stories tall which contrasted with the adjacent two story Eastbourne Ferry Terminal building (just visible by the concrete ' $\mathrm{V}$ ' supporting the projecting middle floors).

The winning entry reflected the contextual difficulty of transitioning from the nearby office buildings to the scale of the pedestrian oriented waterfront and heritage buildings on a narrow portion of the waterfront. Further, the close proximity to the central business area and railway station was a draw for taller buildings and development intensity in all of the waterfront plans, including the proposed 31 story tower in the 1989 Combined Scheme (see section 4.5.2).

WWL continued to work with developers on proposals for the sites and drafted Variation 11 in 2008 partly as a mechanism to give more predictability to what should happen regarding the form and process of future proposals (see section 4.10.2) 
(Forbes, 2013). In February 2012 a new design was proposed for site ten which included five stories of office space over a publicly accessible ground floor (Shelton, 2012). The design met the form and programming criteria outlined in Variation 11, however, a decision on it was delayed as Variation 11 had been challenged in the Environment Court by Waterfront Watch and was pending a decision.

2006 Frank Kitts Park redesign competition

The idea to redesign Frank Kitts Park was proposed in 2005 with development of the design brief continuing to be developed through 2006 and 2007 (WDS, 2005, May 16 Report 2 Appendix 1; WDS, 2006, May 8 Report 2 Appendix 1). The Waterfront Framework, however, did not see redevelopment of this park as a major priority on the waterfront (Waterfront Frameworks, 2001, p. 35). Instead, it recommended small improvements to safety along the Jervois Quay edge, designated parking and drop-off areas along Jervois Quay, better access to the water from the promenade, the possibility of a breakwater to create an activity area on the harbour edge, and better transition to the south end of the Events Centre.

The design brief for the Frank Kitts Park was released by WDS for public consultation in September, 2006 (WDS, 2006, September 4 Minutes). Rather than a complete reconstruction, the brief is focused on incorporating the 3000 sq.m. Chinese garden (see section 4.5.2), improved interaction of the park with Jervois Quay as a part of the WCC 2006 'Greening the Quays’ project, improved safety for children along the edge facing Jervois Quay, improved relationship between the park and the south side of the Events Centre where most of the services were clustered, improved connections with the water and the city, improved views in and out of the park, and retaining the existing covered parking underneath the existing park (WDS, 2006, September 4 Report 4 Appendix 1). Not mentioned in the brief, but also under consideration was a plan for a break water off Frank Kitts Park; however, this was put on hold until plans for the park had been chosen and other development projects had been completed (WDS, 2007, June 25 Minutes).

The design brief was released for a six week public consultation period in late 2006 (WDS, 2006, December 11 Report 4). Following review of the public submissions 
WDS approved the design brief with no changes in December 2006. Similar to the previous two competitions, all interested landscape architecture firms were asked to lodge an expression of interest, a short list of firms selected by WWL were invited to submit concept designs, the entries were publicly displayed and opened for public feedback, and a winner was selected by a jury (informed by public feedback and TAG review) and recommended to WDS for approval (WDS, 2006, December 11 Report 4). While the brief asked for a design covering the whole park area, the design for the Chinese garden was to be undertaken through a separate process (WDS, 2007, June 25 Minutes).

The 2007/08 development plan noted the Frank Kitts Park design competition should proceed; however, construction was to be delayed until 2009 or 2010 to allow for anticipated development income, from the delayed OPT and the hotel on the outer-T projects, to fund WWL's portion of the costs (WDS, 2007, June 25 Report 1).

Eleven firms registered for the competition and five were invited to submit design concepts (WCC, 2007, December 19 Report 1 Appendix A, part 1). To judge the entries, the jury reviewed the Waterfront Framework, the competition design brief, TAG assessment of the Frank Kitts Park entries, 128 public submissions received during the public exhibition of the entries, and feedback from the Wellington Chinese Garden Committee (WCC, 2007, December 19 Report 1 Appendix A, part 2).

The winning entry, shown in figure 4.71, contained three key areas: the green-roofed car park with active edges, a defined Chinese garden and tea house that lay along one of the recovered view shafts through the park, and a revised children's playground on the north end of the park. Complementing these more developed areas were two open grass lawns plus a wetland area adjacent to Jervois Quay (WCC, 2007, December 19 Report 1 Appendix A, part 3]). Although a winner was chosen, the details of the design would continue to be refined with input from TAG and the Wellington Chinese Garden Committee (SPC, 2008, June 18 Report 1 Appendix 1). 


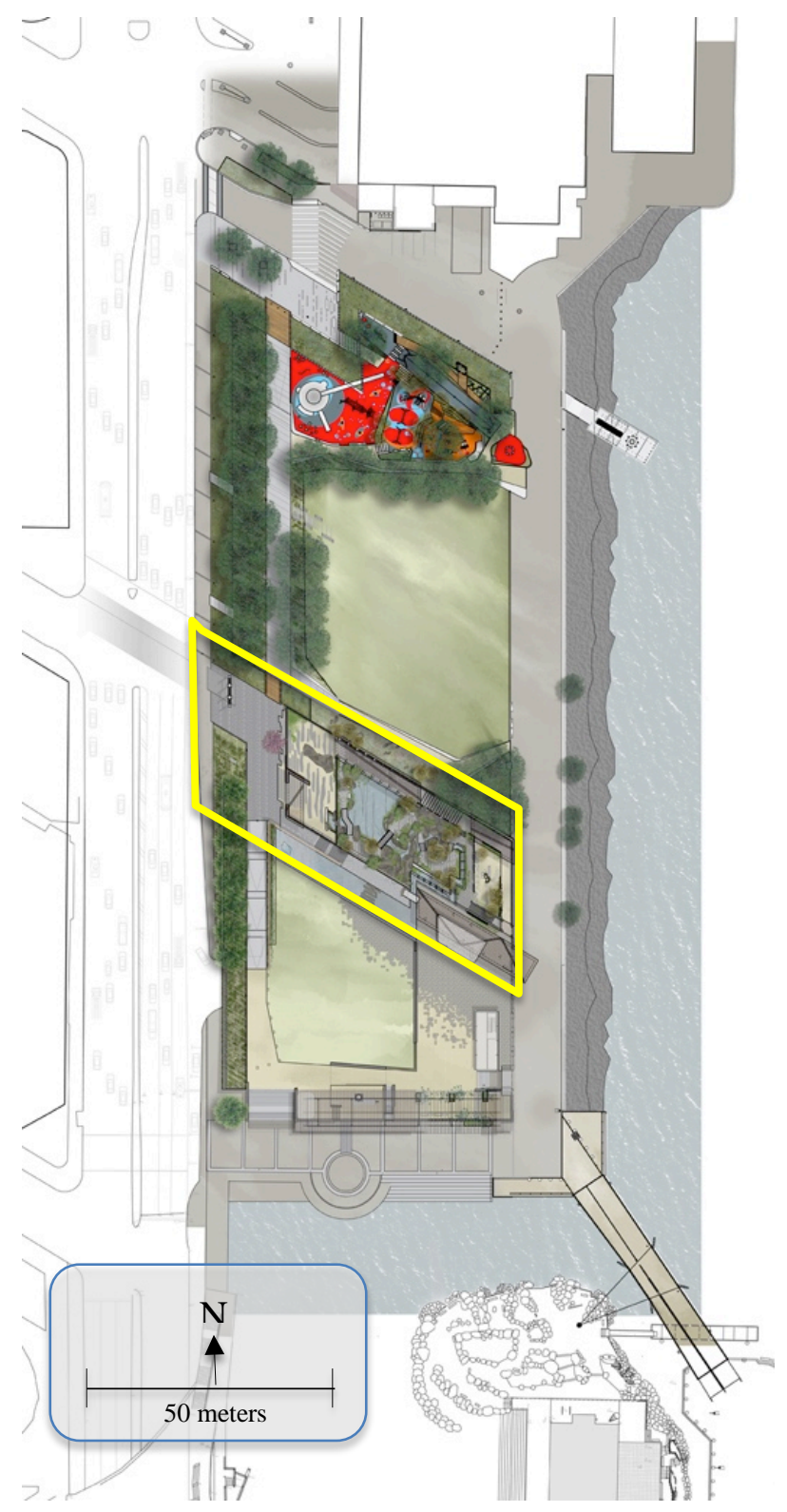

The alignment of the children's playground (marked in red in figure 4.71) and the Chinese garden (outlined in yellow) are positioned to open up and complement views of the harbour down the respective city streets. The open space to the right of the Chinese garden is situated on top of the existing car park, while the open space on the left of it opens up directly onto the promenade. With the exception of retaining the car park, all of the proposed changes reorient the park towards the harbour by removing the existing wall along the promenade.

Figure 4.71. The winning entry for the redesign of Frank Kitts Park. The Chinese Garden is outlined in yellow (image: Wraight \& Associates)

Following the competition, WWL did not have the funding or the mandate to push forward with the detail design and implementation of Frank Kitts Park. A work plan review of the waterfront redevelopment project undertaken in 2008 to decide on the priorities for the following 10 years, combined with the loss of anticipated income from the overturned Hilton Hotel project (described in section 4.5.2) and Environment Court appeal of the OPT resource consent meant the park redevelopment was postponed (SPC, 2008, August 21 Report 4). The 2008/09 development plan did note, however, that commitments by WCC to the Beijing City Council meant the design and planning of the Chinese garden would continue even though the rest of the design was put on hold (SPC, 2008, August 21 Report 4). 


\subsubsection{Form and governance}

While the process did enable public input to inform the selection process, the final choice by WDS was largely directed by the design juries. TAG also had a significant say through drafting the competition briefs, commenting on the entries, and having representation on WDS. This arrangement meant design professionals had a greater say on the winning entries than members of the public, although this is not to suggest that there was a conspiracy to undermine the Leadership Group's intent for a publicly inclusive process. The way decision making was handled, however, and the larger representation of people with design backgrounds involved in making decisions, meant the governance process outlined by Waterfront Framework was less likely to be reflected in the form. This relationship was expressed in the following ways.

In this phase, the winning projects pushed the limits of what the Waterfront Framework recommended. The design competitions generated ideas and options that generally respected the parameters recommended in the Waterfront Framework, but reinterpreted them to allow for other values to be expressed. In the case of the OPT, the Waterfront Framework recommended "retaining and developing”; however, WDS, the GWRC, and TAG supported a OPT proposal that re-envisioned and rebuilt the structure because of the perceived quality of the design.

Guidance in the Waterfront Framework for the Waitangi Park Precinct was inconclusive of the use of buildings to transition between adjacent developments and the public park; however, the winning entry for the Waitangi Park design competition proposed four building sites. The four sites were then incorporated into the design brief for the precinct and the resulting proposals were more iconic in form than transitional structures might have otherwise been conceived. While the proposed buildings did respond to the architecture of the existing buildings in some ways, they were far more contemporary in form, which competed for attention.

Kumutoto has been identified as a continuation of the urban form of the central business area in every plan proposed for the waterfront; however, there is a competing tension between the scale of the existing two to four storey waterfront buildings and the towers of the nearby central business area. The winning entry for site ten was two stories taller than as recommended in the design brief, while those proposed for sites 
eight and nine suggested the form of one large building (though they did accommodate a lane between them).

Frank Kitts Park was identified in the Waterfront Framework as only needing a few changes to its edges to improve how it responded to adjacent areas. Of these, the winning entry only addressed the edge along Jervois Quay. The design brief, however, provided other emphases which the winning design responded to more effectively.

How did the governance influence the form in this phase? By providing designers (including those involved with WDS and TAG) with more freedom than under other phases the winning designs strayed further from the overall existing character of the waterfront and the character of their respective areas.

\subsubsection{Transition stimuli}

The WCC Strategy and Policy Committee (SPC), composed of the mayor and all of the councillors, voted to dissolve the WDS in late 2007 as stage two of the waterfront development process (described in section 4.7.2) was considered to have been completed (SPC, 2008, June 18 Report 1 Appendix 1). Stage one had been the drafting of the Waterfront Framework by the Leadership Group and implementing its suggestions (i.e. Variation 22, establishing WDS, revising the mandate of LHM/ WWL). Stage two had been the development of design briefs for each sub-area of the waterfront by WDS. The third and final stage was to be the implementation of the design briefs by WWL (Waterfront Framework, 2001; WDS, 2006, May 8 Report 2 Appendix 1).

\section{Hilton Hotel decision}

The Environment Court overturned the approval for a hotel on the outer-T of Queens Wharf that would replace shed one in March 2008 (see section 4.5.2 for the background on this project). In the decision, the court argued the overwhelming form and architectural style would negatively impact the heritage and character of the area, the proposal reduced public space and reduced the amenity value of nearby public space, the danger of increased vehicle access to the promenade and pedestrian areas 
was not adequately addressed, and there would be a negative impact on views from the city to the harbour (Environment Court, 2008).

The Environment Court decision upset the planning for that portion of Queens Wharf and the development income WWL had intended to use for work on Taranaki Street Wharf and Frank Kitts Park (SPC, 2008, June 18 Report 1 Appendix 1). Further, strengthening Queens Wharf would have to be done by WWL, using loans from WCC, rather than being a part of the redevelopment agreement. This was an important issue as the pilings were deteriorating to the point where the wharf would have had to be closed to public access (SPC, 2008, June 18 Report 1 Appendix 1). Most importantly from a governance perspective, however, the decision generated doubt in the legitimacy of the operative planning process; therefore, a new planning approach was needed to envision a new future for the sites on Queens Wharf.

\section{Risk}

The 2006/07 Wellington Waterfront Project Business Plan, identified the pattern of delays and increased costs for projects that attracted public scrutiny, particularly in the design brief and resource consent stages, as an ongoing risk to the redevelopment project. The delays and increased costs reduced the cash flow of WWL necessary for maintenance and public space projects and increased costs for developers (WDS, 2006, June 26 Report 6 Appendix 1). For example, delays associated with the OPT and Hilton Hotel (due to challenges in the Environment Court of their planning approvals) reportedly had a negative effect on WWL's cash flow, causing it to use all of the funding allocated by WCC for the waterfront redevelopment, necessitating a line of credit from WCC that would be repaid by later development profits (WDS, 2007, June 25 Report 1 Appendix 1). Previous annual business plans had not raised this issue and, instead, had focused on market conditions and fluctuating construction costs as the primary risk concerns.

The suggested course of action was improved consultation with stakeholders to identify and address concerns earlier in the planning stages (WDS, 2006, June 26 Report 6). Generally, however, the Phase 6 and 6b WDS processes provided ample opportunities for public input and stakeholder engagement; however, some projects 
were more successful than others. For example, the Waitangi Park Precinct design competition provided opportunities for the public to comment on the brief, view and comment on all the entries, and comment on the winning options. The OPT was similar except only the winning proposal had been available for public comment. Even within a process intended to be inclusive, the consultation on some projects was more inclusive than on others.

\subsection{Phase 7 governance (2008 to 2010) - A less inclusive, more streamlined process}

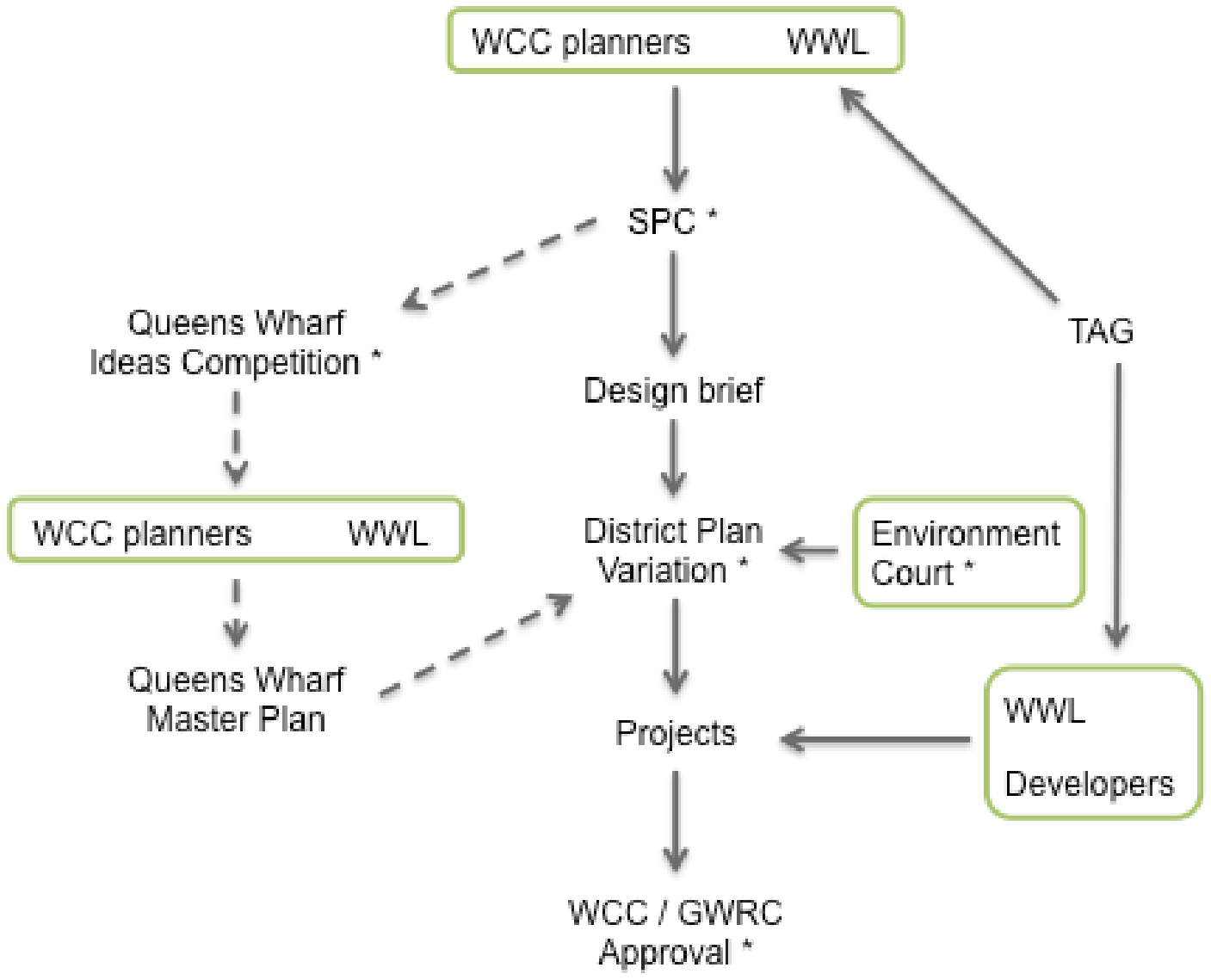

* Included consultation with the public and other stakeholders.

Figure 4.72. Diagram of the phase 7 governance arrangements. In this phase, WWL played a prominent role in decision making on the waterfront with substantial input from WCC planning staff. However, an Environment Court decision had a major impact on the resulting form of the projects considered under this phase. The Queens Wharf process was an adaptation of this governance arrangement, but the decision making structure did not change. Unlike phase 6 and 6b, stakeholders intentionally had fewer opportunities to provide input into decisions about the waterfront. 
A summary of the effects on the form of the waterfront included:

- Development of a campervan park as a temporary use of a future building site;

- One less building site and lower heights for new buildings in North Kumutoto; and,

- A draft plan for Queens Wharf that included a new beacon tower and two small pavilions on the middle portion of the wharf.

\subsubsection{Governance description}

Once the WDS was dissolved, its role was absorbed into the responsibilities of the WCC’s Strategy and Policy Committee (SPC, 2008, June 18 Minutes; SPC, 2008, June 18 Report 1). With design briefs having been completed for all five of the precincts, the SPC's anticipated role was to oversee their implementation with input from TAG as needed (SPC, 2008, June 18 Report 1 Appendix 1). Unlike the WDS, this decision making body no longer included direct representatives of community groups or development professionals; however, the agendas and reports for meetings of the SPC were also advertised ahead of time on the council website and members of the public were allotted time to speak at each meeting.

During this phase WCC and WWL also began identifying options for transitioning waterfront planning and implementation into city departments (SPC, 2008, June 18 Minutes). In December 2008 the SPC approved transfer of the implementation of the waterfront redevelopment from WWL to WCC starting in July, 2010 (SPC, 2008, December 11 Minutes).

Prior suggestions of disbanding WWL and incorporating its operations into regular WCC planning had been reviewed and rejected because WCC would have then lost ownership of the waterfront under the Foreshore and Seabed Act (2004) (SPC, 2008, August 21 Report 4). Under this Act, ownership of the land under the wharves would transfer to the national government if it was owned by a city or regional government body. A later amendment to this Act and continued ownership of the waterfront by WWL prevented this and allowed the role of managing the implementation to transfer to WCC (SPC, 2008, December 11 Report 5). 
A review of the waterfront project was also initiated in 2008 to look at how the waterfront redevelopment project should proceed over the next ten years (SPC, 2008, June 18 Report 1). As project prioritisation was dependent on the work programme review, several projects were delayed until the end of the review. These included the design development of Frank Kitts Park, the design competition for Kumutoto sites 810, and a proposed new planning process for Queens Wharf (SPC, 2008, August 21 Report 4).

From the ten year review, the SPC was presented with three planning and implementation options for the remaining development sites on the waterfront in December 2008 (SPC, 2008 [minutes 11/12/2008]). The first was a four year fast tracking of the waterfront to finalise planning and receive resource consent for all unbuilt development sites in the first two years with construction over the following by two years. A well-funded WWL would have been required to initiate and manage this aggressive schedule (SPC, 2008, December 11 Report 5). The other two options were more gradual 10 year implementation programs. For both options WWL would undertake the planning (over two years) and implementation would either be managed by WWL or WCC over the following eight years (SPC, 2008, December 11 Report 5). SPC agreed to the last approach, where WWL would regain the planning responsibility previously delegated to WDS (but with approvals required from SPC) and facilitate consent applications (SPC, 2009, May 14 Report 2). WWL would continue to manage the project until a review of the WCC Long Term Council Community Plan in 2011 to allow WWL to investigate potential temporary uses of the unbuilt development sites and continue to manage the waterfront while the market was poor (SPC, 2009, September 3 Minutes). The decision to extend the implementation of the waterfront development was influenced by several factors: the public consultation and appeals process required by the Resource Management Act (RMA,1991), several court challenges of planning approvals and resulting delays in development income, the 2008 global recession's effect on the development industry, and the loss of commercial income from delayed development projects (SPC, 2010, June 23 Report 2 Appendix 3).

The structure of this governance phase shown in figure 4.72 consisted of WWL sharing the strategy and planning role with WCC staff, with support from TAG, while 
retaining the responsibilities of managing the waterfront activity and development projects. SPC retained the role of final approving authority; however, the opportunities for public input into the process were intentionally limited to SPC meetings and the formal planning process outlined by the RMA. This streamlined governance structure was formed on the assumption that the design briefs drafted under the WDS, provided adequate guidance on the remaining development of the waterfront. When it was evident further design direction was needed for two subareas, WCC planning staff and WWL collaborated on design briefs for North Kumutoto and a new master plan for Queens Wharf. The design brief was translated into district plan variation that was subsequently dismissed in Environment Court. The Queens Wharf master plan was intended to become the basis for a variation; however, it remained in a draft state. 


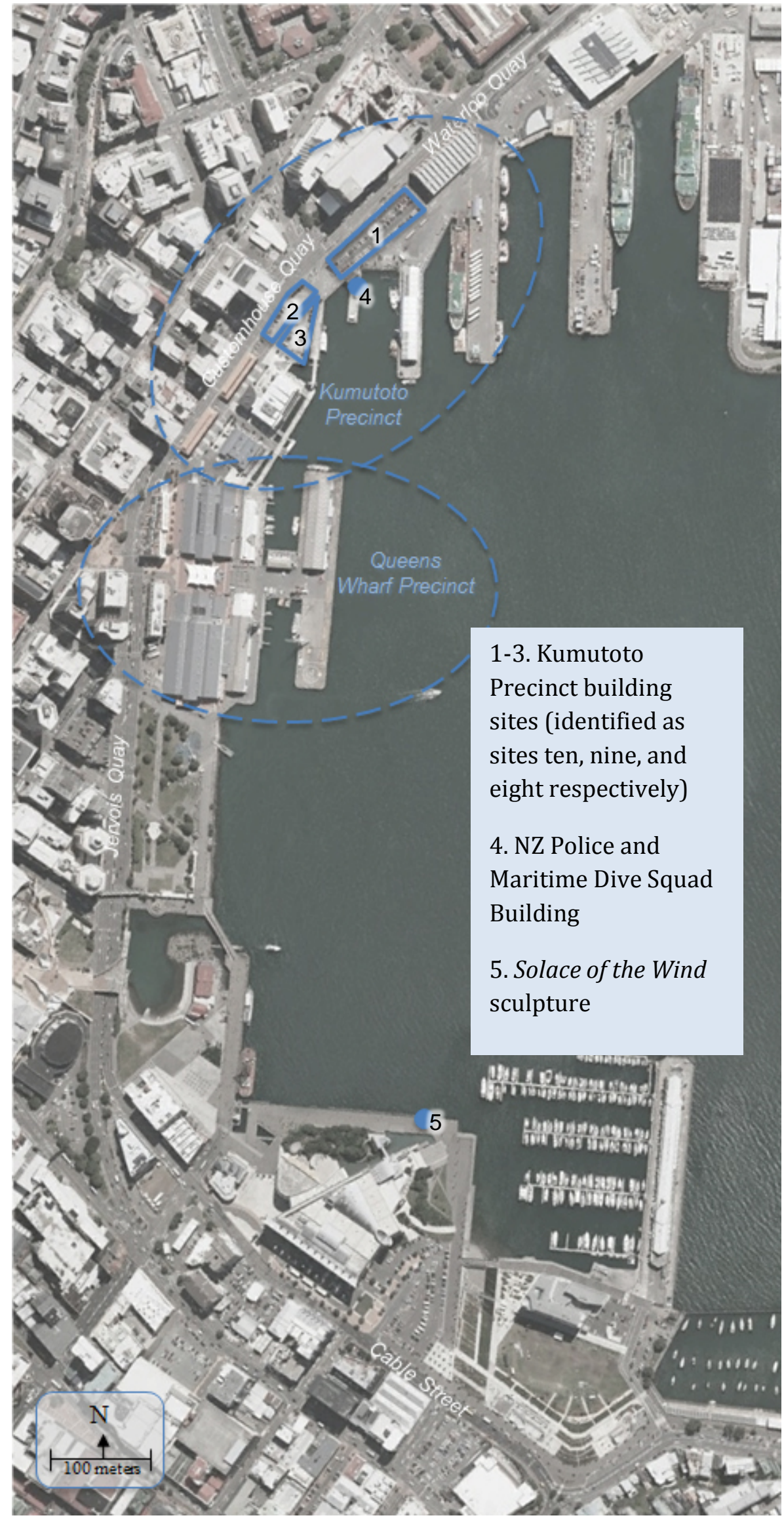

Figure 4.73. Location map of phase seven projects and features. Blue polygons identify constructed projects. Blue squares identify proposed building sites. (base image: Google Earth, accessed November, 2015). 
Projects undertaken during governance phases 6 and $6 \mathrm{~b}$ included public consultation at several stages in the decision making process which prompted a higher degree of confidence in the resulting design briefs and projects. Confidence was evident through the larger number of successful planning and development projects, the lower number of public submissions on individual projects compared to design briefs, and the Environment Court decision upholding the OPT planning consent despite the design brief not being incorporated as statutory policy in the district plan. The relative trust in the process used to draft the Waterfront Framework and the decision making process it initiated, meant stakeholders generally respected the outcomes despite its non-statutory status.

The Hilton Hotel proposal (section 4.5.2) did not follow this same process however, nor did it respect the guidance provided in the Waterfront Framework for the development of Queens Wharf. WWL, obligated by the initial agreement to explore options for a hotel on the outer-T signed in 1993, proceeded instead with managing the proposal outside of the phase 6 governance process and without following many of the recommendations for that site identified in the Waterfront Framework. The size of the proposed building, relatively limited opportunities for public comment, and lack of alignment with the Waterfront Framework damaged the credibility of the governance process for some of the public. Developers, WWL, and WCC were discouraged by the delays and public debate about this and previous projects. As the WDS had been disbanded, WCC had to find a new way forward for waterfront projects through a new governance approach.

The Environment Court decision on the Hilton Hotel ruled the Waterfront Framework was a strategic framework rather than a statutory document (Environment Court, 2008). The court decided it could not be a legal basis for judging resource consent applications because it had not been appropriately incorporated into the District Plan under Variation 22 (see section 4.7.4). Instead, the Central Area Design Guide within the district plan was identified as the appropriate legal design policy (SPC, 2008, December 4 Report 1, p.5). 
The Leadership Group did not intend the Waterfront Framework to serve as a statutory document. Instead, they identified the then immediate need to incorporate the "substance" of the Waterfront Framework into the district plan to replace the operative 1989 Combined Scheme (Waterfront Framework, 2001, p. 43). Once the detailed design briefs were completed for the five precincts, these were to be incorporated into the district plan's Central Area Design Guide to provide specific guidance (Waterfront Framework, 2001, p. 44).

In addition to needing to incorporate design guidance into the proper statutory tools, WCC planning staff identified Variation 22’s “zero meter height restriction” as another point of concern. The zero metre restriction refers to a lack of identified permitted heights intentionally excluded from Variation 22 in order to trigger the requirement for public consultation for all new building developments (Environment Court, 2008). By not specifying heights all new building developments and additions to existing structures would require public consultation as a part of their planning consent application. Following public debates on appropriate heights for several projects, WCC staff and developers were concerned the effective zero metre height limit did not provide a defensible approach for determining acceptable heights for building developments (SPC, 2008, December 4 Report 1, p. 2). Additionally, WCC officers worried the effective zero metre height restriction had the potential to serve as a basis for a legal challenge for stopping future development proposals (SPC, 2008, December 4 Report 1).

Variation 11 attempted to provide clear design direction for the three remaining unbuilt sites in Kumutoto by specifying building heights and footprints, requirements for public access and active edges for the ground floors, while identifying design quality and response to heritage considerations as matters for WCC deliberation when reviewing proposals. The extent of the identified building footprints in Kumutoto were informed by limits created by protected view shafts and requirements for lanes and pedestrian routes through the site (SPC, 2008, December 4 Report 1, p. 8). All buildings were required to provide public access to a minimum of $60 \%$ of the ground floor area, while $60 \%$ of the length of ground floor facades needed to relate through use to adjacent public open space. Heights were limited to $17.5 \mathrm{~m}$, 25.5m, and $30 \mathrm{~m}$ for the three building sites with a maximum 5\% increase allowed, with WCC discretion 
of design merit, without public notification (SPC, 2008, December 4 Minutes]). Identification of permitted building heights also provided a measure of confidence to developers as a mechanism to reduce uncertainties and delays associated with public consultation (Forbes, 2013; SPC, 2010, April 15 Report 1).

Variation 11 was also intended to clarify the process of public participation in the new governance phase. Public input on planning and design was to occur when variations to the district plan were released for public submissions. Once these variations were active it was intended developers would only require WCC approval for design and response to heritage issues, provided they stayed within the building envelopes outlined by the variation. The SPC report on Variation 11 (2008, December 4 Report 1) noted future district plan changes, associated with the design briefs prepared for other waterfront precincts and proposals for buildings or public space that deviated from implemented plan changes, would have to go through their own public consultation process.

Of note is an amendment to Variation 11 passed in the SPC December 4, 2008 meeting minutes: crossed out was the intent for the process to be oriented around public engagement. The amendment emphasised the existing opportunity for public engagement through the formal resource consent process as being sufficient; however, Variation 11 proposed development standards regarding building heights and footprints with the intent to reduce the need for notification (and, therefore, public consultation) (SPC, 2008, December 4 Report 1). The minutes stated, “This will require interested third parties to focus their involvement at the initial plan variation stage as there may not be the opportunity for further challenge and possible appeals when subsequent resource consent applications are made” (SPC, 2008, December 4 Report 1, p. 1).

Variation 11 was released for public comment in December 2008 (SPC, 2008, December 4 Minutes]) and approved by WCC in November 2009 (SPC, 2010, April 15 Report 1). Public submissions on the variation were generally against moving away from the phase 6 governance approach that encouraged public consultation on all projects through the zero metre height restriction in Variation 22. Dissatisfied with the scale of the proposed building envelopes and the lack of public consultation on 
future proposals that met the envelope restrictions, Waterfront Watch successfully challenged the variation in the Environment Court in 2010 (Environment Court, 2012).

The final Environment Court decision, released in April 2012, recommended:

- lowered heights for site ten $(22 \mathrm{~m})$ and site nine (16m at the south end to $19 \mathrm{~m}$ at the north) to reflect adjacent waterfront heritage buildings;

- any development on site ten was to be more than nine metres back from the water's edge to provide a comfortable promenade space,

- site eight was to become public open space; and

- future plans and development proposals were required to be opened to public consultation.

As a result of the court challenge, the 2008 global recession, and a review of the Waterfront Framework (discussed in section 4.7.2), planning and design of North Kumutoto, including proposals for the three building sites were delayed from 2008 through to 2011 (SPC, 2010, April 15 Report 1; SPC, 2011, March 8 Report 1 Appendix 1).

2008 Solace of the wind

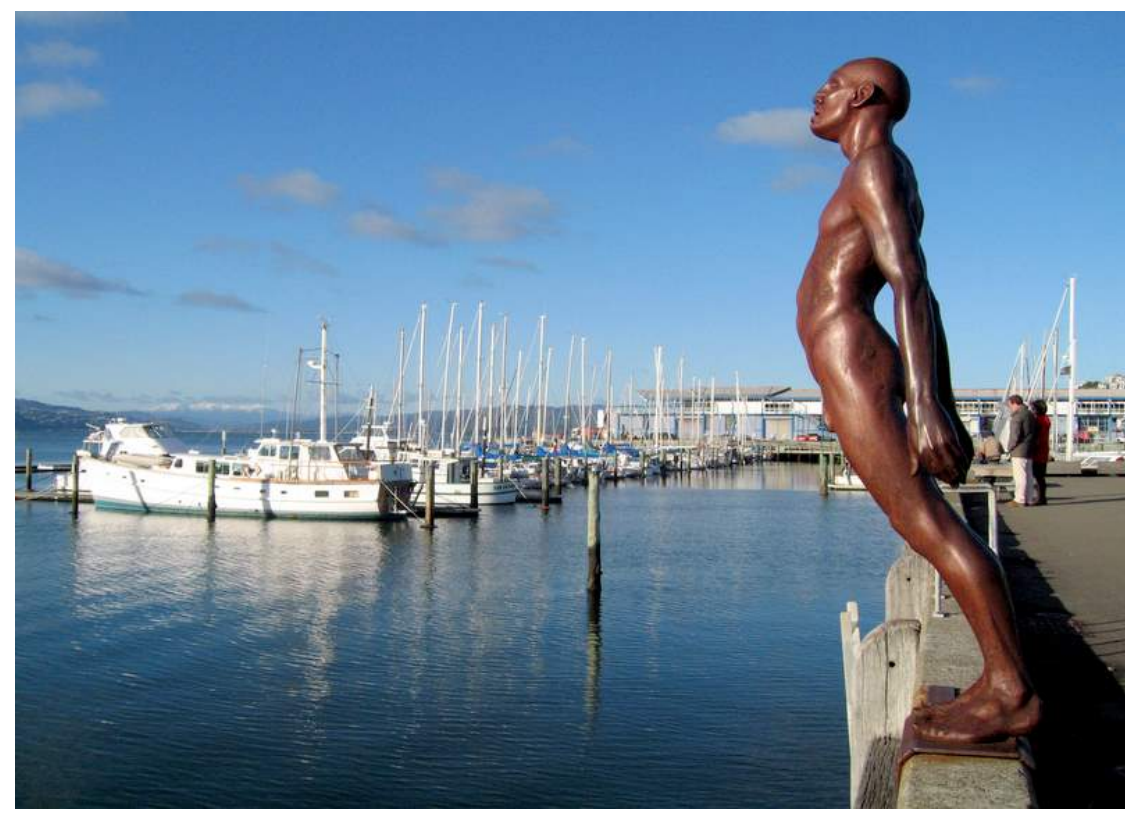

Figure 4.74 . Solace of the wind by Max Patte. (image: Keith Miller, Wellington Sculpture Trust) 
The iron sculpture, Solace of the wind, was installed in 2008. This art installation was a continuation of WWL's program to include art on the waterfront (Wellingtion Sculptures, 2015).

2009 Temporary uses

Development delays and ongoing efforts to promote the waterfront prompted WWL to propose temporary uses for some of the unbuilt development sites. The proposed ideas were intended to diversify the use of existing parking lots, even though parking provided income for WWL. In their proposal, WWL argued these sites could be more appropriately used for activities and events that were more complementary to the waterfront (SPC, 2010, June 23 Report 2 Appendix 3).

WWL initially identified a campervan park on site ten in Kumutoto (see figure 4.54), a temporary ice skating rink on Queens Wharf, and a high tensile tent in Waitangi Park Precinct for events as the most promising ideas for temporary uses (SPC, 2009, September 3 Report 2). After public consultation on these concepts, the campervan park was approved in November 2009. Decisions on the more capital intensive ice rink and high tensile tent proposals were deferred while business cases were prepared and a public ideas competition for Queens Wharf was carried out by WWL (SPC, 2009, November 17 Minutes).

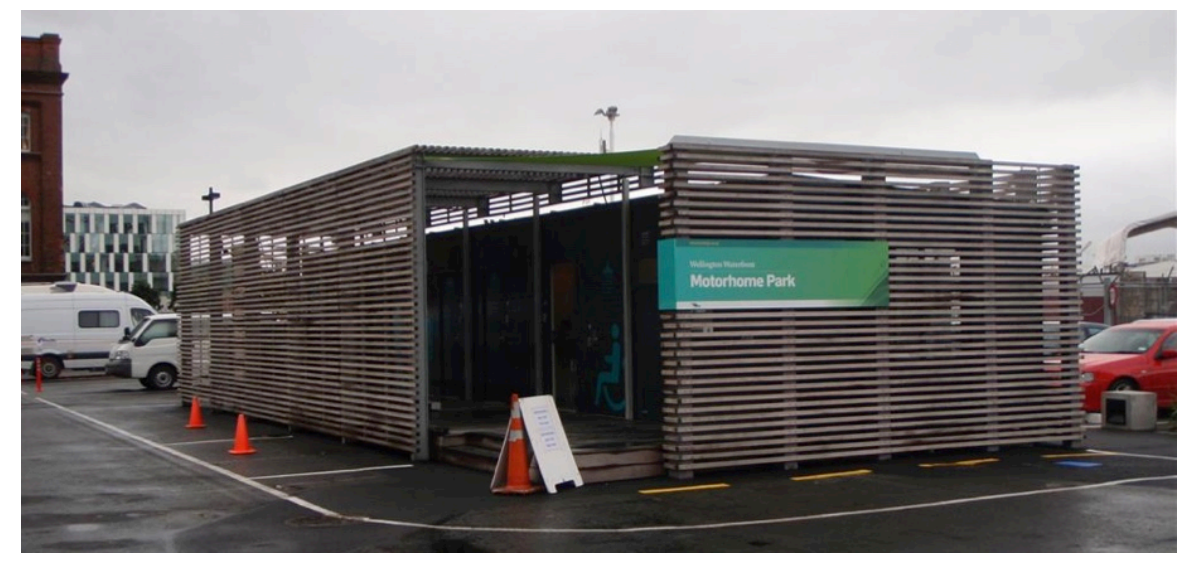

Figure 4.75. Campervan park amenities. (image: author)

Construction of the campervan park was completed in March 2010 with the installation of utility hook-ups (electricity, water, and waste disposal), fencing, and 
installation of dedicated toilet and shower facilities shown in figure 4.75 (SPC, 2010, April 15 Report 1). Feasibility analyses in late 2010 and early 2011, however, determined the ice skating rink on Queens Wharf and high-tensile fabric structure adjacent to Waitangi Park were not viable projects and WWL dropped these from their plans (SPC 2011, March 8 Report 1 Appendix 1).

2009 Queens Wharf precinct master plan

A second response to the 2008 Environment Court decision to overturn the Hilton Hotel resource consent, and as recommended in the Waterfront Framework, was WWL's proposal for a public ideas competition for the Queens Wharf outer-T in May 2009. As the Hilton Hotel development proposal had included repairs and upgrading to Queens Wharf by the developer plus income for WWL to use for other wharf repairs, the Environment Court decision meant WWL now had to cover the costs of these repairs themselves to allow continued public access and use (SPC, 2009, May 14 Report 2). With a clear vision of how the wharf was to be developed, WWL could invest in the appropriate level of wharf repairs and strengthening (SPC, 2009, May 14 Report 2). The second purpose of the competition was to inform a new master plan for the Queens Wharf Precinct, which would be incorporated into the district plan as a variation (SPC, 2009, May 14 Minutes; SPC, 2009, May 14 Report 2).

The brief drafted by WWL for the design competition drew upon the Waterfront Framework to include the following principles (SPC, 2009, May 14 Report 2):

- Ground floors were to provide publicly accessible uses.

- Ground floors were to have active edges that complemented and engaged adjacent public open space.

- View shafts along the spine of the wharf and of prominent city landmarks from the promenade were to be protected.

- Design ideas should reflect the historical uses of the site and evidence of past industrial uses.

- Requirements for vehicle access should be minimised.

- Maritime use and activities should be accommodated and encouraged. 
- The scale and appearance of new buildings should reflect that of existing buildings.

The competition ran between July and August 2009 (SPC, 2010, April 15 Report 2). After reviewing the 178 entries, those that responded to the requirements of the design brief were categorised by the jury based on:

- providing a thoughtful approach to the outer-T and its context;

- offering specific ideas and events for portions of the site that had merit and could be developed into a more complete proposal; and

- those that provided more abstract concepts that provided insight into the sense of place and potential futures.

A jury short-listed six entries to present to the SPC that reflected the principles of the Waterfront Framework, history of the waterfront, other key planning considerations affecting the site, architectural merit, and that were deemed to be reasonably feasible (SPC, 2010, April 15 Report 2).

Drafting of the masterplan by WWL from 2009 to 2010 was informed by ideas from the design competition and through consultation efforts with stakeholders and users of Queens Wharf (SPC, 2009, May 14 Report 2; SPC, 2011, March 8 Report 1). The intent of the masterplan was to "assist in streamlining public consultation and the necessary regulatory processes involved with proposed variations to the District and Regional Coastal Plans and/ or resource consent applications” (SPC, 2010, April 15 Report 2, p. 9). Based on the same reasoning, WWL employed the same approach used to develop Variation 11 as a model for future planning, design, and implementation of Queens Wharf.

As a point of difference from the Variation 11 process, a Queens Wharf Steering Group was formed to advise on and review the master plan. The group was described as including "a wide spectrum of the community"; however, it did not include representatives from public interest or activist groups. Membership did include a representative from Tenths Trust, four design professionals and academics, two advisors on arts and heritage issues, two WWL staff, a WCC urban design officer, and a development industry representative (SPC, 2010, April 15 Report 2). Following direction from the first steering group workshop in February 2010 further analysis by 
WWL looked at: opportunities to attract more cruise ships, market opportunities for the TSB arena, transportation connections and requirements, and a spatial study of Queens Wharf Plaza and Post Office Square across Jervois Quay (SPC, 2009, May 14 Report 2). The Steering Group also recommended the master plan should include considerations of the potential effects of climate change, tsunamis, and storm surges (SPC, 2009, May 14 Report 2).

The master plan for the Queens Wharf Precinct shown in figure 4.76 was developed using ideas from the competition and released for public comment in October 2011 (Burgess, 2011). While it included guidance on the outer-T, revitalisation of shed six, work on TSB Arena (formerly the Events Centre) and adjacent laneways and public spaces, it did not include any changes to the former Retail Centre. WWL described the approved master plan as a "bare-bones proposal" that would be refined over time (Burgess, 2011).

Due to continued effects of the 2008 global recession and a lack of development income WWL recommended gradual implementation of the plan (SPC, 2011, March 8 Report 1 Appendix 1). The Environment Court challenge and subsequent decision on Variation 11 also delayed further work on drafting a variation to incorporate the new master plan as attention remained on drafting a new variation for Kumutoto that responded to the court ruling. 


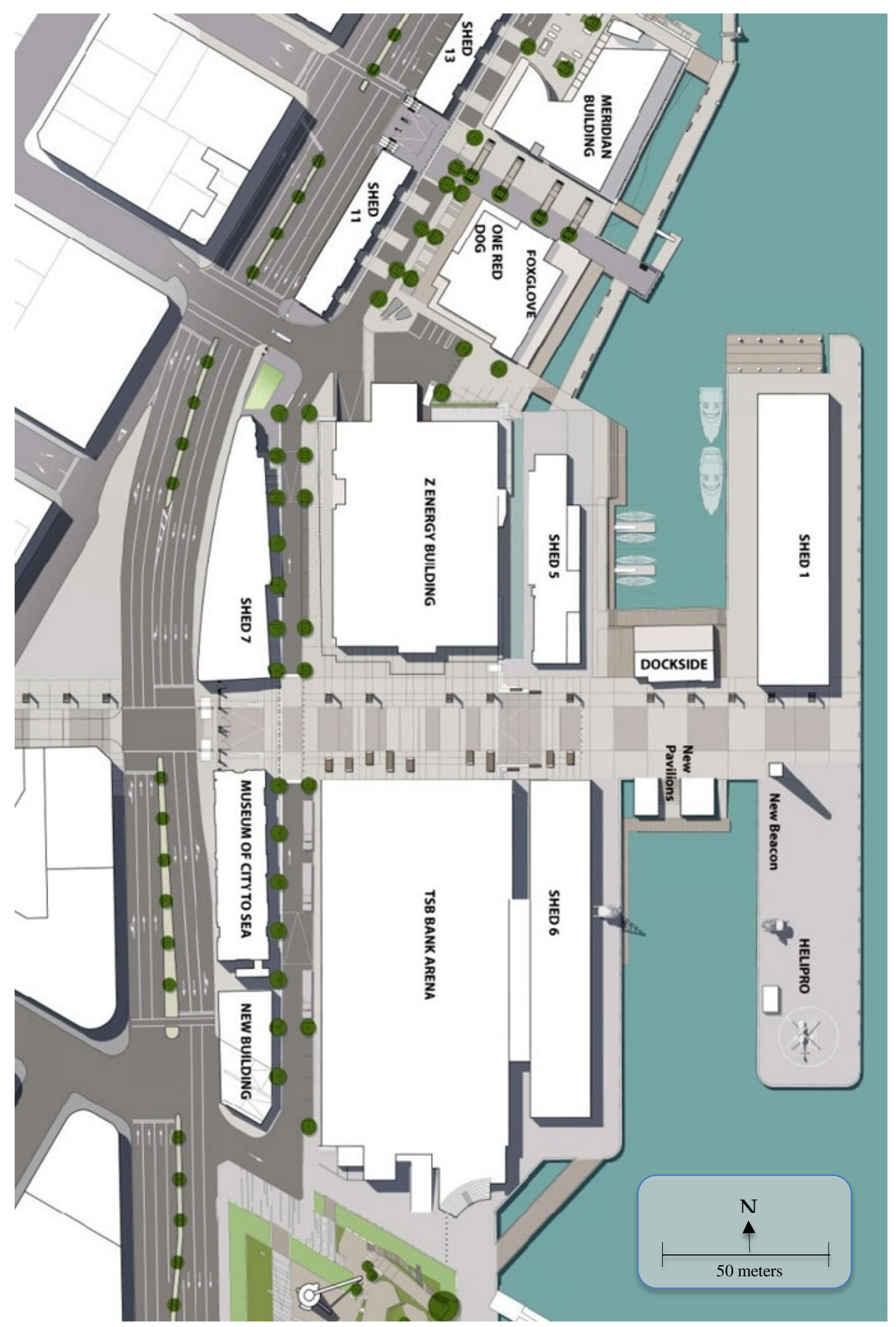

Figure 4.76. 2011 Queens Wharf master plan. (image: Wellington Waterfront Limited) 
2010 NZ Police and National Maritime Dive Squad building

In 2010 WWL was approached by NZ Police and the National Maritime Dive Squad to build a new small building to house their offices and operational needs on the jetty adjacent to their existing office space in the former Eastbourne Ferry Terminal (SPC, 2010, June 23 Report 2 Appendix 3). WWL worked with NZ Police on the planning and design of the building (SPC, 2010, June 23 Report 2 Appendix 3). The project was included in consultation on the 2010/11 Waterfront Development Plan; however, there were no submissions from the public about the project.

\subsubsection{Governance and form}

The streamlined governance process of using the variation process to focus public involvement resulted in a tension between top-down and bottom-up decision making. Had Variation 11 not been challenged, the resulting development would have included three new buildings in Kumutoto whose designs would only be vetted by TAG and WCC staff. Additionally, WWL would have been able to draft a variation for the Queens Wharf precinct and use development income from the Kumutoto projects to build elements of the master plan. However, because the RMA allowed submitters to challenge planning and policy approvals within the Environment Court, the resulting form was two new, lower buildings and more public open space in the Kumutoto area.

A broader effect on the form was unintentionally delaying the planning and construction of several projects. Developments for building sites in Kumutoto and further design and development on Queens Wharf were delayed while Variation 11 was appealed in Environment Court. Additionally, future development projects elsewhere on the waterfront now had to follow the slower, but more inclusive, development process recommended by the 2012 Environment Court ruling.

The Queens Wharf master planning process varied slightly with the use of a public ideas competition and creation of a community advisory group. A few ideas from the public competition were incorporated into the master plan, including the beacon on the outer-T and new pavilions across from shed three. Perhaps because of the Variation 11 appeal, the plan was described as a draft that would continue to evolve 
as a way of responding to expectations of progress from the ideas competition, but while not committing WWL to implementing everything as shown.

\subsubsection{Transition stimuli}

2010 Waterfront Framework review

SPC initiated a review of the Waterfront Framework in December 2010 (SPC, 2011, February 17 Minutes). The review process was intended to test whether the design principles and governance direction in the original Waterfront Framework still reflected the views of the public and waterfront stakeholders (SPC, 2011, May 12 Report 2). The review process included: focus groups with Wellington residents, businesses, and central city employees run by an independent consulting agency; meetings with leaseholders and tenants on the waterfront, interest groups, and consultation with TAG (SPC, 2011, May 12 Report 2).

Issues that prompted the review included (SPC, 2011, May 12 Report 2):

- uncertainty regarding the new planning regime of using district plan variations (e.g. Variation 11 and subsequent appeal to the Environment Court);

- issues with publicly oriented ground floor tenants being economically viable in all parts of the waterfront (e.g. Herd Street Building, former OPT);

- the continued struggle to improve pedestrian access across Jervois, Customhouse and Waterloo Quays between the city and the waterfront; and

- ongoing debate over the balance of open space and building form.

Outcomes of previous focus groups and a 2008 user survey indicated the waterfront was regarded as an important Wellington recreation and leisure destination, with the variety of spaces, activities, and experiences (including a mix of architecture) being highly appreciated (SPC, 2011, May 12 Report 2). Points of concern raised in previous consultation efforts included the potential effects of proposed developments, primarily potential heights and resultant effects of privatisation of space (SPC, 2011, May 12 Report 2).

Ultimately, workshops conducted in May and June of 2011 to review the Waterfront Framework and a review of past consultations concluded that the views of 
Wellingtonians had not changed since the 2001 drafting of the Waterfront Framework (SPC, 2011, September 8 Report 4). Further development work in the northern precincts (Kumutoto and Queens Wharf) was identified in the review as important to improving connections between the waterfront and the city. The mix of built and open space was generally seen as appropriate, though more protection from poor weather was seen as potentially improving use of the waterfront in all seasons. Additionally, the principle of publicly accessible ground floors was regarded as important for attracting users and integrating the waterfront into the city, rather than just creating a recreation and leisure destination (SPC, 2011, September 8 Report 4).

Of particular importance, the review noted there remained concerns with the planning and regulatory environment, especially the role of public consultation efforts in the approval process for resource consents (SPC, 2011, September 8 Report 4). This was a key element of the Variation 11 court challenge and also an important principle of the Waterfront Framework. 


\subsection{Phase 8 governance (2010 to 2012) - Integration of development role with WCC operations}

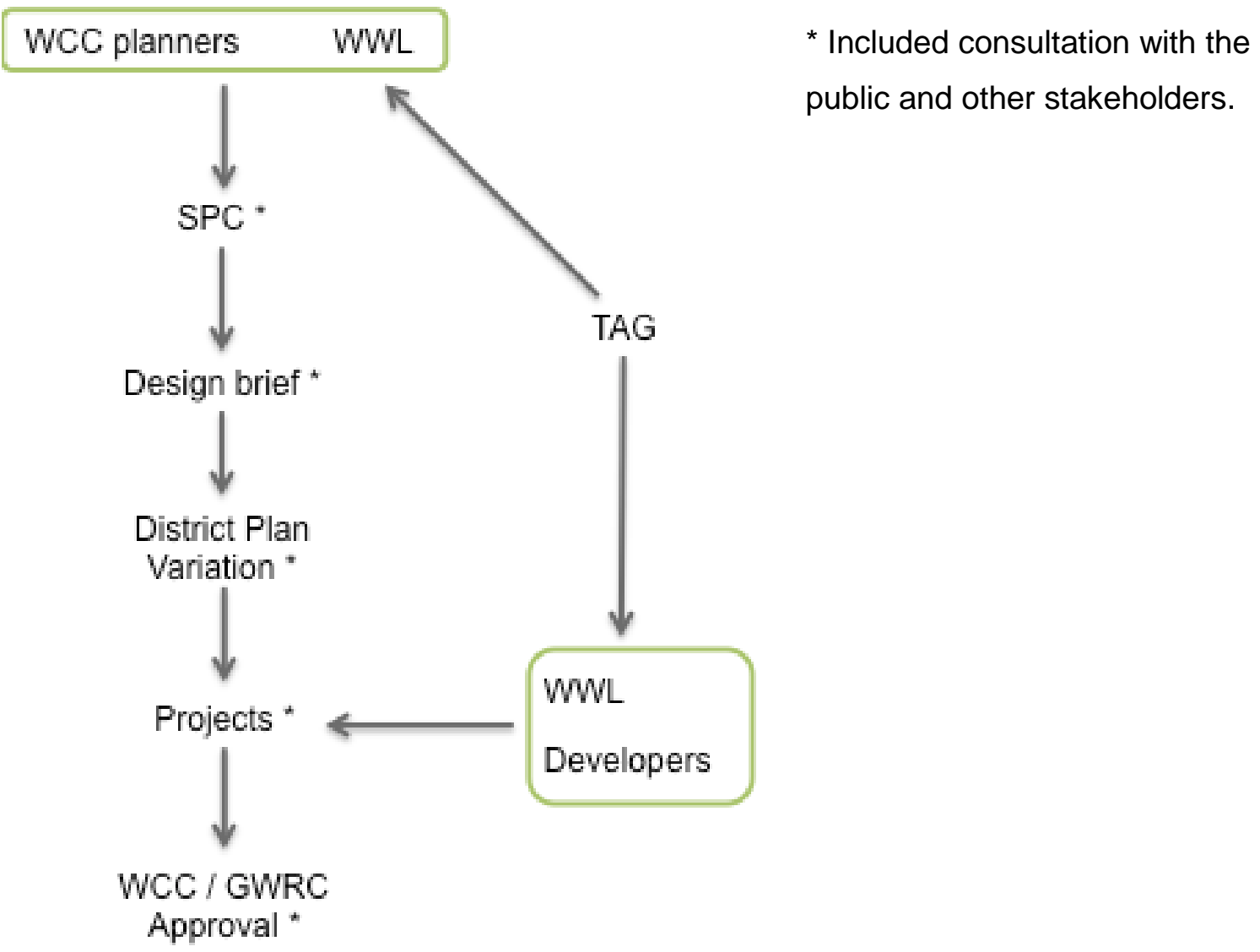

Figure 4.77. Diagram of the phase 8 governance arrangements. This arrangement is very similar to phase 7 except that every stage offers opportunities for public and other stakeholder engagement.

A summary of the effects on the form of the waterfront included:

- more cycling and pedestrian amenities, and

- reflection of the scale and character of the Eastbourne Ferry Building in the design of a new adjacent building.

\subsubsection{Governance description}

Continuing on from the governance changes in 2008 and preparation by WWL for its role to be moved into WCC operations, a review of options for transitioning the role was held in December 2010 (SPC, 2011, February 17 Minutes). Initiated by the WWL board of directors and carried out by WCC, the review examined the remaining planning and development tasks in relation to required staffing and board 
membership. The review process included direct consultation with WWL board, staff and members of TAG and public input through oral submission to the SPC (SPC, 2011, February 17 Minutes).

The SPC approved the advice of the review report to reduce the WWL board further to include only a chair plus two directors (one would be a Councillor) (SPC, 2011, February 17 Minutes). Alternatives had included incorporating WWL as a business unit within WCC; keeping WWL as it was; contracting out WWL's role; and, integrating WWL into WCC's regular work roles (SPC, 2011, February 17 Report 2). Retaining a reduced WWL was supported by WWL board, TAG, and the three public submissions on the report. Despite the costs of maintaining a separate body, retention of WWL was perceived as reducing the risk of failing to carry through the remaining waterfront development projects, retaining an operational focus on the waterfront, while a more streamlined WWL would reduce management costs (SPC, 2011, February 17 Report 2). To allow for potential for shifting workloads due to market changes or changing policy regarding the waterfront, WWL was to be reviewed on a three year cycle in addition to the ongoing monitoring via councillor involvement in board activities and through reporting to the WCC Council Controlled Organisation Subcommittee and SPC (SPC, 2011, February 17 Report 2).

In this governance phase, as illustrated in figure 4.77, planning and design of the waterfront was undertaken by a combination of WCC and WWL staff, with advice from TAG, while SPC was responsible for final approvals of new development plans and projects. While WCC staff had been involved with projects in previous governance phases, their role in this phase was more significant due to the focus on producing a revised variation for the northern part of the Kumutoto precinct. An additional change from the previous governance phase was that SPC required public consultation on the new Kumutoto design brief prior to submitting it into the formal planning consent application process. 


\subsubsection{Phase 8 projects}

2012 North Kumutoto design brief

After Variation 11 was overturned in April 2012, WWL worked with WCC staff to draft a new design brief for Kumutoto that reflected the Environment Court decision (see section 4.10.2). Emphasised in the design brief was that any future development proposals for sites nine and ten would require public consultation before a formal planning consent application could be submitted (which would also include a round of public consultation) (SPC, 2012, October 4 Report 1). As the design brief was based on the June 2012 plans for Kumutoto that had been publicly consulted on and revised to reflect the Environment Court ruling, WWL sought SPC approval for the design brief without public consultation. SPC decided, however, to release the design brief for public comment in October 2012 to provide additional opportunity for public input into the process (SPC, 2012, October 4 Minutes).

The public consultation phase, run between October and November 2012, resulted in 71 submissions and input from 51 members of the public who attended a forum run by WWL. While not a large amount of public feedback, WCC incorporated some of it into the design brief. The revisions addressing the form of future development included (SPC, 2012, November 22 Report 3):

- a greater emphasis on responding to the Eastbourne Ferry Building and other heritage elements;

- clarification on treatment of the Whitmore Street viewshaft and views of the Ferry Building;

- more amenities for cyclists and pedestrians;

- protection of solar access for site eight when designing a building for site nine; and

- clarification on maximum height and site coverage for new buildings.

\subsubsection{Governance and form}

The 2012 North Kumutoto design brief was based on the previous design brief for the same area, but revised by WCC staff to reflect the 2012 Environment Court ruling. 
The public consultation phase, however, generated additional ideas to improve the proposed built form and clarity of the document. Despite a relatively modest number of submissions, WCC actively incorporated several of the points raised by participants. Incorporating ideas raised by a relatively small number of public submissions demonstrated a different approach to decision making than under the previous governance phases. This approach resulted in a more detailed set of considerations for designers working on proposals for building and open space projects in this area.

\subsection{Summary}

Planning legislation that included the Town and Country Planning Act (1977) and its replacement, the Resource Management Act (1991), produced a meta-governance structure that provided a broad, consistent, and formal governance process for all development projects. However, within this overarching context distinct governance phases still existed over the duration of the Wellington waterfront redevelopment. Within these governance phases themselves, individual projects also had their own governance processes; however, analysis of individual projects identified that there was far more in common between projects included in each of the phases above than differences in how they were managed.

This chapter described the nine different governance phases that affected the creation of master plans, design briefs, and development of new buildings and open spaces on the Wellington waterfront between 1974 and 2012. As was discussed, these governance phases demonstrably influenced the built form and comparison of them will show this happened in relatively consistent ways. Consistent relationships between governance arrangements and the built form are based on the degree of topdown decision making, the success of citizen activism, influence of public and stakeholder feedback, and the influence of professional designers.

\section{Phase 1}

Initially, decisions on the use and form of the waterfront were made solely by WHB with some opportunities for the WCC to provide input via the district plan process. Civic Trust lobbied WHB and WCC to turn the waterfront into a public amenity, but 
little action occurred despite some interest from WHB. Initially, WHB's decisions resulted in changes to the waterfront that supported their focus on port activities, including removal of four warehouse sheds. Over time, lobbying (effectively citizen activism) by WCC and Civic Trust resulted in WHB agreeing to the development of Frank Kitts Park, public space improvements around the lagoon, retaining the remaining buildings, and an agreement to allocate land for a new national museum. WHB's instructions on initial plans for the waterfront, however, included retaining berths and space along some of the wharves to retain some port services. This requirement contributed to Frank Kitts Park and, later, Te Papa being setback from the water's edge and their orientation towards the city.

\section{Phase 2}

A public ideas competition organised by Civic Trust generated a large number of submissions and the winning plan by the Paperchase team established many enduring design and governance ideas for the waterfront. While Paperchase team was comprised of design professionals, the competition was effectively a form of public feedback. Once a decision to collaborate on the waterfront was reached, WHB and WCC commissioned a concept plan for the waterfront. The design team, however, had to address the tensions between the public's ideas and direction from WHB and WCC. WCC sought to connect the city and the harbour by improving pedestrian access, protecting views down streets running towards the harbour, provide land uses that were complementary to adjacent areas, and retain existing buildings. WHB required space and berths for some port services and a site for a national museum. Both organisations agreed the project would have to be self funding, therefore the plan needed to use income from developments and commercial uses to fund public space.

The resulting plan included a wide range of commercially oriented projects that responded to the self funding mandate and instructions to provide complementary land uses: large low-rise buildings, slim towers, a marina, parking, hotels, office space, a dense residential neighbourhood, a shopping centre, and a network of small public open spaces. The need to improving pedestrian connections resulted in a 
pedestrian bridge, a waterfront promenade, and design details that would provide shelter from inclement weather for waterfront users.

Ideas from the Civic Trust competition and public consultation by the design team (which was resisted by WHB and WCC) contributed to a wide mix of public amenities and land uses, emphasis on retaining the industrial maritime aesthetic, and retention of existing buildings. The designers themselves contributed to the emphasis on using a maritime aesthetic, but also advocated for providing a network of public open space, using buildings to define open space, and providing a mix of land uses and amenities along the waterfront.

Phase 3

WHB and WCC established LHM to be the central decision maker for the waterfront through a joint agreement. Legislation changes and the structure of the arrangement provided LHM with a high degree of independence to develop the waterfront. In its role as manager of the redevelopment, LHM retained the mandate for the project to be self funding and generally prioritised commercial considerations over design considerations and public consultation. A revised waterfront plan was commissioned by LHM to serve as the interim district plan for the area.

Again, the self funding mandate meant large building sites and commercially oriented projects dominated the plan. Subsequent planning approvals for several large development projects, development of the Retail and Events Centre, an agreement for a hotel on the outer-T of Queens Wharf, and a requirement that building project proposals include wharf repairs and upgrades reflected this development driven approach. At the level of individual projects, prioritisation of commercial considerations over design also contributed to blocked views, the internal orientation of many projects and weak contextual considerations in their layout and design.

Because the same design team was commissioned to develop the concept plan into the interim district plan and they did not consult with the public during this phase, the revised plan reflected the same tensions between public ideas and top-down direction expressed in the concept plan from the previous phase. 
A need to respond to the 1987 stock market crash and stimulate development interest contributed to LHM investing in several public space projects, including: public art and the redesign of Frank Kitts Park and the lagoon. The redesign of Frank Kitts Park included direction (presumably from LHM or WCC) to accommodate the annual car race that ran through the streets of Wellington. Within this requirement, the park designers took the opportunity to incorporate seating areas that provided protection from winds, small spaces for waterfront businesses, and memorials to regional maritime events. Additionally, the rowing and boating clubs were moved to provide some spatial definition and water-based activities to the lagoon. Designers therefore had greater influence on the design of public space projects once the design of public space was given more of a priority as a measure to attract development interest.

\section{Phase 4}

In response to public activism about the planned scale of development and governance of the project, WCC took control of the development process in this phase and placed a moratorium on development until a new plan for the waterfront was developed. The subsequent WCC public consultation process provided direction for a new design team commissioned to draft a new waterfront plan. While WCC retained the central role for making decisions about the development, citizen activism, public feedback, and greater involvement by design professionals influenced decisions on the built form.

WCC retained a desire for the project to continue to be self funding and this was reflected in the scale of development proposed in the new plan. The building foot prints were smaller and there were no towers in the new plan; however, there were more building sites on the northern half of the development area than before and heights ranged from six to ten stories. These heights were taller than the existing one and two story buildings on the waterfront.

Feedback and lobbying from the public and public activists resulted in: a new park site (Waitangi Park) on the site of the earlier dense residential neighbourhood; no towers and smaller building sites; a higher priority for retaining views of the harbour down streets running towards the water; more waterfront amenities for all 
demographic groups; more innovative designs for public spaces; and, a requirement to integrate building architecture with adjacent public space designs. An appeal by the citizen activist group, Waterfront Watch, also resulted in an Environment Court ruling that existing and heritage buildings were to remain in situ.

The design team worked to balance these competing pressures while providing a much more detailed landscape plan that identified six different sub-areas that reflected the different contextual issues for each sub-area. The contextual considerations included proposing a site for a wharewaka (shelter for traditional ceremonial canoes) and better integration of amenities with buildings and public open space design. Professional designers also played an advisory role to the WCC as the Waterfront Monitoring Group. In this capacity they had greater influence on insuring design showed greater innovation and contextual awareness by providing feedback on plans and individual projects.

Tension existed between the design professionals' desire to use buildings to frame public open space and views, pressure from WCC for a plan that was as self funding as possible, and pressure from some members of the public to keep as much open space as usual. This tension resulted in four different options in the new waterfront plan for different densities and building arrangements on the Waitangi Park site.

\section{Phase 5}

The Leadership Group was established as a transparent and inclusive stakeholder committee process to reach a consensus about values that should shape the waterfront redevelopment. Unlike the previous phase, decision making was delegated to the Leadership Group and the WCC facilitated the process. The Leadership Group process was structured to actively consulted with the public and incorporated the feedback into their discussions. The resulting guide for the waterfront was published as the Wellington Waterfront Framework.

Effects of involving public and stakeholder representatives included fewer building sites than previous plans plus a policy for $66 \%$ of the development area to remain public open space. New buildings were to reflect the scale of adjacent waterfront buildings and engage with adjacent public open space (i.e. they were to have active 
edges). All building developments also needed to integrate publicly accessible uses on the ground floor. One point they did not reach consensus on was whether buildings or landscaping should be used to transition heights from Te Papa and the Herd Street building down to the open space of Waitangi Park.

TAG carried on the advisory role from the WMG, both as a design review committee for project proposals and to advise the Leadership Group on urban design strategies. Their influence contributed to insuring new buildings reflected the scale of nearby existing waterfront buildings, clarifying contextual considerations for new developments in the six different sub-areas, and the lack of consensus on new buildings adjacent to Waitangi Park.

Phase 6

In this phase, WDS and TAG collaborated on many key decisions. The organisation of the WDS was less inclusive than the Leadership Group; however, public feedback was collected for design briefs and individual projects. Despite opportunities to provide input, however, public feedback generally had little influence on decisions by the WDS. The Waterfront Framework, which was produced through a very inclusive process, turned out to be the major vehicle for public influence on development decisions during this phase. While the public had little direct influence on decisions, submissions by waterfront tenants and lease holders did influence the design of adjacent public space. These effects included the distribution and quantity of parking, considerations of how vehicles could access to the waterfront, and the positioning of building sites. Where the extensive public consultation did have an effect was to slow the rate of development.

The Waterfront Framework was significant in limiting the built form effects of the top-down approach to decision making used by the WDS. The only significant influence by the top-down approach on the built form was the decision to establish four new building sites along the edges of Waitangi Park. Public input from the previous phase that was embodied in the Waterfront Framework, carried over and influenced plans and projects in this phase. 
Design professionals were members of both WDS and TAG; therefore, they had a strong central influence on decisions during this phase. TAG drafted the sub-area design briefs and closely advised on the design of individual projects. This resulted in a positive effect on improving the quality and creativity of public space and building development proposals. Generally, designs were more integrated and responsive to contextual issues; however, TAG advocated for some projects that stressed creativity and innovation instead. Some examples of projects they had a substantial influence on include: the choice of the winning design for Waitangi Park; the decision to go with bespoke sculptural public toilet facilities in Kumutoto; various art installations along the waterfront; and, providing different ways of interacting with the water (including diving planks and platforms, cut-outs in the wharves to expose the water, and floating platforms).

Phase 6b

As a concurrent phase, the governance approach was similar to phase six except TAG and other design professionals played more dominant roles. The built form was affected by an emphasis on finding creative proposals for specific sites rather than insuring contextual designs. In most cases, the winning competition entries diverged from the waterfront's existing character and heritage aesthetics and led to larger buildings than intended by the Waterfront Framework. For example, the winning Overseas Passenger Terminal design was taller and had less of a maritime aesthetic than the original structure it replaced but was chosen because it was an innovative design.

While public feedback on the competitions had some influence on the choice of the winning entries, it did not have an impact on the resulting designs or built forms. Where the added consultation did have an effect was in extending the time for making a decision on the winning entries and, therefore, slowing the rate of redevelopment.

\section{Phase 7}

The WDS was dissolved once design briefs had been completed for all of the six subareas; therefore, WCC and WWL now shared the planning and managing the waterfront development. TAG still existed as a design review and advisory 
committee, but their role in developing urban design strategies was reduced. As a result of these changes, design professionals no longer had direct involvement in making decisions. WWL took over the role of plan development and, with the WCC, sought to make the development process more efficient. WWL and WCC began drafting district plan variations to serve as official design guides for each area. Within this approach, public and stakeholder feedback was limited to the notification stage of district plan variations. Development proposals that respected the design guides outlined in the variations would proceed without public consultation. This level of consultation was the minimum required under planning legislation.

The first of these district plan variations, Variation 11, was produced within this topdown management approach. It established allowable building envelopes for three building sites in North Kumutoto that responded to the heights of tall buildings in the nearby business district, rather than the heights of shorter adjacent waterfront heritage buildings.

Separately, WWL also proposed temporary public amenities for some of the remaining unbuilt sites to replace surface parking uses. One of these, the caravan park, was eventually built. While the choice of increased building heights in Variation 11 corresponded with what happened in previous examples of top-down management approaches, the proposals for temporary public amenities were a new wrinkle to this pattern. The development process established for this phase was partially a response to delayed development income; therefore, replacing income generating surface parking with less profitable uses seemed counter-intuitive.

In developing a new area plan for Queens Wharf following the Hilton Hotel ruling by Environment Court, WWL launched a public ideas competition. The ideas competition was a suggestion for the area identified by the Leadership Group and provided an opportunity for public input. Development of the plan also included consultation with a steering group to collect feedback from stakeholder and designers. The resulting draft plan included more opportunities to interact with the water, improvements to the public open spaces and building exteriors, plus a beacon tower and two small structures on Queens Wharf. The increased mix of amenities and features was consistent with the built form outcomes from earlier public engagement 
efforts. The relative involvement of professional designers in developing the plan was consistent with the observed increase in design innovation, contextual considerations, and increased integration of buildings and open space observed in other phases.

Public activists challenged the reduced public and stakeholder consultation in the new development process plus the scale of the building envelopes permitted under Variation 11. The Environment Court supported their challenge and the ruling resulted in more public open space, fewer building sites, shorter building heights, and more public consultation (which also meant a slower rate of redevelopment). These effects are consistent with previous phases of strong citizen activism and when public feedback was actively incorporated into decisions about the form of the waterfront.

Phase 8

WCC and WWL still shared the main decision making role, however, WCC reinstated expanded public consultation and was now more involved in plan development. The consultation efforts resulted in more cycling and pedestrian amenities, which is consistent with previous phases. New development proposals reflected the scale of adjacent buildings; however, as these were in response to the Environmental Court ruling, they can be attributed to the citizen activism of the previous phase.

In comparison to the multiple phases described above, art installations and heritage building refurbishment projects (unless otherwise noted) had similar and consistent governance structures over the entire study period. These individual projects were initially collaborative efforts between LHM and the interested developer or community organisations. In phase four WWL and TAG took over LHM's role. Later refurbishment projects were generally more responsive to adjacent public space than those managed by LHM, which is consistent with the increased prioritisation of design quality.

In comparison, the Chinese Garden agreement signed by WCC and LHM, required all of those involved in drafting master plans and design briefs for the waterfront to allocate a 3,000 sq.m. site for the project. Both the initial site and the decision to move it was chosen by WCC and WWL with input from TAG and the Chinese Garden Society. Public feedback on the choice of site was noted, but not incorporated 
into the decisions. Ultimately, site choice played a role in shaping the design of Waitangi Park and, later, a redesign of Frank Kitts Park. Like the agreements for Te Papa and the hotel on the outer-T of Queens Wharf, this top-down agreement to allocate a site for a particular use affected what designers could do and prevented public feedback from influencing decisions on those particular projects.

\subsubsection{Patterns in the different governance approaches and their influence on the built form}

Based on the descriptions of the nine governance approaches, and the summaries above, the following observations can be made about how governance of the development process influenced the built form of the Wellington waterfront. These patterns summarise the effects on the built form when decision making was influenced in a top-down fashion, by citizen activism and public feedback, and by professional designers. The degree of influence these groups had on the decisions about the waterfront influenced the strength of the response in the built form.

Top-down influence by WHB resulted in the retention of wharf space and berths for port activities, which affected the setback of Te Papa and Frank Kitts Park from the water's edge. Additionally, the requirement for the redevelopment to be self funding inspired the use of large building sites and towers in predominantly commerciallyoriented waterfront plans.

Several periods of top-down decision making by WCC, LHM, and WWL were also associated with plans for large buildings, increased number of building sites, building heights that were taller than existing waterfront buildings, and dense land use proposals. Commercially oriented land uses were also encouraged and supplemented with residential to provide some immediate clientele. Commercial considerations included using ground floor retail to encourage active edges for buildings, development of Chaffers Marina, approvals for two large hotel proposals, and construction of the Retail and Events Centre. Commercial considerations were also reflected in the requirement for development proposals to incorporate wharf repairs and upgrades. Improved pedestrian connections between the city and waterfront and mixing public open space and private development were intentional priorities; 
however, many projects were internally oriented as they did not respond to their context in their design.

Professional designers often had to reconcile the tension between top-down direction and the public's visions for the waterfront. When designers had more direct influence on decisions during phases two, four, five, and six, the design of plans and projects generally showed more depth and contextual awareness. The waterfront features that can be attributed to periods when they had more influence include the network of public open space, opportunities to interact with the water, details that provided protection from prevailing winds, inclusion of memorials to maritime events, using buildings to frame open spaces, active edges, and allowing building heights that were taller than existing waterfront structures.

In earlier phases professional designers promoted a consistent character and aesthetic that responded to the waterfront's industrial and cultural heritage, including many industrial artifacts, Civic Theatre, and creative reuse of existing buildings. There was a shift, however, towards prioritising design innovation and creativity, along with distinguishing different sub-areas based on contextual considerations. Prioritisation of design innovation is evident in the form of the sculptural Kumutoto public toilets, the reconstruction of the Overseas Passenger Terminal and other design competition outcomes.

Lastly, successful citizen activism and incorporation of public feedback into decisions was associated with increases in the number and variety of public amenities, more public open space, fewer building sites, building heights that reflected existing waterfront buildings, greater integration of buildings with open space design, publicly accessible ground floor uses, protection of views from the city to the harbour, protection of existing buildings (including that they remain in situ), and a slower rate of redevelopment.

The next chapter describes the findings from interviews with informants representing a range of participant groups in the development process. These will be described and compared with the above findings. 


\section{Interview findings: Governance and built form relationship descriptions}

\subsection{Introduction}

The purpose of the interviews was to compile descriptions of the governance process and its effects on the built form from the perspective of participants. To do this, ten interviewees were sought to balance the views of four consultation groups. The four consultation groups included staff and board members of Wellington Waterfront Ltd. (WWL, the council controlled development agency charged with managing the project) and its predecessor Lambton Harbour Management (LHM), Wellington City Council (WCC) members and staff who had direct and ongoing involvement in the waterfront redevelopment at different stages, development industry professionals and developers who had worked on public and private waterfront projects, and citizen activists who had performed leadership roles in relevant community groups or in the archives were found to have been active in commenting on the process and its outcomes.

These consultation groups were identified to represent the views of different waterfront stakeholders. Broadly speaking, stakeholders were anyone who was affected by changes to the waterfront or decisions made about the waterfront, including those who did not participate in the decision making process (Bryson, 2004, p. 22). For the Wellington waterfront project, stakeholder groups were considered to include the land owners and occupants (i.e. WCC, Wellington residents and community groups, private lease holders, and waterfront tenants); waterfront users (including residents, tourists, and event organizers); tangata whenua (Maori with cultural ties to the area); employees of waterfront-related businesses (including LHM/WWL and commercial tenants); investors (primarily developers and waterfront businesses, and tenants); and, development professionals employed or appointed to advise on waterfront projects (including WCC and GWRC planning and design staff, private design and planning firms, and members of the design competition juries).

As noted in section 3.3.4, most of the interviewees were involved in more than one stakeholder group; therefore, it was thought the chosen mix of interviewees would provide a suitable balance of perspectives and insight into the development process. 
For the purpose of analysis, interviewees were classified into the consultation groups based on the stakeholder role they were most associated with during their total involvement with the waterfront redevelopment (see table 3.1). While stakeholders include those who did not participate in the process, the consultation groups were chosen to favour those stakeholders who participated most actively in the process.

Semi-structured interviews were used to collect perspectives on the governance of the waterfront redevelopment project and allow for comparison. In the design of the interview questions, it was anticipated the interviewees would identify and describe only one or two governance arrangements. The questions were, therefore, structured to ask about different aspects of the governance in depth. The analysis, using the Framework approach described in section 3.3.10, would then compare perspectives on these different aspects and their effect on the form across the four groups.

When conducting the interviews it became apparent there were more than two governance approaches used on the waterfront. The research design needed to be adapted, however, the Framework analysis was still carried out to compare perspectives on the different governance characteristics as intended. The value of undertaking the detailed analysis was to pull apart the descriptions of the governance and provide a deeper understanding of different perspectives and phases. The drawback of this approach was the abstract nature of the results. It presented the governance in isolated descriptions of different aspects that did not clearly address the research question.

The semi-structured interview format, however, enabled an adapted research design to draw more information from analysis of the interviews. This was done by comparing descriptions of key events and phases in the redevelopment process. A combination of comparing the responses using the framework tables and re-coding of the interviews therefore enabled identification of the phases and built-form relationships described here.

The following descriptions are based on common identifications of different governance phases and approaches across the interviews. However, differences of opinion and experiences between stakeholder groups are noted when talking about the 
specifics of each approach and their influence on the built form. Within the descriptions the different organizations and stakeholders have only been described and defined if interviewees elaborated on their role or intended purpose. Readers looking for more complete descriptions are referred to chapter 4.

As will be discussed in the following chapter, analysis of the interviews resulted in descriptions of governance phases that were broadly similar to six of the nine phases described in the findings from the archive analysis. Some of the interviewees provided details that were not evident from the archive analysis; however, there were also some conflicting views and factual errors. To retain links to the data, the descriptions include statements of how many interviewees held a certain perspective and which stakeholder groups they were associated with.

The descriptions of the six governance phases identified in this chapter included discussion of who was involved in the decision making, the management of public and stakeholder feedback, and the influence of professional designers. Several cycles associated with these will be evident in the descriptions. Beginning with a strong tension between top-down management and citizen activism, there was a shift towards more inclusive decision making and then a return to the top-down and bottom-up tension. Similarly, consultation was intense at the beginning, disappeared, then became intense again before being greatly reduced. Input from professional designers also cycled through different levels of influence. Designers had some influence on decisions at the beginning, then their role was reduced because more finance-oriented approaches took priority. Following public protest to the financeoriented approaches, a much higher emphasis on quality design gave designers a great deal of influence, before a return to a limited role that was reminiscent of the first stage. The strength of built form associations with each of these patterns was therefore related to how much influence the public and professional designers had on the decision making process.

The following chapter will compare the findings from the observation and archive analysis with the interview analysis. The purpose will be to triangulate the findings and respond to the research question. 


\subsection{Initiation of the redevelopment}

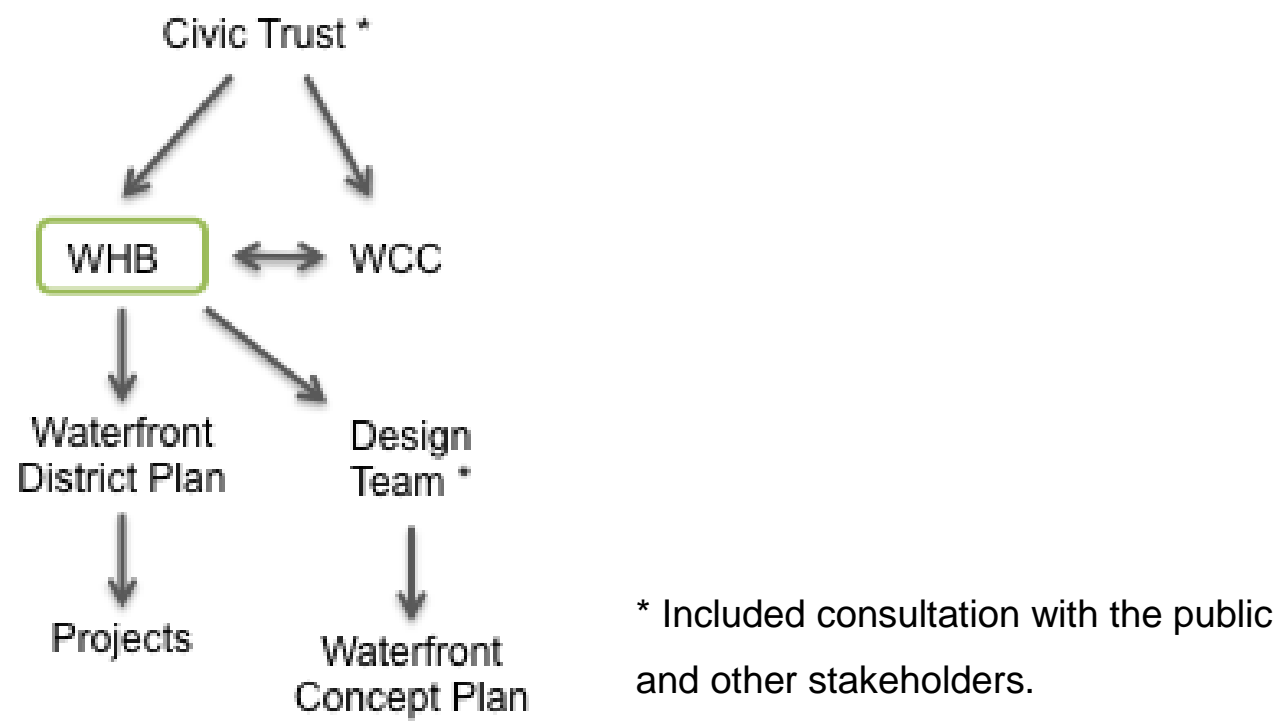

Figure 5.1. Diagram of the initial governance arrangements as identified from the interviews. The green rectangle identifies the Wellington Harbour Board as the central decision maker regarding the form of the waterfront.

A summary of the described effects on the form of the waterfront included:

- initial removal of warehouse sheds, but later protection for remaining buildings;

- landscape improvements to the lagoon and adjacent areas;

- plans for large building developments along the waterfront allowing for mixed uses were realized in the construction of Te Papa and the Retail and Events Centre;

- the City-to-Sea bridge and medians on the streets bounding the site to provide improved pedestrian access;

- some protection of harbor views down streets running towards the water;

- plans for a network of public open spaces along the waterfront with a mix of passive and active recreational amenities, the water's edge promenade having been noted by nearly all interviewees;

- industrial heritage reflected in the materials and aesthetic of the development; and 
- inclusion of cultural amenities that reflected the cultural heritage of Wellington and the waterfront. This included Te Papa, Civic Theatre, art installations, and memorials.

As shown in figure 5.1, interviewees agreed the decision making about the waterfront was initially controlled by the Wellington Harbour Board (WHB). According to two interviewees in the development and WCC groups, the WHB had its own district plan for the waterfront and rejected any proposals for change in use by arguing the land was vital to port operations. It was noted, however, that the local public, the WCC, local iwi, and the Greater Wellington Regional Council all had strong interests in other uses for the waterfront lands and wharves.

In the early 1980s, members of the Wellington Civic Trust reportedly noted that a change in shipping due to the use of containers left areas of the historic waterfront adjacent to the downtown unused. With a desire to provide public access to the harbor, the Civic Trust lobbied to bring WHB and WCC together to discuss redevelopment of the waterfront.

Initially, the Civic Trust organized an ideas competition in 1983 to generate visions of how the waterfront could become a part of the city. The competition attracted a lot of public attention that the Civic Trust used to lobby WCC and WHB. Their goal was for the two organizations to meet and work out a future for the waterfront. According to three interviewees involved early in the process, WCC and WHB failed to take action on the outcomes of the competition so the Civic Trust organized a public conference and a seminar on the waterfront to maintain interest and momentum. According to one citizen activist interviewee, the breakthrough came when the WHB chairperson announced at the seminar that the WHB would support redevelopment of the waterfront.

Once WHB agreed to work with WCC and move forward with redeveloping the waterfront, a professional design team was hired to create an initial concept plan for this. The design team worked in an open-house type situation where anyone could walk in at any time to discuss ideas or approaches to the redevelopment. According to two interviewees involved as designers in this initial group, there was resistance from the WHB to allowing the public direct input; however, the design team threatened to 
quit if they could not consult directly with the public. Reportedly, this consultation and the resulting plan were well received by the public.

Interviewees from all groups described how using income from private development projects to pay for public space and cultural amenities was a key requirement made by WHB and WCC. One interviewee involved early in the process reasoned, “...there wasn’t any government money for the waterfront.” Further, it was noted by one development group and one WCC interviewee that several WCC councillors had been concerned development would affect property values and the commercial viability of other parts of the city. This meant there was political pressure not to invest city funds in the project. The interviewees involved in the design agreed that the initial plans focused on creating a high density of commercial developments that were clustered in large buildings to attempt to retain and pay for public open space. Two citizen activist interviewees saw this prioritization of self funding as dominant in all stages of the redevelopment project and associated it with an ongoing preference for large commercial developments rather than provision of public open space.

It was also argued the requirement to rely only on development income limited the resources needed to realize other values in this initial phase. These secondary values included using high quality materials, providing large amounts of public open space, and employing innovative design for public open space and private projects. The architecture and public open space associated with the Retail and Events Centre were described by several interviewees as an example of this prioritization.

According to one WCC and two development group interviewees, the only time the national government was involved with the waterfront was when it purchased land for a new national museum (later named Te Papa Tongarewa). The planning, design, and development of that project were handled by a team put together by the government with very little input from WHB, WCC, or LHM. Three interviewees established that the choice to only lease land, rather than sell it, was adopted early on, some time shortly after the land for the new National Museum was sold to the national government. 


\subsubsection{Influence on the built form}

All interviewees agreed that the WHB controlled decision making of the waterfront during this initial stage and, with WCC, set the major parameters for the redevelopment. Despite this view the Civic Trust, WCC, and the design team were described as instrumental in identifying and involving the public's interests to inform the initial concept plan.

Two interviewees who worked as design consultants early in the redevelopment process described the WHB initially demolishing several original warehouse sheds as a way of attempting to maintain control of the waterfront. Another interviewee in the development group suggested, however, the changing shipping practices meant these sheds occupied space needed for roll-on/ roll-off cargo loading. Either way, it was noted that WHB attitudes towards land use changed once they made the decision to go ahead with the redevelopment of the waterfront. This change in attitude included protecting the remaining buildings and WHB providing public access to the lagoon and landscaping in the area as a recreational amenity for the city.

Values associated with involvement by the Civic Trust, WCC (as an advocate rather than the management role it adopted in later phases), and the public included providing a variety of uses and amenities, connecting the city and the harbor, ensuring the waterfront was publicly accessible, and integrating the cultural and industrial heritage of the site. It was not clear from the interviews if any of these can be attributed to these groups individually; however, the interviews indicated all of these groups agreed on these principles and promoted them.

Interviewees involved in this phase and in later work on the waterfront described a desire for a vibrant waterfront that incorporated a variety of uses and amenities as an early and ongoing principle. This value was associated with a mix of old and new buildings; facilitation of different land uses for different parts of the waterfront; clustering of bars, cafes, and restaurants; a network of public open spaces relating to the city grid; a waterfront promenade; a marina; cultural attractions; retaining the rowing clubs; providing outdoor seating; and organizing activities and events for the waterfront. From responses by the interviewees, these ideas were incorporated into 
the plans by the design team but were informed by their public consultation efforts and entries in the Civic Trust competition.

Promoted primarily by the WCC and designers, the idea of providing connections between the harbor and the city was another key value singled out in the interviews by all three members of the WCC group and two members from the citizen activist group who had been involved in the initial plans. Improving pedestrian connections to the adjacent neighbourhoods, orientation of Te Papa to the city rather than the waterfront, protection of views between the city and the harbour, the City to Sea Bridge, and a series of spaces linked to the city grid were associated with the influence of this value. Later moves included installation of a median along the busy streets lining the site to improve safety for pedestrians crossing to and from the waterfront.

Ensuring the waterfront was publicly accessible was described as an extension of providing connections between the city and harbor, though this aspect of it was identified as a driving concern for citizens and designers according to two development group interviewees. Built form effects included provision of the water's edge promenade, early improvements around the lagoon, the desire to remove surface parking lots from the waterfront to allow for private development and public space, resistance to privatization perceived to be associated with commercial and dense residential developments, and provision of amenities for a variety of activities (i.e. walking, cycling, events).

A widely discussed early and ongoing value, identified by WWL and citizen activist group interviewees, was to embrace the cultural and industrial heritage of the waterfront. This was associated by the interviewees with refurbishing heritage buildings (including several former warehouses, Steamship Wharf building, rowing clubs, Circa Theatre, Odlins Building, and the OPT); inclusion of Te Papa (National Museum), Circa Theatre, the National Portrait Gallery, and the Museum of City and Sea, and Academy of Fine Arts as cultural attractions; encouraging ships to continue to tie up to the wharves, retaining the patina of past use, and the material palette for open space features (e.g. City to Sea bridge and choice of plants in Waitangi Park). In the early stages of public space development, huge boulders and large marine artifacts were used in the landscaping, and large timbers and hardware were used in the 
construction of the City to Sea Bridge. In later stages of the development, it included reinforcing links and opportunities to interact with the water through opening up parts of the wharves to expose it, construction of the wharewaka, and inclusion of diving platforms and ladders. Later recognition of industrial and cultural heritage was associated with industrial uses on the waterfront like the brewery and a coffee roastery, and creating space for public memorials to local events, and even contemporary culture through inclusion of a graffiti wall and skateboard park according to one WWL interviewee.

Despite the other values guiding the concept plan, however, the self funding mandate was associated by interviewees in all groups with a commercially oriented development approach that favoured a higher density of development. Interviewees associated proposed towers and other large buildings with comparatively less public space with this mandate. 


\subsection{LHM era}

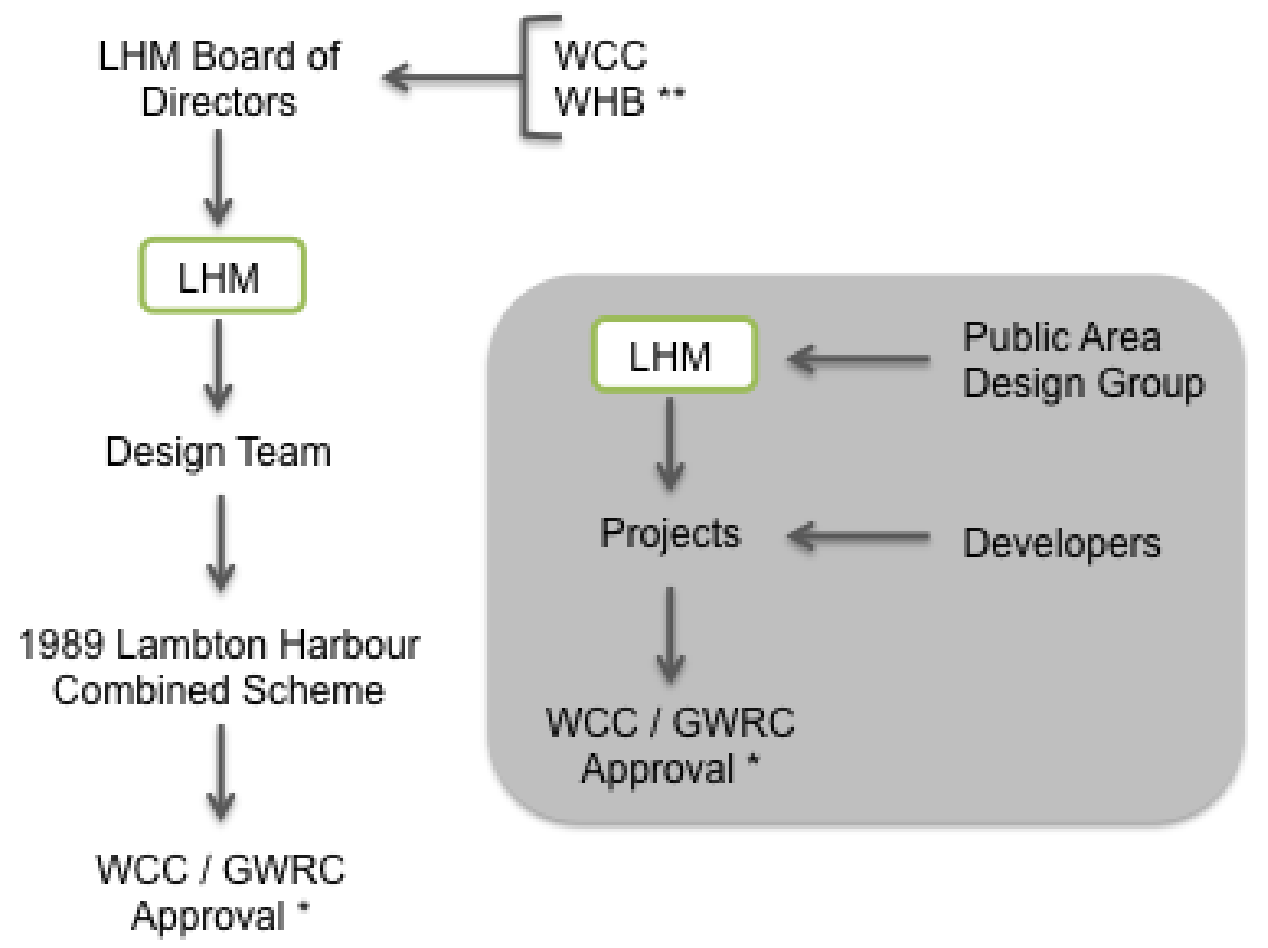

* Included consultation with the public and other stakeholders. Requirements for greater public consultation were included in the Resource Management Act (1991).

** Dissolved in 1989.

Figure 5.2. Diagram of the phase 2 governance arrangements for plans and projects (in grey) as identified from the interviews. The green rectangle identifies the Lambton Harbour Management as the central decision maker on the form of the waterfront for overall planning and for individual projects.

A summary of the described effects on the form of the waterfront included:

- retaining wharf space along Taranaki Street Wharf to load and unload cargo ships;

- large, internally focused development projects that did not respond to the harbor context and interrupted some views;

- a consistent character for projects built during this time;

- development of amenities to attract private investment, including Civic Theatre and Frank Kitts Park;

- development of Chaffers Marina and underground parking; and

- the first residential development on the waterfront. 
Lambton Harbour Management (LHM) was established by a joint agreement between the WHB and WCC; however, with reorganization of the harbor boards in the late 1980s by the national government, WCC became sole owner of the project. According to interviewees in all groups, the role of LHM was to control both the strategy and implementation of the redevelopment as though it were a private development. Under this arrangement, one development group interviewee stated LHM was able to borrow capital and undertake development on its own initiative.

To allow the project to move forward, the national government passed the Lambton Harbour Vesting and Empowerment Act (1987). According to one WCC interviewee the Act specified the development area, allowed for a joint district plan for the area, and allowed joint ownership of the land by WCC and WHB. These specific changes were necessary for LHM to proceed with redevelopment of the waterfront as they were not allowed to do this under previous legislation.

Reportedly the intent of creating a development corporation was to prevent political interference; however, interviewees noted WHB required representation on the LHM board of directors to insure it had some continued influence on the waterfront redevelopment. WCC also contributed city-owned land between the port areas and the Quays to the redevelopment area to increase its stake and have more influence on decisions. Despite a board of directors that included WHB and WCC representatives, interviewees from all groups agreed LHM operated with a great deal of independence as shown in figure 5.2 .

As one of its first actions, LHM brought together a group of design professionals to create the 1986 Lambton Harbour Combined Scheme. According to three interviewees involved in the early stages, this concept design was WHB's and WCC's combined district plan for the waterfront. The design was described as "a conceptual plan to position ideas and basic structure rather than specify development” by one interviewee involved in its development. It was based on the initial concept plan and also used ideas from the Civic Trust competition entries and feedback from the public, iwi, and other stakeholders that were collected by the previous design team. 
When talking about the early phases of redevelopment, six interviewees only referred to one plan that was produced using ideas from the Civic Trust competition and direction from WHB and WCC. Four interviewees (including those whom had been involved in the creation of these plans) described two separate plans, the second being the Combined Scheme. However, those interviewees familiar with the two separate plans described many of the same ideas, principles, and directions being incorporated into both plans. The one difference was WHB reportedly required the new Combined Scheme to retain the ability for large ships to dock alongside Taranaki Street Wharf for loading and unloading.

Once the Combined Scheme was approved by LHM, it followed the statutory process requirements for district plan changes. This process included public notification and hearings, prior to final approval. None of the interviewees spoke about the process directly, but one development group interviewee stated the public process attracted very little attention during the initial stages. One of the designers involved early on in the process stated both of the initial plans were well regarded by the public, so they were likely passed with little argument.

Despite WCC being the land owner, all waterfront project proposals still had to go through a planning consent application process that was similar in principle to what was required of private developers working elsewhere in the city. Applications for development areas over the water (including the wharves) were assessed by GWRC. Land-based development proposals however, were evaluated by independent commissioners because WCC was the land owner for the waterfront and could not grant approvals for its own projects.

Two interviewees involved at the beginning of the project, also reported that some initial projects, including a 31 storey tower and a 10 storey casino and hotel, were given approval before the overall plan and district plan change were complete in order to take advantage of the economic prosperity of the mid-1980s. According to a planner involved at this stage, this was allowed under the planning legislation of the time. While eight interviewees believed this profit focused approach ended with the beginning of the next phase, the three citizen activist group interviewees considered 
maximization of profits continued to guide much of the subsequent waterfront plans and projects.

Following adoption of the plan, a professional group was retained as the Public Area Design Group, to provide WCC with an assessment of how development proposals would fit the intended character of the waterfront. Two interviewees from the development and WCC groups argued, however, the design review was not often listened to as the commercial aspects of projects were given more weight in decision making.

When the Resource Management Act (1991) was introduced, interviewees pointed out it required WCC or GWRC to assess whether a development proposal had more than minor negative effects on the quality of the environment or its enjoyment. If it did not have more than minor effects or had positive effects, then the proposal could be approved to proceed without public consultation (i.e. it would be non-notified). All applications had to show consideration of several factors, including heritage, environmental effects, and urban design effects. Heritage building refurbishment projects, however, generally did not include major changes to the exterior. These types of projects, therefore, were non-notified, meaning they did not require public consultation according to interviewees from the WWL and WCC groups.

While the plan was reportedly applauded for its public engagement, following adoption of the plan, public consultation appears to have ceased. For example, the redesign of Frank Kitts Park took place with no public consultation according to an interviewee from the WCC group.

\subsubsection{Influence on the built form}

This phase was characterized by LHM functioning as the central decision making authority, despite efforts of WHB and WCC to have some influence via the LHM board of directors. The general perception was LHM took a profit-focused approach by continuing with plans for large new developments, granting long leases, and helping gain planning approvals for several of the larger development proposals. 
LHM was described as an independent development corporation and associated with providing a consistent character by the interviewees in all groups. It was also agreed early plans and projects managed by LHM favoured maximizing profits for developers by encouraging large developments. Examples cited by interviewees included the 999-year lease terms for the Retail and Events Centre, the scale of that development, approvals for a 31 storey tower just north of Queens Wharf, and approvals for a ten storey casino and hotel on Taranaki Street Wharf.

After the 1987 global stock market crash, the approved new building projects reportedly stalled as the development market cooled. In an effort to keep some momentum, the redevelopment of Frank Kitts Park and the lagoon, creation of the marina, construction of the Circa Theatre and other projects initiated and managed by LHM were described as mechanisms to stimulate development interest by development and public activist group interviewees. These were reportedly achieved, as with other public projects initiated during slow development phases, using loans from WCC.

One interviewee from the development group argued the feeling of what the waterfront should include changed significantly during the recovery from the stock market crash. Particularly, there was less enthusiasm for large building projects and a greater diversity of what people believed was appropriate for the waterfront. Statements by other interviewees did not agree with this however. All of the other interviewees stated the public reacted strongly to the design of the Retail and Events Centre and that this was the trigger that reduced enthusiasm for large building projects.

Within the larger decision about redeveloping Frank Kitts Park to attract investment and public good will, it was noted by four interviewees in the WCC, citizen activist and development groups that the design was also required to provide underground parking and respond to use of the adjacent waterfront promenade as the starting grid for an annual car race that ran through the city. To accommodate the race, the harbour side of the park was raised one storey to separate spectators from the promenade. This had the effect of orienting the park away from the harbor; however, one interviewee suggested this move was also intended to provide protection from winds off the 
harbor. Te Papa's lack of engagement with the harbor and setback from the water's edge was similarly associated with having to respond to the requirements of the car race. The reasoning behind including underground parking was not specifically addressed by the interviewees, though it was identified by two interviewees in other contexts that LHM received substantial income from parking lots on the waterfront. Other decisions on the form of the park were decisions of designers involved in the project, including provision of small retail spaces fronting onto the waterfront promenade and creating multiple routes through the site.

The redevelopment of the former Harbour Board offices into apartments by LHM was described as a risky move according to one interviewee; however, it was very successful and launched a wave of inner city apartment developments. This was a topdown decision that included limited changes to the building's exterior, but supported the concept of providing a mix of uses along the waterfront.

The Retail and Events Centre was described as the first privately financed development on the waterfront. According to three interviewees involved in the project, the architecture was to reflect a maritime warehouse form that "respected" the scale of the existing buildings; therefore, the original concept for the Retail Centre was much smaller and the design was of higher quality than what was eventually built. However, the developer kept insisting upon larger and larger buildings to insure the project was sufficiently profitable and LHM agreed to their requests despite advice to the contrary from a designer involved in the Public Area Design Group. Similarly, the desire to retain views down the street and out to the harbor were impacted by raising the ground level one metre to reduce costs associated with building a parking garage partially below sea level. Because of these decisions and the lack of response to the comments from a designer asked to review the project, two interviewees in the development and WCC groups noted design advice was not valued by LHM in the early days of the project.

Another interviewee from the development group spoke about how the Events Centre was non-notified as it reflected the ideas represented in the waterfront district plan. In comparison, the Retail Centre was publicly notified and did attract some criticism for being an internally focused, indoor shopping mall on a prominent waterfront location. 
Despite some reservations about their design, however, these projects did not attract the public attention later waterfront projects would and they were approved.

The Retail Centre was intended to attract people to the waterfront, but it quickly failed and was converted into an office building with three businesses fronting onto Queens Wharf plaza. Reportedly it was a struggle at the beginning to build the critical mass to support waterfront retail businesses. Interviewees from all groups agreed the policy of ground floor retail and commercial in all buildings was not necessarily appropriate for all parts of the waterfront and continued to result in vacancies in later projects. For example, there was high turn over for retail in the ground floor of the Herd Street building, which was refurbished at a later date. The citizen activist group argued, however, that ground floor spaces should have included other publicly accessible uses rather than just commercial or retail space.

According to four interviewees, had the 1987 stock market crash not happened much more of the initial plan would have been built, as several of the projects had received approvals. With the loss of capital, development slowed and it was easier for public groups to inspire a shift away from the initial plan.

Another project initiated during this phase was a development agreement for a hotel on the outer-T of Queens Wharf. This eventually resulted in a controversial proposal for a Hilton Hotel, which would be approved by the GWRC, but overturned in the Environment Court. According to one interviewee from the WCC group, WCC did not support the proposal, yet it had to go along with it because of the development agreement. 


\subsection{WCC response to public outcry regarding $R \& E$ centre}

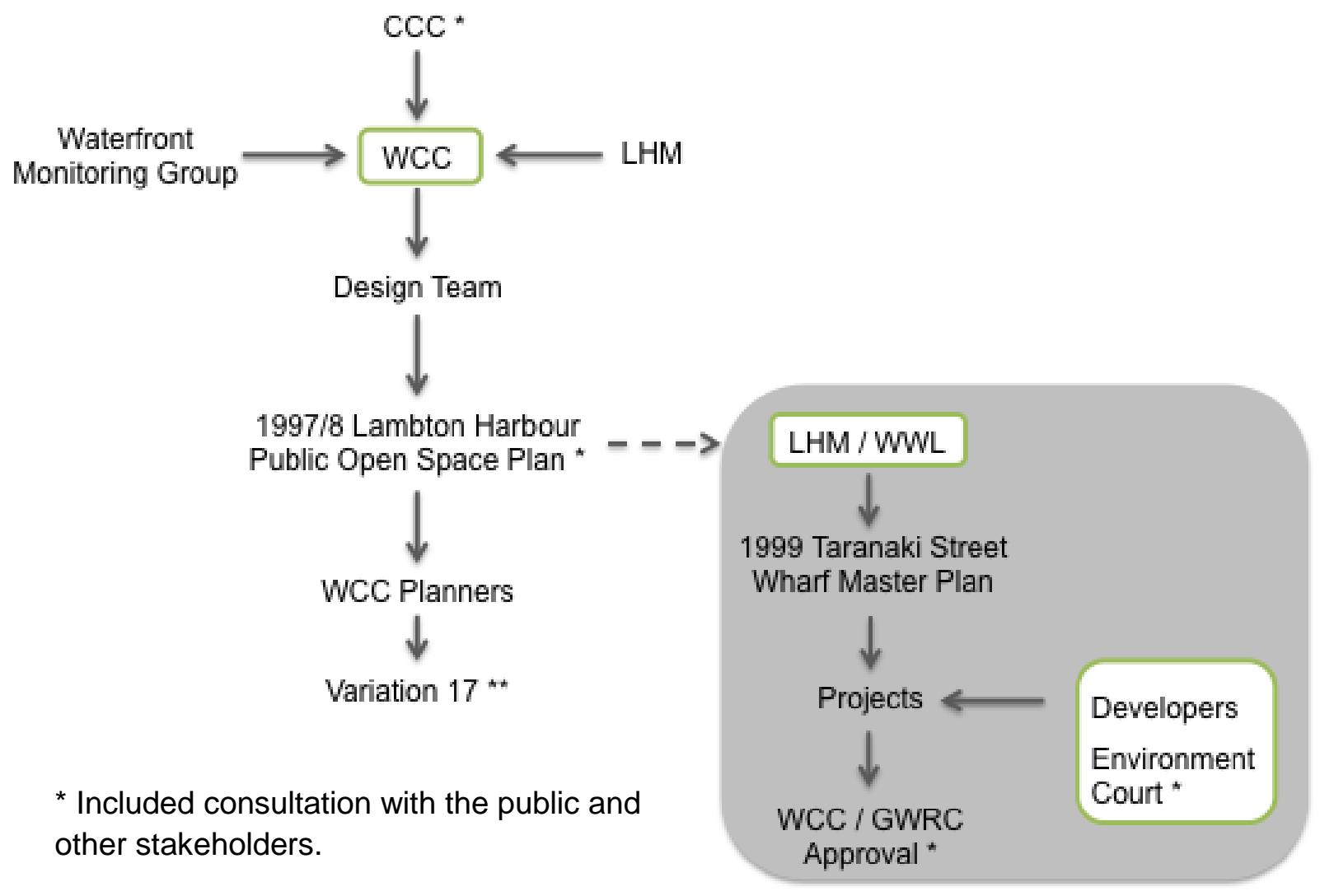

** Withdrawn by WCC due to public protests.

Figure 5.3. Diagram of the phase 3 governance arrangements for plans and projects (in grey) as identified from the interviews. The green rectangle identifies the Wellington City Council as the central decision maker on the form of the waterfront. Individual waterfront projects under this phase were managed by LHM in collaboration with the developers. One project was challenged in the Environment Court by a citizen activist group and the subsequent ruling changed the way the project was built.

A summary of the described effects on the form of the waterfront included:

- Scaled down development and more public open space. This included a minimum of $66 \%$ open space across the entire development and allocation of land for Waitangi Park.

- Perception of increased design quality and public space quality. Examples included better detailing of public space plans, emphasis on contextual designs, and prioritizing active edges for building projects.

- Provision of passive and active recreational amenities for all demographic groups. This was associated with providing a range of public spaces. 
- The Wellington Free Ambulance building and other existing buildings could not be moved.

- The rate of redevelopment was slowed down.

- A site for a wharewaka (shelter for traditional Maori canoes) was provided.

- Different characters were identified for five different sub-areas along the waterfront.

- Lower maximum building heights were established for new developments, for example, the Steamship Wharf and Meridian buildings.

All interviewees agreed the public was very upset with the quality of public open space surrounding the Retail and Events Centre plus the large scale and bland architecture of the buildings. Citizen activist and WCC interviewees also argued the initial plan and development process were regarded by the public as lacking transparency, accountability, and opportunities for feedback. According to two interviewees, these issues began debates over who had a say in decision making and whether it was public land or a private development. To address the public's concerns, the WCC stepped in to manage the process and the mayor eventually called a moratorium on development to allow time for public engagement that would inform a new waterfront plan.

Comparison of the interviews found all agreed that the governance arrangement for this subsequent phase was comprised of centralized decision making primarily by WCC, as shown in figure 5.3. This central role was informed by input from stakeholders via the Community Consultative Committee (CCC), two newly formed citizen activist groups, consultants, LHM, the GWRC, and the Environment Court. However, while the WCC played a central role, it was reported that WCC councillors continued to have varying levels of support for the waterfront redevelopment because it was one of many projects within the city.

The CCC was described by WCC and citizen activist interviewees as a WCC effort to gather the public's views on the future of the waterfront. The committee of community group representatives was formed by the WCC to canvas the public and other stakeholders on what they wanted in the redevelopment of the waterfront. The CCC report was then used as a design brief for a new concept plan for the waterfront 
that was commissioned by the WCC. According to one interviewee in the WCC group, LHM had little influence or contact with the design team hired to work on the plan. While the CCC report served as the design brief, one development group interviewee stated the new concept plan, completed in 1998, was also used to explore building heights to see what might be possible. If correct, WCC gave more direction to the design team than simply passing on the CCC report.

A second CCC consultative effort surveyed the public about the new concept plan and some of the options for different development intensities for different parts of the waterfront. While the WCC, development, and citizen activist groups agreed the CCC effort was successful in their outreach and the plan was well received by the public, they disagreed on whether or not the new concept plan reflected the findings in the CCC's first report. Two citizen activist group interviewees argued the subsequent new master plan for the waterfront did not fully respond to the CCC reports as it still emphasized large-scale development. Further they described the new plan as another case of the WCC favouring the views of consultants over the public's values. WCC interviewees, however, argued the values represented in the new plan represented a shift towards less intense, lower scaled development and prioritization of public space over private development. Where interviewees from both groups did agree was that the new concept plan marked a conscious shift from the waterfront being self funding to requiring some WCC input to offset costs of public space development.

Following the CCC reports and adoption of the new concept plan for the waterfront, WCC staff drafted Variation 17 to establish the new 1998 master plan as the district plan's new design guide for the waterfront. Interviewees from the WCC, development consultant, and citizen activist groups agreed however that Variation 17 did not adequately reflect the master plan and findings from the CCC report, nor was it well communicated to the public. One WCC interviewee stated, "there were some issues with the scale of the [3D] model that was built and there were some issues with the planning controls. They were quite blunt instruments.”

Subsequently, a citizen activist group called Waterfront Watch protested a perceived mismatch between the public's expectations of more public open space with fewer new buildings that were smaller overall compared to the number of building sites and 
the size of building envelopes permitted by Variation 17. Additionally, they were upset that Variation 17 would allow development to occur without public consultation if proposals respected the defined building envelopes. Waterfront Watch's successful public campaign against Variation 17 eventually convinced WCC to withdraw it.

During this time the Public Area Design Group became the Lambton Harbour Waterfront Monitoring Group. Their revised role was to comment on plans and proposals for the waterfront as a form of independent feedback to LHM and WCC. According to two development group interviewees, this mandate was a part of placing design as equal to, if not more important, than financial considerations.

Also based on the new waterfront master plan was a more detailed development plan for Taranaki Street Wharf managed by LHM. While there were reportedly few complaints about the landscape plan, Waterfront Watch launched a legal challenge to moving the Wellington Free Ambulance building that was a part of the proposal. According to citizen activist group interviewees, Waterfront Watch tried to engage WCC in mediation; however, they perceived the city did not listen to their position. By engaging the formal appeals process, they were able to prevent the building from being moved from its existing location.

Waterfront Watch was established to push the idea of the whole waterfront as public open space and was opposed to all new buildings according to interviewees in all groups. However, as one interviewee involved in the waterfront as a designer stated, "All the design consultants who have been involved with the waterfront have advocated for using buildings to define open spaces.” This tension of perspectives has led to ongoing debates over waterfront plans and individual projects.

All interviewees agreed Waterfront Watch was quite successful in promoting public consultation. Some claimed this was particularly true in several instances where WCC and WWL were not effective in communicating with, or listening to, interest groups or the public. For example, in addition to protesting Variation 17 in part due to it limiting public involvement, they later successfully challenged Variation 11 in the Environment Court on the grounds of insufficient public engagement. 
The effects of consultation were described by interviewees in all groups as providing more view points and priorities to consider, resulting in longer decision times.

However, while the pace of development slowed, built projects were considered more successful by interviewees as a result of the consultation (i.e. higher quality, more suitable for the waterfront, and less likely to be challenged in court).

Another citizen activist group, Chaffers Park Make It Happen was credited by WCC, development, and citizen activist interviewees with helping convince WCC and LHM to drop its plans for a residential development east of Te Papa and turn it into a park. This was raised as an option for the area in the new waterfront master plan and was eventually built as Waitangi Park.

The local iwi were actively included in consultations, and one interviewee suggested they were very supportive of the redevelopment. Of greatest interest to them were projects that reflected past traditional uses of the waterfront and illustrated their culture. Projects that reflected past uses included daylighting of the mouth of Kumutoto Stream that was a part of the Meridian Building and the inclusion of the wharewaka near the historic landing area for the village that once stood near the site. Cultural projects included the wharewaka that housed the ceremonial canoes and Te Papa which included cultural displays and a marae (meeting house) for local iwi.

\subsubsection{Influence on the built form}

In this phase the WCC stepped into the central decision making role and launched a community consultation process. The outcomes of the consultation were then used by the WCC to inform a new master plan for the waterfront. While decisions were informed by public engagement, interviewees reported WCC was ultimately in control of the decisions of the form. Despite this centrally controlled process, however, pressure from the public and citizen activist groups still had a large impact on the built form.

After the public outrage over the initial commercially-oriented plan it was reported by most interviewees in all groups that there was a shift by WCC to considering the waterfront as a public amenity rather than a private development. This shift included WCC setting a new policy of designing the public space first rather than having the 
public space design as a secondary consideration to architecture. A new, more detailed, master plan was therefore commissioned as a result of adopting the publicspace-first approach. Interviewees associated this move with provision of amenities for all demographic groups and different characters for separate sub-areas. Amenities discussed by the interviewees included: open spaces of different types that accommodated active and passive uses (e.g. lagoon, playground, Frank Kitts Park, plazas, skate park); cultural features such as the wharewaka, writer's walk, and sculptures; the different character of buildings along the waterfront; various social spaces (e.g. recreational spaces, pubs, cafes); a network of waterfront and internal routes for pedestrians and cyclists; and, provisions for both land and water based activities (e.g. rowing clubs, climbing gym, diving plank, marina).

Additionally, there was reportedly a greater focus on how buildings interacted with adjacent public space and providing a greater range of public spaces. The idea of providing active edges, where building uses and architecture would engage the adjacent public spaces, was identified primarily by those involved in the development group and one member of the WWL group. The interviewees identified all new and refurbished heritage buildings were to support adjacent open space through the inclusion of ground floor retail, office spaces, cafes and other publicly accessible uses.

Despite the reported move away from a commercially-oriented, self funding approach, most interviewees suggested new development was still seen as necessary for the economic health of existing and future waterfront businesses. Therefore, the commercial value of projects was still a necessary consideration, though there were conflicting perspectives between the citizen activist and other interviewee groups about whether this remained a dominant determining factor in decisions about plans and project proposals. Forms associated by interviewees with the need for some commercial development included the diversity of public spaces; replacement of the finger wharves with a continuous edge in places; and, mixing commercial, residential, retail, and cultural uses. Interviewees from the citizen activist and development groups also pointed out the new concept plan and Variation 17 allowed for buildings up to ten storeys suggesting WCC and LHM still saw a need for commercial returns from development sites. 
Quality of design and construction was identified by eight interviewees from all of the groups as having consciously improved following the public backlash to the Retail and Events Centre. Interviewees associated the improvement with the WCC decision to place greater importance on input from the design review committee. Under this policy, proposals were judged equally on design merit and economic returns according to development group interviewees. The improved quality was discussed in terms of later projects, including the design of Waitangi Park, the design of street furniture, the public feedback on refurbished heritage buildings and the premium returns on these, and public feedback and design awards for new developments (e.g. the Meridian Building and Taranaki Street Wharf).

Associated with the improved quality of developments, there was also discussion of new developments respecting the harbor location. Two development group interviewees attributed this with the greater role of the design review committee. Examples of projects that were internally oriented and had little engagement with the harbor included the Retail and Events Centre, Frank Kitts Park, and Te Papa.

Interviewees from all groups described how grassroots pressure by the public and citizen activist groups resulted in the creation of Waitangi Park on the site of a planned residential neighbourhood. Additionally, the demand for the waterfront to remain mostly public land encouraged WCC to set a policy of retaining a minimum of $66 \%$ of the waterfront development area as public open space.

A discussion of what was an appropriate scale for new developments arose in response to the public backlash against the design of the Retail and Events Centre. Interviewees from all groups discussed how the initial plans for the waterfront supported larger buildings, but the effect of this was only realized by the development of the Retail and Events Centre and Te Papa. A debate over what was an appropriate sense of scale remained an ongoing conflict between WCC and citizen activist groups in this and subsequent phases. One interviewee in the WCC group argued there should be a mix of high and low forms along the waterfront rather than a transition in height from the waterfront to the taller buildings of the central business district (CBD) argued for by other stakeholders. It was noted by interviewees in all groups that subsequent projects were smaller and shorter, however, as they were designed at the 
scale of the pedestrian and existing heritage buildings. Examples included: the Steamship Wharf building and the Meridian building. One interviewee from the WWL groups stated, “The Steamship Wharf building was the first immediately after these two large ones [the Retail and Events Centre]...it was a reaction to the public not wanting something big.” This reportedly triggered a shift to include lower types of developments according to WWL and WCC interviewees; however, citizen activist and some development group interviewees criticized the new concept plan and Variation 17 for the proposed scale of new buildings.

\subsection{Leadership Group}

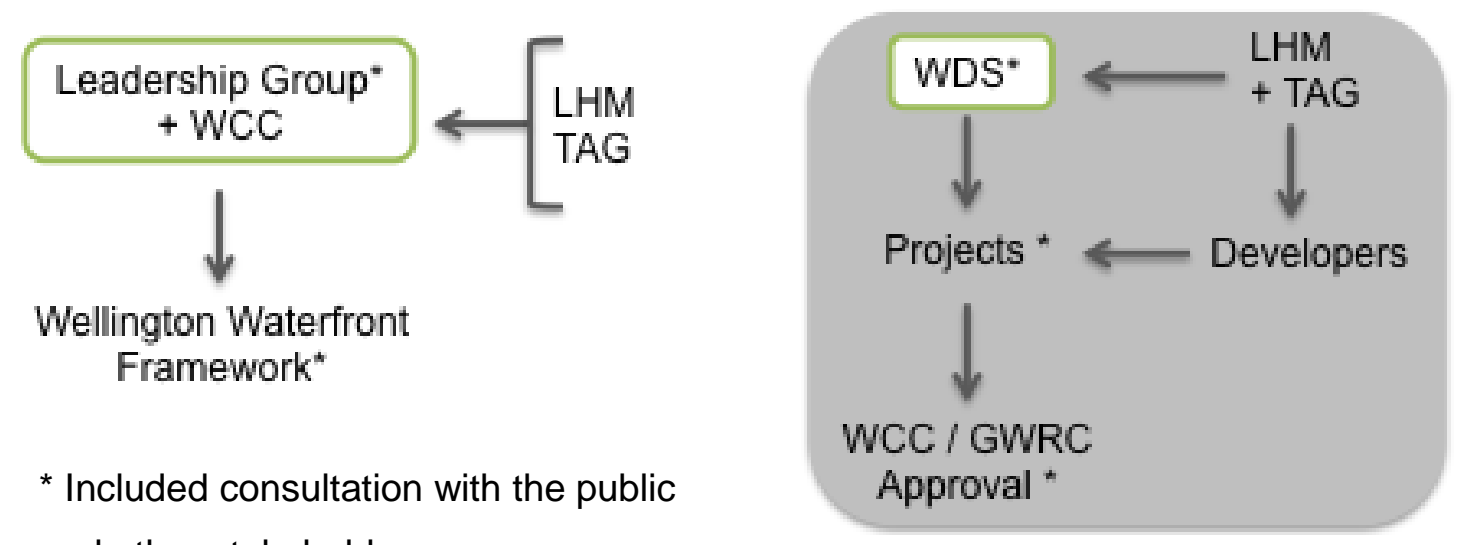

and other stakeholders.

Figure 5.4. Diagram of the phase 4 governance arrangements for plans and projects (in grey) as identified from the interviews. The green rectangle identifies the Wellington City Council and the Leadership Group as sharing the central decision making role on the form of the waterfront. While no projects were identified as being built during this short phase, a new Waterfront Development Sub-committee was identified as the central decision making authority for the anticipated governance arrangement of individual projects.

A summary of the described effects on the form of the waterfront included:

- Identifying and differentiating the five waterfront sub-areas was associated with a lack of design and character consistency across the waterfront.

- The strict consultation requirements and requirements of the Waterfront Framework were associated with conservative designs for new developments.

- The Waterfront Framework reinforced expectations of scaled down development proposals leading to more attention to open space design, publicly accessible ground floor uses, and how these two interacted through the use of active edges. 
Interviewees from all groups agreed that the creation of the Leadership Group was a result of lobbying actions by Waterfront Watch to create an inclusive process. When Waterfront Watch successfully pressured WCC to withdraw Variation 17, the city reportedly consulted with numerous stakeholder groups to identify a new engagement process that could be used to plan the development of the waterfront. The resulting process included a committee of stakeholders, chaired by a WCC representative, who negotiated a guiding set of goals and values for the waterfront.

While the Leadership Group was an inclusive committee of representatives from different stakeholder groups and interested parties, it was reported by citizen activist, WCC, and development group interviewees that the process was tightly controlled by the WCC officer who chaired the group. Therefore, in figure 5.4 WCC and the Leadership Group are shown as sharing the dominant decision making role. In their discussion of the topic, one WCC interviewee argued, the guidelines to manage debate and the different types of input were necessary due to the complexity of issues and diverse stances of the groups represented on the Leadership Group. For example, the same interviewee described how each meeting had to cover specified topics and that topics were very rarely revisited in subsequent meetings. Who set the agendas for the meetings, however, was not clear from the interviews. To retain transparency, however, all of the meetings included opportunities for the public to speak on topics that were under discussion; however, public speakers were limited to three minutes and could not revisit topics from previous meetings.

Also, the Leadership Group was reportedly kept away from four issues by the WCC: the future of the OPT, the then ongoing Environment Court case on moving the Wellington Free Ambulance building and implementation of the design for Taranaki Street Wharf, the Hilton Hotel proposal, and decisions about building sites beside Waitangi Park. Despite these restrictions, the Leadership Group did decide to provide some comment on the status of the OPT as having heritage value, and to provide advice on what to do with the Hilton Hotel site should the proposal be defeated. Reportedly, the Leadership Group also unanimously agreed to not include any new buildings beside Waitangi Park; however, they were later convinced by a representative from WCC to allow the decision to be deferred for the next governance phase. However, another interviewee involved in the process argued the deferral of 
the decisions about buildings adjacent to Waitangi Park was made because the role of the Leadership Group was not to design the waterfront, but to find agreement on the vision and values for the waterfront.

To provide design advice to the Leadership Group and feedback on their decisions, the Lambton Harbour Waterfront Monitoring Group was reconfigured into the Technical Advisory Group (TAG). Membership changed from a mix of planners and designers to all designers. According to a WCC interviewee, the role of TAG to was provide design and development advice on decisions by the Leadership Group and provide design review feedback on plans and proposals to LHM and WCC, and that it was similar to the Monitoring Group that preceded it.

Decisions made by the Leadership Group included consideration of public submissions, public surveys, consultant reports, comments from TAG, and feedback from organizations who had representatives on the Leadership Group. According to four interviewees whom had been involved, the Leadership Group collectively drafted a development and governance strategy for the waterfront called the Wellington Waterfront Framework.

\subsubsection{Influence on the built form}

The Waterfront Framework was described by three interviewees involved in the Leadership Group process as intentionally flexible about the detailed form of the waterfront, but specific about the governance of the project. According to one WCC interviewee, "Much of the Leadership Group work was talking about the waterfront at a high level.” The flexibility of the goals and values, but specificity about the governance to include public consultation, meant the subsequent stages of decision making about the detailed form of the waterfront would require public input to clarify design direction for individual projects and area plans. The resulting form was therefore more influenced by politics and how stakeholders were involved than if there had there been a master plan.

Interviewees representing the development consultants and WWL groups described the Waterfront Framework as providing overall guidance and that it raised specific issues for five different sub-areas of the waterfront. The flexibility within the 
Waterfront Framework however allowed different designers involved with sub-area landscape plans and individual building projects to prioritize different design styles and contextual issues. This led to variety in the character of public spaces along the waterfront in many aspects, including street furniture, amenities, and signage. To find some consistency in form across the waterfront, TAG eventually drafted guidelines for lighting, signage, and street furniture.

The Waterfront Framework also included the requirement for a zero metre maximum height limit over all the waterfront development sites. This was intended by the Leadership Group to establish a requirement for public consultation as all development proposals would need to apply for a planning consent in order to exceed this height. This was a way of insuring the public and interested groups would have a formal opportunity to comment on every project. One interviewee from the development group argued, however, that the governance approach outlined by the Waterfront Framework limited the creative potential of the waterfront. They saw design on the waterfront as a "very rigid, controlled box in terms of height, form and use.” They associated the requirement to consult the public on every project as generating very conservative designs, despite the intended flexibility of the Waterfront Framework.

Overall, it was agreed by most interviewees that the Waterfront Framework was the most effective step in "shifting the waterfront away from a more intensive development path,” as described by a WWL interviewee. For example, land was designated for Waitangi Park and heights for several development sites had been scaled down as a result of the Leadership Group’s discussions.

The Waterfront Framework outlined a governance approach for the waterfront that included an inclusive WCC subcommittee to take control of the waterfront planning and a council-controlled organization (CCO) to run the waterfront and implement the recommendations of the subcommittee. The CCO was established as WWL, which took over the implementation and management functions of LHM. This is represented in the grey portion of figure 5.5 . 


\subsection{Waterfront Development Subcommittee era}

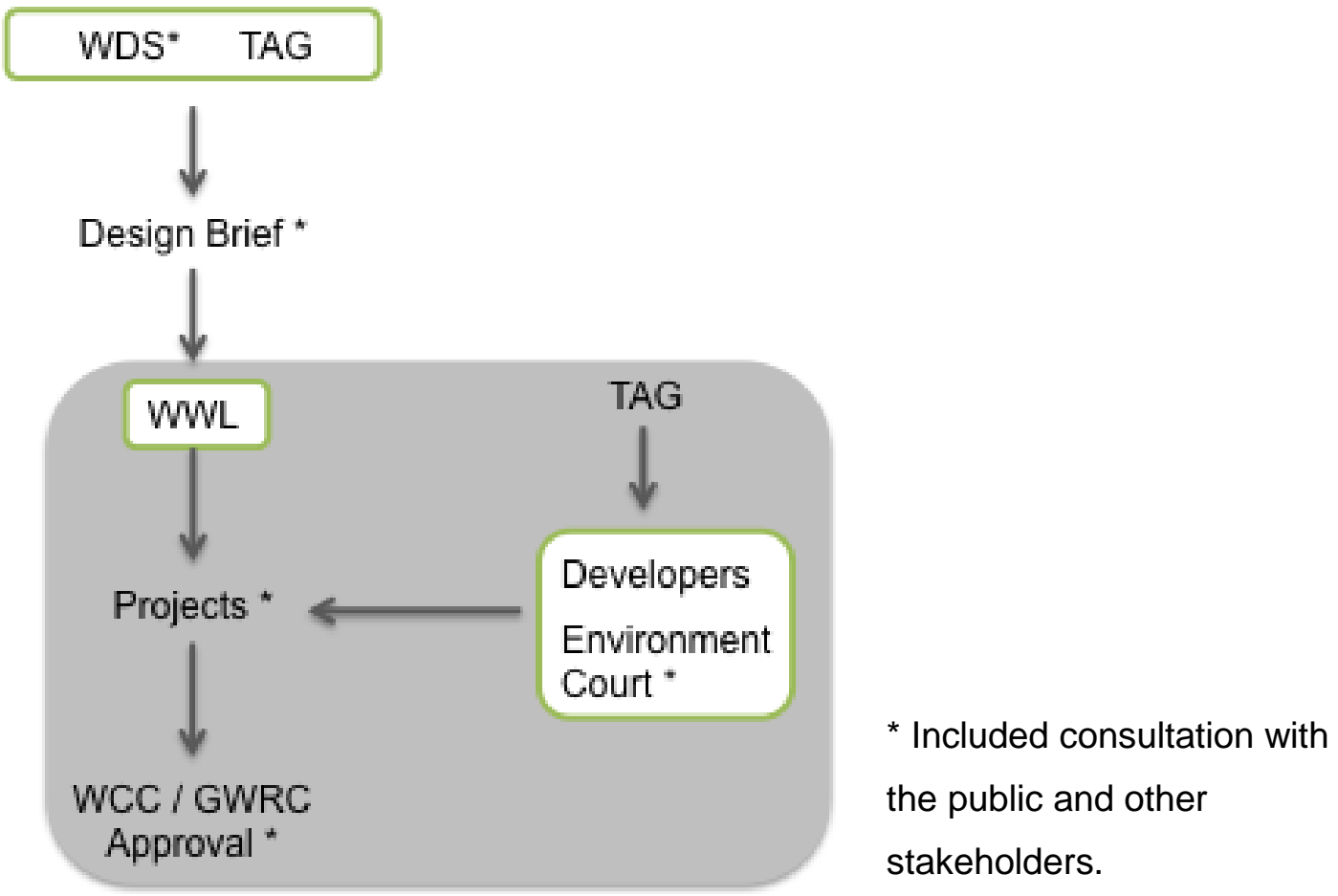

Figure 5.5. Diagram of the phase 5 governance arrangements for plans and projects (in grey) as identified from the interviews. The green rectangle identifies the Waterfront Development Sub-committee and the Technical Advisory Group as sharing the central decision making role on the form of the waterfront. Individual projects built during this phase were influenced by TAG in regards to design decisions and WWL for commercial decisions. Under this arrangement, the public and other stakeholders had opportunities to provide feedback at every stage even though this was often filtered by the WDS.

A summary of the described effects on the form of the waterfront included:

- Interviewees identified a higher quality in the designs and a larger number of successfully built projects. Specific examples identified by the interviewees included the Meridian building and adjacent plazas, Waitangi Park, completion of the Taranaki Street Wharf, and the Overseas Passenger Terminal.

- A transition from rough, industrial character to a smooth, glassy aesthetic.

Despite following the Leadership Group’s recommendation of a WCC subcommittee focused on waterfront planning and strategy that included stakeholders, representation on the WDS was not as diverse as the Leadership Group according to interviewees. Reportedly it included three members from the design community, three councillors, and three community representatives. Of the community representatives, one was 
from Tenths Trust (an organization representing iwi interests). Some members were recruited from the Leadership Group and the chair of TAG was included as one of the design community members. Cross-appointments from the Leadership Group and TAG were intended by WCC to retain institutional knowledge according to two such appointees. Despite having less direct involvement from stakeholder groups, interviewees from the WCC, WWL, and development groups described the process under the WDS as quite transparent.

As illustrated in figure 5.5, the WDS was described as the central decision making body that used many stages of engagement exercises and surveys to collect feedback from the public and other stakeholders on all waterfront strategy and design decisions. For example, draft design briefs and detailed landscape designs were open to public and stakeholder input, additional feedback was actively collected through various outreach efforts, and finally, the final plans and briefs were publicly notified as a part of the statutory planning process.

During this period, the WCC and WWL also reportedly employed many different methods for gathering feedback according to WCC, WWL, and development group interviewees. For example, public consultation included open house days held by WWL and developers of specific projects to share ideas and collect feedback from interested people or groups.

In responding to submissions, interviewees from the WWL, WCC, and development groups argued there were often relatively few submissions and most of those were from those opposed to plans and projects. Because of a perception that people who were happy with the various projects rarely provided feedback, WCC and WWL found it difficult to identify the true level of support for projects. As a result, feedback from the formal consultation on the final plans rarely resulted in changes, according to one WCC interviewee.

The major role of the WDS was to develop detailed design briefs for each of the five sub-areas of the waterfront, as intended by the Leadership Group. These design briefs followed the vision set out in the Waterfront Framework according to interviewees. Subsequently, the Leadership Group intended the design briefs to serve as the 
foundations for district plan variations drafted by WCC staff and consultants. These variations were described as a necessary step for the design briefs that were crafted with substantial public input to become the design guides for the waterfront redevelopment. However, variations were not written during this phase. Instead, the Waterfront Framework and design briefs were often treated as the design guide for the different areas according to WCC and development group interviewees.

Once the five design briefs were completed the role of WDS was merged with another WCC committee in 2006, according to WCC and WWL interviewees. This change marked a transition from one governance approach to the next in all of the interviews.

LHM's role in this phase was reduced to managing the business and implementation of the redevelopment and they were renamed WWL. One interviewee from the citizen activist group claimed, however, they retained their top-down, commercially oriented approach and did not effectively engage the public. A development group interviewee argued this perception was a result of there being separate design decision processes and commercial decision processes. The commercial decision role of WWL was described as coordinating all of the formal steps a development proposal needed to go through. WWL was involved in marketing sites for development, serving as the primary contact for interested developers, coordinating with TAG, helping with the planning consent application, and assisting with managing the construction process. Under this arrangement, it was identified that WWL successfully deflected criticisms from WDS and WCC, retained focus on the redevelopment effort, and kept some of the politics away from the business side of the project. Despite these measures to retain some 'arms' length' management of the waterfront, accountability was reportedly retained through regular reporting to WCC, surveys, budgets, and WCC representation on the WWL board of directors.

Citizen activist interviewees argued WWL continued to market development sites and work with developers to maximize profits. An interviewee from the WWL group, however, stated, “Only when WWL is comfortable it has achieved a balance between public and private needs do we present a proposal to council.” This tension was a part of the ongoing debate between the relative importance of private development and providing sufficient public amenity along the waterfront. The perception of a profit 
focus may have also been related to interactions between the design decision processes and commercial decision processes.

WWL also reportedly retained its own board of directors, appointed by the WCC and which included a councillor. Having a councillor on the board was described as a measure to insure a strong line of communication was retained. According to a WCC interviewee, the remaining members included a mix of lawyers, business people, and design and development representatives. Some members of the board of directors were also former Leadership Group members or involved with the waterfront in other ways. This was an intentional move by WCC to retain institutional knowledge and insure ideas were carried through.

TAG continued the role of a design review panel, but had more influence on decision making as shown in figure 5.5. According to WCC, WWL, and development group interviewees, TAG drafted the design briefs for waterfront areas and specific sites, and provided feedback to WDS on the merit of development proposals and design competition entries. Projects were assessed in part by how they responded to the Waterfront Framework and how the design contributed to the waterfront. According to interviewees involved with WDS and TAG, TAG also worked directly with developers' design teams on refining their ideas to better fit the waterfront context and the goals of the Waterfront Framework. It was agreed among all interviewees that TAG had a positive effect on the overall quality of the redevelopment. Two interviewees noted however, that the rough, weathered, industrial heritage character of earlier proposals slowly transitioned into the smooth, glassy aesthetic of newer buildings and landscape designs. Whether this was a result of changing membership of TAG was not clear from the interviews.

The emphasis on design quality by the WDS process and TAG was described by WCC, WWL, and development group interviewees as being more important when selecting proposed developments than their economic viability under this phase. In comparison, citizen activist interviewees perceived maximizing developer profits as a stronger influence. Interviewees from all groups, however, agreed prioritizing good design was healthy for the waterfront and had resulted in a more amenity rich 
waterfront than would have been built under the Lambton Harbour Combined Scheme.

Also, projects that were more expressive of their context and were perceived to have larger public value generated more support than those that were perceived to leverage their site for private gain. For comparison, the Meridian building was perceived to add some value to the public realm while the Hilton Hotel was thought to be privatizing a prominent waterfront site with little public gain.

In addition to higher design requirements, periods of increased public consultation were associated with higher success rates for projects receiving consent and getting built by interviewees in the development and citizen activist groups. This pattern was seen to be even stronger than the effect of economic cycles on rates of development. For development group and WWL interviewees, however, the downside of longer consultation phases was slower development and greater financial risk. Lack of public consultation, in comparison, often provoked legal challenges. For example, the Hilton Hotel, the plan to move the Free Ambulance Building, and design guides for North Kumutoto were all overturned in the Environment Court due to lack of public consultation.

\subsubsection{Influence on the built form}

Despite TAG's role as a reference group and design review committee, WDS and TAG shared the central decision making influence on the form of the waterfront according to interviewees in all groups. WWL's influence on the form was significantly less though there was some cross over due to their role in managing the commercial business of the redevelopment. The public and citizen activist groups had less direct influence on the form of the development largely because feedback from public engagement exercises was assessed and filtered by WDS. Where citizen activist groups, particularly Waterfront Watch, did have an impact was through their continuous lobbying for public consultation to be a priority in the process.

The Waterfront Framework was supported by all stakeholders involved in this stage, therefore, it served as the basis for most of the design and development decisions on the waterfront. As noted previously, it was intentionally flexible in accommodating 
design ideas resulting in an evolving character for the waterfront. The Waterfront Framework also promoted the continued shift away from a dense, commercially oriented development with more public open space and interaction between buildings and adjacent pedestrian areas.

Waitangi Park and the Meridian building projects both included opportunities for stakeholder feedback through formal consultation processes; however, decisions about the form of these projects were made by the designers, TAG, and WDS, with input from WWL and WCC. The design of Waitangi Park was the product of a design competition with the final design chosen by WDS based on criteria that had been established by the WCC and TAG. One interviewee from the citizen activist group noted this decision by WDS was made despite a public vote on the designs. Two interviewees from the WCC group and one from the development group, however, described the purpose of the public vote as being a mechanism to involve the community and provide an opportunity for public input, but agreed the process was highly managed by the WCC through the WDS.

Design competitions were seen by one WWL and two development group interviewees as opportunities to gather innovative ideas, but they were also described as limiting momentum and innovation because of becoming locked into the winning idea. One interviewee from the WWL group went further and argued they were a disaster because of the gap between expectations and delivery. They raised expectations about what would be built. 


\subsection{Post WDS era}

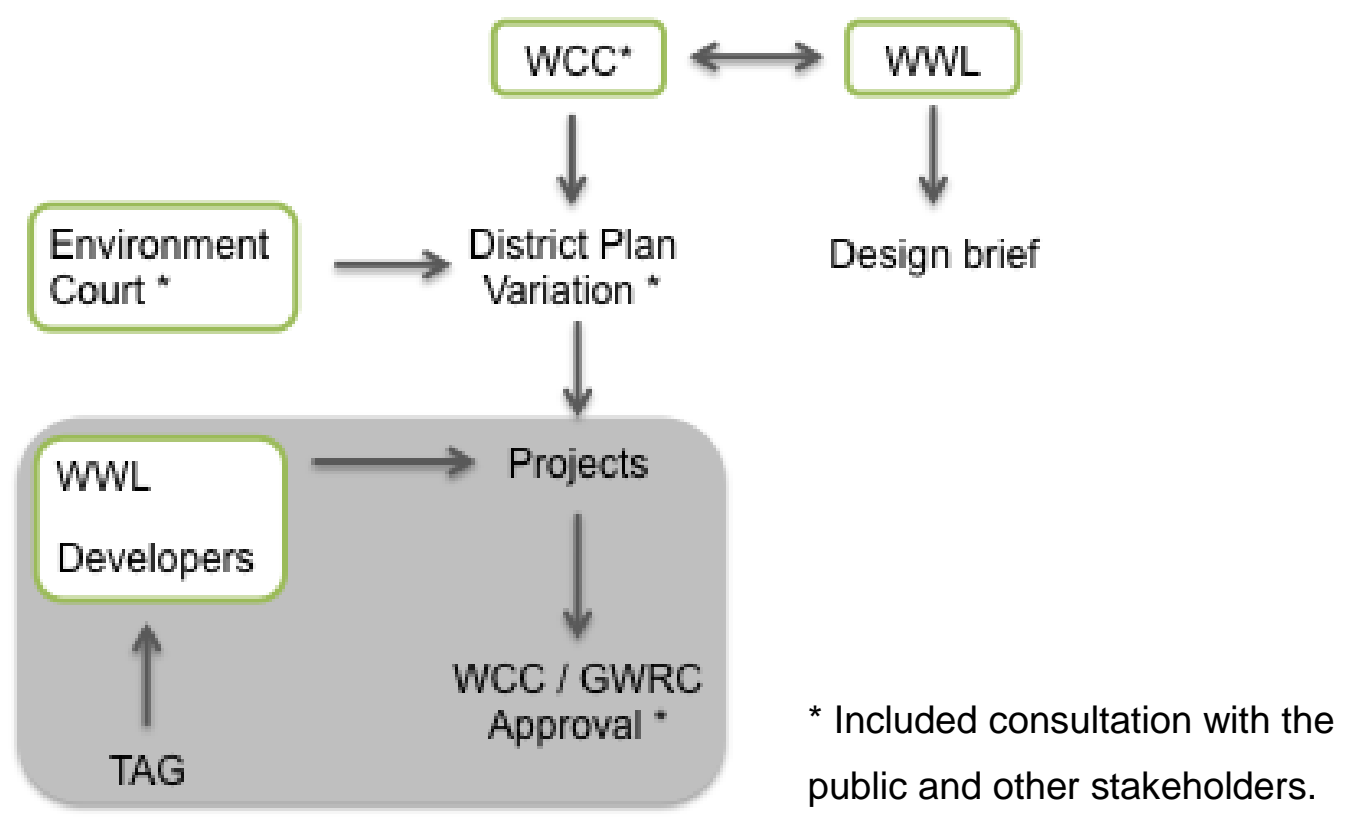

Figure 5.6. Diagram of the phase 6 governance arrangements for plans and projects (in grey) as identified from the interviews. WCC and WWL shared decision making responsibilities; however, they did not always collaborate effectively according to interviewees. An appeal by Waterfront Watch to the Environment Court led to changes in the form of the North Kumutoto area. For individual projects, WWL led most of the design consultation with reduced input from TAG compared to the previous phase.

A summary of the described effects on the form of the waterfront included:

- a slower rate of redevelopment;

- proposals for taller buildings than under the previous governance phases; and

- conservative designs for new buildings that were perceived to be less contextually sensitive.

The WDS was dissolved when the five sub-area design briefs were completed in 2006, and subsequent decision making was reportedly shared by WCC and WWL, as shown in figure 5.6. This change was related to efforts to integrate WDS and WWL activities into regular WCC operations according to WWL and WCC interviewees. One WWL interviewee suggested this was a “natural step” because there were few large development sites left. Despite efforts to integrate the two, one WCC group interviewee stated, "Council does not talk with one voice...no one is really in charge of the process at the moment” and that decision making under this period was quite 
fragmented as a result. Correspondingly, WWL was regarded by interviewees in all groups as having more influence on decision making during this phase.

Similar to the shift from the Leadership Group phase to the WDS phase, interviewees suggested dissolving WDS and integrating WWL into WCC further removed representation of stakeholders in the decision making group. As described by interviewees from the WCC and development groups, input from the public and other stakeholders was reduced to written submissions on final plans and project designs, as required under the statutory planning process, and to designated speaking times at WCC meetings.

Reportedly, there were several competing priorities that re-shaped the decision making process during this period. WWL and development group interviewees described how WWL sought to reduce the financial risks to developers that were associated with lengthy consultation phases by reducing opportunities for public input. One interviewee from the development group added WWL could also charge higher development fees if it could reduce the risks associated with a longer, more public process. Based on these comments from the interviewees, the additional income and faster planning stages would then reduce the need for WCC funds to support wharf and public space upgrades.

Two other development group interviewees stated WWL and WCC felt forced to rethink the development process after the Environment Court overturned project approval for the Hilton Hotel. Even though there had been a design brief written for the area, which had been sufficient under the previous WDS phase, it was reported the court ruled the Waterfront Framework and design briefs were not enforceable. The new development process established by WCC and WWL included jointly drafting district plan variations based on the design briefs. It was claimed by citizen activist and development group interviewees that the process was intentionally set up to limit opportunities for the public to comment on only when they were notified as a part of the statutory requirements. Also, because the variations would specify allowable building envelope dimensions and other design criteria, two citizen activist group interviewees noted proposals meeting these requirements would not have to be publicly consulted upon, which further eroded opportunities for input. 
The first district plan variation under this new process, Variation 11, set out the development parameters for three building sites in North Kumutoto. According to two interviewees from the development group, the city drafted this variation with some consultation with neighboring tenants, but did not consult the public prior to releasing it for public notification. It was claimed by one WWL interviewee that the WCC did not consult because they thought they already knew what the public response would be.

After Variation 11 was approved, Waterfront Watch successfully challenged it in the Environment Court. In its judgment, the Environment Court was critical of WCC and WWL's lack of public consultation on the design and subsequent district plan variation drafted for this area of the waterfront. One interviewee from the development group noted however, that the planning process required under the Resource Management Act did not include an obligation to consult; however, it was considered "best practice”.

After several years of running annual public surveys, the WCC and WWL stopped commissioning them in 2008 because they were not getting any new information, according to two WCC and WWL interviewees. The WCC interviewee thought the belief that public feedback was easily predicted had contributed to the decision to limit opportunities for public comment.

Additionally, two WCC and WWL interviewees described how the outcome from a WCC initiative to review the Waterfront Framework further solidified this belief. Through the use of specific focus groups and a survey WCC sought to check whether the values represented in the Waterfront Framework were still relevant. They reportedly found the vision of the Waterfront Framework still reflected the public and stakeholder's overall preferences for the waterfront development. This was described as contributing to the belief that they knew the direction development should take.

\subsubsection{Influence on the built form}

Interviewees noted that the decline in consultation back to the formal requirements outlined by planning legislation was intended to increase predictability of the decision making process and improve the speed at which developments could proceed. In 
practice, however, it was observed by WWL and development group interviewees that a short period of greater efficiency was followed by a sudden rise in dissatisfaction and involvement. It was suggested this approach significantly slowed the rate of redevelopment. For example, because public consultation efforts were not maintained, a subsequent plan developed for the North Kumutoto area (Variation 11) was appealed and overturned in the Environment Court delaying development of this area by several years. Also, the decision on the Hilton Hotel had a cascading effect as WWL had been relying on the development of the hotel to cover needed repairs and strengthening to Queens Wharf. Instead, the hotel proposal was defeated in an Environment Court ruling and WCC had to use public funds to undertake the repairs, rather than close sections of the wharf that were quickly becoming unsafe due to age.

The building envelope dimensions in Variation 11 were also described by a WWL interviewee as referencing the buildings across the street in the city's central business district, rather than referencing other buildings on the waterfront. One citizen activist interviewee described this approach as reminiscent of LHM's plan for high development intensities along the waterfront.

One development group interviewee described a different mechanism through which engagement was limited in the design process. They believed that when junior employees were tasked with evaluating proposals and serving as initial contacts for developers, design concepts were judged based on the rules rather than a more flexible comparison with the intent of policies. The effect was described as resulting in consistent, but more conservative urban forms because junior planners tended to follow the rules more closely.

Within the design process, one interviewee from the WCC group stated design development remained a collaborative effort between TAG, WCC, and developers. Two development group interviewees suggested TAG had a reduced role, with WWL, WCC and the individual developers making most of the decisions. As a result of the reduced role and design feedback, the two interviewees claimed there was less consistency of character and consideration of context in new plans and proposals than before. 


\subsection{Summary}

The descriptions of the six governance phases identified in this chapter included similarities and differences between who was involved in the decision making, the influence of professional designers, and the management of public and stakeholder feedback. In turn, the built form was affected by each of these three aspects in a relatively predictable fashion.

\section{Phase 1}

The WHB, in its role as the local government authority responsible for the waterfront for the first phase, was characterized as the sole central decision maker. Lobbying and organizing by the Civic Trust raised awareness of the waterfront's potential and initiated discussions with WCC; however, WHB had to make the decision to proceed with the redevelopment. The initial concept plan for the waterfront was informed by several separate sources, including instructions from WHB and WCC, ideas from the Civic Trust public competition, consultation by the design team, and the design team's own sensibilities. WHB and WCC's direction for the waterfront development to be self funding was influenced by each organization's outside responsibilities. Arguably, WHB had the least corporate interest in the project, therefore, the selffunding mandate would have been key to their involvement. Once commissioned, the design team had to address the public and WCC's ideas for the waterfront while prioritizing WHB's terms. This tension, which included WHB's reluctance to consult with the public, resulted in plans for large building developments that worked to incorporate a variety of public amenities.

\section{Phase 2}

LHM was described as a development corporation that operated with a high level of independence from WHB and WCC. Under this centralized governance structure LHM was regarded as focused on maximizing returns on development. This mandate carried over from the previous phase, but was given greater priority. Similar to the concept plan from the first phase, the new plan included large building developments to fund the project, but other income generating projects, including development of the marina and underground parking, were incorporated. Additionally, LHM's 
response to the 1987 stock market crash was to invest in public amenities in part because they would attract investors. Under this structure, input from design professionals and public feedback were reportedly given less importance. The projects built under this phase had a consistent character due to the focus from a dedicated development corporation, but were largely internally focused and did not respond well to their contexts.

Phase 3

When WCC stepped in to manage the third governance phase, the governance structure had similarities to the first phase under WHB. In this case, WCC was the local government authority acting as the central decision maker and there was again strong pressure from citizen activists. In comparison, however, WCC actively sought public and stakeholder feedback and strengthened the role of the design review committee.

The public feedback, supplemented with direction from WCC, was given to a design team to produce a new plan for the waterfront. Additionally, the resulting plan was transposed by WCC staff into a district plan variation, which was seen to promote large scaled developments. Reportedly, council was also still somewhat divided about how much to invest in the waterfront project, therefore, the design team was encouraged to explore the potential for development to pay for public space, despite rescinding the mandate for the project to be self funding. These effects are consistent with the top-down decision making described in the previous two phases.

Like the first phase, citizen activism was effective in shaping the process and the built form by extension. Arguably, citizen activism and WCC's emphasis on public consultation had a strong influence on improving the design quality, as more views were reflected in the built form. Interviewees also credited citizen activism and consultation efforts with delivering more public open space, an increased mix of amenities, diversification of character for different parts of the waterfront, and slowing the rate of redevelopment. Lastly, design professionals were also credited with improving the design quality and diversification of character through the influence of the design team and the design review committee. 
Phase 4

The Leadership Group was established to find consensus on which values were going to drive decision making; however, the WCC did not completely relinquish control of this process. Despite the WCC control, this process was more inclusive than the third governance phase as stakeholder groups were given some direct say in the decision making. Unlike phases one and three, however, a range of ideas were not solicited because the point was to find a unifying approach. Professional designers had a stronger influence through representation on the Leadership Group and through TAG. Under these arrangements, both consensus building by the Leadership Group and the more direct influence of professional designers contributed to a more cohesive design direction, more consideration of context, better integration between buildings and open space, but also more conservative design proposals. The high level of inclusivity was also associated with a slow rate of redevelopment by WCC, WWL, and development group interviewees. The oversight by the WCC was associated with decisions to allocate building sites along the edge of Waitangi Park, which is consistent with previous top-down approaches.

\section{Phase 5}

The fifth stage described by interviewees was also an inclusive structure directed and filtered by WCC. Public and stakeholder feedback was gathered at each stage of decision making, however, except for the planning decisions appealed in the Environment Court, WCC, development, and citizen activist group interviewees felt the feedback had little effect on the decisions. Unlike previous phases where a topdown approach resulted in larger scale development, adoption of the Waterfront Framework to guide decision making appeared to mitigate this pattern.

Design professionals had a strong influence on decisions through representation on WDS, the influential role of TAG, and through the public engagement process. Similar to the previous phase, the Waterfront Framework and role of design professionals appeared to be responsible for the described high quality design that included contextual, integrated buildings and open space. By themselves, the 
influence of designers was associated with a changing waterfront aesthetic, while the weight of public consultation was only associated with a slow rate of redevelopment.

Phase 6

The last governance stage was characterized by greater autonomy for WWL and fragmented decision making which combined aspects of the first and second governance phases. Public consultation was minimized to improve the rate of redevelopment and a greater emphasis was given to attracting development income. Additionally, design professionals did not have strong input into decision making, similar to the early governance phases. Concerns over development income and reduced design oversight were associated with larger development proposals and fewer contextual considerations in their design. Ultimately, formal appeals from citizen activists shaped the process and built form by slowing the rate of redevelopment and establishing smaller development envelopes.

\subsubsection{Patterns in the identified governance approaches and their influence on the built form.}

The trends evident in the above descriptions include patterns associated with strong top-down management by local government and the development corporation, effects of citizen activism and public consultation, and influence of professional designers. The built form was, therefore, influenced by how tightly local government and the development corporation controlled the process, the success of citizen activism, whether public and stakeholder feedback influenced decisions, and how much influence professional designers had on decisions. The degree of influence these groups had on the decisions about the waterfront influenced the strength of the response in the built form.

Strong top-down management by WHB, LHM, WCC, and WWL was associated with buildings that were larger than existing waterfront buildings, more building sites, and projects that responded poorly to their context.

Successful citizen activism that effected change, plus public and stakeholder feedback used in decision making were prominent in phases one, three, four, five, and six. 
These periods of public involvement were associated with: an increased amount of public open space, fewer building sites, buildings that responded to the heights of existing waterfront buildings, an increased variety of amenities for all demographic groups, better integration of buildings and open space with active edges and publicly accessible ground floors, and a slower rate of redevelopment.

When professional designers were able to influence decision in phases three, four, and five (and somewhat in phase one) designs were regarded as being higher in quality and more successful. This was expressed through more cohesive and contextual designs, better integration of buildings with adjacent open space through the use of active edges, use of buildings to frame open spaces, better recognition of contextual issues for the five sub-areas, and a changing aesthetic from a rough industrial look to a more polished finish. 


\section{Discussion}

The purpose of this chapter is to compare and discuss the findings from the previous two chapters that identify how different governance approaches have influenced the built form of the Wellington waterfront. Chapter 4 reported on the influence of nine governance phases identified in the background literature, relevant reports, meeting minutes, and site visits. Chapter 5 described the influence of six governance phases based on interviews with citizen activists, developers and development consultants, and representatives from WCC and WWL who had been involved with the project. Both chapters identified distinct governance phases and how they were found to influence the built form. In each case, general governance-built form relationship patterns were identified that were consistent across the respective governance phases.

As described in more detail in section 3.3.8, the nine governance phases identified in the analysis of archive and background literature were recognized by drafting a detailed narrative of the projects and processes involved in the development of the waterfront. The individual projects and the processes through which they were realized were evaluated to identify commonalities and differences in their governance. These comparisons were used to classify and articulate discernable governance phases. All the projects and plans identified as being a part of each phase were then compared to identify what aspects of the built form were influenced by the governance approach. Observations from the site visits were used to assist with identifying built form relationships between projects that corresponded with the governance phases.

Chapter 5 described six governance phases that were identified from interviews with citizen activists, developers and development consultants, and representatives from WCC and WWL who had been involved with the project. Interviewees were recruited to provide a breadth of involvement and perspectives on the redevelopment project. As described in section 3.3.4, the interviews were analyzed to identify similarities and differences in perspectives on the governance of the redevelopment process and how the different governance approaches were seen to influence the resulting built form.

Despite the different number of phases, both chapters concluded the built form of the Wellington waterfront was influenced by how tightly local government and the 
development corporation controlled the process, the success of citizen activism, whether public and stakeholder feedback influenced decisions, and how much influence professional designers had on decisions. However, the relative influence on decision making varied for all of these groups over the timespan of the redevelopment. The degree of influence these groups had on the decisions about the waterfront, therefore, affected the relative influence they had on the built form at different periods in the waterfront development.

The first section of this chapter will compare the overall findings of the two previous chapters. It will compare the identified effects each of the four groups described above had on the built form when each had a strong influence on decisions. Comparing the findings from the archive analysis, interview analysis, and site visits provides triangulation of results that aids in identifying the level of confidence in the results, as described in section 3.3.11.

The second section will discuss the differences in how the governance phases were described in the two preceding chapters. This will provide additional insight into these patterns and address the strength of the generalizations made in identifying the governance phases.

Finally, the third section will describe the limitations of the findings and identify new questions that arose in response to the study and its results.

\subsection{Comparison of findings}

As described above, both of the previous chapters concluded the built form of the Wellington waterfront was influenced by how tightly local government and the development corporation controlled the process, the success of citizen activism, whether public and stakeholder feedback influenced decisions, and how much influence professional designers had on decisions. This section compiles the findings from the interview and archive analyses, plus the site visits to look for consensus on how the built form was influenced at the time each group had a strong influence on decisions about the waterfront. 


\subsubsection{Influence of strong top-down governance}

In the interviews, governance phases that included strong top-down management by WHB, LHM, WCC, and WWL were associated with buildings and building proposals that were larger than existing waterfront buildings, plans that included more building sites, and built projects that responded poorly to their context. The Retail and Events Centre and dense development plans were cited as early examples of this approach (section 5.3.1) while Variation 11 and the associated proposal for North Kumutoto were more recent examples (section 5.7.1).

Analysis of the archive material agreed with these findings and revealed additional detail about how this approach influenced the built form. The self-funding and commercial prioritization of the top-down approach were both also reflected in the widespread incorporation of ground floor retail in all buildings, the early construction of Chaffers Marina as an amenity and for income, use of vacant building sites for paid parking, approvals for two large hotel proposals that would have had significant effects on the public realm, plus a requirement for proposals to include repairs and upgrades to the aging wharves (see section 4.5.2). Lastly, the wide water's edge promenade along Taranaki Street Wharf, and some open areas on Queens Wharf were influenced by WHB's requirement for retaining wharf space for port services (section 4.4.4).

Including residential development in the mix of land uses was also associated with top-down management in the archive analysis. Conversion of the former Harbour Board offices, shed 21, and the Herd Street Post and Telegraph building were examples of top-down decisions on residential development. These projects were intended to improve the vibrancy of the waterfront and the viability of waterfront businesses.

Site visit observations supported these findings on the top-down influences on the built form. Early developments tended to be larger and more internally oriented (e.g. Frank Kitts Park, Retail and Events Centre, and even some details of the City to Sea Bridge). New and refurbished buildings that did not benefit from strong public feedback or input from design professionals similarly had poor interaction with adjacent public space and the larger waterfront context. Examples of built projects 
that had limited interaction with their surroundings included Te Papa, Queens Wharf apartments, sheds three, six, 21, the Herd Street building, and the Retail and Events Centre.

Also, some features were identified in the site visit that appeared to have been implemented in a top down way rather than as a part of formal plans that involved public consultation. These include the temporary art installations, the memorials to maritime events, the diving tower, the diving plank, and the shower for swimmers. These various features appear to have been implemented by WWL; however, they could also have been installed in response to perceived community requests.

\subsubsection{Influence of strong citizen activism and incorporating public feedback}

Successful citizen activism that effected change was found to have the same effects on the built form as periods when public and stakeholder feedback collected by WCC and WWL influenced decisions about the waterfront. In the interview analysis, periods where these were more influential were associated with: an increased amount of public open space, fewer designated building sites overall, new buildings that responded to the heights of existing waterfront buildings, an increased variety of amenities for all demographic groups (including cycling amenities, a skateboard park, more seating, and different ways of interacting with the water), better integration of buildings and open space with active edges and publicly accessible ground floors, and a slower rate of redevelopment.

Findings from the archive analysis supported all of these effects. They added that both public activism and public feedback also contributed to an increased number of public amenities (in addition to a greater variety), more protection for heritage and existing buildings, and protection of views from the city to the harbour.

From the site visits, it appeared the character of architecture and public open space was inconsistent across the waterfront, with delayed development in some areas that could have been due to the contested nature of the waterfront and key sites. The areas that appeared to have delayed development included Queens Wharf outer-T, Waitangi Park edges, and North Kumutoto. It was inferred the lack of consistency and delayed development was due to public action and feedback because top-down action would 
have probably attempted to market prominent sites for key projects early on, while input from designers would have resulted in some degree of consistency.

It was observed, however, that there was a wide range of amenities for different user groups that contributed to a rich public realm. While these observations do not provide clear evidence for these findings, they do illustrate the extent of these influences.

\subsubsection{Influence of strong input by design professionals}

When design professionals had a strong influence on decisions about the waterfront, interviewees regarded designs as being higher in quality and more successful. This was expressed through more cohesive and contextual designs, better integration of buildings with adjacent open space through the use of active edges, using buildings to frame open spaces, and better recognition of contextual issues for the five sub-areas. The influence of designers was also associated with a changing aesthetic from a rough industrial look to a more polished finish. This influenced the choice of materials and style of different projects.

The findings from the archive analysis again agreed with the interview findings and provided additional built form effects. Strong influence by designers was also found to affect the existence of multiple routes through the site, both along the waterfront promenade and behind the buildings fronting on to it (see figure 4.2). The influence of designers also enabled building heights that were taller than existing waterfront structures, resulted in establishing a variety of opportunities to interact with the water, allowed for features that provided shelter from prevailing winds, and for installing memorials to maritime events.

Many of the qualities of the built form observed during site visits, support the descriptions of the influence of professional designers. Around the waterfront there are elements to shelter users from the wind, including: seating areas in Frank Kitts Park, on the City-to-Sea bridge, near Waitangi Park, and on the harbour side of Te Papa; a wall running the length of the Taranaki Street Wharf pedestrian bridge; and, sheltered routes between buildings. The rough industrial aesthetic was seen in the design and construction of early projects like the City-to-Sea bridge, the patina of use 
evident in retained wharf features, and the maritime and port artifacts that have been installed as landscape features. Additionally, refurbishment projects retained or restored much of the original character of the buildings. For example, the Queens Wharf apartments and the various repurposed sheds were repainted in their original colours. Later projects, however, included more glass and contemporary design cues. These included the Meridian building, Kumutoto plaza, and the Overseas Passenger Terminal building.

\subsubsection{Intentional and unintentional qualities of the relationship patterns}

Because the above comparisons of the findings show consistent support for one another this indicates they are fairly robust patterns of relationship between the governance and built form. However, to take this discussion further, it is worth considering whether the built forms attributed to the different governance types (topdown, citizen-led, and designer-led) are the result of intentional or unintentional behaviours. All of the built form patterns associated with the three governance approaches can also be described by whether they were informed by the driving values of the people involved, whether they were due to changing tastes, whether they were unintentional side effects of the respective actions of those involved, or were an evolution of the waterfront through use. This discussion supports the thesis' aim by providing additional insight into how the built forms relate to the governance phases according to which group of people had a strong influence at the time.

Within these overall relationship patterns, some could be attributable to the driving values of those involved in the respective governance types. For example, framing public space with buildings was attributable to strong involvement by professional designers because this was a conscious design strategy identified in the interviews and the archive analysis. Similarly, the desire to generate development income to pay for public space projects shaped the decisions by WHB, WCC, and LHM/WWL to include more and larger buildings in plans and approve large building proposals. In the case of the citizen activist groups, prioritizing more public open space and fewer buildings was a conscious value around which Waterfront Watch was formed.

Others patterns did not seem to have clear driving values but appear to be a response to changing tastes. For example, the change in preferred aesthetic for the waterfront 
from a cultivated patina that reflected the port and maritime heritage to a more polished look was not a sudden value change. This happened gradually and may have been assisted by the moratorium on development following the public's reaction to the Retail and Event Centre and a subsequent desire for a different approach to designing the waterfront. The observed contrast between the refurbished Steamship Wharf building, the more contemporary looking Meridian building, and the public space surrounding the two marks a point of cross over between the two aesthetics. However, this change could also be attributable to a gradual change in aesthetics that might be reflected in the whole of central Wellington, although this was not investigated here.

Some patterns are, however, unintentional and could be attributed to the governance processes. For example, the inconsistent character along the waterfront is partially a result of delayed development of some areas or sites. Delays were caused by requirements for lengthy consultation processes on area plans and by Environment Court challenges that overturned plans and projects. Inconsistent character can also be partially attributed to different governance approaches during which different parts of the waterfront were developed. For example, Te Papa was developed by the national government panel, the Waitangi Park precinct was heavily influenced by design competitions, and Taranaki Street Wharf includes design elements from separate LHM- and WDS-era plans.

Lastly, a few details appear to be a response to how the waterfront was used. Examples include installation of the diving tower, diving plank, swimmers' shower, and floating platform. These were described as top-down patterns, but are the result of changes that respond to the use of the waterfront. Like any built environment, the form changes in response to how it is used. The decision of how it will change is generally some combination of formal, top-down changes by those that manage the waterfront and informal, bottom-up (or user-led) modifications.

The aim of the thesis was to look for evidence on how different forms of governance produced different types of built form in an urban design context. Although some changes will be in response to evolving uses (e.g. amenities for swimming) these changes would not have happened without the deliberate decision to improve the 
public amenity value of the waterfront. They are also a smaller scale of urban intervention from the building and large open space scale that make up the overall urban form, and that is the focus of this research. The aim here has been to look simply at who made the decisions and what type of built form resulted.

\subsection{Comparison of governance descriptions:}

The research design chapter described how the shared purpose of employing a case study and using triangulation of methods was to develop a rich understanding of the subject and object of study (see section 3.2). In this thesis, the two previous chapters outlined the evidence and findings from the different methods and, therefore, provided detailed descriptions of the case study and the relationship between the governance of the redevelopment and the resulting built form. The previous section contrasted the findings from the different methods to provide more insight into the governance-built form relationship. Similarly, this section of the discussion builds upon our understanding of the separate findings by comparing the descriptions of the different governance approaches. While the previous section specifically addresses the aim of the thesis, this discussion addresses the aim of undertaking a case study by clarifying how the different methods contributed to a deeper understanding of the different governance approaches used on the waterfront.

Overall, the interview findings outlined the broad governance approaches while the findings from the archive analysis provide more detailed differences within these larger approaches. While there are some differences in the specific details between the governance descriptions in the two chapters, the governance descriptions are consistent with one another. Rather than repeating the descriptions from both chapters, however, the governance approaches identified from the interview analysis will be summarized and supplemented with comparisons to the archive analysis findings. 


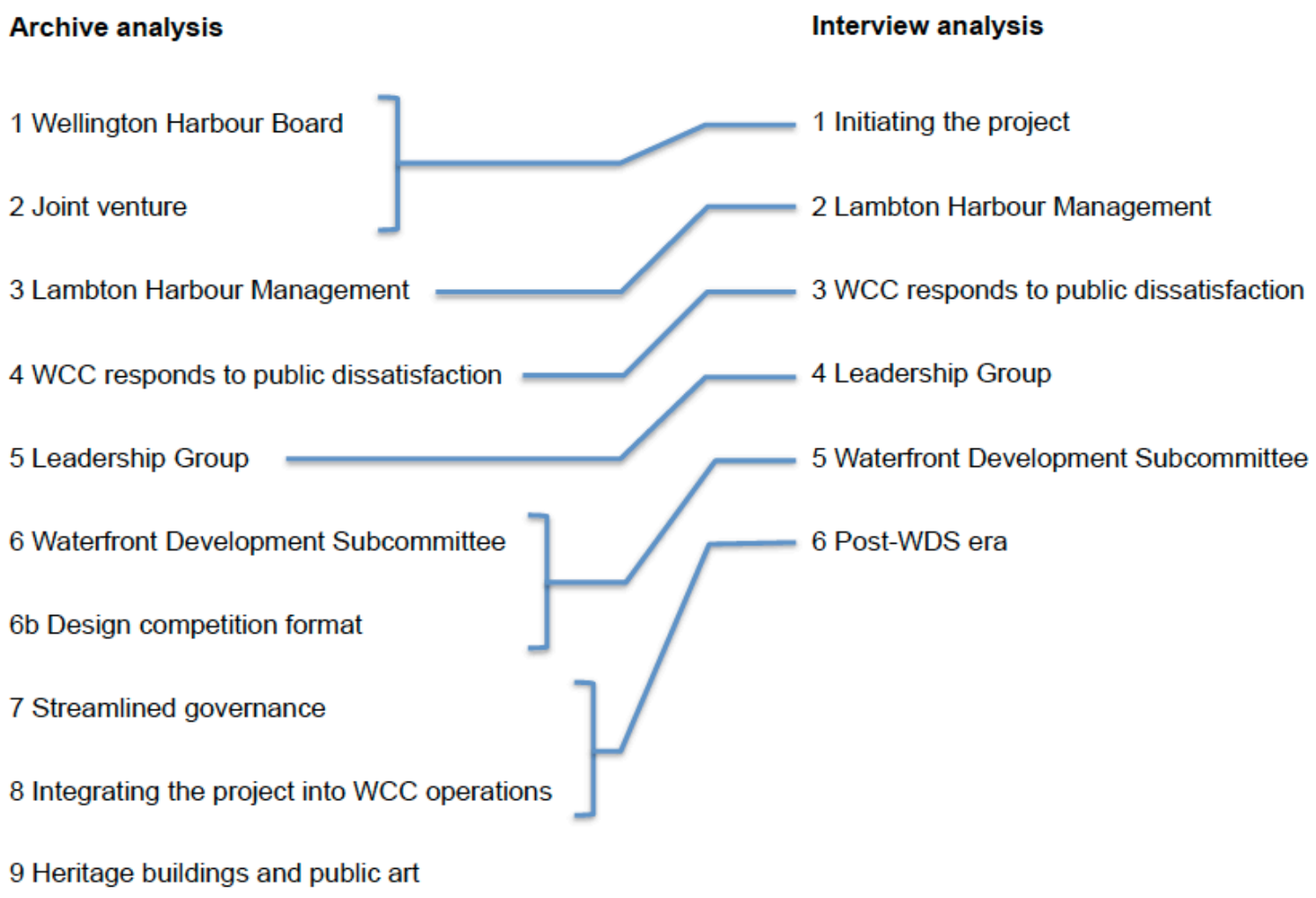

Figure 6.1. Illustration showing how the governance approaches identified in the archive analysis corresponded to those identified in the interview analysis.

The archive and interview findings described different numbers of governance phases for the waterfront (see figure 6.1). Whether there were nine or six governance phases, however, was a matter of perspective. The goal was not to produce a definitive list of governance types, but to articulate different governance approaches that were used for the redevelopment of the Wellington waterfront.

\subsubsection{The initial stage}

The initial governance approach identified from the interviews was described as a top-down approach controlled by the WHB (section 5.2). According to the interviewees, WHB had its own district plan for the waterfront and was more independent from the WCC than was identified in the archive analysis. This largely top-down management approach was influenced, however, by pressure from the WCC, Civic Trust, and the public to redevelop the waterfront. Later, WCC involvement and the designers hired to draft the initial waterfront concept plan promoted additional values that influenced plans for the waterfront. Despite these 
inputs, however, the initial plan was described as being largely directed by the WHB requirement for the project to be self-funding.

The archive analysis findings separated this stage into two phases to differentiate between the initial WHB-controlled stage and the more collaborative effort with the WCC (sections 4.3.1 and 4.4.1). The governance descriptions were similar to the findings from the interviews; however, the archive analysis provided more details about the events and influences that pressured WHB to consider redevelopment.

The first phase, as described in the archive analysis was marked by the Civic Trust ideas competition and subsequent conferences. WHB's agreement with the national government for a site for a new national museum, plus announcing the decision to redevelop the waterfront in collaboration with the WCC marked a shift in governance. The second phase, as in the interview findings, was collaboration between the WHB and WCC. Together they commissioned a concept plan for the waterfront whose process was equally described in the interview and archive analysis findings.

\subsubsection{Lambton Harbour Management Ltd.}

Establishing LHM under a joint agreement initiated the second broad governance phase for the waterfront redevelopment according to the interview findings (section 5.3). In addition to the joint agreement, the authority and independence of LHM was enabled by the Wellington Harbour Board and Wellington City Council Vesting and Empowering Act (1987). The Act was passed by the national government to support the redevelopment project. LHM's independence was a mechanism to prevent political interference, yet the board of directors for LHM included WCC and WHB representatives to provide some oversight. The governance approach for this phase was therefore described by interviewees as a top-down management structure led by LHM with some input on decisions by designers involved in the process.

Reportedly, LHM's first act was to commission a team of designers to produce the Lambton Harbour Combined Scheme. The influence of professional designers on decision making during this phase was a result of their work on the Combined Scheme, public engagement activities, and the design review committee. Despite 
these roles, however, interviewees described LHM as having tightly managed the process.

Input into the decision making by the public and designers was further limited by the district plan status of the Combined Scheme as this meant some development projects could proceed without public consultation (e.g. the Events Centre). Other projects that did require public consultation often did not receive many submissions, which probably facilitated the central role of LHM.

The 1987 stock market crash muted the ability to develop the waterfront as envisioned, so LHM invested in public space and other projects to stimulate development interest. However, while the stock market crash stalled development activity, it did not appear to change the governance structure described by the interviewees.

The archive analysis findings provided the same general description of the governance structure (section 4.5.1); however, the insight from the interviewees involved in this phase provided more details for this governance approach as reported above.

\subsubsection{The Community Consultative Committee}

Public outcry about the scale and form of the Retail and Events Centre, the intensity of development proposed for the rest of the waterfront, and the non-inclusive governance approach by LHM were found in the interview analysis to stimulate a change of governance (section 5.4). To respond to the outcry, it was reported the WCC took control of the redevelopment process and initiated the CCC public consultation process. This process was a WCC effort to gather public feedback on the future of the waterfront.

While the public input did influence the new waterfront plan commissioned by the WCC, the new master plan and the subsequent district plan variation still reflected the development intensity associated with the self funding focus established in the initial stages. This was attributed to direction from WCC to the design team to explore options for taller buildings within the new plan. The interview findings, therefore, 
suggested WCC retained control of the development strategy and design for the waterfront by filtering the input from the public and the designers in order to achieve what they considered to be a suitable balance of public amenity and development.

Public influence was partly associated by interviewees with the formation of two new citizen activist groups: Chaffers Park Make it Happen and Waterfront Watch. While both groups lobbied for more public open space, Waterfront Watch was particularly focused on stopping the development of new buildings on the waterfront. These groups were described as successful in helping shift the values driving the planning and design away from the more development intensive route of previous phases.

Other complaints about the perceived poor designs of early projects resulted in the WCC placing greater value on feedback from the design review committee for decisions about individual projects than LHM had done in the previous phase. This emphasis on improving the quality of the waterfront designs was also reflected in the decision to commission a detailed master plan for the entire waterfront to replace the development oriented Combined Scheme.

The archive analysis findings were consistent with the above description from the interview findings (section 4.6.1). They did not, however, include the details about the evolving role of the design review committee or the influence of public feedback on the Meridian and Steamship Wharf buildings. Instead, the Meridian and Steamship Wharf buildings were associated with the later WDS phase in the archive analysis because of the timing of the projects, and because the more inclusive nature of the process for these projects was similar to a later phase.

Where the archive analysis did include more detail was on the reduced role of LHM and that the intent for the waterfront to be self funding was never formally abandoned.

\subsubsection{The Leadership Group}

According to the interviewees, the transition from the governance of the previous phase to the Leadership Group phase was stimulated by poor public reception of the district plan variation drafted by WCC staff (i.e. Variation 17). Waterfront Watch led 
a successful campaign to stop Variation 17 and the WCC's response was to initiate a new, more inclusive, public process.

As stated in the interview findings (section 5.5), WCC recruited members from different stakeholder groups and interested parties to form the Leadership Group committee. Their role was to develop a guiding framework to direct the planning and design of the waterfront. While the committee and the process were described as being inclusive and open, some interviewees described the process as tightly managed by the WCC. The outcome of the Leadership Group process was the Wellington Waterfront Framework, drafted to provide direction on the governance and development strategy of the waterfront.

To contribute to the Leadership Group's discussions, the design review committee was given greater scope to comment on overall strategy and design for the waterfront. The urban design professionals who were a part of this design advisory committee, however, did not have direct input into the final decisions of the Leadership Group.

As with the previous two phases, the archive analysis findings provided a similar overall description of the governance of this phase (section 4.4.1). Where the findings differed was in the types of details of how the governance arrangements were structured. The archive findings provided more detail on the broader structure, while the interview findings provided more detail on how the structure was experienced. For example, the archive findings outlined the membership and process for the Leadership Group; however, it did not provide insight into how the WCC managed the process. Additionally, the interviewees could not provide the same level of insight into the governance and development strategy advice outlined in the Waterfront Framework; however, their accounts offered insight into what was prioritized by the Leadership Group.

\subsubsection{The Waterfront Development Sub-committee}

Once the Waterfront Framework was adopted, interviewees described how WCC established a governance structure for the waterfront redevelopment that drew upon the recommendations outlined in the Framework (section 5.6). The WDS was established as a sub-committee of the city council that was responsible for planning 
and managing the development strategy. Membership included a mix of councillors, community representatives, and professional designers. Their responsibilities included developing design briefs for each of the five sub-areas of the waterfront, overseeing the ongoing development of the waterfront, reviewing development proposals, and actively engaging the public and other stakeholders.

The governance approach was described as providing many opportunities for public and stakeholder feedback on plans and projects at all scales. However, interviewees suggested the collected feedback had little impact on the decisions because WCC and WWL staff found it difficult to assess whether submissions adequately represented the public opinion.

The design advisory committee continued its design review role, but was more actively engaged in this phase according to the interviewees. It was tasked by the WDS to write the design briefs for the five sub-areas, the committee chair was a member of the WDS, and the committee worked directly with developers and their consultants to improve their proposals. Because of all of these activities, the members of the design advisory committee had significant influence into the planning and design of the waterfront.

The development corporation's mandate was limited to managing the business and implementation of the redevelopment. While its focus was on the commercial aspects of the project, including attracting and working with developers, their decisions were overseen by the WDS. Through the commercial planning and ongoing management of the waterfront, the development corporation continued to have some influence on the continuing evolution of the waterfront, but this was limited by the governance structure.

Again, the archive analysis provided more details about how the governance was structured; however, the key points were consistent with the interview findings (section 4.8.1). For example, the archive analysis findings reported a different mix of WDS members with non-council representatives predominantly from the development industry rather than a mix of 'community representatives'. While this 
did not appear to change how decisions were made or input was collected, it could have altered what values were used to shape decisions by the WDS.

In their discussions, the interviewees did not distinguish between the WDS governance structure and the design competition approaches that were separated in the archive analysis findings (section 4.9.1). While the two governance arrangements were very similar, the archive findings explained how the competition governance provided both additional opportunities for public and stakeholder input and greater emphasis on creative (rather than contextual) design ideas.

\subsubsection{Post-WDS}

The phase following the disbanding of the WDS was treated as one phase by the interviewees, while the archive analysis divided it into two. The interviewees described a more streamlined governance process where WWL sought to make the development process more efficient and would assist in transitioning the responsibilities of the development corporation into regular city operations (section 5.7). WCC was described as being in favour of the new approach because of an Environment Court ruling on the Hilton Hotel proposal for the outer-T of Queens Wharf that put into question the utility of the previous governance approach. The new approach reportedly included an emphasis on incorporating the design briefs into the district plan, which would have limited public consultation and reduced risk for developers by clarifying expectations. This change was successfully challenged in the Environment Court by Waterfront Watch.

The archive analysis findings reported a more collaborative governance structure between WCC and WWL than was reported by the interviewees (section 4.10.1). Additionally, the decision to use district plan variations to integrate the design briefs into the Wellington District Plan was identified as being influenced by the recommended governance strategy outlined in the Waterfront Framework, as well as for the reasons above suggested by the interviewees.

The archive analysis also provided information about WWL's process of developing a new master plan for Queens Wharf that was not addressed by the interviewees (section 4.10.2). This process was intended to precede drafting a district plan variation 
for this part of the waterfront. It included a public ideas competition and forming a stakeholder steering group to advise on the design of the master plan. Because this process was intended to eventuate in a district plan variation, and it was managed by WWL in a top-down fashion, it used the same governance approach as described by the interviewees. However, its discussion provides additional depth to understanding how decisions were made during this period.

The second governance approach of this phase was differentiated in the archive analysis findings (section 4.11.1). It was similar in structure to that described above, but promoted public and stakeholder consultation at all stages of decision making.

\subsubsection{Historic buildings and public art projects}

The interviewees did not discuss how decision making over refurbishment projects or art installations differed from the other governance approaches. In fact, the interviewees provided very little comment on these aspects of the waterfront redevelopment, possibly because they were largely uncontested. The only refurbishment-type projects that were mentioned were those that involved substantial changes to the structure of the building (including the Overseas Passenger Terminal in section 5.6), moving buildings as a part of a landscape plan (the St. John’s Ambulance building in section 5.4), or that influenced how the public perceived the waterfront redevelopment (Steamship Wharf building and Wellington Harbour Board office building in sections 5.4.1 and 5.3.1). With the exception of the Overseas Passenger Terminal, however, the discussion of these projects focused on the governance of the larger area plans and landscape designs than the governance associated with their refurbishment.

The archive findings provided more insight into the governance of heritage building refurbishment and public art projects (section 4.12). Both were collaborations between the development corporation and the respective developers and art organizations, with some input from the design review committee. This governance structure was consistent over the study period regardless of what was happening with other plans and projects. 
The comparison above when taken together with the comparison of the findings in the previous section, shows the value and utility of combining different data collection methods to evaluate the development process of the Wellington waterfront. The different methods provided complementary insights into the governance approaches and a more nuanced understanding of how the development process evolved over the study period.

\subsection{Limitations of the study}

As noted in section 3.4, there are limitations to the methodology, methods, and findings. The purpose of discussing the limitations at this stage is to articulate the utility of the findings and assess the research design as being appropriate for achieving the research aim.

First, if we revisit the methodology underpinning the research design (section 3.2), the constructivist perspective of the study and thematic analysis means the governance phases and built form relationships are only one potential interpretation of the collected archive and background data. Evidence for this can be seen in the different number of governance phases reported in the findings of chapters four and five. Similarly, the interview data itself is only representative of those individuals who were interviewed, at the time they were interviewed. Also, the site visits were interpretations of the morphology and could not assess how it was created. To mitigate these limitations, multiple methods were used to triangulate the findings and develop a more comprehensive, robust description of the case study overall while maintaining links to the collected data during analysis and when reporting the findings. While the triangulation of methods and gathering a wide range of perspectives offer a variety of perspectives into the development process, the potential for different interpretations remains.

The qualitative nature of the findings also means it is impossible to discuss the relative strength of the identified patterns. A follow up survey with a statistically valid number of people who were involved in the redevelopment process would provide the necessary data to assess the strength of the patterns. This would enable more accurate identification of which relationships were due to values, changes in taste, or were unintentional effects, or due to the evolution of the waterfront. However, as noted in 
section 3.1, the shortage of literature identifying different types of these relationship patterns meant such patterns needed to be identified and described before research could be conducted on how they have been applied.

The method used to generalize the governance-form relationship from individual development projects to broader governance approaches meant the complexity of values and agendas brought to the redevelopment process by different actors and agencies involved in the process was not fully articulated by this research. Within a stakeholder group (see section 5.1) individual actors will have varied opinions and agendas. In some stakeholder groups (e.g. Wellington City Council planners and staff or Environment Court representatives) their ability to express those values and agendas may be shaped by their position or role. In other stakeholder groups (e.g. Waterfront Watch or tangata whenua) there may be much less variation in values and agendas held regarding the waterfront development.

The aim of the research was to identify the different governance approaches and their influence on the built form. However, because of this emphasis on the built form as a product of the values that were prioritized through the governance of the process, the analytical approach and findings emphasized the dominant values held by different stakeholder groups and how these were prioritized in the governance approaches used on the redevelopment. This analytical approach did not identify, or track, all of the values and agendas held by all of the actors involved in the process. Instead, the analysis generalized the values of actors involved in each development project across their respective stakeholder groups. Comparison of the development projects to identify governance approaches further reduced the values and agendas of the different stakeholder groups to those that were seen as dominant in each approach. These were necessary steps to respond to the aim of the thesis. In doing so, however, the thesis does not include analysis of how actors and stakeholder groups with internally and collectively varied perspectives and agendas (e.g. designers, planners, and citizen activists) navigated the governance phases. This application of rational actor analysis (see section 2.1.3) would be a useful extension of this study.

Other limitations should also be recognized in regards to the methods used in the thesis and the resultant findings. The strength of using an exemplar case study (see 
section 3.3.1) was so analysis of multiple governance approaches used in the same redevelopment project would eliminate as many potential variables that could have influenced the governance and the built form as possible. These other variables include cultural differences, different policy and planning environments, different locational and geographical influences, different building codes and construction methods, and different funding environments.

In comparison, a limitation of investigating a single case study, despite the multiple governance approaches identified in the analysis, is that the findings do not reflect the full range of potential governance arrangements. Except for the general principle that different governance approaches within a development project have different effects on the built form, the patterns and relationships identified here can only be discussed as being relevant to this context and should not be generalized beyond this single case. It would take many more studies of other development projects to properly identify a generalizable typology of this relationship between governance and the built form.

In regards to the analytical methods used, the use of an a priori analytical framework for analysis of the interviews risked confirmation bias (see sections 3.3.7 and 3.3.10). The framework also considered the driving values, the network of those involved, how the different groups were involved, and the variables that stimulated change in the governance process separately. Analysis of these characteristics of governance in isolation provided interesting insights into the governance, but these findings were too abstract to identify the different governance approaches that were used on the project. As a result, the findings from this method did not directly shape the overall findings. Instead, it offered one way to understand the governance process for the waterfront. An inductive approach was used for the final analytical steps, which provided its own descriptions of governance and built form for both the archive and interview analysis steps.

Similarly, from the comparison of the findings it is evident there was strong agreement between the archive analysis and interview analysis. An issue that was always a concern was agreement due to single researcher bias. Ideally, a study such as this would have benefitted from having a two or more people code the narrative from 
the archive analysis and the interviews to identify governance phases and built form relationships. Comparison between multiple codings would provide an additional check. As discussed in section 3.1, however, efforts were made to avoid this bias by maintaining links to the source data and double checking the coding of the development narrative and interviews to insure the reported findings were supported by the evidence. The structure of the reported findings reflects the connection between the data and the findings.

Lastly, what could not be avoided due to the requirements of the research context, were the limitations of the single researcher. Additional researchers would have provided more perspectives on the data and findings, which would help to explore whether more patterns could be found that were not apparent to a single researcher.

\subsection{Future research}

Future research can address some of these limitations with additional case studies of development projects that look at governance-built form relationship patterns. These added case studies, and comparisons between them, would articulate governance approaches used in other forms of development and how they influenced the respective built forms. A larger number of case studies in different contexts would provide further insight into the variety of detailed governance approaches and governance-built form patterns.

The choice of additional case studies should include duplication of development types (e.g. waterfront developments using development corporations) and contrasting case studies (e.g. greenfield housing co-operative developments). This would increase the external validity of the findings, while including a statistically valid number of interviewees to allow reporting on the strength of these patterns would increase the internal validity of each case study.

Other research opportunities stemming from this line of inquiry could include action research on the governance of development processes. Here researchers would work with communities to design governance approaches and development processes that would be likely to help realize the desired built forms. Assessment and reflection on 
the process and the built form outcomes of such studies would provide insight into the process and controls that are not available to researchers looking at past projects. 


\section{Conclusion}

This study was prompted by an interest in how different decision making approaches in a development process were expressed in the resulting built form. As described in chapter two, investigation into this link between the built form and the societal processes involved in its creation is an active and ongoing research area in the fields of urban design (e.g. Carmona, 2014; Calderon \& Chelleri, 2013; Gillem, 2007) and urban morphology (e.g. Larkham \& Conzen, 2014; Moore, 2008; Whitehand, 1993).

Through analysis of governance processes, a number of studies into development and urban design processes have explored the relationship between governance processes and patterns (see chapter two). Within the studies that have investigated this relationship, however, there is a mix of those that have employed analytical frameworks from the literature on governance theory and others that developed and applied their own analytical frameworks. Some of these ad hoc frameworks resembled established governance frameworks but the reported findings often stressed a particular component of governance, or the findings have focused on specific governance outcomes. Those that employed a framework similar to Pierre's urban governance theory (section 2.1.4), however, provided more comprehensive descriptions and analysis of the observed governance approaches.

Despite the use of ad hoc frameworks or frameworks grounded in governance theory, studies in this area have generally identified single, overall governance approaches rather than a set of different governance approaches associated with different phases or aspects of the case study (e.g. Calderon \& Chelleri, 2013; Carmona, 2014). Additionally, relatively few studies in this area have effectively linked their analysis of the governance approaches with the form of the built environment, which is what this thesis has attempted.

Urban morphology case studies have provided stronger evidence of connections between governance approaches and the built form. Earlier case studies analyzed the evolution of the physical form of the built landscape and the influence of specific decisions and events. More recent research, however, has expanded these types of investigation to include complete descriptions of the changing governance associated with landscape changes (Larkham \& Conzen, 2014). This line of research, however, 
has treated governance as though it were a continuous processes rather than a sequence of different governance approaches.

This thesis, therefore, set out to address the apparent lack of studies in the literature that have articulated the presence of multiple governance approaches in a single case study of development and urban design processes, and whether and how each of these governance approaches influenced the built form. Formally stated, the aim of this thesis was to identify the influence different governance approaches had on the form of a neighbourhood-scale development project. In response to this aim, the Wellington waterfront redevelopment was chosen as a case study primarily because preliminary background research demonstrated that it went through several different governance phases. Therefore, the research question became: how did the governance of the planning and design decision making processes influence the built form of the Wellington, New Zealand waterfront redevelopment?

\subsection{Methods}

The research design used triangulation of archive analysis, interviews, and site visits to develop a rich description of the case study, identify the different governance approaches, and identify their influence on the built form. These three methods provided different insights into the project and the influence of governance on the built form. When comparing the findings, however, there was general agreement on the descriptions of the different governance approaches and their influence on the built form, which provided greater confidence in the results.

Analysis of the archive material and interviews were modeled on the institutional and urban governance frameworks described in section 2.1.4. This entailed describing the history of the project, including discussion of the structural context and how this changed over the study period; the actors who were involved and their influence on the decision making process; the goals and values of the different actor groups; and, how decisions were made. While previous urban governance, urban design, and development studies have applied similar analytical frameworks to identify single, overall governance approaches (chapter two), the method used here described the multiple governance approaches observed in this case study and what stimulated change from one to another. 


\subsection{Findings}

In answer to the research question, seven different governance approaches, with variations on two of these, were identified in this case study of the Wellington waterfront redevelopment. The descriptions of these different governance approaches included identifying how they influenced the built form and the events and decisions that stimulated transitions between them. These findings support the idea that development processes can include more than one governance approach and that this type of case study investigation can provide a unique understanding of the governance practices and their influence on a development project. This study, therefore, addresses the earlier criticisms of similar studies in urban morphology, urban design, and development processes discussed in chapter two. While the descriptions of the different approaches are not directly generalizable, the method used for identifying these different governance approaches could be useful for exploring other case studies.

\section{Governance patterns}

\begin{tabular}{|c|c|c|c|c|}
\hline \multirow{8}{*}{ 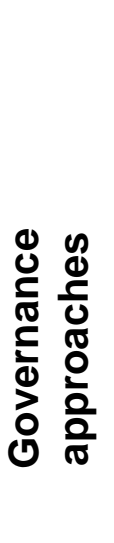 } & & Hierarchical & Citizen led & $\begin{array}{c}\text { Led by } \\
\text { professional } \\
\text { designers }\end{array}$ \\
\hline & 1 & $x$ & 0 & \\
\hline & 2 & $x$ & & \\
\hline & 3 & 0 & $x$ & \\
\hline & 4 & 0 & $x$ & \\
\hline & 5 & 0 & & $x$ \\
\hline & 6 & $x$ & & \\
\hline & 7 & $x$ & & 0 \\
\hline
\end{tabular}

Table 7.1. A summary of how the seven governance types described in section 6.2 match with the three broad governance patterns. X's indicate the dominant pattern in each phase while O’s indicate lesser influences.

Subsequent comparison of these seven governance approaches produced three general patterns of how the governance approaches used in the redevelopment influenced the built form (see table 7.1). The three patterns represent the influence on the built form of: hierarchical decision making approaches, approaches marked by successful citizen activism and incorporation of public and stakeholder feedback, and those that had the direct involvement of professional designers in the decision making process. 
As described in more detail in section 6.1, the governance approaches that operated in a strong top-down fashion primarily involved municipal staff and the development corporation as the key decision makers. The values emphasized by these actors included a desire for the project to be self-funding, prioritization of commercial projects, and a desire for a vibrant atmosphere. Within governance approaches organized in a top-down fashion, these values contributed to widespread implementation of ground floor retail, buildings and building proposals that were larger than existing waterfront buildings, built projects that responded poorly to their context due to a more internal orientation, plans that included more building sites, a mix of land uses, public art, and amenities to support the uses of public space (including a playground, washrooms, diving features, and showers for swimmers).

Governance approaches marked by strong citizen activism and attention to public feedback had different decision making processes but resulted in similar outcomes in the built form. Citizen activism influenced the decision making process informally through public campaigning and formally using legal challenges. In comparison, inclusion of public and stakeholder feedback into the decision making process was a top-down decision to incorporate a wider set of values. The values embodied in both approaches included a desire for increased public amenity, less privatization of the waterfront through commercial development, the protection of views, the protection of existing and heritage buildings, and more public consultation on all aspects of the redevelopment.

The governance approaches that were driven by bottom-up citizen activism and more inclusive decision making therefore resulted in more public open space, fewer building sites and buildings in scale with existing waterfront buildings, more amenity features to support passive and active waterfront activities (including seating, weather protection, skateboard park, and cycling amenities), more ways of interacting with the water, publicly accessible ground floors, a slower rate of redevelopment, and less consistency in the character over the redevelopment area.

Within the analysis, the inconsistent character of the redevelopment was also identified as an unintentional effect of the governance process. Development delays from court challenges, lengthy consultation processes, changing governance 
approaches, and changing development priorities all contributed to different areas and projects having characteristics forms and details that were not necessarily reflected elsewhere on the waterfront.

Design professionals had ongoing involvement in the project, but in some governance approaches designers were incorporated into the central decision making body and had direct involvement in making decisions. The values brought to the process by the designers included a greater emphasis on contextual materials and forms, creativity, and cohesive designs. Over time, however, there was a shift away from a rougher, maritime aesthetic towards a sleeker, more modern aesthetic that appeared to be unintentional. Interestingly, the importance of public consultation was inconsistent among governance phases that had strong designer involvement.

Built form outcomes from these governance phases included better integration of buildings and public open space design and uses by incorporating active edges, buildings that were used to frame public open spaces, multiple routes being established through the site, new and proposed buildings taller than existing buildings, designs that introduced a greater variety of ways to interact with the water, and pedestrian amenities that offer some protection from inclement weather.

These broad patterns support Pierre's (2014) urban governance theory model (section 2.1.4) and the similar model represented in figure 1.1 that identify governance as a human filter that translates policy, economic and political pressures, and cultural institutions into actions. In the case of this development process, the intent was the redevelopment of the waterfront. Grouping the different governance approaches by who had strong influence on the decision making, made it possible to identify how different values held by those with influence over the governance approaches influenced the outcomes (i.e. the built form). Because some of the governance approaches were a combination of these three patterns, the built form produced during these phases was a product of the competing actors and values involved in the process.

Overall, these findings add credence to employing urban governance frameworks in the study of development processes and urban morphology. They also show how 
stronger links between studies of governance processes and urban morphology can result in new insights into the social production of the built environment. In the single case of the Wellington waterfront redevelopment, the detailed descriptions of the seven governance phases and the broad patterns derived from them answered the research question asking how the governance process of this project influenced the built form. As described in section 6.4, however, comparison of these findings with similar case studies could eventuate in a typology of governance approaches used in development projects and tools that could assist communities in managing development processes. 


\section{References}

Adams, D., \& Tiesdell, S. (2012). Shaping places: Urban planning, design and development. London, England: Routledge.

Altes, W. K. (2002). Local government and the decentralisation of urban regeneration policies in The Netherlands. Urban Studies, 39(8), 1439-1452.

http://doi.org/10.1080/00420980220142718

Ansell, C., \& Gash, A. (2007). Collaborative governance in theory and practice. Journal of Public Administration Research and Theory, 18, 543-571.

Ashton, P. J. (2007). The role of good governance in sustainable development: Implications for integrated water resource management in southern Africa. In D. A. R. Turton, M. H. J. Hattingh, M. G. A. Maree, D. D. J. Roux, D. M. Claassen, \& M. W. F. Strydom (Eds.), Governance as a Trialogue: Government-Society-Science in Transition (pp. 77-100). Berlin: Springer. Retrieved from http://link.springer.com/chapter/10.1007/978-3-540-46266-8_5

Ataov, A., \& Eraydin, A. (2011). Different forms of governance: Responses of two metropolitan regions in Turkey to state restructuring. Urban Affairs Review, 47(1), 84-128. http://doi.org/10.1177/1078087410372608

Baeten, G. (2012). Normalising neoliberal planning: The sase of Malmö, Sweden. In T. Tasan-Kok \& G. Baeten (Eds.), Contradictions of Neoliberal Planning (pp. 21-42). Netherlands: Springer. Retrieved from http://link.springer.com/chapter/10.1007/978-90-4818924-3_2

Ball, M. (1998). Institutions in British property research: A review. Urban Studies, 35(9), 1501-1517.

Barnekov, T., Boyle, R., \& Rich, D. (1989). Privatism and urban policy in Britain and the United States. Oxford, UK: Oxford University Press.

Barnett, J. (1982). An introduction to urban design. New York, NY: Harper \& Row.

Bhaskar, R. (1978). A realist theory of science (2nd ed.). Hassocks: Harvester Press.

Bhatt, C. (2012). Coding and analysing qualitative data. In C. Seale (Ed.), Researching society and culture (3rd ed., pp. 153-178). Los Angeles, CA: SAGE Publications.

Birkmann, J., Garschagen, M., Kraas, F., \& Quang, N. (2010). Adaptive urban governance: New challenges for the second generation of urban adaptation strategies to climate change. Sustainability Science, 5(2), 185-206. http://doi.org/10.1007/s11625-010-0111-3 
Blaikie, N. W. H. (1991). A critique of the use of triangulation in social research. Quality and Quantity, 25, 115-136.

Blaikie, N. W. H. (2007). Approaches to social enquiry: advancing knowledge (2nd ed.). Cambridge, UK: Polity.

Breda-Vazquez, I., Conceicao, P., \& Fernandes, R. (2009). Partnership diversity and governance culture: Evidence from urban regeneration policies in Portugal. Urban Studies, 46(10), 2213-2238. http://doi.org/10.1177/0042098009339433

Bryson, J. M. (2004). What to do when Stakeholders matter: Stakeholder Identification and Analysis Techniques. Public Management Review, 6(1), 21-53.

https://doi.org/10.1080/14719030410001675722

Burris, S., Hancock, T., Lin, V., \& Herzog, A. (2007). Emerging strategies for healthy urban governance. Journal of Urban Health, 84(1), 154-163. http://doi.org/10.1007/s11524-0079174-6

Byrne, D. S. (2009). Case-based methods: Why we need them; what they are; how to do them. In D. S. Byrne \& C. C. Ragin (Eds.), The SAGE handbook of case-based methods (pp. 1-10). London, England: SAGE.

Calderon, C., \& Chelleri, L. (2013). Social processes in the production of public spaces: Structuring forces and actors in the renewal of a deprived neighbourhood in Barcelona. Journal of Urban Design, 18(3), 409-428. http://doi.org/10.1080/13574809.2013.800449

Carmona, M. (2014). The place-shaping continuum: A theory of urban design process. Journal of Urban Design, 19(1), 2-36. http://doi.org/10.1080/13574809.2013.854695

Carmona, M., Heath, T., Oc, T., \& Tiesdell, S. (2010). Public places urban spaces: The dimensions of urban design. London, England: Routledge.

Carmona, M., \& Wunderlich, F. (2012). Capital spaces, the multiple complex spaces of a global city. London, England: Routledge.

Castells, M. (1983). The city and the grassroots: A cross-cultural theory of urban social movements. Berkeley, CA: University of California Press.

Chapman, D. (2011). Engaging places: Localizing urban design and development planning. Journal of Urban Design, 16(4), 511-530. http://doi.org/10.1080/13574809.2011.585840

Claessens, F. (2005). Mapping urban and social space: Towards a socio-cultural understanding of the built environment. In Doing, thinking, feeling home: The mental geography of residential environments: Conference, Delft, The Netherlands, October (Vol. 14, p. 8). 
Clark, T. N. (2000). Old and new paradigms for urban research: Globalization and the fiscal austerity and urban innovation. Urban Affairs Review, 36(1), 3-45.

Coaffee, J., \& Healey, P. (2003). "My voice: My place”: Tracking transformations in urban governance. Urban Studies, 40(10), 1979-1999.

http://doi.org/10.1080/0042098032000116077

Condon, P. M. (2008). Design charrettes for sustainable communities. Washington, DC: Island Press.

Crespo, J. L., \& Cabral, J. (2010). The institutional dimension to urban governance and territorial management in the Lisbon metropolitan area. Análise Social, 45(197), 639-662.

Cullen, G. (1971). The concise townscape. London, England: Architectural Press.

Cuthbert, A. R. (2007). Urban design: Requiem for an era - review and critique of the last 50 years. Urban Design International, 12(4), 177-223.

http://doi.org/http://dx.doi.org.helicon.vuw.ac.nz/10.1057/palgrave.udi.9000200

DiGaetano, A. (2006). Creating the public domain: Nineteenth-century local state formation in Britain and the United States. Urban Affairs Review, 41(4), 427-466.

http://doi.org/10.1177/1078087405283164

DiGaetano, A., \& Strom, E. (2003). Comparative urban governance: An integrated approach. Urban Affairs Review, 38(3), 356-395. http://doi.org/10.1177/1078087402238806

Dovey, K. (2005). Fluid city: Transforming Melbourne's urban waterfront. London, England: Routledge.

Duany, A., Plater-Zyberk, E., \& Speck, J. (2000). Suburban nation: The rise of sprawl and the decline of the American Dream. New York: North Point Press.

Flyvbjerg, B. (2001). Making social science matter: Why social inquiry fails and how it can succeed again. Cambridge, England: Cambridge University Press.

Fraser, J., Bazuin, J. T., \& Hornberger, G. (2016). The privatization of neighborhood governance and the production of urban space. Environment and Planning A, 48(5), 844-870. http://doi.org/10.1177/0308518X15621656

Gailing, L., \& Kilper, H. (2009). Shaping cultural landscapes through regional governance. In W. Strubelt (Ed.): Guiding principles for spatial development in Germany (German annual of spatial research and policy) (pp. 113-123). Berlin.

Gailing, L., \& Leibenath, M. (2013). The social construction of landscapes: Two theoretical lenses and their empirical applications. Landscape Research, 40(2), 123 - 138.

http://doi.org/10.1080/01426397.2013.775233 
Gehl, J. (1996). Life between buildings: Using public space (3rd ed.). Copenhagen: Arkitektens Forlag.

Gehl, J., \& Svarre, B. (2013). How to study public life (2nd ed.). Washington, DC: Island Press.

Gelman, V. (2011). State power, governance, and local regimes in Russia. Russian Politics and Law, 49(4), 42-52. http://doi.org/10.2753/RUP1061-1940490405

Gerring, J. (2012). Social science methodology: A unified framework (2nd ed.). Cambridge, England: Cambridge University Press.

Giddens, A. (1984). The constitution of society: Outline of the theory of structuration. Cambridge, MA: Polity.

Gidley, B. (2012). Coding and analysing qualitative data. In C. Seale (Ed.), Researching society and culture (3rd ed., pp. 263-282). Los Angeles, CA: SAGE Publications.

Gillem, M. L. (2007). America town: Building the outposts of empire. Minneapolis, MN: University Of Minnesota Press.

Glaser, B. G., \& Strauss, A. L. (1967). The discovery of grounded theory: Strategies for qualitative research. Chicago, IL: Aldine Publishin Co.

Golubchikov, O., \& Phelps, N. A. (2011). The political economy of place at the post-socialist urban periphery: Governing growth on the edge of Moscow. Transactions of the Institute of British Geographers, 36(3), 425-440. http://doi.org/10.1111/j.1475-5661.2011.00427.x

Gunder, M. (2011). Commentary: Is urban design still urban planning? An exploration and response. Journal of Planning Education and Research, 31(2), 184-195.

http://doi.org/10.1177/0739456X10393358

Gurran, N., Blakely, E. J., \& Squires, C. (2007). Governance responses to rapid growth in environmentally sensitive areas of coastal Australia. Coastal Management, 35(4), 445-465. http://doi.org/10.1080/08920750701525776

Guy, S., \& Henneberry, J. (2000). Understanding urban development processes: Integrating the economic and the social in property research. Urban Studies, 37(13), 2399-2416.

http://doi.org/10.1080/00420980020005398

Hall, C. M. (2011). A typology of governance and its implications for tourism policy analysis. Journal of Sustainable Tourism, 19(4-5), 437-457.

http://doi.org/10.1080/09669582.2011.570346

Hankins, K. B. (2015). Regime politics in geography. Urban Affairs Review, 51(1), 150-160. http://doi.org/10.1177/1078087414559606 
Healey, P. (1991). Models of the development process: A review. Journal of Property Research, 8(3), 219-238. http://doi.org/10.1080/09599919108724039

Healey, P. (1992). An institutional model of the development process. Journal of Property Research, 9(1), 33-44. http://doi.org/10.1080/09599919208724049

Healey, P. (1999). Institutionalist analysis, communicative planning, and shaping places. Journal of Planning Education and Research, 19(2), 111-121. http://doi.org/10.1177/0739456X9901900201

Healey, P. (2007). Urban complexity and spatial strategies towards a relational planning for our times. London, England: Routledge. Retrieved from http://site.ebrary.com/id/10155685

Healey, P. (2010). Making better places: The planning project in the twenty-first century. London, England: Palgrave Macmillan.

Hooper, A. (1992). The construction of theory: A comment. Journal of Property Research, 9, $45-48$.

Hughes, J. A., \& Sharrock, W. W. (1997). The philosophy of social research. London, England: Longman.

Jacobs, A. B. (1995). Great streets. Cambridge, MA: MIT Press.

Jacobs, J. (1961). The death and life of great American cities. New York: Random House.

Jessop, B. (2002). Governance and meta-governance in the face of complexity: On the roles of requisite variety, reflexive observation, and romantic irony in participatory governance. In H. Heinelt, P. Getimis, G. Kafkalas, R. Smith, \& E. Swyngedouw (Eds.), Participatory governance in multi-level context (pp. 33-58). VS Verlag für Sozialwissenschaften. Retrieved from http://link.springer.com/chapter/10.1007/978-3-663-11005-7_2

Kelbaugh, D. (1997). Common place: Toward neighborhood and regional design. Seattle, WA: University of Washington Press.

Kersbergen, K. V. \& Waarden, F. V. (2004). “Governance” as a bridge between disciplines: Cross-disciplinary inspiration regarding shifts in governance and problems of governability, accountability and legitimacy. European Journal of Political Research, 43(2), 143-171. http://doi.org/10.1111/j.1475-6765.2004.00149.x

Knox, P., \& Ozolins, P. (2000). Design professionals and the built environment: An introduction. London, England: Wiley.

Kostof, S. (1999). The city shaped: Urban patterns and meanings through history. Boston, MA: Little, Brown and Co. 
Kostof, S., \& Castillo, G. (2005). The city assembled: The elements of urban form through history. New York, NY: Thames \& Hudson.

Lang, J. T. (1994). Urban design: The American experience. New York, NY: John Wiley \& Sons.

Lang, J. T. (2005). Urban design: A typology of procedures and products. Amsterdam, The Netherlands: Elsevier/Architectural Press.

Larkham, P. J., \& Conzen, M. P. (2014). Shapers of urban form: Explorations in morphological agency. London, England: Routledge.

Lefebvre, H. (1991). The production of space, trans. D. Nicholson-Smith. Oxford: Blackwell.

Liu, W. K. (2011). Managing change: Tensions between urban morphology and everyday life in the heterotopic urban context of Tainan (Doctoral Thesis). Edinburgh, Scotland: The University of Edinburgh. Retrieved from http://hdl.handle.net/1842/5515

Lynch, K. (1960). The image of the city. Cambridge, MA: MIT Press.

Lynch, K. (1984). Good city form. Cambridge, MA: MIT Press.

MacLaran, A. (2014). Making space: Property development and urban planning. London, England: Routledge.

Madanipour, A. (1996). Design of urban space: An inquiry into a socio-spatial process. Chichester, England: John Wiley \& Sons, Ltd.

Madanipour, A. (1997). Ambiguities of urban design. The Town Planning Review, 68(3), 363-383.

Madanipour, A. (2003). Design in the city: Actors and context. In S. Menin (Ed.), Constructing place: Mind and matter. London, England: Routledge.

Madill, A., Jordan, A., \& Shirley, C. (2000). Objectivity and reliability in qualitative analysis: Realist, contextualist and radical constructionist epistemologies. British Journal of Psychology, 91(1), 1-20. http://doi.org/10.1348/000712600161646

Massey, D. B. (2005). For space. London, England: SAGE.

McGlynn, S., \& Murrain, P. (1994). The politics of urban design. Planning Practice \& Research, 9(3), 311-322.

McGlynn, S., \& Samuels, I. (2000). The funnel, the siev and the template: Towards an operational urban morphology. Urban Morphology, 4(2), 79-89. 
Moore, N. (2008). Dublin docklands reinvented: The post-industrial regeneration of a European city quarter. (J. Brady \& A. Simms, Eds.). Dublin, Ireland: Four Courts Press Ltd.

Moudon, A. V. (1989). Built for change: Neighborhood architecture in San Francisco. Cambridge, MA: MIT Press.

Moudon, A. V. (1997). Urban morphology as an emerging interdisciplinary field. Urban Morphology, 1, 3-10.

Mumford, L. (1961). The city in history: Its origins, its transformations, and its prospects. London, England: Secker \& Warburg.

Oliveira, V., \& Pinho, P. (2006). Study of urban form in Portugal: a comparative analysis of the cities of Lisbon and Oporto. Urban Design International, 11(3-4), 187-201. http://doi.org/10.1057/palgrave.udi.9000175

Pierre, J. (1999). Models of urban governance: The institutional dimension of urban politics. Urban Affairs Review, 34(3), 372-396. http://doi.org/10.1177/10780879922183988

Pierre, J. (2005). Comparative urban governance: Uncovering complex causalities. Urban Affairs Review, 40(4), 446-462. http://doi.org/10.1177/1078087404273442

Pierre, J. (2014). Can urban regimes travel in time and space? Urban regime theory, urban governance theory, and comparative urban politics. Urban Affairs Review, 50(6), 864-889. http://doi.org/10.1177/1078087413518175

Pierre, J., \& Peters, B. G. (2000). Governance, politics and the state. New York, NY: St. Martin's Press.

Pinho, P., \& Oliveira, V. (2009). Different approaches in the study of urban form. Journal of Urbanism: International Research on Placemaking and Urban Sustainability, 2(2), 103-125. http://doi.org/10.1080/17549170903083676

Punter, J. (2002). Urban design as public policy: Evaluating the design dimension of Vancouver's planning system. International Planning Studies, 7(4), 265-282. http://doi.org/10.1080/1356347022000027710

Punter, J. (2007). Developing urban design as public policy: Best practice principles for design review and development management. Journal of Urban Design, 12(2), 167-202. http://doi.org/10.1080/13574800701306195

Punter, J., \& Carmona, M. (1997). The design dimension of planning: Theory, content, and best practice for design policies. London, England: E \& FN Spon. 
Punter, J. V. (1992). Design control and the regeneration of docklands: The example of Bristol. Journal of Property Research, 9(1), 49-78.

http://doi.org/10.1080/09599919208724051

Rhodes, R. A. W. (2007). Understanding governance: Ten years on. Organization Studies, 28(8), 1243-1264. http://doi.org/10.1177/0170840607076586

Rhodes, R. A. W. (1996). The new governance: Governing without government. Political Studies, 44(4), 652-667. http://doi.org/10.1111/j.1467-9248.1996.tb01747.x

Rhodes, R. A. W. (1997). Understanding governance: Policy networks, governance, reflexivity and accountability. Buckingham, England: Open University Press.

Richards, L., \& Morse, J. M. (2013). Readme first for a user's guide to qualitative methods (3rd ed.). Thousand Oaks, CA: Sage.

Ritchie, J., Lewis, J., McNaughton Nicholls, C., \& Ormston, R. (2014). Qualitative research practice: A guide for social science students and researchers (2nd ed.). Los Angeles, CA: SAGE.

Rivas, C. (2012). Coding and analysing qualitative data. In C. Seale (Ed.), Researching society and culture (3rd ed., pp. 366-392). Los Angeles, CA: SAGE.

Robson, C. (2002). Real world research: A resource for social scientists and practitionerresearchers (2nd ed.). Oxford, England: Blackwell Publishers.

Rutterford, C. (2012). Research design. In C. Seale (Ed.), Researching society and culture (3rd ed., pp. 118-131). Los Angeles, CA: SAGE.

Seale, C. (1999). Quality in qualitative research. Qualitative Inquiry, 5(4), 465-478. http://doi.org/10.1177/107780049900500402

Seale, C. (2012a). Generating grounded theory. In C. Seale (Ed.), Researching society and culture (3rd ed., pp. 393-404). Los Angeles, CA: SAGE.

Seale, C. (2012b). Sampling. In C. Seale (Ed.), Researching society and culture (3rd ed., pp. 134-152). Los Angeles, CA: SAGE.

Sellers, J. M. (2002). The nation-state and urban governance: Toward multilevel analysis. Urban Affairs Review, 37(5), 611-641. http://doi.org/10.1177/107808740203700501

Sennett, R. (1992). The conscience of the eye: The design and social life of cities. New York, NY: W. W. Norton. 
Sepe, M. (2013). Urban history and cultural resources in urban regeneration: A case of creative waterfront renewal. Planning Perspectives, 28(4), 595-613.

http://doi.org/10.1080/02665433.2013.774539

Spencer, L., Ritchie, J., O’Connor, W., Morrelll, G., \& Ormston, R. (2014). Analysis in practice. In Qualitative research practice : A guide for social science students and researchers (2nd ed., pp. 296-347). Los Angeles, CA: SAGE.

Srivastava, A., \& Thomson, B. (2009). Framework analysis: A qualitative methodology for applied policy research. Journal of Administration and Governance, 4(2), 72-79.

Stoker, G., \& Mossberger, K. (1994). Urban regime theory in comparative perspective. Environment and Planning C: Government and Policy, 12(2), 195 - 212.

http://doi.org/10.1068/c120195

Stoker, G. (1995). Regime theory and urban politics. In D. Judge, G. Stoker, \& H. Wolman (Eds.), Theories of urban politics (pp. 54-71). London, England: SAGE.

Stoker, G. (1998). Governance as theory: Five propositions. International Social Science Journal, 50(155), 17-28. http://doi.org/10.1111/1468-2451.00106

Stoker, G. (2011). Was local governance such a good idea? A global comparative perspective. Public Administration, 89(1), 15-31. http://doi.org/10.1111/j.1467-9299.2011.01900.x

Stone, C. N. (1993). Urban regimes and the capacity to govern: A political economy approach. Journal of Urban Affairs, 15(1), 1-28.

Stone, C. N. (2015). Reflections on regime politics from governing coalition to urban political order. Urban Affairs Review, 51(1), 101-137. http://doi.org/10.1177/1078087414558948

Thomas, G. (2011). How to do your case study : A guide for students and researchers. Los Angeles, CA: SAGE.

Treib, O., Bähr, H., \& Falkner, G. (2007). Modes of governance: Towards a conceptual clarification. Journal of European Public Policy, 14(1), 1-20.

http://doi.org/10.1080/135017606061071406

UNCHS (Habitat). (2000). UNCHS (Habitat): The global campaign for good urban governance. Environment and Urbanization, 12(1), 197-202.

http://doi.org/10.1177/095624780001200114

UNFPA. (2009). State of the world population 2009: Facing a changing world: Women, population and climate (Annual) (p. 94). New York, NY: United Nations Population Fund (UNFPA). 
Warren, C. (2001). Qualitative interviewing. In Handbook of Interview Research (pp. 83103). Thousand Oaks, CA.: SAGE. Retrieved from http://dx.doi.org/10.4135/9781412973588

Washburn, A. (2013). The nature of urban design: A New York perspective on resilience. Washington, DC: Island Press.

Whitehand, J. W. R. (1972). Building cycles and the spatial pattern of urban growth. Transactions of the Institute of British Geographers, (56), 39-55.

http://doi.org/10.2307/621541

Whitehand, J. W. R. (1993). The making of the urban landscape. Hoboken, NJ: John Wiley \& Sons.

Whitehand, J. W. R. (2001). British urban morphology: The Conzenian tradition. Urban Morphology, 5(2), 103-109.

Whitehand, J. W. R., \& Larkham, P. J. (1992). Urban landscapes : International perspectives. London; New York: Routledge.

Whitehand, J. W. R., \& Larkham, P. J. (2013). The urban landscape: Issues and perspectives. In P. J. Larkham \& J. W. R. Whitehand (Eds.), Urban Landscapes: International Perspectives (pp. 1-22). London, England: Routledge.

Whyte, W. H. (1980). The social life of small urban spaces. Washington, DC: Conservation Foundation.

Yeo, A., Legard, R., Keegan, J., Ward, K., McNaughton Nicholls, C., \& Lewis, J. (2014). Indepth interviews. In J. Ritchie, J. Lewis, C. McNaughton Nicholls, \& R. Ormston (Eds.), Qualitative research practice: A guide for social science students and researchers $\left(2^{\text {nd }}\right.$ ed., pp. 177-209). Los Angeles, CA: SAGE. 


\section{Appendix 1 Ethics approval}
a) Original ethics approval
b) Approval for an amended list of questions 


\begin{tabular}{l|l}
\hline TO & Colin O'Byrne \\
\hline COPY TO & $\begin{array}{l}\text { Brenda Vale } \\
\text { Penny Allan }\end{array}$ \\
\hline FROM & Dr Allison Kirkman, Convener, Human Ethics Committee \\
\hline \multicolumn{2}{|l}{} \\
\hline DATE & 1 August 2011 \\
\hline PAGES & 1 \\
\hline SUBJECT & $\begin{array}{l}\text { Ethics Approval: } 18574 \text { - Evaluating the Urban Development } \\
\text { Process: Adaptive governance as a model }\end{array}$ \\
\hline
\end{tabular}

Thank you for your application for ethical approval, which has now been considered by the Standing Committee of the Human Ethics Committee.

Your application has been approved from the above date and this approval continues until 31 December 2012. If your data collection is not completed by this date you should apply to the Human Ethics Committee for an extension to this approval.

Best wishes with the research.

Allison Kirkman

Human Ethics Committee 


\begin{tabular}{l|l}
\hline TO & Colin O'Byrne \\
\hline COPY TO & $\begin{array}{l}\text { Brenda Vale } \\
\text { Penny Allan }\end{array}$ \\
\hline FROM & Dr Allison Kirkman, Convener, Human Ethics Committee \\
\hline
\end{tabular}

\begin{tabular}{l|l}
\hline DATE & 30 May 2012 \\
\hline PAGES & 1 \\
\hline
\end{tabular}

SUBJECT Ethics Approval: 18574

Evaluating the Urban Development Process: Adaptive Governance as a Model

Thank you for your request to amend your ethics approval. This has now been considered and the request granted.

Your application has approval until 31 December 2012. If your data collection is not completed by this date you should apply to the Human Ethics Committee for an extension to this approval.

Best wishes with your research.

Allison Kirkman

Human Ethics Committee 


\section{Appendix 2 Interview recruitment material and interview questions}
a) Recruitment letter
b) List of interview questions 


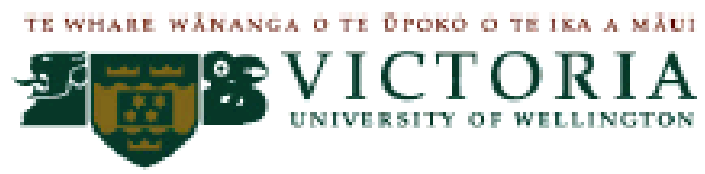

14 June 2012

Dear Sir or Madam,

I would like to invite you to participate in a study of the redevelopment of the Wellington waterfont from an industrial district to a more publicly accessible and mixed use urban environment. It is only through the participation of people such as yourself, who have been involved with the redevelopment process, that this type of research is possible. Involvement will consist of an interview that should take only an hour or two of your time.

The study explores the relationship between governance and urban form. As governance includes the formal and informal means through which we, as a society, organize ourselves, this research will review social processes and types of interaction between the state and community stakeholders. Through interviewing those involved in the redevelopment of former industrial waterfront lands of Wellington, New Zealand and Halifax, Canada, this study will establish an understanding of the governance structure and processes associated with the resulting built form. The analysis should illuminate those aspects of governance that have the greatest influence in shaping the built environment.

Ultimately, the point of this research is to identify how urban governance is reflected in the built environment and articulate possible approaches to improve the policy and governance processes used to realize urban projects. With over half the world's population currently living in cities, according to the UN, and growth rates exceeding those of rural populations, it is important to understand what forces contribute most to shaping urban environments, and how these work. A greater understanding of the societal processes that influence the built form will enable communities and decision-makers to make better informed choices and more effectively guide future development efforts.

To identify potential participants I reviewed council records, newspaper archives, and other publicly available material related to the project to see who was involved in the planning and design processes. The interview questions cover the governance process and outcomes relating to the waterfront redevelopment process. Depending on timing and availability, the interviews may be conducted in person or via telephone with potential follow-up questions at a later date. The interviews will be recorded through notes and on a dictaphone to ensure accuracy. Recordings of your interview, or the portions relevant to the study, will be available upon request.

The information gathered from the interview will be available only to my supervisors and I. All information will be kept in a secured form (under lock and/or password protection) for up to three years following completion of my thesis. Following this time period the information will be erased and/or destroyed.

Results will mainly be presented in a non-identifiable format. However, if there is a need to disclose your identity through the publication or presentation of the results of this research, in any form, every effort will be made to obtain your permission and provide you with a copy of the material for confirmation prior to its release.

Once the research is completed, the finished thesis will be available digitally through the Victoria University of Wellington Library website. Should you wish to be notified of its availability, please tick the appropriate box on the attached consent form.

If you have further questions, I am available either via email: obyrncoli@myvuw.ac.nz or telephone: $+64(0) 44728433$. 


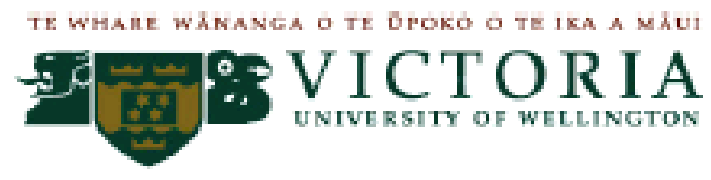

My supervisors are also available via email and telephone:

Professor Brenda Vale

Email: brenda.vale@vuw.ac.nz

Telephone: $+64(0) 44790253$

Associate Professor Penny Allan

Email: penny.allan@vuw.ac.nz

Telephone: +64 (0)4 4639460

Should you wish to participate, please return the attached consent form electronically to obymcoli@myvuw.ac.nz or via regular post to:

\section{Colin O'Byrne}

c/o School of Architecture and Design

139 Vivian Street

PO Box 600

Wellington

New Zealand

This study has received ethics approval from the Victoria University of Wellington Human Ethics Committee.

Thank you very much for your time and I look forward to hearing from you.

Kind regards,

\section{Colin O'Byme \\ PhD Candidate}

School of Architecture and Design

Victoria University of Wellington 


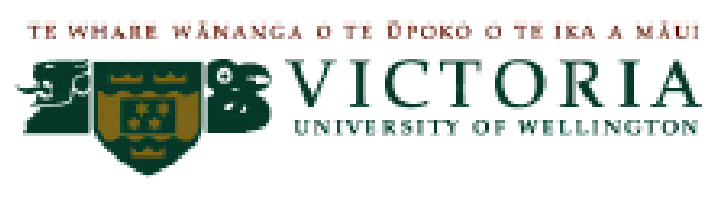

Title of research: A method for evaluating the relationship between urban governance and urban form

I, consent to participate in this research. I agree to be contacted for an interview and follow-up questions. I also understand that I may withdraw from this study within two weeks of consenting to participate without having to provide an explanation. To do so I will notify the investigator in writing or via email.

$\square$ I wish to receive a recording of the interview.

I wish to receive a tabular summary of the interview covering only those parts relevant to the study.

I wish to be notified when the completed thesis is available.

Signed:

Date:

Please provide your preferred contact details below. Forms can be returned electronically to obymcoli@myvuw.ac.nz or via post to:

Colin O'Byrne

c/o School of Architecture and Design

139 Vivian Street

PO Box 600

Wellington

New Zealand

Preferred method of contact:

Telephone: Best time to call:

Email:

Thank you time and I look forward to speaking with you.

Kind regards,

Colin O'Byrne

$\mathrm{PhD}$ Candidate

School of Architecture and Design

Victoria University of Wellington 


\section{Waterfront Redevelopment Interview Questions}

The aim of the following questions is to gather information that will help explore the relationship between urban governance and form in regards to the redevelopment of the waterfront. Governance, in this context, includes all the ways a society organizes itself and makes decisions; this research, therefore, hypothesizes different aspects of governance will direct the evolution of the urban form in different ways. This survey seeks to clarify some of those aspects related to the redevelopment of the waterfront and how they influenced its evolution into the way it looks today.

- Please identify the role you played in the redevelopment of the Wellington waterfront.

Governance structure describes how social, political, and economic networks are connected; and how they interact. Basic network structures can be described as:

- Fragmented: little cooperation or communication between network elements; organizations and groups work in isolation from others at different scales and with overlapping territories.

- Centralized: communication, interactions, and cooperation among groups or organizations are coordinated through a central node or governing body.

- Mixed: independent organizations working collaboratively, with some central organization of select services; effective communication.

- Comprehensive: Well organized groups in control of all local services and development; weakly connected with each other.

- Please describe your perception of the type of governance structure involved in the waterfront redevelopment.

- Please describe how communication occurred/occurs between groups or organizations.

- Has the governance structure related to the waterfront redevelopment changed over time? If so, how? 
- Does the governance structure appear to have had an effect on the evolving character or form of the waterfront and if so, how?

- What groups or roles have had the largest impact on the redevelopment process?

- What do you feel are the common values and concerns guiding re-development of the waterfront? (including those considered 'good' or 'bad') Have these changed over time? (i.e. focus on jobs, concern over public and/or open space, preference for high density residential, inclusive public space, high profits and/or taxes, etc.)

- What values and traditions do you feel are embodied in the waterfront redevelopment?

- What were some of the key decisions that influenced the character and form of the waterfront redevelopment? These may be about development direction, specific projects, process requirements, design strategies, form and aesthetics, or something else.

- What are some of the most prominent features of the waterfront? (i.e. What defines its character?

- What are the best loved and most used features or spaces? What are some of the least used features or spaces?

Governance functional types are basic models of how the urban governance system operates, identifying characteristic methods of interaction between formal (i.e. government, business, etc.) and informal (i.e. community clubs, voluntary organizations, etc.) organizations. Based on the literature, interactions between levels of government and non-governmental organizations/ institutions (including businesses) can be characterized as:

- Clientelistic/progrowth: political favoritism towards interests or clients.

- Welfare: passive local government combined with a stagnant or declining local economy; economically and politically reliant on central government.

- Managerial: formal, bureaucratic, or contractual top-down approach with 
a focus on effectiveness and efficiency.

- Pluralist: government serves as a power-broker for private interests; decision-making occurs through negotiation where power centres on key actors.

- Investigative: academic; process oriented; collaborative; employs surveys and other feedback mechanisms; place and system focused.

- Corporatist: a collaborative approach between government and civic leaders; very inclusive with delegation of authority to special interest organizations.

- Populist: grassroots mobilization influences policy. This approach is very inclusive, but power tends to rest with community organizers or very vocal special interest groups.

- Often governance is experienced as a combination of above approaches. What approach(es) do you think has/have been most dominant? Or, have certain approaches been most apparent at different times? If so, when?

- In light of this: (Repeat question \#6)

- How are goals and values identified? How do the functional types you have selected impact how goals and values are identified or selected?

- Do you feel there were times when a certain approach resulted in certain types of development? If so, please explain.

- What measurements have been used to evaluate the success of the waterfront or of stakeholder satisfaction? How often are these measured?

- Did the number of stakeholders involved in the redevelopment and consultation processes change over time? If so, do you know why this occurred? (i.e. this could be the result of changing satisfaction with how the redevelopment process was being handled, changing demographics, new opportunities for involvement being introduced, a culturally significant/valuable site being up for redevelopment, or proposed redevelopment for a particular site being at odds with the interest of public stakeholders)

- From your perspective, has the redevelopment process occurred largely through formal, legislated processes and decision-making channels (i.e. a set schedule of 
submissions, consultations, and approvals), or has it been more informal and less organized/predictable (i.e. through lobbying, special meetings, varying levels of public consultation at different points of project design, decisionmaking handled by different groups/levels of government for different phases/projects, etc.)?

- If some projects stall, at which point is it common for them to have issues? Do different types of projects tend to stall at different stages in the decision-making process (i.e. public space projects versus mixed use developments)? 


\section{Appendix 3 Archive analysis bibliography}

\section{Books}

Harper, J., \& Lister, A. (2007). Wellington: A city for sculpture. Wellington, NZ: Victoria University Press.

Johnson, D. (1996). Wellington Harbour. Wellington NZ: Wellington Maritime Museum Trust. Retrieved from

http://www.wcl.govt.nz/carlweb/jsp/DoSearch?databaseID=2540\&count=10\&terms=0958349 800\&index $=\mathrm{i}$

O’Regan, R. (1974). A view of the future. Wellington, NZ: Wellington Harbour Board.

\section{Environment Court decisions}

Intercontinental Hotel v Waterfront Investments Limited W015/2008, No. 72 (Environment Court March 14, 2008). Retrieved from http://www.nzlii.org/cgibin/sinodisp/nz/cases/NZEnvC/2008/72.html?query=hotel\%20wellington\%20waterfront

Waterfront Watch Incorporated v Wellington Regional Council W88/2001, No. 452 (Environment Court December 13, 2001). Retrieved from http://www.nzlii.org/cgibin/sinodisp/nz/cases/NZEnvC/2001/452.html?query=wellington\%20waterfront

Waterfront Watch Incorporated v Wellington Regional Council W095/2009, No. 341 (Environment Court December 2, 2009). Retrieved from http://www.nzlii.org/cgibin/sinodisp/nz/cases/NZEnvC/2009/341.html?query=wellington\%20waterfront

\section{Journal articles}

Doorne, S. (1998). Power, Participation and Perception: An Insider's Perspective on the Politics of the Wellington Waterfront Redevelopment. Current Issues in Tourism, 1(2), 129166. http://doi.org/10.1080/13683509808667836

Hutchison, A. J. H. (1973). Reclamations in Wellington Harbour with special reference to recent developments. New Zealand Engineering, 28(8), 217.

McEldowney, L. (1986). Extensive development planned for Wellington's waterfront. New Zealand Engineering, 41(11), 13-18.

Morrison, P. S., \& McMurray, S. (1999). The inner-city apartment versus the suburb: Housing sub-markets in a New Zealand city. Urban Studies, 36(2), 377-397. http://doi.org/10.1080/0042098993655 
Shadwell, G. (1989). Planning for the country's 'most significant building': A new museum complex for NZ. New Zealand Engineering, 44(1), 29.

\section{Legislation}

Harbours Act 1950, Pub. L. No. 1950 No 34 (1950). Retrieved from

http://www.nzlii.org/nz/legis/hist_act/ha19501950n34142/

Local Government Act 2002, Pub. L. No. 2002 No 84 (2002). Retrieved from http://www.legislation.govt.nz/act/public/2002/0084/latest/DLM170873.html

Port Companies Act 1988, Pub. L. No. 1988 No 91 (1988). Retrieved from http://www.legislation.govt.nz/act/public/1988/0091/latest/DLM131688.html

Resource Management Act 1991, Pub. L. No. 1991 No 69 (1991). Retrieved from http://www.rmaguide.org.nz/rma/introduction/historical.cfm

Wellington Harbour Board and Corporation Land Act 1880, Pub. L. No. 1880 No 21 (1880). Retrieved from http://www.legislation.govt.nz/act/local/1880/0021/latest/DLM15180.html

Wellington Harbour Board and Wellington City Council Vesting and Empowering Act 1987, Pub. L. No. 1987 No 5 (1987). Retrieved from

http://www.legislation.govt.nz/act/local/1987/0005/latest/DLM78107.html

\section{Newspaper and online media reports}

Burgess, D. (2011, October 27). Queens Wharf development plans revealed. Stuff.co.nz. Retrieved from http://www.stuff.co.nz/dominion-post/news/5864039/Queens-Wharfdevelopment-plans-revealed

Cayford, J. (2014, August 8). Reflections on Auckland planning: Wellington waterfront planning history. Retrieved from http://joelcayford.blogspot.co.nz/2014/08/wellingtonwaterfront-planning-history.html

Donoghue, B. T. (2009, December 5). Wellington waterfront waka house gets go-ahead. Stuff.co.nz. New Zealand. Retrieved from http://www.stuff.co.nz/national/3129418/Wellington-waterfront-waka-house-gets-go-ahead

Forbes, M. (2013, November 26). Proposal heightens interest in waterfront. Stuff.co.nz. Retrieved from http://www.stuff.co.nz/dominion-post/news/9440854/Proposal-heightensinterest-in-waterfront

Shelton, L. (2012, February 8). Big new six-storey building proposed for waterfront park near station. Wellington.scoop.co.nz. New Zealand Retrieved from http://wellington.scoop.co.nz/?p=42252 
Unknown. (2007, October 29). Kumutoto Option A. WellUrban. Retrieved from http://wellurban.blogspot.co.nz/2007/10/kumutoto-option.html

\section{Online resources}

Blackley, R. (2014). Art galleries and collections - Modernisation and contemporary collecting, 1970s to 2000s [Web page]. Retrieved August 19, 2015, from http://www.teara.govt.nz/en/art-galleries-and-collections/page-3

Wellington Sculptures. (2011). Kupe Statue [Web page]. Retrieved August 25, 2015, from http://www.sculptures.org.nz/tours/waterfront-tour/kupe-statue

Wellington Waterfront Watch. (n.d.). History [Web page]. Retrieved August 21, 2014, from http://www.waterfrontwatch.org.nz/history/

Circa Theatre. (n.d.). History [Web page]. Retrieved November 25, 2015, from http://www.circa.co.nz/site/About/History

Willis Bond \& Co. (n.d.). Queens Wharf [Web page]. Retrieved March 19, 2011, from http://willisbond.co.nz/projects/queens-wharf/

STQRY. (n.d.). Frank Kitts [Web page]. Park Retrieved August 12, 2015, from https://www.stqry.com/v/Frank-Kitts-Park/i_9f50a0ae91cf031311ed3f7fb54041d2

STQRY. (n.d.). Odlin building [Web page]. Retrieved August 19, 2015, from https://discover.stqry.com/v/architecture/s/b7aba982b4f045872996f1a46c3a99dd

STQRY. (n.d.). Overseas Passenger Terminal [Web page]. Retrieved August 23, 2015, from https://discover.stqry.com/v/overseas-passengerterminal/s/4727b2fc55d1d54c5d6d067ba94aa415

STQRY. (n.d.). Wharf offices [Web page]. Retrieved August 1, 2015, from https://discover.stqry.com/v/architecture/s/1b15000e4295549a41e763d439ae1a02

Heritage New Zealand. (n.d.). Wellington Harbour Board Head Office and Bond Store [Web page]. Retrieved June 20, 2015, from http://www.heritage.org.nz/the-list/details/234

Heritage New Zealand. (n.d.) Wellington Harbour Board Shed 13 [Web page]. Retrieved May 20, 2016, from http://www.heritage.org.nz/the-list/details/236

\section{Pamphlets}

Waterfront Watch. (1999). Stop the wall. Wellington, NZ: Waterfront Watch. 
Wellington City Council. (n.d.). Old Shoreline Heritage Trail [guide book]. Wellington, NZ: Wellington City Council.

\section{Photographs and images}

Athfield Architects Ltd. (2007). Kumutoto building proposals [Architectural rendering]. Retrieved December 4, 2015, from http://wellurban.blogspot.ca/2007/10/kumutotooption.html

Athfield Architects Ltd. (2004). Overseas Passenger Terminal [Architectural rendering]. Retrieved November 13, 2015, from Athfield Architects Ltd.

http://www.athfieldarchitects.co.nz/

Athfield Architects Ltd. (2004). Taranaki Street Wharf [Master plan]. Retrieved November 13, 2015, from Athfield Architects Ltd. http://www.athfieldarchitects.co.nz/

Eileen Duggan - Writers Walk [Photograph]. (n.d.). Retrieved November 11, 2015, from Wellington Writers Walk. http://www.wellingtonwriterswalk.co.nz/the-sculptures/

Gorrie, A., (circa 2006). [Untitled photograph of developers holding model of proposed Hilton Hotel]. Retrieved January 1, 2016, from http://www.stuff.co.nz/dominionpost/news/70070617/wellingtons-waterfront--20-years-in-the-making

John Wardle Architects. (2005). Proposal for Waitangi Precinct buildings [Architectural rendering]. Retrieved November 13, 2015, from

http://www.johnwardlearchitects.com/projects

Klajban, M. (November 24, 2014). Odlins building, Wellington, New Zealand [Photograph]. Retrieved April 10, 2016, from Wikimedia Commons.

https://commons.wikimedia.org/wiki/File:Odlins_Building,_Wellington,_New_Zealand_\%28 10\%29.JPG

Klajban, M. (November 24, 2014). Shed 22, Wellington, New Zealand [Photograph]. Retrieved April 10, 2016, from Wikimedia Commons.

https://commons.wikimedia.org/wiki/File:Shed_22,_Wellington,_New_Zealand_\%281\%29.J PG

Lanma726lme. (April 13, 2008). Wellington Harbour Board Head Office and Bond Store [Photograph]. Retrieved April 10, 2016, from Wikimedia Commons.

https://commons.wikimedia.org/wiki/File:Wellington_Harbour_Board_Head_Office_and_Bo nd_Store.png

Le Roy, P. (August 10, 2014). Wellington Harbour Board Shed 21 [Photograph]. Retrieved March 10, 2014, from Heritage New Zealand. http://www.heritage.org.nz/the-list/details/237 
Lloyd, P. (December 21, 2009). Kupe Group statue [Photograph]. Retrieved April 10, 2016, from Wikimedia Commons.

https://commons.wikimedia.org/wiki/File:Kupe_Group_Statue.jpg

Louis Johnson - Writers Walk [Photograph]. (n.d.). Retrieved November 11, 2015, from Wellington Writers Walk. http://www.wellingtonwriterswalk.co.nz/the-sculptures/

Marine Park [Photograph]. (circa 1974). Retrieved November 1, 2015 from Dominion Post Collection, Alexander Turnbull Library, Wellington, NZ.

http://ndhadeliver.natlib.govt.nz/delivery/DeliveryManagerServlet?dps_pid=IE5162238\&dps _custom_att_1=tapuhi

Miller, K. (August 20, 2011). Solace of the wind [Photograph]. Retrieved April 11, 2016, from http://www.sculptures.org.nz/tours/waterfront-tour/solace-of-the-wind

Peddlethorp Architects Ltd. (circa 2006). Meridian Building façade from quay [Photograph]. Retrieved November 13, 2015 from Peddlethorp Architects.

http://www.peddlethorp.co.nz/projects/show/the-meridian-building/

Queens Wharf apartments [Photograph]. (1993). Retrieved November 22, 2015, from Dominion Post Collection, Alexander Turnbull Library, Wellington, NZ.

http://ndhadeliver.natlib.govt.nz/delivery/DeliveryManagerServlet?dps_pid=IE1210583\&dps _custom_att_1=tapuhi

Queens Wharf retail centre [Photograph]. (1996). Retrieved November 3, 2015, from http://www.stuff.co.nz/dominion-post/news/70318188/wellingtons-queens-wharf-failed-tofire--150-years-of-news

Studio Pacific Architecture. (2011). Elevations of Kumutoto public toilets [Elevation renderings]. Retrieved April 11, 2016, from http://www.studiopacific.co.nz

Tiller, J. (1989). Moving the Star Boating Club and Wellington Rowing Club buildings [Photograph]. Retrieved November 22, 2015, from Dominion Post Collection, Alexander Turnbull Library, Wellington, NZ.

http://ndhadeliver.natlib.govt.nz/delivery/DeliveryManagerServlet?dps_pid=IE1411978\&dps _custom_att_1=tapuhi

Tiller, J. (1970). [Untitled photograph of waterfront reclamation work]. Retrieved November 1, 2015 from Dominion Post Collection, Alexander Turnbull Library, Wellington, NZ. http://ndhadeliver.natlib.govt.nz/delivery/DeliveryManagerServlet?dps_pid=IE0911978\&dps _custom_att_1=tapuhi

Tiller, J. (1993). Westport Chambers building façade [Photograph]. Retrieved January 28, 2016, from Dominion Post Collection, Alexander Turnbull Library, Wellington, NZ. http://natlib.govt.nz/records/22855430 
UN Studio. (2005). Proposal for extension of Te Papa [Architectural rendering]. Retrieved November 13, 2015, from http://www.unstudio.com

[Untitled photo of 1989 Combined Scheme model]. (n.d.). Retrieved December 17, 2014, from http://www.wellington.govt.nz

[Untitled photograph of Frank Kitts Park construction]. (1989). Retrieved November 1, 2015 from Dominion Post Collection, Alexander Turnbull Library, Wellington, NZ.

http://ndhadeliver.natlib.govt.nz/delivery/DeliveryManagerServlet?dps_pid=IE6347208\&dps _custom_att_1=tapuhi

[Untitled photograph of shops along Frank Kitts Park promenade]. (n.d.). Retrieved January 25, 2014, from http://www.wellingtonnz.com

[Untitled photograph of The Albatross by Tanya Ashken]. (n.d.). Retrieved January 2, 2016, from http://www.sculpture.org.nz/the-sculptures/albatross

[Untitled photograph of Water Whirler by Len Lye]. (n.d.). Retrieved January 2, 2016, from http://www.sculpture.org.nz/the-sculptures/waterwhirler

Wellington City Council. (n.d.). Waterfront reclamations [Map]. Retrieved February 12, 2011, from http://wellington.govt.nz/about-wellington/history/history-of-wellingtonwaterfront/waterfront-reclamation

Wraight, M. (2007). Frank Kitts Park [Master plan]. Retrieved November 14, 2015, from Wraight \& Associates Landscape Architecture and Urban Design. http://www.waal.co.nz/ourprojects/urban/frank-kitts-park/

Wraight, M. (2004). Waitangi Park [Master plan]. Retrieved November 14, 2015, from Wraight \& Associates Landscape Architecture and Urban Design.

http://www.waal.co.nz/wsud/waitangi-park/

\section{Waterfront plans}

Design Team. (1997). Lambton Harbor public spaces concept plan. Wellington City Archives, Wellington, NZ.

Design Team. (1998). Wellington Harbor open space master plan. Wellington City Archives, Wellington, NZ.

Gabites, Porter \& Partners. (1986). Lambton Harbour urban design concept. Wellington City Archives, Wellington, NZ.

Gabites, Porter \& Partners. (1989). Lambton Harbour combined scheme. Wellington City Archives, Wellington, NZ. 
Paperchase. (1983). Harbour city competition: The winning entry. Wellington Civic Trust. Private collection.

Waterfront Leadership Group. (2001, April). The Wellington Waterfront Framework: Report of the Waterfront Leadership Group. Wellington, NZ: Wellington City Council.

\section{Waterfront studies and reports}

Buchan, D. (2006). Supplementary submission on resource consent application Construction of a hotel on the outer-T, Queens Wharf (Submission). Retrieved from http://www.wellingtoncivictrust.org/wpcontent/uploads/2008/05/submissionouterthiltonhotelqueenswharfjuly06buchan_000.pdf

Buchan, D. (2011). Aspects of engagement: Conflict and collaboration. In P. Brooks (Ed.), Twenty-five years of waterfront planning: Achievements, disappointments and hopes. Wellington NZ: Wellington Civic Trust.

Cochran, C., Murray, R., Kelly, M., \& Dodd, A. (2012). Coastal historic heritage of the Wellington region: Survey for the Coastal Plan review. Wellington NZ: Greater Wellington Regional Council.

Greater Wellington Regional Council. (2008). Consent granted for Overseas Passenger Terminal redevelopment. Wellington, NZ: Greater Wellington Regional Council. Retrieved September 19, 2015, from http://www.gw.govt.nz/Consent-granted-for-Overseas-PassengerTerminal-redevelopment/

Harris, K. (2000). Briefing paper: Removal of shed 31. Wellington NZ: CentrePort Wellington. Retrieved from http://www.gw.govt.nz/assets/councilreports/Report_PDFs/2000_561_5_attach.pdf

Hastings, A., \& Young, B. (1997). Community consultation on funding of Lambton Harbour's future development (1997). Wellington NZ: Wellington City Council. Retrieved from http://www.digitalnz.org/records/21128661

Kernohan, D. (2011). Wellington's waterfront: An architect’s view. In P. Brooks (Ed.), Twenty-five years of waterfront planning: Achievements, disappointments and hopes. Wellington NZ: Wellington Civic Trust.

Pene, J. (2008). Consent application for redevelopment of the Overseas Passenger Terminal. Wellington, NZ: Greater Wellington Regional Council. Retrieved from http://www.gw.govt.nz/assets/Resource-Consents/4948_CapitalWharfLimi_s9964.pdf

Shelton, L. (2011). A waterfront watcher's guide to the good, the bad and the ugly. In P. Brooks (Ed.), Twenty-five years of waterfront planning: Achievements, disappointments and hopes. Wellington NZ: Wellington Civic Trust. 
Smith, A. (2011). Welcome. In P. Brooks (Ed.), Twenty-five years of waterfront planning: Achievements, disappointments and hopes. Wellington NZ: Wellington Civic Trust.

Urban Perspectives Ltd. (2014). Assessment of effects on the environment - Proposed development - North Kumutoto Precinct. Wellington, NZ: Greater Wellington Regional Council. Retrieved from http://www.gw.govt.nz/assets/Resource-Consents/North-KumutotoProject---Wellington-Waterfront/Document-10-Assessment-of-Environmental-EffectsReport.pdf

\section{Wellington City Council meeting minutes and reports}

District Plan Policy Group. (1999, September 30). District Plan Policy Group 30 September 1999 Report: Lambton Harbour Development - Proposed District Plan Variation 17. Wellington City Archives, Wellington, NZ.

Strategy and Policy Committee. (2005, November 9). Strategy and Policy Committee 9 November 2005 Report 2: Approval of lease - Site 7 Kumutoto. Wellington City Archives, Wellington, NZ.

Strategy and Policy Committee. (2007, June 7). Strategy and Policy Committee 7 June 2007 Report 4: Events Centre (TSB Bank Arena) redevelopment. Retrieved from http://wellington.govt.nz/ /media/your-council/meetings/committees/strategy-and-policycommittee/2007/06/07/files/04_tsb_arena_redevelopment.pdf?la=en

Strategy and Policy Committee. (2007, June 27). Strategy and Policy Committee 27 June 2007 Minutes. Retrieved from http://wellington.govt.nz/ /media/yourcouncil/meetings/committees/strategy-and-policy-committee/2007/06/27/files/06_27.pdf

Strategy and Policy Committee. (2007, June 27). Strategy and Policy Committee 27 June 2007 Report 1: Overseas Passenger Terminal proposal report 1 - authorization of 125 year ground lease. Retrieved from http://wellington.govt.nz/ /media/yourcouncil/meetings/committees/strategy-and-policycommittee/2007/06/27/files/report_1_opt1.pdf?la=en

Strategy and Policy Committee. (2007, June 27). Strategy and Policy Committee 27 June 2007 Report 1 - Appendix 1: Overseas Passenger Terminal - concept design proposal. Retrieved from http://wellington.govt.nz/ /media/your-council/meetings/committees/strategyand-policy-committee/2007/06/27/files/report_1_opt_1_app_1.pdf?la=en

Strategy and Policy Committee (2008, June 18). Strategy and Policy Committee 18 June 2008 Minutes. Retrieved from http://wellington.govt.nz/ /media/yourcouncil/meetings/committees/strategy-and-policy-committee/2008/06/18/files/06_18.pdf

Strategy and Policy Committee (2008, June 18). Strategy and Policy Committee 18 June 2008 Report 1: Draft waterfront development plan 2008/09. Retrieved from 
http://wellington.govt.nz/ /media/your-council/meetings/committees/strategy-and-policycommittee/2008/06/18/files/1_draft_waterfront_development_plan.pdf?la=en

Strategy and Policy Committee (2008, June 18). Strategy and Policy Committee 18 June 2008 Report 1 - Appendix 1: Draft waterfront development plan 2008/09. Retrieved from http://wellington.govt.nz/ /media/your-council/meetings/committees/strategy-and-policycommittee/2008/06/18/files/1_app_1_dwdp.pdf?la=en

Strategy and Policy Committee (2008, August 21). Strategy and Policy Committee 21 August 2008 Report 4: Feedback on the 08/09 draft waterfront development plan. Retrieved from http://wellington.govt.nz/ /media/your-council/meetings/committees/strategy-and-policycommittee/2008/08/21/files/4_waterfront.pdf?la=en

Strategy and Policy Committee (2008, December 4). Strategy and Policy Committee 4 December 2008 Minutes. Retrieved from http://wellington.govt.nz/ /media/yourcouncil/meetings/committees/strategy-and-policy-committee/2008/12/04/files/12_04.pdf

Strategy and Policy Committee (2008, December 4). Strategy and Policy Committee 4 December 2008 Report 1: Proposed district plan variation 11 - Amendments to proposed district plan change 48 (central area review) - Wellington waterfront. Retrieved from http://wellington.govt.nz/ /media/your-council/meetings/committees/strategy-and-policycommittee/2008/12/04/files/report_1_part_1_waterfront_district_plan_change.pdf?la=en

Strategy and Policy Committee (2008, December 4). Strategy and Policy Committee 4 December 2008 Report 1 - Appendix 2, attachment 1: Validity of redevelopment at 'North' Kumutoto. Retrieved from http://wellington.govt.nz/ /media/yourcouncil/meetings/committees/strategy-and-policycommittee/2008/12/04/files/report_1_part_4_gb_s32_attachment_variation_11.pdf?la=en

Strategy and Policy Committee (2008, December 11). Strategy and Policy Committee 11 December 2008 Minutes. Retrieved from http://wellington.govt.nz/ /media/yourcouncil/meetings/committees/strategy-and-policy-committee/2008/12/11/files/12_11.pdf

Strategy and Policy Committee (2008, December 11). Strategy and Policy Committee 11 December 2008 Report 5: Options for waterfront project. Retrieved from http://wellington.govt.nz/ /media/your-council/meetings/committees/strategy-and-policycommittee/2008/12/11/files/5_waterfront_report.pdf?la=en

Strategy and Policy Committee (2009, May 14). Strategy and Policy Committee 14 May 2009 Report 2: Queens Wharf Precinct. Retrieved from http://wellington.govt.nz/ /media/yourcouncil/meetings/committees/strategy-and-policycommittee/2009/05/14/files/2_wellington_waterfront.pdf?la=en

Strategy and Policy Committee (2009, August 26). Strategy and Policy Committee 26 August 2009 - Appendix 1: Our work in detail (draft for Annual Report). Retrieved from http://wellington.govt.nz/ /media/your-council/meetings/committees/strategy-and-policycommittee/2009/08/26/files/5_urban.pdf?la=en 
Strategy and Policy Committee (2009, September 3). Strategy and Policy Committee 3 September 2009 Minutes. Retrieved from http://wellington.govt.nz/ /media/yourcouncil/meetings/committees/strategy-and-policy-committee/2009/09/03/files/09_03.pdf

Strategy and Policy Committee (2009, September 3). Strategy and Policy Committee 3 September 2009 Report 2: Draft waterfront development plan for consultation. Retrieved from http://wellington.govt.nz/ /media/your-council/meetings/committees/strategy-andpolicy-committee/2009/09/03/files/02_waterfront.pdf?la=en

Strategy and Policy Committee (2009, November 17). Strategy and Policy Committee 17 November 2009 Minutes. Retrieved from http://wellington.govt.nz/ /media/yourcouncil/meetings/committees/strategy-and-policy-committee/2009/11/17/files/11_17.pdf

Strategy and Policy Committee (2009, November 17). Strategy and Policy Committee 17 November 2009 Report 3: Feedback on the 2009/10 draft waterfront development plan. Retrieved from http://wellington.govt.nz/ /media/your-council/meetings/committees/strategyand-policy-committee/2009/11/17/files/03_waterfront_feedback_report.pdf?la=en

Strategy and Policy Committee (2009, November 17). Strategy and Policy Committee 17 November 2009 Report 3 - appendix 3. Part 1. Draft waterfront development plan 2009/10. Retrieved from http://wellington.govt.nz/ /media/your-council/meetings/committees/strategyand-policy-

committee/2009/11/17/files/03_waterfront_feedback_appendix_3_part_1_draft_waterfront_pl an_post_consultation.pdf?la=en

Strategy and Policy Committee (2010, April 15). Strategy and Policy Committee 15 April 2010 Minutes. Retrieved from http://wellington.govt.nz/ /media/your-

council/meetings/committees/strategy-and-policy-

committee/2010/04/15/files/2010_april_15_minutes.pdf

Strategy and Policy Committee (2010, April 15). Strategy and Policy Committee 15 April 2010 Report 1: Draft 2010/11 waterfront development plan. Retrieved from http://wellington.govt.nz/ /media/your-council/meetings/committees/strategy-and-policycommittee/2010/04/15/files/2010_april_15_report_1_wwl_development_plan.pdf?la=en

Strategy and Policy Committee (2010, April 15). Strategy and Policy Committee 15 April 2010 Report 1 - Appendix 1: Draft 2010/11 waterfront development plan. Retrieved from http://wellington.govt.nz/ /media/your-council/meetings/committees/strategy-and-policycommittee/2010/04/15/files/2010_april_15_report_1_appendix_1.pdf?la=en

Strategy and Policy Committee (2010, April 15). Strategy and Policy Committee 15 April 2010 Report 2: Queens Wharf Precinct - Development of a master plan. Retrieved from http://wellington.govt.nz/ /media/your-council/meetings/committees/strategy-and-policycommittee/2010/04/15/files/2010_april_15_report_2_queens_wharf.pdf?la=en

Strategy and Policy Committee (2010, June 23). Strategy and Policy Committee 23 June 2010 Report 2 - Appendix 3: Draft 2010/ll waterfront development plan. Retrieved from 
http://wellington.govt.nz/ /media/your-council/meetings/committees/strategy-and-policycommittee/2010/06/23/files/report_2_appendix_3.pdf?la=en

Strategy and Policy Committee (2011, February 17). Strategy and Policy Committee 17 February 2011 Minutes. Retrieved from http://wellington.govt.nz/ /media/yourcouncil/meetings/committees/strategy-and-policycommittee/2011/02/17/files/2011_february_17_spc_minutes.pdf?la=en

Strategy and Policy Committee (2011, February 17). Strategy and Policy Committee 17 February 2011 Report 2: Review of implementation agency for the waterfront. Retrieved from http://wellington.govt.nz/ /media/your-council/meetings/committees/strategy-andpolicy-committee/2011/02/17/files/2_-_waterfront.pdf?la=en

Strategy and Policy Committee (2011, March 8). Strategy and Policy Committee 8 March 2011 Report 1: 2011/2012 Draft waterfront development plan for consultation. Retrieved from http://wellington.govt.nz/ /media/your-council/meetings/committees/strategy-andpolicy-

committee/2011/03/08/files/8_march_2011_report_1_waterfront_development_plan.pdf?la=e $\mathrm{n}$

Strategy and Policy Committee (2011, March 8). Strategy and Policy Committee 8 March 2011 Report 1 - Appendix 1: 2011/12 Draft waterfront development plan. Retrieved from http://wellington.govt.nz/ /media/your-council/meetings/committees/strategy-and-policycommittee/2011/03/08/files/8_march_2011_report_1_waterfront_development_plan_appendi x_1_2011-12_dap_version.pdf?la=en

Strategy and Policy Committee (2011, May 12). Strategy and Policy Committee 12 May 2011 Report 2: Scoping paper for the review of the Wellington Waterfront Framework. Retrieved from http://wellington.govt.nz/ /media/your-council/meetings/committees/strategy-andpolicy-committee/2011/05/12/files/water.pdf?la=en

Strategy and Policy Committee (2011, September 8). Strategy and Policy Committee 8 September 2011 Report 4: Waterfront framework review. Retrieved from http://wellington.govt.nz/ /media/your-council/meetings/committees/strategy-and-policycommittee/2011/09/08/files/8_september_2011_report_4_waterfront_framework_final.pdf?la =en

Strategy and Policy Committee (2012, October 4). Strategy and Policy Committee 4 October 2012 Minutes. Retrieved from http://wellington.govt.nz/ /media/your-

council/meetings/committees/strategy-and-policy-

committee/2012/10/04/files/4_october_2012_minutes.pdf

Strategy and Policy Committee (2012, October 4). Strategy and Policy Committee 4 October 2012 Report 1: North Kumutoto design brief. Retrieved from http://wellington.govt.nz/ /media/your-council/meetings/committees/strategy-and-policycommittee/2012/10/04/files/4_october_2012_report_1_north_kumutoto_design_brief.pdf?la= en 
Strategy and Policy Committee (2012, November 22). Strategy and Policy Committee 22 November Report 3: Adoption of North Kumutoto design brief. Retrieved from http://wellington.govt.nz/ /media/your-council/meetings/committees/strategy-and-policycommittee/2012/11/22/files/22_november_2012_report_3a_north_kumutoto_design_brief_pa per.pdf?la=en

Waterfront Development Subcommittee. (2004, May 6). Waterfront Development Subcommittee 06 May 2004 Minutes. Wellington City Archives, Wellington, NZ.

Waterfront Development Subcommittee. (2004, May 6). Waterfront Development Subcommittee Report 3 - Appendix 1: Design brief for overseas passenger terminal. (Prepared by the Technical Advisory Group). Wellington City Archives, Wellington, NZ.

Waterfront Development Subcommittee (2004, May 27). Waterfront Development Subcommittee 27 May 2004 Minutes. Wellington City Archives, Wellington, NZ.

Waterfront Development Subcommittee (2004, May 27). Waterfront Development Subcommittee 27 May 2004 Report 3 - Appendix 1: Draft waterfront development plan 2004/05. Wellington City Archives, Wellington, NZ.

Waterfront Development Subcommittee. (2004, September 2). Waterfront Development Subcommittee 2 September 2004 Report 6: Taranaki St. wharf (bridge \& lagoon extension) and associated whare waka \& whare nui building project. Wellington City Archives, Wellington, NZ.

Waterfront Development Subcommittee. (2004, September 2). Waterfront Development Subcommittee 2 September 2004 Report 6 - Appendix 1: Proposed site plan at August 2004 option A: Plan for outline specification. Wellington City Archives, Wellington, NZ.

Waterfront Development Subcommittee. (2004, September 30). Waterfront Development Subcommittee 30 September 2004 Report 1: Kumutoto public space and site 7. Wellington City Archives, Wellington, NZ.

Waterfront Development Subcommittee. (2004, December 13). Waterfront Development Subcommittee 13 December 2004 Minutes. Wellington City Archives, Wellington, NZ.

Waterfront Development Subcommittee. (2004, December 13). Waterfront Development Subcommittee 13 December 2004 Report 4: Feedback on the wharewaka and wharenui/wharekai - Taranaki Street Wharf concept designs. Wellington City Archives, Wellington, NZ.

Waterfront Development Subcommittee. (2004, December 13). Waterfront Development Subcommittee 13 December 2004 Report 4 - Appendix 1: Wharewaka and wharenui Taranaki Street Wharf. Wellington City Archives, Wellington, NZ. 
Waterfront Development Subcommittee. (2004, December 13). Waterfront Development Subcommittee 13 December 2004 Report 5: Feedback on the Kumutoto public space and Site 7 building concept design. Wellington City Archives, Wellington, NZ.

Waterfront Development Subcommittee. (2005, May 16). Waterfront Development Subcommittee 16 May 2005 Report 1: Wellington waterfront project business plan 2005/06. Wellington City Archives, Wellington, NZ.

Waterfront Development Subcommittee. (2005, May 16). Waterfront Development Subcommittee 16 May 2005 Report 2: Draft waterfront development plan. Wellington City Archives, Wellington, NZ.

Waterfront Development Subcommittee. (2005, May 16). Waterfront Development Subcommittee 16 May 2005 Report 2 - Appendix 1: Draft waterfront development plan 2005/06. Wellington City Archives, Wellington, NZ.

Waterfront Development Subcommittee. (2005, June 20). Waterfront Development Subcommittee 20 June 2005 Report 1: Waitangi Park sites 1 - 4 design brief. Wellington City Archives, Wellington, NZ.

Waterfront Development Subcommittee. (2005, June 20). Waterfront Development Subcommittee 20 June 2005 Report 1 - Appendix 1: Waitangi Precinct design competition brief: Draft for discussion. Wellington City Archives, Wellington, NZ.

Waterfront Development Subcommittee. (2005, August 1). Waterfront Development Subcommittee 1 August 2005 Minutes. Wellington City Archives, Wellington, NZ.

Waterfront Development Subcommittee. (2005, August 1). Waterfront Development Subcommittee 1 August 2005 Report 2 - Appendix 1: Submissions to the draft waterfront development plan 2005/2006. Wellington City Archives, Wellington, NZ.

Waterfront Development Subcommittee. (2005, November 28). Waterfront Development Subcommittee 28 November 2005 Report 1: Waitangi Precinct buildings - jury recommendation. Wellington City Archives, Wellington, NZ.

Waterfront Development Subcommittee. (2006, May 8). Waterfront Development Subcommittee 8 May 2006 Report 1 - Appendix 3: OPT redevelopment design review report from the Technical Advisory Group. Retrieved from http://wellington.govt.nz/ /media/yourcouncil/meetings/committees/waterfront\%20development\%20committee/2006/05/08/files/1_ app_3.pdf?la=en

Waterfront Development Subcommittee. (2006, May 8). Waterfront Development Subcommittee 8 May 2006 Report 2: Draft waterfront development plan 2006/07. Retrieved from http://wellington.govt.nz/ /media/yourcouncil/meetings/committees/waterfront\%20development\%20committee/2006/05/08/files/2_ draft_development_plan2006_07.pdf?la=en 
Waterfront Development Subcommittee. (2006, May 8). Waterfront Development Subcommittee 8 May 2006 Report 2 - Appendix 1: Draft waterfront development plan 2006/07. Retrieved from http://wellington.govt.nz/ /media/yourcouncil/meetings/committees/waterfront\%20development\%20committee/2006/05/08/files/2_ app_1.pdf?la=en

Waterfront Development Subcommittee. (2006, June 26). Waterfront Development Subcommittee 26 June 2006 Minutes. Retrieved from http://wellington.govt.nz/ /media/yourcouncil/meetings/committees/waterfront\%20development\%20committee/2006/06/26/files/06 _26.pdf

Waterfront Development Subcommittee (2006, June 26). Waterfront Development Subcommittee 26 June 2006 Report 1 - Appendix 1: List of submitters. Retrieved from http://wellington.govt.nz/ /media/yourcouncil/meetings/committees/waterfront\%20development\%20committee/2006/06/26/files/1_ app1_list_of_submitters.pdf?la=en

Waterfront Development Subcommittee (2006, June 26). Waterfront Development Subcommittee 26 June 2006 Report 4: Feedback on the 2006/07 draft Waterfront Development Plan. Retrieved from http://wellington.govt.nz/ /media/yourcouncil/meetings/committees/waterfront\%20development\%20committee/2006/06/26/files/1_ app1_list_of_submitters.pdf?la=en

Waterfront Development Subcommittee (2006, June 26). Waterfront Development Subcommittee 26 June 2006 Report 5: Feedback on the Overseas Passenger Terminal concept design proposal. Retrieved from http://wellington.govt.nz/ /media/yourcouncil/meetings/committees/waterfront\%20development\%20committee/2006/06/26/files/5_ opt_consultation_feedback.pdf?la=en

Waterfront Development Subcommittee (2006, June 26). Waterfront Development Subcommittee 26 June 2006 Report 6: Wellington waterfront project business plan 2006/07. Retrieved from http://wellington.govt.nz/ /media/yourcouncil/meetings/committees/waterfront\%20development\%20committee/2006/06/26/files/6_ wwp_2006_07_business_plan.pdf?la=en

Waterfront Development Subcommittee (2006, June 26). Waterfront Development Subcommittee 26 June 2006 Report 6 - Appendix 1: Wellington Waterfront Limited: Strategic plan 2006 - 2009, business plan 2006 - 2007. Retrieved from http://wellington.govt.nz/ /media/yourcouncil/meetings/committees/waterfront\%20development\%20committee/2006/06/26/files/6_ app1_wwl_draft_strat_bus_plan_2006_07.pdf?la=en

Waterfront Development Subcommittee (2006, September 4). Waterfront Development Subcommittee 4 September 2006 Minutes. Retrieved from http://wellington.govt.nz/ /media/yourcouncil/meetings/committees/waterfront\%20development\%20committee/2006/09/04/files/09 _04.pdf 
Waterfront Development Subcommittee (2006, September 4). Waterfront Development Subcommittee 4 September 2006 Report 3: Taranaki Wharf (west) public space design brief. Retrieved from http://wellington.govt.nz/ /media/yourcouncil/meetings/committees/waterfront\%20development\%20committee/2006/09/04/files/3_t aranaki_wharf_design_brief_report.pdf?la=en

Waterfront Development Subcommittee (2006, September 4). Waterfront Development Subcommittee 4 September 2006 Report 3 - Appendix 1: Design brief: Taranaki Wharf (west) public space. Retrieved from http://wellington.govt.nz/ /media/yourcouncil/meetings/committees/waterfront\%20development\%20committee/2006/09/04/files/3_ app1_taranaki_wharf_design_brief.pdf?la=en

Waterfront Development Subcommittee (2006, September 4). Waterfront Development Subcommittee 4 September 2006 Report 4: Design brief for Frank Kitts Park. Retrieved from http://wellington.govt.nz/ /media/yourcouncil/meetings/committees/waterfront\%20development\%20committee/2006/09/04/files/4_f rank_kitts_park_design_brief_report1.pdf?la=en

Waterfront Development Subcommittee (2006, September 4). Waterfront Development Subcommittee 4 September 2006 Report 4 - Appendix 1: Design brief for Frank Kitts Park redevelopment including a chinese garden. Retrieved from http://wellington.govt.nz/ /media/yourcouncil/meetings/committees/waterfront\%20development\%20committee/2006/09/04/files/4_ app1_frank_kitts_design_brief.pdf?la=en

Waterfront Development Subcommittee (2006, December 11). Waterfront Development Subcommittee 11 December 2006 Report 4: Feedback on the proposed design brief for Frank Kitts Park. Retrieved from http://wellington.govt.nz/ /media/yourcouncil/meetings/committees/waterfront\%20development\%20committee/2006/12/11/files/2_f k_feedback.pdf?la=en

Waterfront Development Subcommittee (2007, June 25). Waterfront Development Subcommittee 25 June 2007 Minutes. Retrieved from http://wellington.govt.nz/ /media/yourcouncil/meetings/committees/waterfront\%20development\%20committee/2007/06/25/files/06 25.pdf

Waterfront Development Subcommittee (2007, June 25). Waterfront Development Subcommittee 25 June 2007 Report 1: Draft waterfront development plan 2007/08. Retrieved from http://wellington.govt.nz/ /media/yourcouncil/meetings/committees/waterfront\%20development\%20committee/2007/06/25/files/01 _wdsc_report_on_draft_development_plan_2007_08_v6ntc.pdf?la=en

Waterfront Development Subcommittee (2007, June 25). Waterfront Development Subcommittee 25 June 2007 Report 1 - Appendix 1: Draft waterfront development plan 2007/08. Retrieved from http://wellington.govt.nz/ /media/yourcouncil/meetings/committees/waterfront\%20development\%20committee/2007/06/25/files/01 _app_1_wdsc_draft_waterfront_development_plan_2007_08_v11ntcfinal.pdf?la=en 
Waterfront Development Subcommittee (2007, August 22). Waterfront Development Subcommittee 22 August 2007 Report 4: Feedback on the 2007/08 draft waterfront development plan. Retrieved from http://wellington.govt.nz/ /media/yourcouncil/meetings/committees/waterfront\%20development\%20committee/2007/08/22/files/4_ wdp_consultation_feedback.pdf?la=en

Waterfront Development Subcommittee (2007, August 22). Waterfront Development Subcommittee 22 August 2007 Report 4 - Appendix 2: Draft waterfront development plan 2007/08. Retrieved from http://wellington.govt.nz/ /media/yourcouncil/meetings/committees/waterfront\%20development\%20committee/2007/08/22/files/4_ app2_wdsc_dwdp2007_08_pdf.pdf?la=en

Wellington City Council (2007, December 19). Wellington City Council 19 December 2007 Report 1 - Appendix A, part 1: Frank Kitts Park redevelopment recommendation and report by the jury to Wellington Waterfront Limited. Retrieved from http://wellington.govt.nz/ /media/yourcouncil/meetings/council/2007/12/19/files/01_frank_kitts_park_development_appendix_a_pa rt_1_jury_report_.pdf?la=en

Wellington City Council (2007, December 19). Wellington City Council 19 December 2007 Report 1 - Appendix A, part 2: Wellington chinese garden, Frank Kitts Park masterplan competition, Wellington waterfront - report from the Wellington Chinese Garden Committee 12th November 2007. Retrieved from http://wellington.govt.nz/ /media/yourcouncil/meetings/council/2007/12/19/files/01_frank_kitts_park_development_appendix_a_pa rt_2_wellington_chinese_garden_report.pdf?la=en

Wellington City Council (2007, December 19). Wellington City Council 19 December 2007 Report 1 - Appendix A, part 3: Technical Advisory Group assessment report for Frank Kitts Park competition. Retrieved from http://wellington.govt.nz/ /media/yourcouncil/meetings/council/2007/12/19/files/01_frank_kitts_park_development_appendix_a_pa rt_3_tag.pdf?la=en 
